\title{
The Politics of Social Discourses about Youth in New Zealand 1950-1965 and 1990-2005
}

\author{
By
}

Jean-Christopher Somers

A thesis submitted to the Victoria University of Wellington in fulfilment of the requirements for the degree of Doctor of Philosophy

Victoria University of Wellington

2015 



\section{Contents}

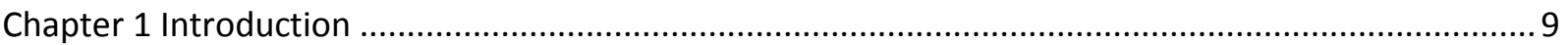

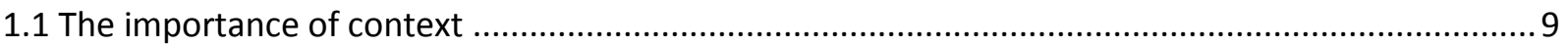

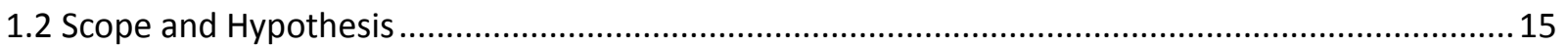

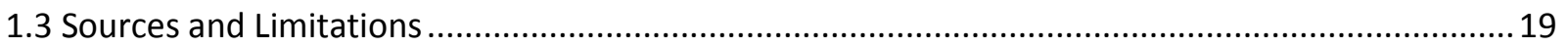

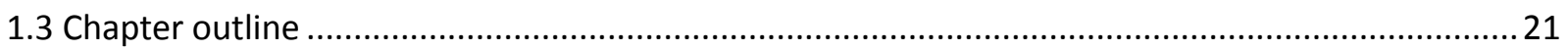

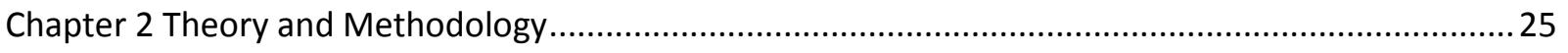

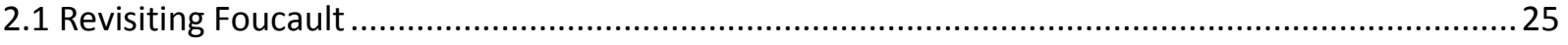

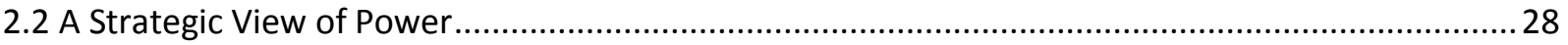

2.2.1 Reconceptualising neoliberalism and the welfare state...................................................... 31

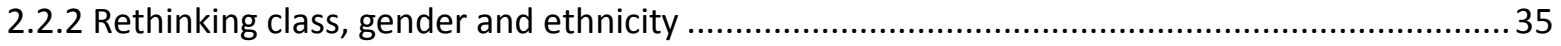

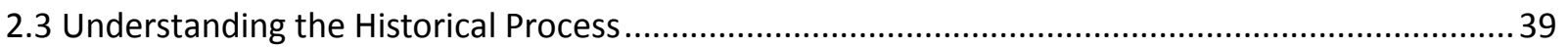

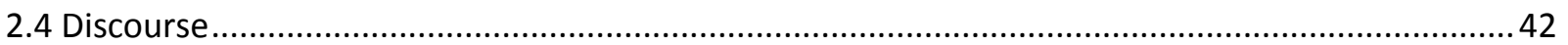

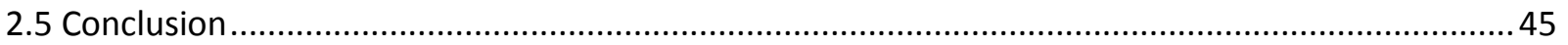

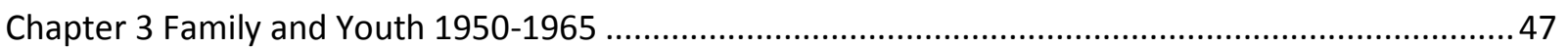

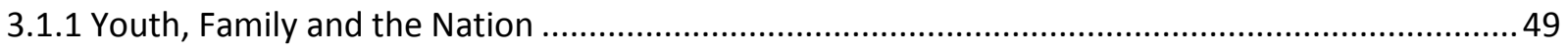

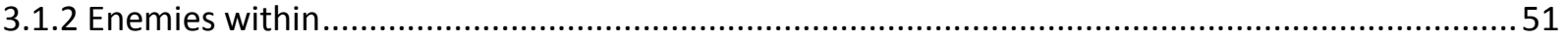

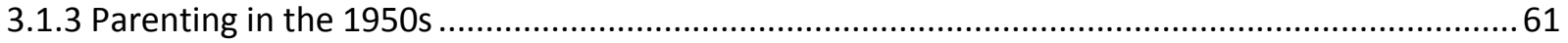

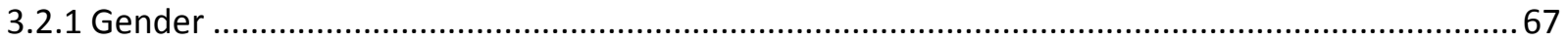

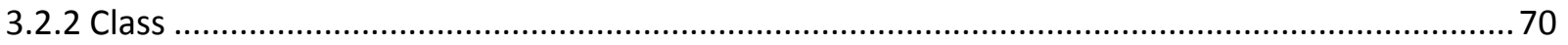

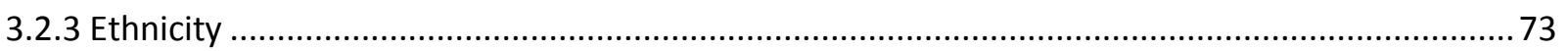

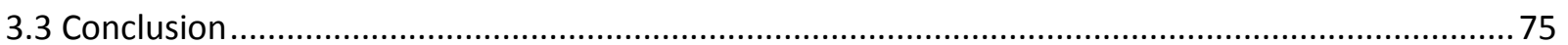

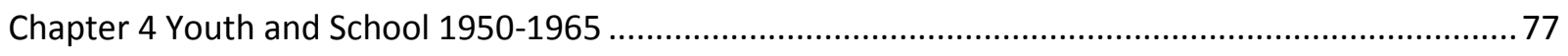

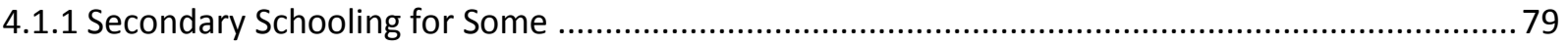

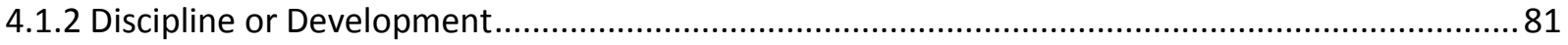

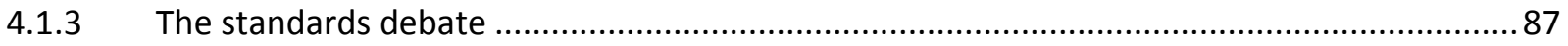

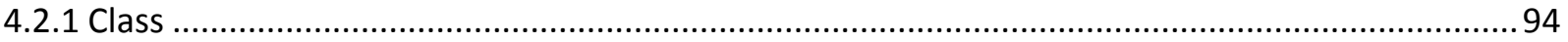




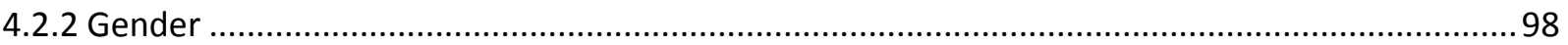

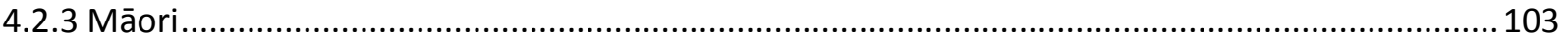

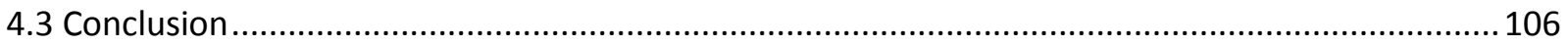

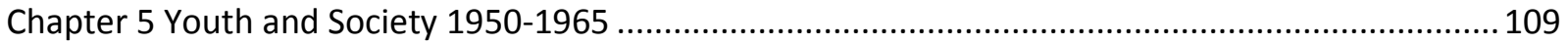

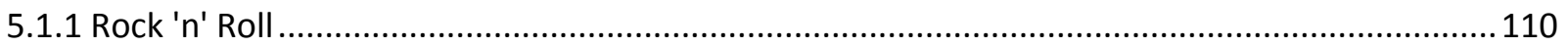

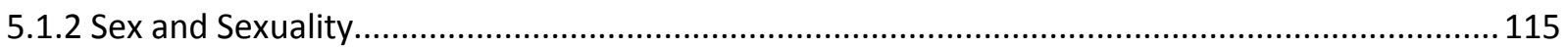

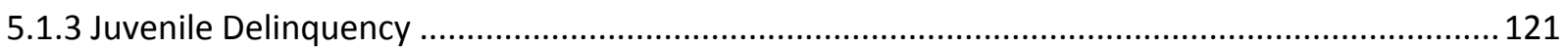

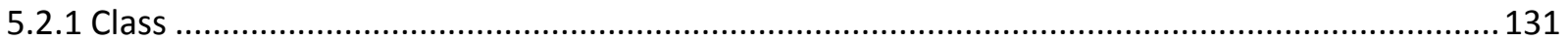

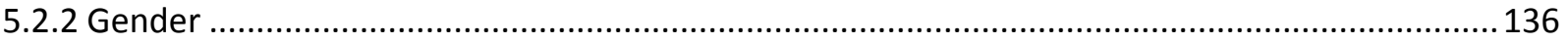

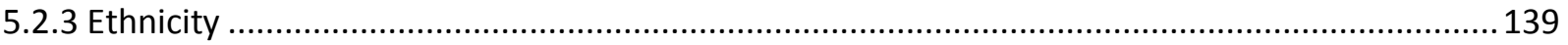

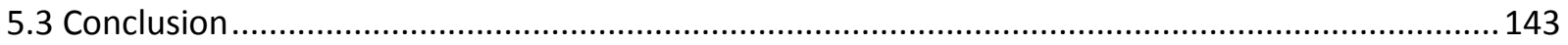

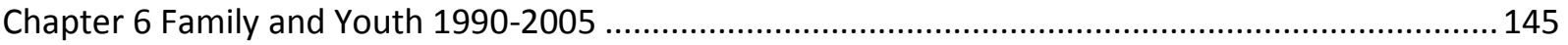

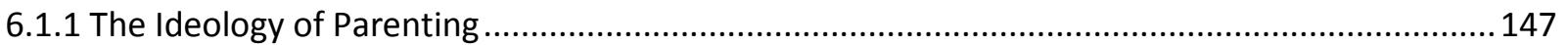

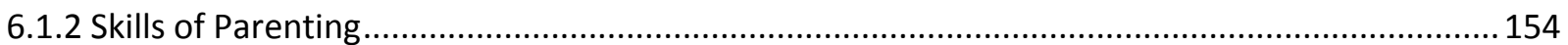

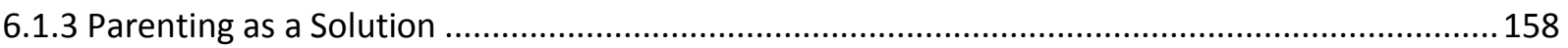

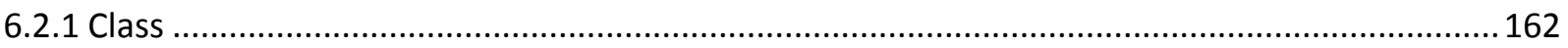

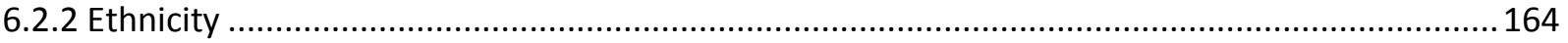

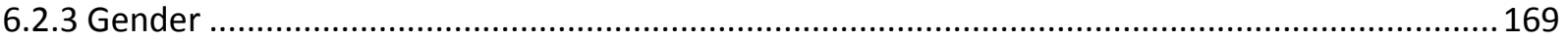

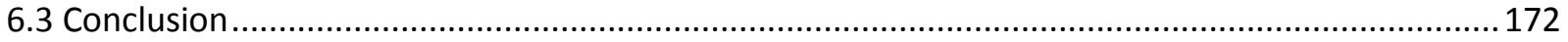

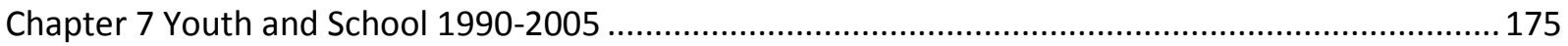

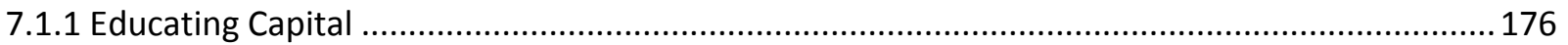

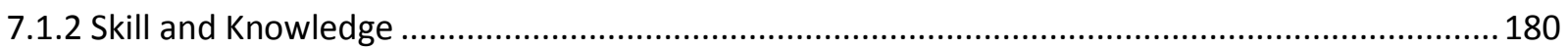

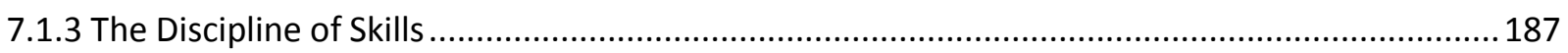

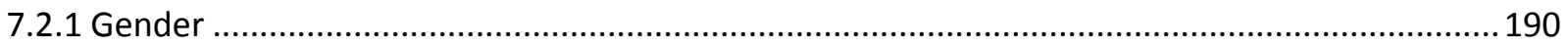

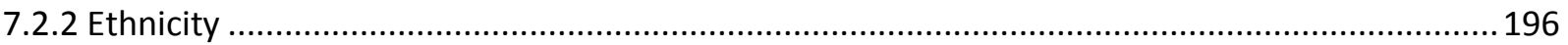

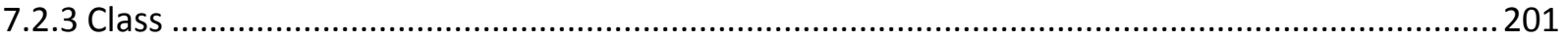

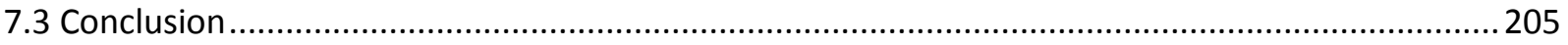

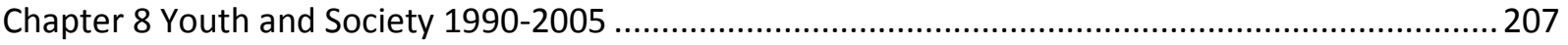

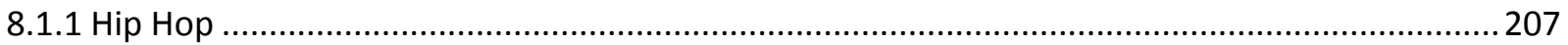

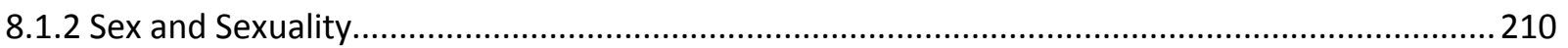

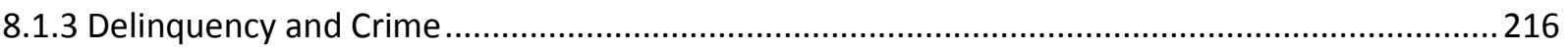

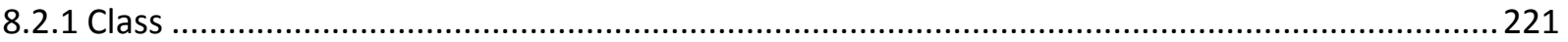

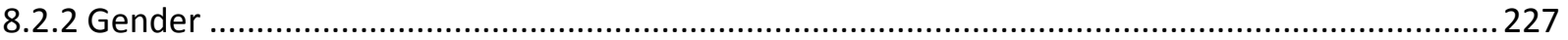


8.3 Conclusion

Chapter 9 Conclusion

Bibliography

249

Abstract:

This thesis explores the politics of changing discourses around the youth question in New Zealand's postwar (1950-1965) and near-contemporary history (1990-2005). Building on a modified Foucaultian framework, it examines for both periods anxieties over young people's relationships with home, school and the wider society. It also contrasts the two periods to illustrate the ideological shift from the welfare state to neoliberalism, as it was played out through youth-related discourses. This thesis goes beyond the moral panic approach, especially regarding the postwar period. It will demonstrate that rethinking what is conventionally condensed and marginalised as 'context' is key to understanding the politics of youth discourses. Postwar debates about young people, because youth were conceived as being in social crisis, served to expose ideological differences that the welfare state had ostensibly overcome. That in turn destabilized the apparent moral consensus and opened up opportunities for resistance and subversion. By contrast, the liberal and emancipatory discourse of society in the 1990s and early 2000s served to insulate neoliberal politics from volatile public concerns. This in turn paradoxically provides a stronger and more efficient foundation for social control over youth. 

Acknowledgements:

First and foremost I offer my sincerest gratitude to Dr Malcolm McKinnon, who has supported me throughout my thesis with his patience and knowledge whilst allowing me the room to work in my own way. A very special thank you goes to Dr Pat Maloney, whose expertise, understanding, and patience added considerably to my graduate experience over the first three years of this project. I would like to thank Dr Allison Kirkman for assistance and feedback she provided throughout this long journey. One simply could not wish for better supervisors.

I would also like to express my gratitude to Dr Stevan Eldred-Grigg, both as a teacher and a friend.

I must acknowledge the support of the Department of Politics throughout my $\mathrm{PhD}$, and especially departmental staff Adrienne Nolan and Philippa Race, for their sustained and wholehearted support. My thanks also go to the staff at the Faculty of Graduate Administration. I am grateful to Matthew Smith and Sonny Jim for their help with the proof-reading.

My sincere thanks to the University of Victoria which provided a full scholarship for me. And last but not least, my partner Jason Frick for his support. 



\section{Chapter 1 Introduction}

\subsection{The importance of context}

This thesis offers a political analysis of the changing discourses around the youth question in New Zealand's postwar (1950-1965) and near-contemporary history (1990-2005). Building on a modified Foucaultian framework, it examines for both periods anxieties over young people's relationships with home, school and the wider society, and attempted solutions to them. My objective is not simply to uncover a correspondence between changing discourses about youth and the shift from the welfare state to neoliberalism. Rather it is to pursue a better understanding of how the welfare state and neoliberalism themselves worked by examining discourses about youth (the methodological importance of this 'how' question is discussed in Chapter Two).

If we are serious about the centrality of politics and history to understanding youth, then it is necessary to take the discussion beyond a hurried overview of 'context' and ask what discourses about youth reveal about the social process. It will require more than spotting differences and similarities between the past and the present in an effort to unearth 'hidden' political judgments. A historical approach will proceed from the assumption that change and instability are the norm, and any ostensibly stable pattern must be unpacked. This enables us to pursue a different task than the self-evident one of showing how distinct the challenges facing different generations are. Rather it is possible to find out how a society in different eras negotiated the same open-ended conflict between what was and what could be, not just over the youth question, but in other spheres of social life at the same time. The concern here is with what falls within the scope of political and critical discourse, rather than some extraneous imperative, for example the coming of a 'risk society', which by definition permits no alternatives.

My approach aims to go beyond the limits of current engagement between youth studies and political analysis, which I will briefly examine, from both angles. Critical scholarship on youth often introduces politics into analysis via a critique of the (allegedly) continuing dominance of the functionalist (and thus political) logic which shaped the foundational concept and theories of youth (Côté 2014:528; Jones 2009:1-29; Tyyskä 2014:6-12). Although functionalism no longer monopolizes the sociological imagination, as Roberts (2003:14-15) points out bluntly, it still 
keeps much of youth research going among those who 'work with their eyes down in search of social problems and their hands up seeking research funds'. Scholarship with this narrow focus cannot the inability to account for political as well as social and cultural ambiguities and complexities, and produces oversimplified and deterministic arguments, be they the classical storm-and-stress narrative or the new-fangled 'brain science' of adolescence (for critiques of 'brain science' see Gabriel 2013; France 2012). To identify the political and historical dimensions from such analyses is then a very efficient way of challenging their validity.

On the other hand, when political analysis is used to theorise youth, rather than to analyse social relationships more broadly, the critique is easily derailed. Too much time is spent critqueing a caricatured view of the-adolescent-as-problem. This approach risks neglecting the broader political and historical contexts which produce these 'essentialist' symptoms. As such it is easily outmanoeuvred by new permutations of 'essentialist' logic. With a 'positive' turn in contemporary youth research, that defines itself precisely against outdated negative stereotypes, politics is sidelined again. This outcome is forcefully challenged by (Sukarieh \& Tannock 2011:688-9). This does nothing to help us understand how stereotypes, both negative and positive, are generated and mobilized in changing social and economic contexts overtime Before advancing my own approach for bringing youth study and politics together, I will explore two other debates that have a bearing on this enquiry, first that of structure and agency; second, that of social generation theory. These two approaches cross the divide from different sides, and are usefully illustrations of pitfalls to be avoided.

There is no shortage of vigorous debates between the 'culturalist' and 'transition' camps of youth scholars about the relative importance of structure and agency (McDonald et al. 2001; Roberts 2012; Threadgold 2011; Woodman 2009). ${ }^{1}$ Disagreements about the meaning and significance of agency, and attempts to reconcile agency with structure and/or go beyond dichotomous deadends are precisely what define the theoretical cutting edge of the field (Coffey \& Farrugia 2014; Furlong et al. 2011). The stake is, however, nearly always firmly planted in the middle ground, since no scholars commit themselves to the extremes of either agency or structure. The issue, as Coffey \& Farrugia see it, is that this commonplace solution begs the question rather than resolves

\footnotetext{
${ }^{1}$ To oversimplify, the 'culturalists' are often criticised for underplaying the importance of structural constraints, and 'transition' studies are criticised for underplaying the importance of individual agency.
} 
it. In their view, agency is still theorised unsatisfactorily as 'always in a tense relationship with, and always opposed to structures'. Analytically, it becomes a 'mysterious black box' which contains all that is not explained or described in structural terms. And this analytical notion that agency is 'bounded by and works against structures' provides a normative basis where agency is conflated with young people's resistance against social structure (2014:468). In other words, there is a limit upon how much 'structure' can be brought into youth studies, since the presumption is that social structure cannot and should not account for young people's agency. Coffey and Farrugia's solution to this problem is to reformulate the notion of agency very much along the standard post-modernist line which sees agency, like structure, as 'continually constituted' through power relationships (op.cit.:469; also Farrugia 2013). Youth scholars, nonetheless, have yet to show as much interest in deconstructing agency as deconstructing structural notions. An alternative may well lie, as others suggest, in the revival of the old 'political economy' model, with necessary modifications (Côté 2014; Mizen 2002). These are undoubtedly important conversations. Still they are a continuation of the great debate over agency and structure. Such debates might contribute to a better understanding of these fundamental tensions or perhaps to resolve them, but in themselves they do not tell us how people actually lived given such epistemological certainties.

Crossing the disciplinary divide from the other direction is no less perilous, not least because political science has not yet attached the same importance to the youth question as scholars of youth have to questions of politics. Youth scholars have made a convincing case that debates over youth are often not just about youth. Not only has the 'youth question', as France (2007:151-2) argues, 'symbolically reflected wider concerns about the state of the nation', it has also been continually drawn upon to reflect on the state of civilisation at particular moments in time. The irony is that youth theorists have extensively utilised terms such as 'governmentality' and 'agency' which would be immediately intelligible to political theorists. The reverse is not the case. It is in fact difficult to find any extensive engagement with youth issues within the conventional frame of political theory, except as specific issues of political participation, or as applied case studies. To this end the terms of political economy also need updating. 
This need has become more apparent in recent times. Politics, after all, requires social flashpoints such as debates over youth in order to articulate its abstractions, as much as the construction of youth needs its political context. Iin fact, one might argue that construction of youth already plays a key, if unrecognised, role in mainstream political and social theorising.

The symbolic use of youth was particularly salient under neoliberalism during the 1990s and early 2000s. There was a close relationship between the construct of youth, as a necessary embodiment of agency, both in popular imagination and academic discourse, and the fundamental premise of neoliberalism which presumed individuals to be free so that they might all be compelled to exercise their freedom. The notion of youth was put to work in a neoliberal political order in increasingly explicit ways. Some young people might appear to have been permanently 'at risk' in a neoliberal society, but the only way to succeed in a 'risk society', for adults as well as youth, was to take risks, to accept the uncertainties and to commit oneself to a permanent process of 'becoming', or in other words, to be young and enterprising (cf. Kelly 2006:27-9). This apparent inversion of the conventional age hierarchy was part of what was new about neoliberal society. All the more important for us to examine the relationship between youth and the welfare state more closely, without presuming repression was all there was to it. Did neoliberal society usher in an age of youth, or did generational shift make neoliberalism possible? Posing the questions in such ways presents an apparent opportunity for radical retheorising of ideological shifts by taking 'youth' to politics. It may be that political shifts are not to be explained solely in conventional terms of political science, but as a generational shift in social patterns.

For a more concrete example here I will focus on the social generation theory, which claims a genealogy from Karl Mannheim, reflects, somewhat belatedly, the 'risk society' or reflexive modernity theses from Beck and Giddens which have long dominated the analysis of late modern society. Over recent years the social generation theory led by two prominent theorists of youth has gained increasing currency as the key to understanding this relationship (Woodman 2013; Woodman \& Wyn 2013; Wyn \& Woodman 2006; also Andres \& Wyn 2010; Cuervo \& Wyn 2011; 2014). Indeed, the social generation paradigm revolves almost exclusively around the 'new' generation of youth since the 1990s who were said to be subjected to unprecedented forces of individualisation and social fragmentation, in sharp contrast to the 'baby boomer' generation. 
The recent literature appears more an application of the Beck-Giddens thesis than a new paradigm. $^{2}$

This approach has been critiqued (Roberts 2007; 2012; France \& Roberts 2014). A significant part of the debate has been played out in tandem with the debate over structure/agency and youth transition/culture discussed above. One particular criticism from France and Roberts is that, while proponents of social generation have claimed to take social change seriously, they are unable to identify the 'types of changes which are significant and more importantly ... the driving force behind social change'. Instead, these are all assumed as contextual features which are self-evidently significant. This shortfall does not invalidate the social generation perspective as a valuable heuristic device for contemporary youth experiences, but it does run counter, among other things, to an emphasis on politics. The unwillingness or inability to reflect upon the construction of generational difference in specific contexts may, as France and Roberts note, undermine the conceptual stability of the same generation theory. On the one hand, it identifies young people as a generation in themselves, because the growth of individualisation has swept away old collective identities such as class or culture. On the other, if the force of individualisation is indeed so overpowering, why would young people see themselves as a 'social generation', or commit themselves to the abstract ideal of reflexive self, or indeed comprehend a shared identity of 'youth' (France \& Roberts 2014:6)?

In fact, the prescriptions of social generation theory run the risk of reinforcing its assumptions about generational differences. Woodman \& Wyn (2013:271) for example claim that, since 'youth policy may be based on the understandings of youth held by policy makers who themselves grew up as part of a different generation', it is essential for them to come to terms with the reality of the new generation if they wish to tackle the issue of inequality. This says very little about inequalities within or across generations that persist over time. ${ }^{3}$ Moreover, the

\footnotetext{
${ }^{2}$ Mannheim's theory was originally applied to 1920 s youth. And a dated body of literature has sought to apply it to explain the patterns of postwar generations (see Pilcher 1994). But the recent theory of social generation has not yet been re-applied retrospectively. Whether the theory was ever intended to be applied to past or future generational changes is not entirely clear.

${ }^{3}$ The potential difficulty in accounting for intra-generational divisions, say in class terms, is explicitly acknowledged by social class theorists (Furlong et al. 2011:367). But this qualification is central to the utility of a social generation approach to the field of youth studies. Either it is addressing a different question from those where the 'traditional' and 'outdated' theoretical methods still apply, or it is a general framework that applies to inequality where it matters; it cannot be both.
} 
'reality' of generational differences conceal the ideological choices involved. There is no good reason to reject collective fictions of class, gender and ethnicities just because they are inadequate - though no more so than 'generations' - abstractions of 'reality'. And those oncepowerful notions are no more inadequate just because that 'reality' is complex and changing, as indeed it has always been.

In such policy commentaries, the larger political implication can already be discerned. But theories like social generation, especially when framed within the larger theory of risk society, has more direct and more radical implications for analysis of politics since they it transcends explanations of society as a whole. The demarcation between generations and social patterns, which runs all too neatly alongside the ideological faultline, suggests, even if only by logical fallacy, an alternative cause of political shifts. The notion of a 'conformist social pattern' upon which the whole theoretical enterprise rests, however, can readily be demolished by a careful empirical analysis that is attentive to both social and political complexities. And by focusing on this more modest inquiry, we may save ourselves from becoming entangled in a theoretical struggle that pits social against political scientists.

It is easy, perhaps, to make a point about complexity and fluidity from the heights of theory by pointing to what has been 'missing' in previous analysis. But it is equally difficult to apply the borrowed insights in such a way that heeds these very dangers. In this thesis I wish to focus, as it were, on the ground where political and social patterns intersect, not just because they have to theoretically and analytically, nor because the juxtaposition of these two patterns produces better insights about some epistemological riddles, but because they do in the actual historical process, in different ways, involving differing degrees of awareness among the people who participate in that process. And the focus of the analysis, and of this thesis, is to find out how political and social patterns came together, not necessarily by design, and how they were formed and changed by these collisions. 


\subsection{Scope and Hypothesis}

This focus lends itself to studies of administrative and policy histories, where political considerations were directly applied, albeit sometimes implicitly, to social issues. In this respect there is already some solid groundwork in the antipodes. New Zealand literature is well served by historical scholarship on social policy, especially welfare and its administration. And many historians traverse some of the same grounds as this thesis, although they tend to be relatively light on class. The work of Australian scholars Terry Irving, David Maunders and Geoff Sherington, whose study Youth in Australia was published in 1995, is particularly valuable. ${ }^{4}$ The authors' superb account of how youth came to be defined as a field for politics in postwar Australia, and emerged as a subject for integrated policy, links youth among other things to the changing notions of citizenship (e.g. 1995:19;41;101-116). While their analysis ends in the early 1990s, the authors have a keen sense of radical changes in the politics of the age order to come (1995:339). This study is valuable not only because of the similarity between the Australian and New Zealand cases, especially in the postwar period - both, for example, convened special committees of inquiry into youth issues that provide rich archival sources for later researchers (also see Irving's earlier work on the Dewar committee) - but also because I too want to 'age questions' on an equal footing with 'class, gender and ethnicity' (1995:xvi). What is needed now, of course, is to ensure that class receive sufficient attention alongside the growing volume of literature on gender and to a lesser extent ethnicity, much of it from an identitarian perspective.

This thesis does not, however, seek to evaluate policy-making. Administrative and policy discourses are, of course, still an important part of the material. But rather than identifying the effects of the social and political context upon any particular policy or regime, this thesis instead examines closely what these contexts were, and how the 'contexts' and the 'issues' came together. I am not so much concerned with whether the solutions to youth problems were 'logical' or not, as systems of political and social logic explicated and articulated in the process, which might not be about 'youth' at all. Nor do I offer a self-contained explanation of why

\footnotetext{
${ }^{4}$ See Tanner (1996)'s study for Canada; and Dalley (1998) in New Zealand. Dalley's book, while containing a wealth of material, focuses more narrowly on the development of child welfare, rather than the political context or implications.
} 
certain actions were taken or not. My thesis says nothing about the intention of the actors, or their material capability. Those questions are for others to investigate.

Furthermore, the focus of this thesis is on discursive developments. I do not see such developments as distinct or separated from 'material' or non-material reality, as I shall explain in section 2.3. A discursive pattern of 'classlessness', with its inherent ambiguities and contradictions, was a part of the material reality, and so were the classed relations of production. But the latter is outside the scope of this thesis. Any conclusion one may draw about discursive reality is not automatically superior to any other, nor immediately - or ever - more generalizable to the reality. The contradictions between different facets of reality may exist, to be sure, but it is beyond the scope of this thesis to explain why they should exist, or to explain them away. It is also outside the scope of this thesis to prove or disprove certain 'facts', say the actual rate of youth unemployment and its objective effects. The meaning of these 'facts', however, is within my purview.

To follow the same logic, this thesis does not furnish new theories of the welfare regime or neoliberalism in their entirety, except to make it clear from a new perspective (also 2.2.1) what must be accounted for in the development of such theories. The focus on youth in this thesis is not a short-cut to the truth of either regime. It is primarily about exposing 'deep' structural patterns, as refracted through discourses around youth. The thesis focuses on whether such patterns contradict or complement existing theories about 'regimes of power'. The thesis will show that concepts like the conformist society are not particularly useful, and indeed inhibit, our understanding of what constitutes the differences between the welfare state and the neoliberal regime. The thesis on its own cannot offer new and better abstractions about those regimes themselves. To improve on the theory, at any rate, will require a meta-analysis of different structures unearthed through other empirical studies and how they fit together. That larger theoretical and empirical labour is far beyond what this thesis can undertake.

In addition, this thesis does not seek to explain why social and political patterns came to be what they were, or why regime shift occurred. If anything, the argument here cautions reading too much into apparent parallels between shifts in attitudes about youth and other ideological changes, and seeing too little in the actual overlapping patterns themselves. These are not analytical dots to be connected. Rather they were already linked within a particular historical 
context, and this thesis intends to find out how. Upon that basis, we can rule out explanations which depend upon those assumptions about, say, the apparent stability of the welfare consensus (and hence a structural collapse) and the apparent liberalisation of social attitudes (that made neoliberalism look more tolerable). This does not preclude the same conclusions being reached without spurious appeals to social context. It may well be the case that the welfare state did have a central economic structure, relatively autonomous from its social and political structure, which did collapse. Nor does my investigation imply, or intend to offer, a positive hypothesis of regime change.

To explain regimes and regime changes, above all, requires more extensive discussion of those epistemological paradoxes - 'reality' vs. experience; determination vs. contingencies; agency vs. structure - than this thesis can offer. It is a cliché now that these cannot be dichotomies, and I will take for granted that social and political patterns are shaped by the effects of both. The focus on discursive development should not be read as an endorsement of postmodern subjectivism. The actors could, of course, say one thing, and think and act another. And their discursive freedom and power were not necessarily the same thing as economic power. This thesis is not concerned with which type of power ought to triumph in the final analysis. It is up to others to argue why deeply structured discursive developments could be overridden by material dictates, and how they, and we, could reconcile the contradictions.

Finally, this thesis is not offered as a general history of youth. Such a general history may choose to examine, for example, improved means of transport and its effects on youth behaviour. It would also give more weight to, say, the trends in young people's aesthetic tastes, or changes in their attitudes towards friendship and intimate relations, whose effects and importance are certainly not wholly determined by politics. In this thesis, however, I am only concerned when such matters enter public discourse and thus inevitably become intertwined with political rationales.

At a more practical level, the scope of this thesis is limited to New Zealand. This supplies both a manageable and concrete subject for inquiry. It covers two fifteen-year periods, one from 1950 to 1965, and another from 1990 to $2005 .{ }^{5}$ The rationale is two-fold. The first period is commonly

\footnotetext{
${ }^{5}$ Needless to say, periodization of neither postwar society nor neoliberal society need follow standard decade limits. The commitment of New Zealand troops to Vietnam in 1965, for example, is a much more meaningful
} 
regarded as the heyday of the welfare state in New Zealand or the postwar 'golden weather', while the second saw the ascendency of neoliberalism. This is a sharp and therefore useful contrast. The fifteen-year span for both periods is also practical in that it provides sufficient material across a range of youth issues which tend to flare up intermittently and thus may not be captured in a shorter timeframe.

The discussion in Part 2 of class, gender, and ethnicity is similarly limited by practical concerns (the theoretical limits are discussed in Chapter Two). The discussion about class is primarily concerned with the socio-economic division between the working class, and others, as it was articulated in public discourse. I am not concerned with the class structure, as a whole, nor its effects. The discussion of gender is heavily concentrated on heterosexual masculinity, especially in the second period. Finally Māori/Pākehā relations constitute the primary focus of discussion about ethnicity. This thesis is not a treatise on class, gender or ethnicity. It simply seeks to unpack the classed, gendered, and 'ethnicised' patterns that inform both periods. The space limitation also precludes a wider discussion. And it is inherently difficult to do justice to such a discussion given the limited availability of material, especially during the post-war period (for example, say on the full spectrum of gender diversity during the postwar period).

The scope now delimited, we may proceed to formulate the hypothesis: that youth and politics intersect in different ways under the regimes of welfarism and neoliberalism. The 'youth question' was dealt with less adequately during the postwar era than in the 1990s neoliberal era. Such a difference cannot be understood satisfactorily, however, by reference to juxtaposition between the welfare state and social conformism on the one hand, and that between neoliberalism and diversity on the other, and worse still, to take this oversimplified conceptualisation as a starting point.

In fact, a key contrast is precisely in how political logics were worked out, or failed to be worked out, in historical process. The individualising logic of the neoliberal state provided it with a more effective and insidious way of controlling youth. This is largely consistent with contemporary

demarcation between the end of the seemingly 'conformist' 1950s and the 1960s with its counterculture and protests (cf. Phillips in Dalley \& McLean 2005:338) than is 1960. Equally, the starting points for both periods could be extended further back, to 1945 and 1984 respectively. But In the first case, the war still cast a shadow and would complicate the issue too much. In the second, while the path to radical reform was paved prior to 1990, the neoliberal regime only took complete shape in the early 1990s. 
scholarship on neoliberalism. The collective logic of the welfare state, by contrast, was incapable of containing the youth question; the attempts to articulate taken-for-granted norms of control and conformity, paradoxically, produced discursive diversions and cracks in making visible deep political and social divisions within adult society. This finding challenges the conventional constructs of both the welfare consensus and the conformist thesis.

This is a study about both youth and politics. It shows not only that there is a link, but that the link in itself is a fruitful subject of analysis. For youth studies, my thesis not only reinforces the point that discourses about youth are deeply political. It also shows that such discourses could themselves be politically productive, both of ideological and social alternatives. For political science, this thesis offers a robust characterisation of regime difference through empirical study. Moreover, any attempt to apply political theory to the historical process, or to borrow social constructs for political analysis, while they may serve to bridge the perceived gap, risks overlooking the space where the political and the social actually overlap. My thesis helps to address this. Finally, this study adds to the empirical data which could be used to inform further investigation, both in terms of how regimes work, more generally, and why they change.

\subsection{Sources and Limitations}

This thesis carves out a new area of inquiry, one which straddles political history and youth studies. There is little existing literature, in New Zealand or elsewhere, which does this outside education history. In New Zealand's case the latter often takes a constructivist/governmentality approach and has a strong grounding in political analysis, but it remains tightly focused on its particular subject matter.

In every other respect much of the available research approaches the issue from widely different angles, and therefore cannot be adequately discussed in a literature review. It is useful here nonetheless to outline the shape of what literature there is. There has been an exponential growth of scholarship on young people and adolescence since the 1990s in New Zealand. That growth has been accompanied by a characteristic fragmentation and specialisation in developmental psychology, education, criminology, public policy and cultural/media studies, which in 
themselves can be seen as a reflection of the 'post-modern' condition in which youth problems and solutions to them appear to proliferate.

Few New Zealand scholars pitch their research at the level of a 'youth study', as a distinct field of inquiry. By contrast, New Zealand boasts several world-leading longitudinal studies. These include the Christchurch and Dunedin Health and Development Studies, since the 1970s, with a strong quantitative emphasis on developmental psychology and medicine (Fergusson 1998; Silva \& Warren eds. 1996). The New Zealand Council of Education 'Pathways and Prospects' project examines specifically youth transition after school (Wylie et al. 2004; Wylie \& Hipkins 2006). A more recent addition is a sociological study of 93 young New Zealanders from 2003 to 2007, which focuses on their identity-work after leaving school, and falls within the social generational approach discussed above (Nairn et al. 2012).

On the whole, then, the current shape of research vindicates Wyn and Harris' impression that, outside the discipline of sociology, youth research in Australia and New Zealand is still heavily 'functionalist' and orientated towards (social) problem solving (2004:276). In contrast to this enormous field, the literature on postwar youth is sparse. The dominant interpretation of postwar youth is that of Yska (1993)'s popular account, which revolves around a rather simplified notion of moral panic. This account, tellingly, continues to be cited as evidence even by academic texts in social policy, demography and history (e.g. Dalley 1998; Pool et al. 2007; Belich 2001). Yska's conventional view of postwar era is in turn heavily reliant upon a fairly limited number of well-known official and academic sources, notably the Mazengarb report.

A closer look at primary sources is therefore necessary. It takes in a range of material from official publications, academic writing, professional journals (e.g. teachers' journals), popular literature (e.g. self-help books), and other mainly print media sources. ${ }^{6}$ The challenge posed by the limited availability of postwar material is tackled in two ways. First, the thesis scrutinises in detail key sources such as the Mazengarb report, alongside related material, for example, parliamentary papers and sex education pamphlets, as well as the written and oral submissions to the Mazengarb inquiry. Second, an extensive search of press reports has been carried out around key events/dates, such as the Mazengarb inquiry or the Blossoms Festival 'riots' (these materials have not yet been digitised at the time of writing). This included examining all issues of

\footnotetext{
${ }^{6}$ Some exceptions are made, for example, for the texts of music lyrics which are not strictly a print media source. 
periodicals such as the weekly NZ Listener, and monthly National Education, for the entire period. A number of collections, for example, the Department of Education and Evening Post clippings, held at the Archives New Zealand and Wellington library respectively, provided further information. Through a close reading of these materials, this thesis will seek to remedy the impoverished characterization of the postwar era.

This thesis only considers public discourses, that is, broadly, institutional discourses intended for public consumption.

Furthermore, the selection will be confined to materials published during the period, especially in Part 1 of each chapter (see below 1.3). Retrospective accounts of contemporary discourse, for example in general education history, are generally excluded as primary sources. This is justified because the primary objective in Part 1 of each chapter is to show that primary sources can themselves convey a range of political discourses. By contrast the discussions in Part 2 of each chapter are analytical and reflexive in nature and more recent material may be employed where appropriate to elucidate the abstractions of class, gender, and ethnicity.

There are inevitably some limitations with this approach. For one thing, it is assumed that archival material is a fair representation of public discourse. But the informal discourses and practices of, for want of a better word, ordinary people, which are rarely captured in institutional records, are necessarily 'under-represented'. Moreover, the postwar data consists mainly of primary sources, e.g. press and government reports. These are not mediated by much academic interpretation and therefore require some deep reading. The second period, by contrast, contains a large amount of academic research and other secondary material which can be fruitfully juxtaposed with primary sources. The different methods may thus skew the findings.

\subsection{Chapter outline}

All chapters, except for Two and Nine, are separated into two parts. Part 1 of each chapter draws out the underlying political discourses. Part 2 considers the implications of those discourses for class, gender and ethnicity, refracted through debates over youth.

Chapter Two, the theoretical chapter, critically engages with conventional Foucaultian ideas of governmentality. It affirms Foucault's insights into the complex and contingent nature of history, 
and the central importance of discourse. It argues however that more attention needs to be paid to Foucault's own ideas about the dispersal of power and rethinks the characterisation of the welfare state and neoliberalism in terms of the 'intensity' in the ways power was exercised under the two regimes. Furthermore, it provides a theoretical basis upon which we can incorporate other structural notions such as class, gender and ethnicity into the analysis.

Chapters Three, Four and Five address the 1950-1965 period, and Chapters Six, Seven and Eight deal with the 1990-2005 period. Collectively they paint a broad composite picture of social discourses about home, schools and society, and consider the 'usual suspect' of youth culture last. This is a deliberate device to counter the narrow focus on youth culture which, for the 1950s in particular biased analysis towards 'moral panic'. A broader view of society is a more fruitful starting point than the spectacular differences in taste between some adults and some youth. This is especially so when the intention is to capture a discursive diversity that, especially in the first period, has so often been overlooked. Such a view will also make it easier, in the second period, to look beyond the ostensible explosion of 'choices' in the second period.

Chapter Three argues that as the role of the family became a central subject of public discourse about youth, attention was drawn to adult society. Contradictions and weaknesses within the seemingly unassailable ideology of domesticity were exposed. Discourses about broken homes and working mothers both reinforced and subtly undermined a gendered ideal of family. The ideal of domesticity also had a class inflection: this produced a divisive debate as working class women did not conform to the ideal as completely as did middle class women. Finally, not only the constructs of domesticity, but the debates around it, completely overlooked the experience of Māori and other minority families. All of these debates, in their own way, raised questions about the welfare state itself, and its ambiguous relationship with the domesticity ideal that it is ostensibly committed to.

Chapter Four looks at the postwar debates over secondary schooling. It demonstrates that, while juvenile delinquency often triggered such debates, the debates themselves were ideological rather than moral. Postwar-schooling was not simply the 'fist' of social or moral control delivered in the velvet glove of an egalitarian myth. Some powerful critics of postwar education remained sceptical about any mass education, whilst others called for more competition and meritocracy on the one hand, and better discipline on the other. Paradoxically, the school regimes also opened 
up new debates, about class, gender and racial inequalities, debates which in theory should have been redundant in a fully-realised egalitarian system. It would be spurious, thus, to regard postwar schooling as a failed experiment in egalitarian, or liberal, humanism. It is much more productive to look closely at those ideological cracks which debates over education help to unearth.

Chapter Five discusses reactions to rock n' roll, sexual 'immorality' and juvenile delinquency. It argues that seeing the era in terms of moral panic underestimates the many contradictions in responses that could be so labelled. Moral signposts regarding leisure, sex and criminality were already shifting in adult society. Conflicts about the relationship between a consumerist society and the welfare state contributed to the complexity. Again, both the seemingly monolithic social pattern and the apparently secure welfare consensus were subjected to strain, not just from youth outsiders and their 'new' problems, but also importantly from the already existing ambivalence and uncertainty of adult society about its consumerism and culture.

Chapter Six, the first of the chapters dealing with the period 1990-2005, identifies a significant shift from a collective discourse of family to a privatised narrative of parenting, articulated increasingly outside the state and its affiliated institutions. 'Parenting' reinforced the ideological imperative that young people and their families must become responsible for their own welfare. Dysfunctional parenting displaced socio-economic disadvantage as a key explanation of young people's failures, co-opting the alternative discourse of whanau [family] in the process. This in turn allowed the state and others to vilify the 'dysfunctional parents' whether they are working class, 'underclass', Māori parents, or single mothers. The heterosexual Pākehā nuclear family, with all its prejudices, was reconstructed, not as a compulsory social norm which obliged the state to support it, but a model which individuals should emulate.

Chapter Seven analyses changes in schooling between 1990 and 2005. The school's role as an agent of social control was replaced by its role as an institution turning out individuals fitted for a market society. Whereas the postwar regime tripped up over egalitarianism, the 1990 to 2005 regime advanced a largely uncontested purpose: to prepare individuals for a competitive society while filtering out those who failed its meritocratic standards. It is this implicit commitment that structured schooling's response to class, gender and ethnic inequalities in education. Schooling was no longer a redistributive mechanisms to overcome disadvantage, and to challenge 
prejudices. On the contrary, participation in this inherently unequal competitive meritocracy was increasingly regarded as the only route for young people to improve their life chances.

Chapter Eight explores the emergence of hip hop, the liberalising of sexuality and the heightened anxiety about youth crime, which broadly paralleled the areas of concern in the postwar era. Cultural consumption and sexual behaviour now fragmented rather than concentrated public concerns. In practice, they became sites of different modes of regulation that emphasized not conformity to certain norms but the private cultivation of individual responsibility, a practice entirely consistent with the demands of a neoliberal society. By contrast, increasing public anxiety about youth crime placed the emphasis on individual irresponsibility. The legitimation of youth culture as well as the disappearance of moralistic fear about delinquency was not all good news for young people in the 1990s. Irresponsible youths were now to be contained and punished much as their adult analogies.

Chapter Nine (the conclusion) reiterates the central theme of this thesis. Postwar debates about young people (1950-1965) exposed ideological differences that the welfare state had ostensibly overcome. The debates destabilized the apparent moral consensus and opened up opportunities for other discourses. By contrast, the liberal and emancipatory discourse of neoliberalism (19902005) served to insulate neoliberal politics from volatile public concerns, and paradoxically provided a stronger and more efficient structural foundation for social control over youth. 


\section{Chapter 2 Theory and Methodology}

\subsection{Revisiting Foucault}

The theoretical and methodological framework for this thesis builds upon a critical engagement with the work of Michel Foucault. Foucault's theorizing brings together insights into the decentering of history, 'governmentalities' of the welfare state and neoliberalism and the regime of discourse. These parallel the objectives of this thesis (cf. Chapter 1.3).

The attraction of Foucault also lies in the fact that, although a theorist par excellence, Foucault did his best to resist a closed and reductionist analysis (Weeks 2005:191). This is not a Foucaultian innovation; arguably such practices are the basis of the Anglo-Saxon tradition of empirical social/cultural history which among other things has been a particularly fertile field of youth research. Historians do the hard work, in a way, from the bottom up. Foucault by contrast soars immediately to a theoretical height. This is both an advantage and a weakness. It is common practice thus to qualify the use of a Foucaultian framework by referring to his 'toolbox'. In order to maximise Foucault's utility, we must, Weeks advises, 'use Foucault as a box of tools to take up and put down as necessary and in the process probably deform it, making it groan and protest' (2005:186-7). Nonetheless, it is still necessary to consider what makes Foucault, with his contradictions, a whole, and that in turn limits the range of possibilities to which the parts might be put to use.

In this examination, I am not interested in the larger philosophical points - for example the ethical superiority of "parrhesia" ${ }^{7}$ - but merely the implications of such insights for a political and historical analysis. This may be done by examining the conventional narrative of Foucault, as Nealon (2008:5) aptly puts it, as a 'Bildungsroman', in which a series of failures led to higher knowledge. Foucault was a romantic. The effervescent youth, having discovered the metaphysical truth that the world is made up of uncertainties, contingencies and complexities, and taking these to be the last words, did not seem to know what to do with the insight. It made for a respectable and pedestrian middle-age, a retreat into the self. We may take either the young

\footnotetext{
${ }^{7}$ To oversimplify, parrhesia refers to 'speaking truthfully'. Foucault in his last years (lectures $81-83$ ) became fascinated by this aspect of ancient Greek political ethics.
} 
or the middle-aged version of Foucault and construct a theoretical framework which will lead us to exactly where, as I have discussed in the previous chapter, youth studies have stalled. In the first period, exemplified by History of Sexuality vol.1 and Discipline \& Punish, Foucault struck an iconoclastic stance against 'total history' and 'sovereign power'. Foucault's objective was to 'cut off the King's head' in 'political thought and analysis' (1980a:89). He did so by displacing the monopoly of the so-called 'juridico-discursive' conceptualisation of power as repressive discipline with an analysis of regimes of truths, in medical discourses among others, which produced subjects in certain ways. Lemke (2010:33) points out that in practice Foucault simply reversed the juridical model and adopted 'the exact opposite'. The medical/'psy'-expertise which was explored extensively by Foucault and Nikolas Rose $(1998 ; 1999)$ - commonly labelled developmental psychology in youth studies - has remained an extremely popular target for contemporary Foucaultian/social constructivist critique. The attraction is much the same: it shows that the exercise of power underneath the apolitical appearance of expertise is no less coercive, only more technologically advanced and thus potentially more dangerous.

The problem with this line of analysis - for example, focusing exclusively on the operation of 'psy'-expertise on youth issues - is that it is of much less help against blatant assertions of political power which do not need such pretences. It is true that we are now less likely to mistake the king's head for the 'real' seat of power. But we are still none the wiser when we see all the other heads of the hydra. Nor does it mean that we necessarily have a better understanding of how that particular head of the state worked in the first place. As Kelly (2010:39) argues, cutting the head off the King is 'analogous' to the 'death of God': 'God, if dead, never existed; the king, if decapitated, was never the absolute he appeared to be'. This leaves open the possibility that the illusions might still come back, in spite of what we know about how power really works.

Foucault himself helps to conceal, rather than resolves such difficulties, by claiming to focus on places where power relations were already making themselves amenable to analysis. He simply seeks to 'understand power by looking at its extremities, at where its exercise became less and less juridical' (Foucault 2003:28). In other words a microphysics of power 'from [the] bottom up', which stays silent about what, if anything, happens at the top. Nonetheless, Foucault tries to go further: from the microphysics of power, to biopower, to governmentalities, he attempts to show how the state, which he has rejected as an explanation of power 'is nothing but the mobile 
effect of a regime of multiple governmentalities' (Foucault 2008:77). These works provide a micro-foundation for macro-analysis, to be sure (cf. Jessop 2010), though they give no straight answer to the merits of studying the state, or indeed any other institutions, unless it is to show that they were to be explained by something else. And something else did later take Foucault's fancy, namely, the 'ethics of self' currently in vogue in Foucaultian scholarship. Foucault here turns to ancient Greece to rescue the possibilities of an ethical art of the self ('parrhesia') which could resist the 'government of individualisation' (cf. McNay 2009:67). And the privileging of reflexive self-creation through aesthetic means is clearly an amenable proposition, given the already dominant focus on youth agency (e.g. Besley 2006; Besley \& Peters 2007:91-2). But as Myers (2008:137-40) warns, the imaginative practice of 'care of the self' risks collapsing into solipsism, without explaining how these possibilities are limited by, and impose limits on, our relations with others. Foucault moreover was simply shelving the doubts he himself had raised about the very possibility of there being this privileged space of self. It leaves unanswered the question whether his own playful attempt at truth was anything more than a novel opening gambit. It is telling that some of Foucault's apologists end up resuscitating none other than the abstract autonomous individual, as one critic puts it, 'beyond knowledge and power', who supports the regime of economic liberalism (Paras 2006; Behrent 2009). The myth of individualism is resurrected because it is 'necessary' ethically, while the 'necessary fictions' such as social justice and equality are left behind, conveniently, given their analytical inadequacies. If this was a game, it left the players even fewer cards to play with than previously.

Is it possible, then, to apply Foucault's critical insights about historical change and social complexity in a way which does not inevitably collapse into a rarefied exercise in self-regarding ethics? Part of the answer lies in setting aside the obsession with 'truth', as Foucault might have advised himself. Why is it so important to know that there is no teleological truth unless one must behave accordingly? Why, after all, must we be fixated upon the rational maximisation of resistance or agency, unless we have also presumed that this is what people really want (or should want in the eyes of philosophers). Rather than focusing only on the dubious claims to truth/power, we may instead find out how people actually make the most of the inferior material, what scope of possibilities they have within the constraints they find themselves in, whether or not they can ever be truly 'free'. 
Political constructs can never be indisputable claims of truth, but they provide the necessary mediation between the insidious workings of power and the impossible demands of agency/resistance. The necessary 'fictions' of political constructs are precisely what keep power circulating. It allows 'tactical' movement where power relations, 'connecting up with one another, attracting and propagating one another, finding their support and their conditions elsewhere, end up describing the whole systems'. Such movements are essential in Foucault's conceptualisation of power relations as organised in a complex and evolving network, rather than in a fixed line of command that can be simply abolished (Foucault 1980a:94-5). All this, in turn, provides more or less scope for strategic action, and varied experiences. The capacity of the network in this sense, rather than a particular play of dominance and resistance, is the focus of this thesis.

\subsection{A Strategic View of Power}

An apparent difficulty in utilizing Foucault in a political analysis is his dislike of 'metanarratives', including ideologies. Foucault's particular bête noire, long dead now, is the Althusserian 'base-superstructure' metaphor. A brief summary of his objection will suffice here. On the one hand, the master force of history moves the 'economic' base through successive modes of production. On the other hand, this seemingly deterministic history has nonetheless a heroic subject, the proletariat, which only has to throw off its false consciousness to become one with history (Foucault 1998:301). This for Foucault is utterly unsatisfactory, so much so that he wants to do away with the notion of ideology, which has its root in Marx's dialectics, altogether. Ideology, Foucault argues, necessarily presupposes something else which counts as truth, a subject as the carrier of that truth, and a reductionist focus on material economic determinants (Foucault 2000:119). That is no great discovery. Foucault however succeeds in showing some of its more insidious taken-for-granted dichotomies which reinforce the ideological one, for example, between power and knowledge, between domination and resistance. In this way Foucault saves political analysis from some tedious detours: there would be no need to 'speak truth to power', if power would willingly listen to those who did not have it in the first place.

The problem however is Foucault's strategic approach to this point. The analysis of power, as Foucault claims, should be concerned 'with power at its extremities, in its ultimate destination, 
with those points where it becomes capillary', rather than with 'regulated and legitimate forms of power in their central locations' (1980b:96). Accordingly Foucault's subject is not the politics of nation-states but sexuality, medicine and madness. But this does not engage with the political centre; it attacks where the defence is necessarily weakened by the misplaced focus on the centre. It is one thing to say the 'centre' is no longer central, but quite another to explain what to do with what used to be there. Foucault himself later back-pedals from this explicit privileging of the micro by claiming that such a study of the microphysics of power is 'simply ... a point of view' (2008b:186; also 2002b:326-7).

I am not arguing for the restoration of ideology's centrality, but rather that the 'de-centering' approach should not become a mechanical never-ending reversion. If globalising and 'totalising' concepts of ideologies are not what they claim to be, then it is necessary to find out what they are. If the error, as E P Thompson identifies in the common enemy of Althusserian structuralism, lies in 'the radical confusion introduced by a chance metaphor of basesuperstructure', then the alternative might be found in a more appropriate and less mechanistic metaphor (Thompson 1994:361; also 1978:109). We may reconceptualise 'structure', in E P Thompson's words, as 'the setting of limits and the exertion of forces', as 'actuation (limits and pressures) within a social formation which remains protean in its forms' (1978:110-1). A social structure is not a fortress but a living windbreak, which allows air to flow through, and bends and stretches in response to stress. Moreover, it functions as a strategic whole in response to pressures over time. It is not the individual trunk that resists change but the supple branches, which, joined together, distribute pressure.

The structural notion of ideology then may be thought of as epiphytic, and therefore distinct from the 'branches' of other social structures such as class, gender or ethnicity to which ideologies attach themselves. Ideologies, thus conceived, might appear 'fragile'; not immutable 'superstructures' anchored upon a permanent 'base'. But I would emphasize that ideologies are nevertheless a higher order of organism. More importantly this approach serves to highlight the paradoxical nature of ideologies. For one thing, epiphytes are not parasitic. The survival strategy is not to overwhelm the host, whose existence is already precarious. For another, the survival of ideologies also depends upon their flexibility and adaptability, rather than their robustness, to 
succeed. The delicate adventitious roots allow them not only to search easily for new bases of support but also to penetrate deeply into their hosts, capable of forming impressive mass. ${ }^{8}$

There is always a limit upon how much can be explained by analogy of course. I do not wish to suggest that ideologies just 'grow', nor that their degree of adaptability evinces certain 'laws of nature'. The metaphor is descriptive, not prescriptive.

Here one can call into operation another of Foucault's ideas, namely, the 'dispersion' of power. Foucault uses this idea in Discipline \& Punish, for example to describe the way 'power' is not a possession of the sovereign, but distributed throughout the whole social body in forms of knowledge and discourse (1995:299-305; cf. Jessop 2007:39; 2010). How certain logic of power is positioned, thus, confers strategic advantages or disadvantages upon those who use it. The more it manages to entangle and colonise other structures, the more energy it can pilfer from a variety of sources, the less likely that it will wither or die from sudden shocks. The logic of power is, in Foucaultian terms, 'strategic' in its outcomes (but not its 'intent').

This 'strategic' notion of power also offers, without resorting to the too convenient 'false consciousness', a measure of 'horizontal' or dynamic stability. The contradictions and weaknesses of ideological logic at the core might not become so imminent a threat if the same logic has a hold, or many logics have a hold, elsewhere on the social body. The traditional focus on 'sovereign power', we can see here, not only overestimates the vertical stability of the ideological 'superstructure', but underestimates the structural support from elsewhere; for example, when young people and their parents are socialised into a neoliberal mode of thinking through parenting advice long before they begin to deliberate on political issues. Likewise, the absence of strategic diffusion may mean the whole structure has to be steered hither and thither simply in response to unfamiliar shocks, and otherwise concealed contradictions and weaknesses might be disclosed in this messy process.

\footnotetext{
${ }^{8}$ Epiphytes such as New Zealand species Griselinia are capable of growing up to 20 metres tall for example.
} 


\subsubsection{Reconceptualising neoliberalism and the welfare state}

It is necessary now to sketch my approach to the notions of neoliberalism and the welfare state. We can gain a better understanding of the regimes by looking, in line with the observations above, not at what neoliberalism or the welfare state is - there are many possible definitions of their essence but at the deeply structural pattern in the way they worked through the youth questions.

I will begin with neoliberalism (even though chronologically it comes second) since it is often subject to Foucaultian analysis, where notions of technologies of government, or 'governmentalities' and more recently 'bio-politics' are employed. Thomas Lemke argues that, with such concepts, Foucault tries to grapple with the macro-political questions of the state which he sets aside in his earlier work, without falling back upon a reified notion of sovereign power. In light of this framework, Lemke says

What we observe today is not a diminishment or a reduction of state sovereignty and planning capacities but a displacement from formal to informal techniques of government and the appearance of new actors on the scene of government (e.g. NGOs), that indicate fundamental transformations in statehood and a new relation between state and civil society actors (Lemke 2002:57-8).

This may be taken as a working definition of neoliberal logic. Lemke elsewhere is more critical about the outcome. Neoliberal governmentality, he argues, is 'above all a political project that endeavours to create a social reality that it suggests already exists'. It is not just 'simply a reproduction of existing social asymmetries or their ideological obfuscation, but . . . the product of a re-coding of social mechanisms of exploitation and domination on the basis of a new topography of the social' (op.cit.:60). Lemke argues that this sophisticated apparatus of governmentality has served since the 1990s to entrench the more primitive violence of market fundamentalism; others on the left have agreed (Brown 2003; Dean 2008; Harvey 2005; Jessop 2010; 2013; Read 2009). Neoliberalism creates a powerful illusion that by saying no to state/bureaucratic power, and the associated claim to expert or scientific knowledge, to paraphrase Foucault's catchphrase in the History of Sexuality, one is saying yes to freedom. Within a neoliberal regime, becoming self-responsible is the only possible way of being free. 
The scope of critique however is heavily circumscribed if one were to read Foucault narrowly. Flew (2012:47) is certainly right to argue that Foucault could not possibly have anticipated contemporary critiques of neoconservatism, neoliberalism, or the 'Third-way' mutation that came after his death. The respectable Foucaultian has to abandon political critique in favour of suprapolitical or rather apolitical, and thus supposedly more permanent, notions of contingency, multiplicity and so on. In these suprapolitical terms, we are presented with one of two alternatives: either to dismiss neoliberalism as nothing more than a historical contingency, or to seek beyond its temporal manifestation in politics for a transcending 'parrhesia'.

In order to apply Foucault's insights, it is necessary to pick up where Foucault leaves off, namely, with the question of how. ${ }^{9}$ To begin with an analysis of how, we should see power, not as a 'thing' that exists, but 'the ensemble of mechanisms and procedures which have as their role or function and theme, even if they do not reach it, precisely securing power' (Foucault 2007:167). The implication is that, as Jeffrey Nealon (2008:32-42) explicates, while power is not a thing - and thus neither a good nor bad thing in itself - some ways of exercising power may still be more dangerous than others. And this is just where neoliberalism is particularly problematic, because it is inherently more 'intensive'. Nealon unpacks this notion of intensification in terms of efficiency and saturation.

'Efficiency' means a general avoidance of the costly mechanisms of explicitly coercive discipline and domination, which inevitably, as Foucault would argue, 'produce' resistance with commensurate strength. There is also less need to find justifications for such coercions which tends to beg the question of legitimacy. 'Saturation' emphasizes the shifting focus of power from a specific instance - the criminal, the deviant, the juvenile delinquent - to the whole social body (op.cit.:33). This is achieved, paradoxically, not by focusing on the social and its protean forms, but the underlay of the market with its singular coordinate of rational self-interest that serves as a conduit of power. In other words 'power' has come to terms with its own logic of selfpreservation (cf. above Foucault 2007:16-7). A key characteristic of the neoliberal regime, in other words, is its capability to exploit the self-reinforcing properties of power.

\footnotetext{
${ }^{9}$ One benefit of this formulation is that it dissolves the apparent difference between neoliberalism and 'Third-Way' ideology. It is debatable certainly whether the rise of the latter in New Zealand with the election of the 1999 Labour Government meant a return of certain social democratic values (the 'what'). The point was precisely that such values were meant to be delivered through the market (the 'how').
} 
To think of neoliberalism as an intensive mode of power does not require radical reconceptualization. It does, however, necessitate a tighter focus on the 'how' of power. We may then worry less about whether neoliberalism could be used to deliver a more ethical way of living, and whether it provides a better balance between agency and structure. Rather, we want to find out its strategic configuration, through which such potentials could be achieved, and how the deepening of inequality, for example, was realised.

The implications of this approach are much greater when we return to the welfare state. The usual approach to the 'governmentality' of the welfare state cannot resist pointing to its supposed hypocrisy, and often goes little beyond it. The lofty aims of equality and welfare often failed to deliver the goods and ended up as a mechanism of control (more coercive, though perhaps less efficient). This 'what' of the welfare state is not, however, an analytical equivalent of the 'how' of the welfare state. We still need an analysis of how it failed, not to be confused with the question of how successfully or not the welfare state delivered the goods of equality. We ought also to look at what it actually produced, if not full equality. And a close study of social pattern will allow a more comprehensive identification of these effects.

Through this approach, I wish to find an alternative to the implicit (intellectual) position in which any critique of neoliberalism as governmentality must also reject the welfare state, the latter being deemed to have been as duplicitous as the former by concealing coercion in a rhetoric of equality, as opposed to the rhetoric of freedom of neoliberalism. This says nothing about the welfare state as an alternative mode of control.

I propose an alternative to capture the characteristics of the welfare state. Instead of treating its rhetoric of equality as the rope from which to hang it, we can instead look at how it was put to work, alongside other rhetorics, within characteristic structures of discourse and power, and what effects the articulation of equality and other notions had on apparent political and social norms. In this way we can also see beyond the absence of a theoretically precise notion of the welfare state. Admittedly Veit-Wilson (2000:22)'s charge that most of the academic 'welfare state industry' fails to meet the 'elementary' test of 'discrimination' and 'usefulness' of its subject matter has not yet given birth to a new consensus (see also Levi-Faur 2014:4-5; Wincott 2013). But this analytical difficulty does not therefore negate the existence of the welfare state. In fact we may take it as a useful pointer towards some other way of understanding. 
The stubborn resistance of the welfare state to being reduced to an essence is itself rather revealing. In many respects the way power was exercised under the welfare regime suggests a textbook example of how power ought not be exercised. It was often explicitly top-down, coercive, 'juridico-political' in its manner, emanating chiefly from the state, in other words quite the wrong way to conceptualise power, as Foucault might suggest. But it is not conceptual questions that we should ask about, at least not here, but rather what actually happened when power was exercised in this way. We might find such attempts were constantly frustrated by distractions, and all too often they ran up against obstacles, for example class divisions, the very existence of which the regime vigorously denied. We might also find that the seemingly easy task of imposing conformity on the few actually revealed differences among the many. In this way, the exercise of power was productive of social and political diversity, in spite of, or rather because of, its conceptual failure to account for them. The methodological point is that our analysis should capture these characteristic paradoxes, because it was how the welfare state operated in spite of its lack of success. This is far preferable than seeking to explain those paradoxes away.

This proposition breaks away from a particular trajectory of Foucaultian orthodoxy, which takes the rise of bureaucratic and professional expertise under the welfare state, or more broadly an appeal to a positivist human science, to represent a mode of governmentality. The thesis has impeccable pedigree in Foucaultian scholarship (Rose 1993:284-5; 1996:38-50). As I will show, however, in the case of postwar New Zealand, the operation of this expert knowledge/power mechanism depended explicitly and critically on unstable notions such as welfare and egalitarianism rather than depoliticised constructs of individual responsibility as was the case in the neoliberal period. It could therefore never entirely separate itself from social complexity and conflicts. Expert discourse often became part of a much larger and more complicated political discourse about the meaning and implications of welfare and did not drown out other voices. Moreover, the complexities and conflicts, including class, gender and racial divisions were compounded rather than ameliorated when they were simply assumed away by appeal to a moral consensus, instead of being managed carefully through discursive and non-discursive means., 


\subsubsection{Rethinking class, gender and ethnicity}

The analytics of welfare state and neoliberalism constitutes one layer of analysis. The other layer of analysis examines class, gender and ethnicities, in terms of how social divisions may be constructed, or articulated, in these terms, given the particular configuration of ideological regimes. Here then is another break with the orthodox Foucaultian approach, which has done much to undermine confidence in the utility of such terms.

'Class' is clearly the most problematic of the three, because of its central place in the Marxist 'metanarrative' as well as in the New Zealand variant of the 'classlessness' myth. ${ }^{10}$ The myth is easy to dispel, if we look close enough at its construction. The conceptualisation of class presents a more fundamental challenge. My goal here, however, is not to provide an updated definition of what class was/is. There have been many recent efforts along these lines (Atkinson et al. eds. 2013; Eley \& Neild 2007; Savage 2000; Skeggs 2004; Strangleman 2008; Wright et al. eds 2005). But such attempts to revive class analysis runs the risk of collapsing into, as Crompton (2010:22) puts it, 'pseudo-debates' over definition. This does not mean that the risk cannot be minimised. It will be counter-productive, nonetheless, to attempt to prove the objective existence of socio-economic classes in New Zealand, and then trace its reflections in discourses about youth and society.

One can still talk about 'class', to follow E P Thompson, in terms of its making or unmaking without having to present a product that could only really be finished by the historical process itself rather than by analysis. To see class in this light allows one to reconcile class analysis with Foucault, notwithstanding his phobia about anything that comes into contact with structural determination. To frame it in Foucaultian terms, one can focus on the 'how' rather than the 'what' of class. How socio-economic inequalities are constructed into class, or deconstructed into something else, is precisely how class is put to work in social relationships. The 'base' and 'superstructure' may be bound together, but there are or can be differences in their movement against forces that may come at them from different directions. A relative reduction in the scale of inequality then does not in itself necessarily imply a political ideology of classlessness (or vice versa). And a political ideology of classlessness does not foreclose, in turn, the possibilities of class being articulated in other spheres in other ways. The point is that they are not

\footnotetext{
${ }^{10}$ For a recent review on 'lacuna' of class analysis in New Zealand see Crothers 2013.
} 
autonomous from each other. The crown goes one way, the trunk another and the risk is that it may snap. It is possible to isolate potential points of pressure where ideologies, cultures and other forces pull in different directions. And in doing so we rationalize the way class operates, or in other words, deploy a certain 'governmentality' of class.

Gender and ethnicity, in contemporary New Zealand scholarship, are less problematic. The limits upon their utility as analytical concepts however are exactly the opposite of those of class. The fear of the deterministic power of class is mirrored by the embrace of the liberating/emancipatory potential of gender and ethnicity, framed particularly in terms of identity politics. The development of critical notions of gender owed much in its early days to the vigour of opposition to reductionist class analysis. And some feminist theorists unsurprisingly find a natural fit both in their own challenge to the 'metanarrative' of class in Foucault, whose writings, however, said very little about women explicitly, and in post-structuralism/postmodernism (Ramazanoglu \& Holland 2002:89-90). But gender studies have long moved on. And the distance is marked by the very term 'gender'. We can now take for granted that it is not just about women and feminism, but gendered relationships, albeit still tethered to the inequality between men and women. It has been more than a decade since the field of masculinity 'came of age' (Kimmel 2002:ix; also Connell 2005). And there is Queer Theory which has been complicating scholarship on sex, gender and sexuality for some time. Women, men and queers, all in the plural, have more recently been joined by a resurgent 'men's studies' which among other things represents a step away from gender in searching for the equivalence of the long-established 'women's studies'.

One way to deal with the vast output on 'gender' is to take up again the theoretical instrument of 'decentering' which feminist scholars have deployed successfully against 'class' dominance. And just as one need not begin from class as completed structures, gender analysis may begin elsewhere than in the identities produced. There is no need to labour the point that identities, gendered or otherwise, are always in the making. What we need is new ways of posing the question about how they are made. Moreover, there needs to be more ways out of the dilemma of identity politics than more creative ways of playing at the game of essentialism, say, by employing postcolonial scholar Gayatri Spivak's 'strategic essentialism'. 11

\footnotetext{
${ }^{11}$ See Avril Bell's 2004 PhD thesis for application to Māori.
} 
This is not as hard as it may seem. After all, identities are not responses to essay questions. They are not often thought of as a 'way of becoming'. Nor is there a mysterious force which confronts individuals with the existential question 'who are you?', and such a force does not stop to muse about 'what is power', as Foucault might say. Analysis should be concerned not with individual identities as such - that must be left to human agency - but rather with social structures which influence the making of those identities. In other words it is possible to be led towards a gendered way of thinking, though never to a conclusion about gender.

Equally, analysis should be concerned not just with the 'hard' limits upon gender identities, for example traditional ideals of domesticity or heterosexism. It must also be concerned about the efficacy of these rules which, once imposed, have to be lived out by people themselves. These rules may be contradictory or ambiguous. The contradictions and ambiguities, more importantly, might be mediated by other structural notions or ideological constructs so that they are amplified or muted. Conversely they may themselves mediate other social relations. In this complex circuit, there are different entry points to bring pressure to bear upon 'gender': one can begin from 'sex role' or the heterosexist logic of sexual pleasure, with long or short routes to the interior of identities. And tensions may simply be redirected to other parts, thus posing more of a threat of instability to the whole, or they may be absorbed and dissipated in the process.

To take this viewpoint, I also consciously avoid the influential notion of 'intersectionality' - the idea that oppressive institutions, sexism, racism and so on cannot be studied separated from each other - but not because of the lack of its utility. More recent scholarship has emphasized the importance of (structural) power in producing intersecting inequalities against the charge that intersectionality privileged identities over structural power. Cho et al. argue that intersectionality can help to reveal 'how power works in diffuse and differentiated ways through the creation and deployment of overlapping identity categories' (Cho et al.:2013:797-800; see also Anthias 2013:15; Kerner 2012). There is much common ground, but in line with the general Foucaultian thrust of this thesis, I wish to examine how diffused and differentiated are these different ways of exercising power, and how varied are these resulting categories of identities. In the same way ethnicity can be brought into this analysis, one which goes beyond the impossible choice between the limit of identity politics on the one hand and the arrogance of structural theory on the other. To think of power as diffused and distributed Foucaultian governmentality, and as 
power relations, helps us think more carefully about who bears, or should bear, the responsibility and burden of identity making, and what the consequences for politics are. It makes explicit the terms of 'recognition': 'you figure out how to be different enough so we can feel you are not me, but not so different that I am forced to annihilate you and thereby fracture the foundation of my exceptionalism’ (Povinelli 2002; 2012:81).

This game of power implies an inherent power imbalance where the onus of identity politics falls on the weaker player, Māori society, in the New Zealand context. Pākehā identity, by contrast, was not under constant scrutiny and authorisation by others. Pākehā society could get on with reinforcing the material structures; for example, capitalism, which was also part of its identity. This had not always been the case, of course. For example, when postwar [Pākehā] society got anxious about its non-conformist young people, it was lured into a battle over identity. And this was precisely when Pākehā society became so over-confident about its own identity, and took that mistakenly to mean not only ideological monopoly but also cultural homogeneity, that the whole façade fell apart.

Taking class, race, and ethnicity together as overlapping analytical lenses broadens the possibilities for analysis of the political dimension of historical changes (also see section 2.3). We can again think of the making of 'structures' as entangled growth: they do not always come from the same tree at the same time. Equally importantly, it also means that the analysis of this entanglement as a whole need not be handicapped by radical breaks or sudden growth which seem to lead nowhere. For example, the postwar discourse of 'working mothers' is radically different from the 1990s discourse of 'fatherless sons'. The (Foucaultian) lesson we can take away from a radical break like this is not simply the inherent instability of a gender order in the face of social change. Nor is it only an epistemological point about historical contingencies and openness of identity categories. Instead, we can explore how the changing construction of gender allows new structural formations to emerge around a changed political logic. We can think of gendered regimes not as structures per se, but structured ways of exercising power. The question then is not whether such 'structures' are stable, but rather their stabilising capacity, a factor which is critically dependent upon their strategic alignments with other structural forces, and the overarching political logic. From the opposite perspective, we may find out how people 
themselves make sense of these interlocking mechanisms they find themselves in. Instead of asking how they can break through certain structures of gender, class or ethnicity, we may pay more attention to how they respond strategically to multiple pressures. This kind of analysis recognises, as Foucault does, that 'resistance' should not be conceptualised as a simple negation of power/oppression. Resistance can, and often does, consist of making use of the contradictions and inconsistencies within a complex network of power. It is important then to look at the extent to which people can move in such a network and question the operation of power from different angles, without having to be on the 'outside' of power.

\subsection{Understanding the Historical Process}

The possibility of such a political analysis depends critically upon the conceptualisation of history, which provides its content. And here, Foucault poses both a challenge and an opportunity. Foucault's conceptualisation of history, as a series of radical discontinuities, has often been reduced to the statement that history is not progress. This might, in turn, be easily conflated with a crude positivism where one contingency succeeds another. But Foucault wants, on the contrary, to dispense with 'abstract, general and monotonous' forms of changes for which 'one so willingly thinks in terms of succession', and instead to conduct analyses of 'different types of transformation' (quoted in Olssen 1999:206; also Flynn 2005:120). Moreover, it is only through such a 'structuralist' analysis of social transformation that paradoxically one can 'really grasp both the discontinuities of events and the transformation of societies' (Foucault 1998:431). 'History, then', says Foucault, 'is not a single time space' but a 'multiplicities of timespans that entangle and envelop each other' (1998:430).

The problem is that this challenge to 'traditional history' is a two-step process. The first, arguably, is now the consensus, that is, to do without a totalising historical narrative revolving around an essentialised notion of the subject, for example, a history of youth. One may write about how different notions of young people might be constructed in different historical periods (Savage 2008; Eisenbichler ed.2002; Heywood 2001). Yet this first step, rather than preparing 
for the second - the analysis of the entanglements - often appears to overshadow the latter. Foucault's own attempt to disentangle 'traditional history', for instance, produces a bewildering list of 'series', 'levels', and 'positivities' that complicate the matter even further than is necessary (2002a:187-95).

This long retreat from metanarratives risks distorting Foucault's insight about the relationship between history and politics. Foucault's quarrel with 'traditional' history is that it could not help but be political. For Foucault, the more historians try to write 'history' by excising human prejudices and caprice, the more they reinforce the Enlightenment ideology of the subject which will learn history's rational lesson (Foucault 2002a:13). That particular ideology is no longer fashionable in historical narrative, but Foucault's critique implicitly raises a different question, again, of 'how'. If history is political, then it is important to ask how it plays the political role, whatever that role might be. The risk is that as history disassociates itself from unpopular 'metanarratives', and retreats into the background, it is capable of exercising far more subtle influence with much less potential opposition. As 'traditional history' stops trying to explain too much, it is able to defend its ideological foothold rather more efficiently. This is not unlike the dilemma of the state: it could lay claim to controlling all human activities, and potentially overburden itself; or it may find other more cost-effective levers of exercising power. A modified 'traditionalist' narrative, in this way, can provide effective reinforcement of the new mode of governing under neoliberalism.

One example, crucial to this thesis, are the notions of a 'conformist postwar New Zealand', and its heterogeneous successor, which persist in both serious and popular histories.

Postwar 'New Zealanders', according to one respected historian Michael King, 'mostly valued conformity and predictability in the behavior of fellow citizens'. A few 'cracks in the plinth' appeared, but the 'real rebellion awaited the 1960s and 1970s' (King 2004:431,434, italics added). King offers as support for this thesis the 'social pattern': 'clothes of the day tended to be drab by previous and later standards, and short-back-and-sides haircuts were part of the national male uniform' and so on. And indeed, 'the only apparent interruption to the even tenor of New Zealand life was the Mazengarb inquiry, a case of conformism going over the top' (King 2004:431-2, italics added). This brief, though categorical, statement about 'New Zealand society', is followed by extensive and careful discussions about rebellions framed in terms of 
gender and ethnicity in the following two decades, which are the centre-piece of two chapters on 'revolution'. The 'social' appears therefore but is fractured by this sharp differentiation between 'conformism' on the one hand and 'revolutions' on the other. For the postwar era the political consensus - 'the welfare state was an institution most New Zealanders wanted to retain' (2004:423) - allows the political and the social to coincide happily on the historian's chart. The $\mathrm{X}$ axis reads 1950s; the $\mathrm{Y}$ axis tracks of 'political consensus' and 'social conformity' are close enough.

Such narratives are inevitably informed by, and in turn inform, social and political discourses. The ideological implications of accounts in contemporary popular histories such as Frontier of Dreams (Dalley \& McLean 2005) are implicit but unmistakable. The chapter on the 1950s, 'Golden Weather', is stuffed full of stimulating data, and the 'status quo' is described as 'more interesting than is often assumed' (op.cit.:330-1), but this nudges rather than overturns the conformist thesis. The real excitement, the authors make clear, comes later. 'Breaking Free: 1984-2005' is the title:

The big revolution was social. Early $21^{\text {st }}$ century New Zealand - less blokey and egalitarian, more racially divided, ethnically diverse, pluralistic, urban and better educated - was more culturally self-confident, and culture leads politics. The stage has been set for the dreams of the under 30s who now shop at Asian food markets, listen to Polynesian or Māori radio as often as ZMFM, and whose career and lifestyle choices may be between Amsterdam and Auckland, Dunhuang or Dunedin (op. cit.:365).

We can argue about the tone and the content of such passages, whether they are exciting or depressing. But what then escapes notice is the way that history is thereby epistemologically 'flattened' into discrete 'choices', so one might have a little less of egalitarianism and more of ethnic diversity, but not both at the same time. And within this construction of the historical context, the scope of political action is inherently limited.

What is curious about this sweeping picture of historical change is that it relies as much, if not more, upon the contrast between the 'conformist' patterns and non-conformist ones as upon the actual unpacking of either. It is especially the case of the 'conformist' thesis, which without 
exception comes down upon the Mazengarb inquiry ${ }^{12}$ and the characterisation of it as a moral panic $^{13}$ as its trump (and often only) card. The society was conformist, because it panicked over morals. And yet the 'moral panic' has narrative more to do with the lack of alternative assumptions about society other than that it was 'conformist' and thus obsessed with morality, than with the multitude of discourses that emerged in the Mazengarb inquiry, as I examine below. That multitude of discourses has tended to be dismissed as noise. ${ }^{14}$ So here we have a circular argument.

Why not instead explore whether the maintenance of a consensus in the 1950s was itself at least as 'revolutionary' - assuming that 'revolution' is a useful label- as the strongly individualist causes that marked the following era? Who, after all, set the stage for the triumph of 'youth'? This will enable us to identify what exactly was contingent in the past, and those forces which continue to function in the present. And in this investigation, we need to pay attention not just to the 'excluded' but to those who did the 'excluding', and avoid creating a contrived sense of closure.

\subsection{Discourse}

Discourse analysis has a privileged place in Foucaultian studies. As Foucault himself puts it, power could not be operated without 'the production, accumulation, circulation and function of a discourse’ (1980b:93). My analysis demonstrates, as Norman Fairclough, the leading scholar on 'Critical Discourse Analysis' argues, a dialectical relationship between meaning-making devices in text or language and social process (Fairclough 2013:230-1). The material is largely composed

\footnotetext{
12 The Mazengarb inquiry (formally Special Committee on Moral Delinquency in Children and Adolescents) was set up by the National Government after an outcry over teenagers' sexual misbehaviour in Lower Hutt and other incidents.

${ }^{13}$ It is worth noting that more recently social theorists have moved away from the simplistic model of 'social regulation, manipulation by the powerful and deviance amplification', towards a less loaded theory of 'everyday ... process of moral regulation within and beyond the State' (Hier et al. 2011:260; also Ungar 2001:277; also Critcher 2008a; 2009; Hier 2003; 2008; Rohloff \& Wright 2010). Yet the application of such theories seem to replicate the very problem that it seeks to address: the new theories were applied almost exclusively to 'new' problems of 'risk societies', rather than challenging the misconceptualisation of the past.

${ }^{14}$ There is, of course, one alternative explanation. Guy (2009:436) also protested about the extensive link between the Mazengarb inquiry and moral panic. His reasoning, however, is that postwar society cannot be accused of overreacting when it was acting out its conservative morality.
} 
of archival research of public discourses produced by popular media, academia, government and the market.

My justification for this 'methodology' is partly pragmatic, and fundamentally political. I do not particularly wish to distinguish this methodology from other possible ways of dealing with discourse, e.g. 'levels of discourses' versus 'socio-cognitive', as is often done in dissertations now (see Wodak \& Meyer eds. 2009 for an overview of different methods). As Fairclough (2013:227) rightly argues it is 'misleading' to 'overemphasize' and 'institutionalize' such differences. Nor would I claim that as a methodology it is necessarily superior to, say, qualitative studies or autobiographical research, which are different entry points to the dialectical relationships between individual experience and social structure. It is not methodologically superior either to even the 'worst' kind of 'traditional history', in Foucault's terms. In whatever way researchers position themselves and clean their lenses, before they look, they are still looking at the dialectical relationship between text and non-text, discourse and power. More important is how analysis is actually carried out, whether or not researchers acknowledge what they find. In fact, if the 'utility' of methodology is the only concern, it ought not matter whether the analysis still harbours false hope for the ultimate truth or 'objectivity'; useful knowledge might still be produced efficiently in the process with all the necessary contradictions.

The real advantage and the argument of discourse analysis, however, is political. And this aligns with the political orientation of this thesis, as I have set out in Chapter One. Indeed, a central risk to the legitimacy of discourse analysis as one useful tool comes from those who are eager to decouple the method from political or moral critique (Kendall \& Wickham 1999; 2006). Foucault himself provides the cannon fodder for this 'anti-politics' of discourse analysis. Much could be made, for example, of his use of 'surface'. Kendall \& Wickham (1999:37-38)'s much cited textbook Using Foucault's Method goes so far as to write 'we cannot go beyond this discursive "surface" to a "deeper inside" of "thought": the surface is all there is'. For example an industrial relations law, explain the authors, is not about industrial 'things', which have no independent existence outside the discursive realm of law. Conversely union strikes are to be thought of in their own discourse and therefore are no more real. This is a rather long-winded way to teach an old lesson, namely, that one must 'suspend second-order judgment', i.e. political claims (Kendall \& Wickham 1999:14-15). And moreover, it is difficult to see how else one can 
describe this discursive 'surface' as anything other than a thing-in-itself, which guarantees objectivity if one looks at nothing else. This is not very much different from the reification of social structures into 'material reality', a process which dismisses inconvenient contradictions as 'unreal'.

More recent Foucaultian scholarship has, however, gone some distance from this particular deviation of what might be called the 'linguistic' turn. Different ways to bring the 'real' back into discursive analysis have been suggested. Bacchi and Bonham propose to break away from the symbolic/material distinction $(2014: 175,191)$. The solution, as they seem to imply, quite rightly, is not just to substitute the reality 'out there' with the reality 'in here'. Yet there is a dilemma: how then does one capture this pervasive dialectical relationship, except perhaps by returning to the traditional pursuit of balance between description and interpretation of historical events?

I propose an alternative. Instead of trying to figure out the exact nature of 'discourses' through epistemological debates, we can make sense of them in the course of political analysis.

Discourses are material. They are connected to extra-discursive practices and fractured by their own contradictions. But this is what political and historical events are. This has two implications.

First, one cannot conceive a discourse as a determinant field. A discursive fragment, then, does not reveal its own causes or effects, or the 'necessary contradictions' that explain it. Instead it throws light upon the 'limits of acceptable speech', as Butler puts it (1997:34; 129-33). This is what one must endeavour to find out, that is, the general contours of a political terrain where a number of contradictory discourses can coexist.

Second, there is no reason to privilege one particular discourse over another. There are no rare archives in themselves which will yield special insights superior to run-of-the-mill editorials or parliamentary speeches. The risk is that one makes implicit judgment about what is really power, psychological text or legislative violence. That is not to say that they are all the same. The discourse of a parliamentary report on juvenile morals naturally invokes a different kind of power than the discourse of self-help parenting experts. Yet both discourses reveal how power might be exercised, in a particular society, on bigger or smaller subjects.

\section{4}




\subsection{Conclusion}

Discourses, as I have just argued, are not textual 'surfaces', abstract objects of analysis, but rather material parts of the historical process. This last point is consistent with the overall argument of this thesis that a Foucaultian framework needs to be made more concrete, and it needs, first and foremost, look beyond the epistemological 'decentring' of political power and 'deconstructing' of structural concepts, as it is commonly conceived. We may instead begin with Foucault's strategic notion of power. The first task of analysis is to understand how ideological narratives, including those of class, gender and ethnicity, were positioned across the social landscape under different regimes. The second, perhaps more importantly, is how they managed the actual collisions of the social and the political, and with what effects. This differing degree of strategic capacity - their relative 'intensity' - is a key point of difference as I argue between the welfare state and neoliberalism. To undertake such an analysis requires a sensitivity to historical complexity, a [modified] Foucaultian framework recognises that this complexity cannot be adequately accounted for by insisting on abstract 'discontinuities' which, in its dogmatic rejection of 'metanarratives', also refuse to look at the ways political narratives were more or less strategically interwoven into the rich fabric of social discourses. Social patterns, thus 'depoliticised', lend themselves to simplifications no better than ahistorical (ideological) metanarratives that they sometimes purport to challenge. It is necessary, in this thesis, then to unpack the conventional notions of the social as well as political patterns. 



\section{Chapter 3 Family and Youth 1950-1965}

By instinct as much as by reason, postwar society looked to the 'home' for an answer to the 'new' social problem of youth (The broader question of juvenile delinquency is discussed in Chapter 5, which necessarily overlaps with this chapter with its focus on the discourses around family). The centrality of the family, as an ideal construct, was evident in the almost invariable emphasis on parental control, or the lack of, in the discourses about juvenile 'immorality'. Commentators seldom challenged the principle of discipline, even though they often disagreed about its form and purpose, nor did they seriously contest the underlying presumption which saw no difference between young people and children as dependent subjects of parental authority.

It has been too easy, then, to fold this authoritarian impression of the postwar family into a general thesis about the 'conformist', and by implication repressive, social pattern. Historians talk about a 'reversion' to the interwar 'cult of romantic domesticity'. 'It romanticised not only marriage and women's domestic lives, but also childhood, parenthood and married men's lives'; in short an all-encompassing ideology, driven by, as Belich has it, a desire to return to a 'normality' disrupted by the recent war (Belich 2001:490-1). More importantly perhaps, it was a state-sponsored domesticity, symbolized by the ideas of family wage and family benefits. It was the conservative underbelly of the seemingly 'progressive' welfare society.

This return-to-domesticity thesis remains the conventional wisdom. While most historians are not blind to inconsistencies in the reality, the domestic ideology is still portrayed as hegemonic in most accounts. Philippa Smith refers to a 'collective identity framed by domestic ideals, marriage and the family' fostered by postwar governments (2012:195). The Frontier of Dreams decries a 'cult of domesticity' in post-WWI New Zealand imposed on middle-class women, 'reinforcing Victorian beliefs that their rightful role was as homemaker, nurturer of children and dutiful companion to their husbands' (Atkinson in Dalley \& McLean 2005:264). Yet 'comfort, security and return to normality was all that most people wanted in the 1950s and 1960s' (Dalley in Dalley \& Mclean 2005:308). A recent history on postwar New Zealand says nothing new, when after 'mounting tensions' are laboriously underlined, it returns safely to the 'settled domestic idyll of young suburban families'. It was a 'vision [which] accorded with wishes for 
much of the population'; a 'consensus ... about what New Zealanders wanted and how they envisioned the future'; 'an aspirational ideal based on hard-working, happy nuclear families in a culturally homogenous dominion still deeply loyal to Britain' (Carlyon \& Morrow 2013:43).

The impression is that the twin pillars of domesticity and welfare were built upon something strong, even if unanalysable and irrational. It offers itself as a ready explanation for the way things turned out with regard to young people in the 1950s. A society so firmly attached to a conservative patriarchal mode of domesticity, bent upon tethering its womenfolk to the kitchen, could hardly be anything but oppressive for the teenagers. And it is unsurprising that working mothers were blamed for juvenile delinquency, for they were just as much an enemy of domesticity as rebellious teenagers.

This chapter challenges the conformist thesis. It argues that discourses around youth brought domestic morality into public debate and exposed underlying social and political divisions. It was an important opportunity, for adult society, to rethink the fundamental role of the family in relation to state and society, the rights and responsibilities of mothers and fathers within the family, as well as their relationships with young people, as will be discussed in 3.1. These discussions made domesticity a social issue like the youth question, and not just a moral construct. The debate over domesticity also helped to bring to the surface otherwise often unnoticed changes in postwar class, gender and ethnicity regimes (3.2). In this way, the discourses of domesticity often served to raise difficult questions about what social norms were, or should be, within a new political context, rather than how families might be regulated more effectively in line with social expectations. Far from being dominated by mid-century expert wisdom about child-rearing, there was a rich discussion about the meaning and implications of the welfare society. 


\section{Part 1}

\subsubsection{Youth, Family and the Nation}

Instead of domesticating the social problem of youth, the conflation of home and society in the discourse about young people placed the home, which could no longer be understood as a selfenclosed and self-sufficient moral refuge, in a social context and opened it to public scrutiny. And the critical spotlight often fell upon the grown-ups, not just in terms of their inadequacy as parents, but also their moral failings as adult citizens. In other words the contradiction between virtuous parents within and 'irresponsible' adults who shaped the society without undermined the line of discipline.

The list of 'adult delinquencies' was virtually endless. The adage that there were no delinquent children but delinquent parents, and even 'delinquent society', was frequently bandied about in public discourse and, combined with the haphazard search for 'root causes', threw up a whole host of potential adult delinquents competing for attention with their younger counterparts. 'Selfish' working mothers were obvious but not the only targets. Gambling and drinking were other obvious causes of adult delinquency. 'The T.A.B., the New Zealand drinking hours and the five-day week', rather than working mothers, were the 'chief causes of immorality' as one letter-writer put it (Dominion 27 September 1954). And this was not an unusual claim. The demon drink was denounced publicly, alongside 'pagan homes', by no less than the Minister of Police, supported by his officers (NZ Herald 11 Oct 1954). And one senior magistrate, widely reported by national media, blamed the T.A.B.: he was adamant that gambling in its various forms was 'the root cause of practically all crime, of practically all neglect of children, [and] of most broken homes' (Waikato Times 7 Oct 1954). If the father came home and talked about gambling or betting or 'how he put one over the boss today', it could not but 'instil in the young minds the idea of easy money or getting something from nothing' (Evening Post 7 Oct 1954). An editorial in the Auckland Star went further. It blamed the whole 'social environment' created by adults, which included 'the spectacle ... of excessive drinking and gambling, with the state itself drawing additional revenue from every excess'. It included also as part of the 'way of life', 'two days in every seven in which a considerable number of adults, being forbidden to work, find little useful to do' (August 14 1954). Parental examples, rather than parenting skills, were often what 
exercised the mind of those worried about youth out of control. The Mazengarb report mentioned both gambling and drinking (1954:32-3;36-7). And its final words were pointedly directed at adult behaviour. Firm control was necessary. Yet what was 'most needed', as the committee stressed, was that 'all people should, by right living and by the regularity of their own conduct, afford the best example for the conduct of the rising generation' (1954:64).

Such claims about adult delinquency were perhaps nowhere near the 'real' causes of juvenile delinquency, although neither were they any further than the alleged effects of working mothers and broken homes. Nonetheless the point was that the moralising rhetoric had worked itself into a corner. Too much talk about conformity, or 'social adjustment', as the ultimate objective of parental discipline, made it difficult to overlook the fact that the 'conformist' society was not without its adult detractors. The authority figure of the ideal parent was fatally undermined. But in its place one might see the reflection of real diversity of postwar families. There was a wider cast than the pre-war bourgeois cult of domesticity, which, to start with, had no place for the postwar teenager, rebellious or not. Neither did it have room for overworked housewives or hardliving 'blokes' among the less respectable classes, let alone working mothers.

The state itself played an ambiguous role which can easily be overlooked since domesticity and welfarism were often conflated in retrospective memories of the postwar years. Many turned a blind eye to the state's intrusion into private affairs of the family in the form of a special inquiry on juvenile delinquency viz. the Mazengarb report. But there were significant traces of deeper distrust. The state, after all, was perfectly happy to share in the 'profit' of adult delinquency, as the Auckland Star editor quoted above argued. And more broadly, the state played the role of indulgent parents by dispensing its maternal welfare with seemingly reckless regard for morality or merit. And even if the state had good intentions, it might still supplant the private morality of the family. Upon the announcement of the appointment of the Mazengarb committee, the Bay of Plenty Times warned sternly against using 'state paternalism' as 'a community escape mechanism':

Today, the majority of people expect Governments and officialdom to do the correction. Rather than check their children's reading, they ask the Government to ban the so-called comics. They blame the schools for lax discipline when the fault is to be found in a refusal to recognise that the example should be set at home and that home is the first 
place where the parental hand should be applied. If the home atmosphere is consciously one of 'the world owes us a good time' then there is no cause for wonder when the children absorb the same idea.

The 'real remedy' was not 'child reformation' but 'adult reformation' (July 13 1954). Another warned that one should not fall for 'the modern tendency to consider the State as an omnipotent but benevolent father of its citizens, capable of assuming responsibility for all social ills'. The problem of juvenile delinquency proved the 'falsity of this concept' (Gisborne Herald Mar 7 1955).The report of the Mazengarb committee itself reminded its readers that the duty remained with them. New laws and stricter enforcement might allay the fear of parents about juvenile misbehaviour. 'It would be a pity, however, if parents were thereby led into relaxation' (1954:64). The conclusion was seized upon by the head of Otago Dental School. Quoting verbatim, he further argued the state had encouraged parents to do precisely that by, among other things, free dental service for children. It denied wise parents the opportunity to demonstrate their individual responsibility by paying fees (Otago Daily Time 26 Mar 1955). Yet even with all this it was hard to avoid the impression that the helping hand was no longer optional, and the 'family' could no longer be a self-sufficient fortress.

Here then was the first obstacle. The family could no longer be separated from the changing social context, and scrutiny of the former necessarily led to difficult questions about the latter.

\subsubsection{Enemies within}

As the ideal of the family became entangled in social changes, its internal dynamics also appeared increasingly problematic. Postwar domesticity could not simply be organised upon the old basis of patriarchal authority.

The new watchword of domesticity was not 'obedience' but security, which echoed the public ideal of social security. The pursuit of security for its own sake certainly had a dark side. At its darkest the exhortation of security functioned as emotional blackmail, especially of women. The suggestion was that adult challenges to social norms were necessarily at the expense of the younger generation's feelings of security. Opponents of the liberalisation of divorce laws seized upon the issue of juvenile delinquency to make their case. In an address to the New Zealand 
Institute of Public Administration, H G Miller, a noted intellectual and librarian of Victoria University, blamed juvenile delinquency on the 'decline' of the marriage sacrament which 'had become in New Zealand ... a contract that might be terminated by mutual consent with little trouble'. Children suffered as a result, he argued, because a 'clever' child who saw he was 'only an incident in a liaison that may not last' and whose ideas about sex were picked up elsewhere from the permanent bond of marriage '[did] not need to be neglected and ill-used for the trouble to start' (Marlborough Express 3 Jun 1955). The Anglican Bishop of Nelson, similarly, thought adults who broke the permanent bond of matrimony had no regard for 'the disintegration of society' and 'untold misery of individuals' that necessarily ensued. Every child from 'broken' homes, he declared, was a 'problem child' (Nelson Evening Mail 3 September 1954). Even the chairman of the Mazengarb committee appeared to let the appeal to emotion overrun legal logic when he attacked social acceptance 'of civil marriage and of judicial divorce without considering the totality of their effects on the future of society'. Society, 'for its own happy continuance' depended upon children who 'suffer most' when the parents preferred 'to part rather than compose their differences', he argued (Evening Post 22 May 1956). It was not insignificant that patriarchal norms, instead of being taken for granted, now had to resort to these tenuous thinking-of-the-children arguments. All the same, such arguments imposed significant costs on non-conforming adults, especially wives and mothers.

Preoccupied with social conformity, conservative commentators often did not bother to differentiate divorcees from working mothers. For them, both equated to rebellious women who refused to sacrifice their own welfare for the sake of 'home'. Indeed, 'broken homes' sometimes explicitly included families where mothers worked. Homes were 'broken' not 'necessarily ... by divorce or separation but by having both parents away working', as the American ambassador emphasized to his Wellington audience (Dominion 19 Jul 1955). Working mothers were chastised by a popular Methodist clergyman in Auckland who argued 'neglected families and the nation's loose morals are the price we pay for women's selfishness' (Evening Post 20 Jul 1954). They could go on enjoying all the privileges of marriage, lectured the chairman of the Mazengarb committee without 'giving up the advantages which spinsters enjoy as free agents earning big money' (Evening Post 22 May 1956). 
Pious indignation about working mothers was sometimes more a matter of spleen than argument. But secular authorities often reinforced the stigma of 'broken homes'. Official statistics that took 'broken' homes or working mothers as meaningful variables of juvenile delinquency, for example, not so much 'uncovered' as simply applied the conventional wisdom. The numbers themselves were often ambiguous. One analysis immediately before the discovery of juvenile 'immorality' found one third of mothers working in all cases of young delinquents, and over a fifth with 'broken homes', half of which were the products of separations and divorce. But while the press took this to mean a link between 'broken homes' and juvenile delinquency, senior bureaucrats prevaricated (NZ Herald 19 Apr 1954). Most 'broken homes' did not produce delinquents, acknowledged the Secretary of Justice, who was nonetheless convinced that criminality seemed to 'thrive in the wreckage of many a broken home'. Much more could be made out of such malleable evidence. Magistrates, for instance, frequently went further than public servants in their public pronouncements. The annual report for the Magistrate's Association singled out working mothers as 'one of the chief causes of juvenile crime', 'children who know their mothers are out at work may lose their sense of security. That may lead to delinquent behaviour' (quoted in NZPD 1954:2020).

The interplay between thick emotion and thin 'evidence' was also evident during the Mazengarb hearing. A senior school inspector for Wellington, for example, told the committee that homes where both parents worked were 'perhaps most disturbing of all' the things brought to his notice by social workers and others. And he was struck 'again and again' by 'what a terrible thing that split home [was]'. He clearly struck a chord in the committee chairman, who set his reply in a sentimental homily to the domestic scene. 'Don't you think', the chairman asked rhetorically, 'the happiest sort of home is the one where the child comes running in the front door and says "Mum what's for dinner tonight"” (1954:5A2 $\left.{ }^{15}\right)$ ? Such vignettes of an idealised middle class domesticity - be it the family kitchen or the family Bible - served as the anchor point for conservative commentators. Even Dr McLeod, the Director of Child Hygiene and member of the Mazengarb committee, was convinced that children who came home to a locked house before their mothers must invariably suffer from a sense of insecurity, which he believed was the root

\footnotetext{
${ }^{15}$ Transcripts of hearings of the Mazengarb Inquiry were not paginated, but instead indexed with a letter-numeral reference (5A2, 2W, 3X1, etc.). Hereafter I will use the style (Date: Index reference). The transcriptions are sourced from the Alexander Turnbull Library (ref: MS-Papers-2384).
} 
cause of delinquency, an assertion he repeated on various occasions (Nelson Evening Mail 6 Dec 1954; Dominion 4 August 1955). Feelings like this already foreshadowed the conclusion of the Mazengarb report. 'Happy and desirable' was 'the home where the children burst in expectantly or full of news concerning something that interested them', the report gushed (1954:36).

It is also worth noting that the particular section ('Home Environment', 37-9) on absent parents began immediately with a substantial discussion on 'feelings of insecurity' and the 'unloved child', which was clearly meant to lay out the underlying logic of its case.

Any child who feels unloved, unwanted, or jealous of the care and attention given to other members of the household suffers from a feeling of insecurity. This feeling of insecurity renders the child more susceptible to influences leading to delinquency. The mother's attitude to the child is of prime importance. There is a psychological link between mother and child from the very moment of birth - a link that can be substantially strengthened by breast feeding as far as it is practicable. The attitude of the mother to the child, even before birth, may well have a marked effect upon the child's sense of security $(1954: 37)$.

This was however more Plunket speak than psychobabble. And while it seemed a logical enough extension of the Plunket philosophy of mothercraft, it was not at all clear what all this had to do with adolescence. It lacked an explanation, say, of the notion of development and associated theories of 'early intervention', which would tie adolescent misbehaviour back to the individual/psychological problem of mothering, rather than to external social factors. The contemporary jargon of attachment theory or developmental psychology might easily have bridged these gaps. Urging the Mazengarb committee to set up child guidance clinics, Jean Archibald, a lecturer at Ardmore College, referenced Bowlby's attachment theory (WSMC 1954). ${ }^{16}$ The Christchurch Psychological Society made a go of Freudian psychoanalysis by pointing out the 'clear' parallel between infantile attachment to mother's nipple and sexual intercourse, but much of this seemed to have gone over the head of its audience (1954:5T2). The Mazengarb report simply reassured parents that they had no need for 'feelings of inadequacy owing to a spate of modern knowledge often expressed in semi-technical terms' (1954:39).

\footnotetext{
${ }^{16}$ Written submissions to the Mazengarb inquiry are sourced from Archive New Zealand (ref: AAFD 7523 W4198 172 Part $1 \& 2$ ). Submissions were not collected into a single file. They will be cited in abbreviated form (WSMC $1954)$ and included in the bibliography as a whole.
} 
Moreover, the notion of 'maternal deprivation', as a cause of insecurity and then delinquency, was meant to naturalise the gendered 'nurturing' role and responsibility of women. Yet too much stress on this point often seemed to defy the purpose by making all too clear and tangible the costs for women: the central imagery of Mother-in-the-Kitchen seemed to demand that women give up their careers and aspirations for nothing better than a couple of hours of after-school childcare. Certainly some women took the virtues of sacrifice seriously, and reverted to a somewhat older ideal of motherhood. It seemed to 'Poor Parent' that 'in saving your children you destroy yourself' and she could only hope, with an almost macabre sense of maternal duty, 'that if the children finally destroy me, I will find Heaven at the end' (Waikato Times 20 Jan 1956). By contrast an Auckland letter writer suggested, since juvenile delinquents had too much pampering and not enough discipline, as soon as they reached 14 years of age, 'they should be then be made to understand that having been housed and fed all those years they must then start to earn their own keep' (Auckland Star 16 Jul 1954). Between these two extremes something had to give.

The majority of women found one way or another to cope with the demand, made heavier not the least by growing concerns about youth, for their domestic labour. While the Mazengarb report rebuked working women - and it was not a blanket reproach - it also censured two other groups of inadequate mothers: women who unduly extended their 'social, and even their public, activities' and 'absentee' mothers who preferred to have some leisure time to themselves by sending their children off to the cinema (1954:39). The report drew attention, inadvertently, to a discontent within the domestic ideology which many housewives themselves might find easier to identify with than they would with radical notions of gender equality. Charity work had long been a respectable flight from domestic tedium, particularly for middle-class women. And one could only speculate that tea-parties and gossip afternoons provided for even more housewives a welcome reprieve from hard work. An uncompromising insistence on women's place in the kitchen precluded pragmatic negotiations that went on in that exact locale which paradoxically made the austere ideals of domesticity tolerable, and even enjoyable, in practice. In a curious way, the Mazengarb committee were presenting women with the same impossible choices 'housewives or human-beings' - as posed by Margot Roth from the other end of the political and social spectrum in a controversial broadcast in 1959 (20 Nov 1959:6-7). Roth wanted women to exchange their domestic work and domestic interests for the more edifying, and by no 
means less onerous, 'cultural' pursuits. Many women, however, worked with and around the contradictions. One correspondent in the Listener could be frank about her way of life:

We buy labour saving devices just so we can escape the drudgery of housework and get out a bit. Children do need you at first, but once they start school you should be able to have time for yourself. Everybody has their own way of extending themselves; I don't see why it should always be cultural, most of us aren't made that way. Me, I like this activity and the people I meet.

So wrote 'Louise', a part-time worker at a coffee bar, and mother of two (Listener op. cit.:7). Ordinary parents like Louise did not see only a 'choice' between paid work and unpaid labour; they wanted time and pleasure for themselves. 'It must be accepted', declared the Dunedin Evening Star that 'the practice of sending children off to the pictures or on to the streets so that parents are free to follow their own inclinations has become a factor of first importance in the spread of unhealthy associations' (26 Feb 1955).

Here working mothers found one response to criticisms levelled at them while they negotiated, like their stay-at-home sisters, the ideas of domesticity and gender norms. A common strategy was to appeal to the image of the 'good working mother' which attempted to outflank the prejudice against women's employment by insisting that working women were more than capable mothers ${ }^{17}$. This strategy was highly problematic, of course, since work was constructed as a necessary and selfless sacrifice of married women on top of their non-negotiable maternal duty, rather than as a right or choice as such. And it often pitted working women against housewives, rather than the patriarchal norms. One working mother, for example, turned the dewy eyed image of family kitchen on its head. It was true that there were not any hot meals waiting for the children when they came home. But 'how many mothers who stay home have a hot meal waiting at 3 p.m.', 'one of the working fraternity' asked rhetorically (Christchurch Star-Sun 4 August 1954). Another was indignant at the suggestion that working mothers were 'selfish'. She argued most mothers had to go to work when their children reached secondary schools 'to buy the clothes their children need and pay for this "so-called" free schooling'. Their wages helped to save husbands from overtime and get home early. Many were paying off homes

\footnotetext{
${ }^{17}$ Wilson (2005:216-22) demonstrates that the strategy, though not without significant costs to working mothers and other women, had considerable success in Britain.
} 
and very few indulged in drinks and racing. In fact, a married worker often spent 'more time at home than her more fortunate sisters' who enjoyed cinema matinées and spent frivolously on drink, morning tea, and ice creams. 'Not a penny of this [came] from their own efforts to help' (Auckland Star 21 Jul 1954). The debate could, of course, be less acrimonious and divisive. But by asserting their place within the gendered order, these working mothers were testing how far it could be stretched. Some might have actually tried to outdo the housewives, and vice versa, by ever more virtuous and deserving conduct. Others would catch on to the limits of recrimination and think critically about the underlying construct of womanhood, whatever form it took.

The domestic ideology came under stress from outside as well as within. The quaint image of mother-in-the-kitchen was certainly of enduring charm, but it was not all there was to the postwar ideal of 'security' in family life, which was increasingly indexed, in public policy as in private life, to an ever-increasing range of desires-cum-necessities. The automatic exemption from public scrutiny of women for whom it was 'necessary' to work was constantly grinding against varying definitions of 'necessary' (cf. Wilson 2005:216). 'Tamsin', a clergywoman and columnist for the Otago Daily Times, believed that what drove mothers of teenagers out to business was 'so often not a desire to escape housework, or to have a greater freedom from financial worries, but a desire to have the wherewithal for furthering children's education' towards a university degree, or a professional career, things which ordinary families could not dream of in the past (31 Jul 1954). Even a Napier minister who suggested that mothers should be banned from employment from 3.p.m. (and offered an increased family allowance) made allowance for women who wanted to send sons and daughters to university as well as those who wanted refrigerators and home appliances. 'And who are we to blame them - to sit in judgment on them? It is not easy to say that a woman should not want a higher standard of living', he said (Daily Telegraph 5 Oct 1954). The limits of necessity could not be extended indefinitely, and as will be discussed later in relation to social class (3.2.2), goods like refrigerators could be extremely controversial. But so long as the articulation of domesticity in a postwar society was based upon an old pre-war, and indeed pre-modern, template, there must be new needs which it could not have envisaged, and must thus accommodate. And this certainly applied to emblematic aspirations of postwar society, vague as they were, such as better education and better housing. 
This powerful notion of 'necessity' serves as a useful reminder that the conventional narrative of the return to gendered domesticity, driven by moral conservatism or exaggerated fear of insecurity, risks underplaying the significance and complexity of the postwar debates about paid and unpaid work. For many women and families decisions were still about securing the breadline - even if the 'breadline' was considerably higher than it was - and work of the kind available to them was a means to secure it. And if they appeared somewhat stupefied by grand questions about rights and duties, they knew how to drive a bargain. Labour politicians too understood this pragmatic reasoning and used it to their advantage, attacking the government rather than the mother. Labour MP Phil Connolly was typical. During a broadside on the budget, he made a point of working mothers and juvenile delinquency even before the Hutt Valley scandal. Brandishing a report from the Dunedin probation officer about high numbers of delinquents whose mothers were working, he continued, 'I consider that a wife has the right to go out to work if she wants to'. But he remained concerned that 'in some of the cases ... of mother going out to work the cause is the economic circumstances in which the families are placed' (NZPD 1954:27). It was not women's work but economic necessity, so central to the ethical imperative of waged labour, that was abnormal. Working people understood the strategy of forestalling attacks on the undeserving poor by insisting on righting the larger social injustice first. This strategy, unsurprisingly, failed sometimes. The Waterfront, a militant trade union journal, concluded from its interviews with working mothers that 'the principal reason' for mothers to go out to work was that the family wage was not enough to maintain 'a fair standard of living in these days of high price levels'. 'There are not many family women who would not prefer to be housewives and look after the interests and welfare of their husbands and children if they were in the economic position to do so and if they had that home of their own which is the objective of the great majority of our womenfolk' (reprinted in The Standard 8 Dec 1954). The tone was patronising, though the argument was robust. No one, after all, was talking about the right to a rewarding, or even edifying, career. The decision to work was about the 'necessity' of a certain living standard that could be met without backbreaking drudgery because the state could, or should, be compelled to provide it.

It may well be a testimony to the strength of postwar welfarism that this last link in the chain was seldom questioned. This placed conservative critics of working mothers on an awkward back foot, given that they were not often convinced of social security as much as they were of 
maternal security. A characteristic workaround was simply to assert that such necessities were no longer pressing in an era of unprecedented prosperity. 'Any man's wage nowadays will provide the necessities of life' wrote 'Family Manager' to the Auckland Star, 'I consider it an outrage for mothers of children under the age of 15 years to waste their time and intellect in industry instead of giving them freely to their families and home' (16 Jul 1954). The Minister of Social Security in the National government argued that there was no necessity for married women to have an independent income: New Zealand was enjoying 'so much prosperity that married women with children should wake up to their responsibilities in the home and stay at home' (15 Jun 1955 quoted in May 1992:144) . 'Seven or eight beautifully furnished rooms do not make a good home' she commented elsewhere; 'it was where the spirit of affection was that counted' (Evening Post 8 Nov 1955). The trouble was that such easy assumptions often served to highlight precisely the extent to which the reality of postwar society fell short of the prosperity gospel. Families crammed into two, or if they were lucky enough, three-bedroom state houses, could be forgiven if they thought these gospels of prosperity were not meant for them. Another letter writer thought it was obvious that juvenile delinquency was caused by mothers being compelled to work by high-living costs; 'yet, over the air comes the pronouncement of our Prime Minister, pumping into the people the idea that everything and everybody are happy and prosperous'. 'It just does not add up', he complained (Christchurch Star-Sun 15 Oct 1954). Such arguments were not really over the merit of work for women. They simply threw the spotlight back onto the state's commitments to domesticity and the broader notion of security.

Governments, while they were more than willing to listen to warnings of family and social decline, shut their ears to the clamour for a ban on women's employment. Four years later, a commentator in Parent \& Child, a widely-read magazine of the Parent and Teachers Association, observed that the warning about working mothers

has not been taken to heart by the citizens of N.Z. Income tax rebates favouring both parents working still remain, legislation does not exist to encourage 'mother' to stay at home, even when her children are found to be troublesome, nor are there well-run activities for the middle group of children who are bundled off to the pictures, by a certain section of the populace (Sep/Oct 1958:16). 
Among other things, politicians knew capital needed women workers. On the political right this economic necessity sometimes overrode social conservatism. While not letting women off their mothering duties, the National MP for Roskill thought nonetheless it was good that wives 'should go out to work'. 'How would we get on if some of our married women did not go out to work', he asked rhetorically; 'we rely on them to a great extent'. Even consumerism seemed a good thing: 'I know from the statistics ... that those married women are getting some of the amenities that they should have around their homes, and they are making their lives happier because they are going out to work' (NZPD 1954:26). The National government's budget introduced, around the same time as the Hutt Valley scandal, tax relief for working wives earning up to $£ 500 .^{18}$

Official support for domesticity clearly had a limit, and even the grave problem of juvenile delinquency did not sway it. This did not mean that one could underestimate the extent of state support, but as Melanie Nolan (2000; 2002; 2003; 2009) has argued persuasively, family policy during this period was inconsistent and contradictory. The state itself did not flinch from employing married women workers in teaching, nursing and the public service, shelving moral anxieties for pragmatic solutions to a labour 'shortage' partly caused by its own expansion of social security. It even went as far as taking over some burdens of women's work-life conflicts by, for example, providing maternal leave and extending training (Nolan 2000:219-29). Similarly, its attitude towards housewives and the 'traditional' family was ambivalent. The 'family wage' was relatively generous, although relative to what was another story. ${ }^{19}$ A family benefit eroded by the inflation that came with postwar prosperity was also indicative of the state's half-hearted attitude towards domesticity. The benefit, which was paid directly to women for teenagers and children alike under 18 as dependants, had in fact lost nearly a third of its value by 1958 (Nolan 2000:208-9).

\footnotetext{
${ }^{18}$ The average income for a labourer in 1954 was $£ 487$. The relief exempted working women under the threshold from having to aggregate their income with their husband (and therefore within a higher tax bracket). Without counting other exemptions, a crude calculation with the husband earning $£ 500$ annually and wife at $£ 200$ would give $f 12$ and 10s, which was slightly less than half of the family allowance (NZ Official Yearbook 1954:s.34). ${ }^{19}$ The 'affluent' male breadwinner in popular memory seems to have been constructed on a somewhat small foundation of modest rising GDP per capita and the slightly compressed distribution that economic historians have identified (Betram 2009:523-4; Easton 2013:30; Roper 2005:97). Whether the wage packet met the perceived needs of him and his family in an allegedly egalitarian, prosperous, society was an open question (also Nolan 2009:376).
} 
The state itself was thus caught in a difficult position. It was subjected to continuous lobbying for the increase of the family benefit. And the difficulty was often as much about fundamental roles of the state as pragmatic solutions to the specific 'problems' of working mothers as discussed previously. The miserly benefit, as one Labour MP saw it, meant the state was 'paying lip service to the family men' and making them work excessive overtime. The state had a 'duty' and a 'responsibility' to increase the benefit in line with the cost of living which would not only save the mothers from being forced out to work, but also pay for the breadwinner to be with their family at home more. The problem of juvenile delinquency, which he cited for support, added to the urgency (NZPD 1955:1555). But this attempt to defend the conventional family man also undermined him. Glossing over the question of how a man could or should manage his family within his means, it bypassed the patriarchal economic order, and took the demands of its members, children, mothers, and fathers directly to the state. This was, of course, what family benefit was intended for, as Nolan $(2002: 80 ; 2007: 125)$ points out, namely to dampen the wage demand by men. In other words, domesticity was meant as a cheaper substitute for security. But as questions of juvenile delinquency and working mothers pushed domesticity under the limelight, families were asserting their own needs and desires, and not just those of the patriarchal head, leveraging off the bargaining strength of working men.

The debate around juvenile delinquency, and particularly its focus on the working mother, was partly a reflection of outdated gender prejudice. But it also served to place the gendered regime of domesticity itself under public scrutiny.

\subsubsection{Parenting in the $1950 \mathrm{~s}$}

Talks about maternal care and psychological security were frequently preoccupied with changes in women's domestic and public roles, rather than parents' relationships with children and young people. The old top-down paternalistic style of discipline persisted, certainly. Even the Minister for Social Security still thought 'the first duty of a child' was 'to obey God through its mother and father' (Manawatu Evening Standard 14 Oct 1955). There was never any question of taking away the rod, literally and metaphorically, from parents. 'Spare the Rod' was the favourite penname for many letter writers. But parental attention and affection, in secular emotional and psychological terms, were plainly not optional extras to the imperative of familial authority. 
Rather a new parenting discourse had to be fashioned from competing emphases on care and discipline. The debates over the 'new' problems of youth accelerated this development.

In the first place, there was a growing recognition that the parenting of teenagers was a somewhat different matter from child-minding, and important in itself. There began a 'vain hope', as one NZ Herald editorial put it in reference to the Mazengarb report, that 'the principles of upbringing will presently become as much a part of the national consciousness as Sir Truby King's principles of mothercraft have been these many years' (20 Jun 1955). Yet public discourse about parental control still took Plunket mothercraft, and its associated terms, as the default starting point. It was evident, for example, in the Mazengarb committee's commentary on home and environment, quoted above (1954:37). The fixation with the needs of babies and children inevitably supplanted the ostensible focus on the emergent 'teenagers'. Moreover, with its heavy emphasis on the moral significance of physical health itself, 'Mothercraft' avoided rather than addressed the question of authority. ${ }^{20}$ This was not necessarily a fatal handicap. After all the idea of teenagers, since it was still very much in the making, was not a sure foundation for a new regime of 'upbringing'. ${ }^{21}$ But, having to do without the convenient template of adolescence, the reinvention of parenting had to confront directly the necessary contradiction between 'sparing the rod' and 'spoiling the child'; 'spoiled' among other things by postwar affluence and 'permissiveness', which filtered downwards into family relationships upon all its members.

This delicate balancing act took some unexpected turns. The Presbyterian Church, for example, thought it was natural and inevitable that in every home there should be 'anarchy' to be reconciled by patience and tolerance. It condemned instead the domestic dictators who '[sacrificed] love and justice in the interests of peace and order'. 'Justice in family conflicts is impossible without honest speaking about real feelings; and love is impossible without justice. Without love and justice there is no security for children', it reasoned ('Outlook' quoted in

\footnotetext{
${ }^{20}$ As Bryder (2003:118-26) documented, in the postwar era, the Plunket regime of routine and discipline came under pressure from the more 'permissive' approaches, via Freud, Spock and Bowlby, of child psychology in New Zealand. The debate raged over infant care and zoomed in on the symbolic act of breastfeeding but the supposed causation between maternal attachment and social adjustment implicitly downplayed the importance of adolescence.

${ }^{21}$ The idea of adolescence, built upon the Sturm-und-Drang model of developmental psychology, was welldeveloped and highly influential, but it was nonetheless not the same thing as the social construct of postwar teenagers.
} 
Christchurch Star-Sun 16 September 1954). More commonly commentators took the easier and less idealistic middle-road. Being too firm was just as bad as being too lax, and the Mazengarb committee blamed both for producing delinquents (1954:45). 'Over-strictness', reported the $N Z$ Herald on the authority of Cyril Burt, a British educational psychologist, featured in ten percent of delinquency cases, though no two sets of parents would be found to agree on what was 'correct strictness' (19 Apr 1956). And readers of Parent \& Child were warned that they could not be complacent about the 'docile teenager' who might 'fail to rebel' and must 'overhaul' their family relationship if that was the case (Sep/Oct 1959:9).

There were other ways of imagining home life which sidestepped altogether the paradox of discipline. One such way was to substitute the 'use of leisure' question for problems of discipline. It was 'extremely important', according to Health, official bulletin of the Department of Health, that 'the home should provide as many facilities as possible so that the [sic] young people are not forced to go elsewhere for physical exercise, pleasure and recreation'. Not only should parents encourage adolescent hobbies, the articles advised, they 'must take an active and not a passive interest in these pursuits, even to the extent of being forced to reveal their own inferiority in games of skill' (June 1956:9). One article in Parent and Child went further and blamed the parents for failing to provide young people with 'means of creative expression'. 'How many provided some means of music' the author demanded to know, 'how many worked at plays and games - dramatizing the events of the day after tea, creating points of interest and a commentary on life and action? And how many used the same principle and continually widened horizons by the use of books' (Jan 1956:9). Fun was taken perhaps too seriously here, but nonetheless it indicated that good parents were no longer thought of as merely providers and disciplinarians, but also companions and playmates.

Between these diversions, there were frequent cries for firmer control. 'Children need a boss' thundered the Dominion in 1955 (21 Mar 1955). Too many parents had bought the 'danger of repression' nonsense from psychology 'experts', it warned, and were consequently 'too disposed to let Johnny have his own way'. Not only did children need discipline, in fact they 'really like and respect firm control, so long as it is just'. 'So do adults; ask any soldier' it added. But, more importantly, there were the 'unpleasant consequences' when having been led to believe there was no boss, the child had to come up, eventually, against 'the hard fact of the boss'. It was a strong 
argument, which begged the question even more strongly. But what one should make of the fact of the boss in an egalitarian society was perhaps a question too difficult to answer.

The Dominion editorial, remarkably, also indulged in heavy nostalgia for what were supposedly the 'old days when the child was afraid of the parent':

The parent was then master in the home, and his or her control was not subject to anything like the number of outside influences that operate today. There was less education, less popular reading, and no radio or television. The family was far more stayat-home. And there were few, if any, psychiatrists to fill the minds of parents with fears and doubts, to tell them that punishment, even scolding, might have serious results in after life (ibid.)

This construction of the past was highly ambivalent. It strongly suggested that, while the pendulum might have swung too far, there could be no question of putting it back exactly where it was. Rather new balances had to be struck between vague and open-ended notions of consistency, fairness and security.

The discourse of parenting was constructed not only in terms of these abstract values, of course, it was also made up of practical advice from various authorities and experts. The Evening Post, for example, reprinted a long article written by an American judge on 'how to make your child a delinquent' (28 Sep 1954). Some were only to be expected: 'don't give your son any religious or spiritual training. Just take care of his bodily needs'. Others were more a mixed bag. 'In his presence ... [don't] be respectable of "dames", and the Courts, the police, public officials, the school, the church and business'. Nonetheless, there were well-meaning lessons for the delinquent parents. 'Don't try to reason with him ... your father was the boss of home and the kids may as well learn the hard way'. 'A local variation was 'Recipe for Raising a Delinquent Son', prepared by an interdepartmental committee on adolescent offenders:

Encourage any aggression and rebellion against authority. (It's a hard world he's going to grow up in and he'll have to learn to fight his own battles. If he shows any aggressive tendencies when you yourself are tired or under the weather, of course, beat him up yourself to show who's the boss. However, don't be consistent in this or he'll know what to expect) (Inter-Departmental Committee on Adolescent Offenders 1959:Appendix). 
The problem was constructed not so much as a deficiency in control or parenting techniques as adult attitudes, which simultaneously shifted attention away from youth.

In these popular discourses about parenting, psychological expertise played a relatively minor supplementary role, though its influence was slowly consolidating. NZ Woman's Weekly warned parents that they must 'face all facts, however painful they may be' and that they 'owed it to [their] youngsters to consult psychologists or psychiatrists' if necessary. It made no particular reference to teenagers. A list of twenty diagnostic questions was provided to guide them to determine the need, beginning with quarrels between parents and ending with repressed sexual fears or guilt in the child (10 Nov 1955:13).

There were other ways through which new parenting knowledge reached postwar parents. New Zealand parents could read, for example, the reprinted pamphlets on 'Adolescence' from the British National Association of Mental Health by Isobel Stirling (Parent \& Child Sep 1955:17; Jan/Feb 1959:10-11; 30-31). And the Canadian 'Dr Spock' (the prominent educational psychiatrist Samuel Laycock) instructed them about 'Guiding Teenagers to Hold Friends' and the 'Conflicts between Parents and Teenagers', among others (Parent \& Child Summer 19545:8-10; Aug 1956:14-15). ${ }^{22}$ Lectures on 'modern youth' from Professor Ralph Winterbourne, New Zealand pioneer in educational psychology, at the University of Auckland often appeared as feature articles. In this expert discourse, there was an incipient idea that control could, or should, come from within the individual, following a 'natural' course of development. This idea was to become central, as will be discussed later, to late-twentieth century parenting regime. Brian Knight, a well-known Auckland psychologist, was already laying out its basic logic in 1956. Rejecting what he saw as a mistake of early child psychology with its emphasis on free expression, he argued that discipline was - or rather should be - 'natural'. 'True' discipline, according to Knight, was precisely 'not imposing outside restraint'. The point was rather to achieve an 'inner harmony' through fair and democratic decision-making within the family which would 'automatically [bring] us into harmony with any healthy form of society' (Parent \& Child Apr 1956:20-1).

\footnotetext{
${ }^{22}$ Laycock's instrumental role in shaping postwar Canadian discourse about family and youth, and more generally the heteronormative ideal, has been highlighted by Gleason (1999:37-51)'s detailed study.
} 
Experts could not keep their focus on the process of adjustment, however. Stirling's pamphlets, for example, contended that while adolescence was often spoken of 'as if it were a stage in itself and the adolescent as a person', really it was a 'halfway house' between childhood and adulthood, suffering from the 'handicap' of both. This particular construction of development highlighted not so much the well-ordered stages as the contradictions. And anxiety about adjustment was projected forward onto parents. 'More important than what parents can do is what parents are', the author argued in conclusion, because 'when their children are facing the adjustments of adolescence, the parents themselves are facing the adjustments of middle age' (Jan/Feb 1959:31). It was possible, of course, to go the other way. Max Riske, a Wellington educationalist, had no sooner begun his task 'Let's take a look at Teen-agers' than defied the point himself by declaring categorically that 'nearly all' adolescent misbehaviour was rooted in babyhood and it was "nearly always too late to do much but weakly try to repair the damage permanently inflicted years beforehand' (Parent and Child June 1957:4). The psychological theory of parenting was, in short, still in search of a stable subject and a stable context.

Experts moreover were often puzzled by the contradictions and ambiguities of what people did in practice. Harold Bourne, an English psychiatrist and recent migrant, was apparently appalled by New Zealanders' attitude to family and domestic discipline (Listener Oct 4 1957:4-5). New Zealand parents had not only an 'excessive anxiety' about the moral laxity and pleasure seeking of the young - Bourne cited the Mazengarb inquiry as an example - but also 'an extreme alertness to quell such moves'. Worse still, he found domestic 'tyranny' not only reigned over 'unsophisticated' working class households but penetrated deep into the middle-class consciousness. It was exactly the opposite of harmonious discipline proposed by Knight. The New Zealand child found grown-ups were 'heavy, arbitrary and immovable', 'to be obeyed or to be outwitted, but not to be influence by opposition'. Having been thus trained, the New Zealander, he complained, only knew two moves when it came to authority - 'flat disregard when unseen, and passive compliance otherwise'. But it was never genuine compliance with authority. The seemingly authoritarian approach, in other words, did not in fact produce a conformist society. It lacked more 'sophisticated' means to manage the reactions of those it attempted to control as well as its own contradictions. 


\section{Part 2}

\subsubsection{Gender}

The obsession about working mothers and their contributions to the problem of juvenile delinquency reflected postwar society's preoccupation with gender. The discourse, as shown above, fell far short of an unambiguous commitment to patriarchy. Nonetheless the postwar familial ideology was simply incapable of imagining boys and girls to be anything other than men and wives, even if wives were no longer strictly kitchen-bound.

Mary Murphy, a 'mother of four' and 'holder of University Diploma in education and Child Psychology' wrote, for example:

A girl will lavish at this stage an intense devotion on a cat, dog or horse. This will exasperate less if it is remembered that this is merely a rehearsal of the mother role which the girl will play in later life, and goes only a stage further than the devotion to a doll ... Boys are in the same way rehearsing grown up parts when they hero worship a popular sportsman or character in fiction (Parent \& Child Sep/Oct 1959:9).

The writer's point was that parents must be more tolerant of adolescents, though she was utterly oblivious of the way gender prejudices were inscribed into adult imagination of adolescence.

But the gendered signposts for adulthood were shifting. While girls must become women, there was nonetheless an increasingly real choice between the kitchen and the workplace, with or without husbands and children (cf. 3.1.2 above). Conversely, motherhood had an increasing importance. The Plunket invention of mothering as a craft already elevated the status of childrearing; now the concerns about juvenile delinquency made mothers responsible for an even more complex task of discipline and development. Motherhood, now encompassing the full spectrum of human development, was not unskilled, inferior, labour. Moreover, this extension of the conventional feminine role of the mother, as contemporary observers saw it, was in fact 
chipping away at the monopoly of disciplinary authority formally ${ }^{23}$ belonging to the father. And carrots rather than sticks were what was needed to keep women at home. As May (1992:115-6) points out, the idealised notion of marriage, homemaking, and motherhood as a 'career' had taken root. The homemakers no longer saw themselves as merely doing their feminine duty, but as undertaking their half of the tasks in a necessary division of labour that demanded recognition and reward. And in this they had the sympathy of public opinion. 'I am always very sorry for the woman who feels she has to go out to business so she can feel secure', wrote a columnist in the Otago Daily Times on the subject of working mothers and delinquency, 'and very angry with the man who creates this situation':

[T]he crank who regards his salary as his alone, and parts with it reluctantly. It's a case of masculine logic slipping a bit! A woman gives up her earning power when she marries ... certainly a man gets less for himself after marriage ... but so does the woman (31 Jul 1954).

Marriage might still be a bad bargain, but women were increasingly insistent upon their fair share.

While New Zealand society was not prepared to go as far as 'wages for wives' which became a subject of public debate in early postwar years, the cause was never quite forgotten. A mother wrote to the Evening Post as late as 1962 urging that:

The Government recognise their co-workers in the cause of training fine New Zealand citizens by making hardworking but non-earning mothers worth more than $£ 156$ in tax exemption. ... It would help some men to regain the pride they once had in being the breadwinner to a family where the word teenager is not synonymous with trouble (20 Jun 1962).

The assumption that the state would be not only supportive of domestic ideology but also willing to pay for it was wishful thinking. The tide was already turning towards an emphasis on selfindependence, even if it might be at the expense of the familial ideology. But clearly some women were no longer content that their domestic labour should count for nothing.

\footnotetext{
${ }^{23}$ That paternal role had already been weakened by the strong moral claim of motherhood during the $19^{\text {th }}$ century among the more well-to-do (see Tosh 2007 [1999]: 151-6 for UK).
} 
The role of the father, moreover, was subjected to increasing public scrutiny which itself reflected the subtle changes in the gender order. The Mazengarb report, while laying most of the blame on women, did not forget to chastise the fathers. As breadwinners fathers were 'necessarily ... away from home throughout the day' but, the report insisted, they had 'opportunities in the evenings and at week-ends to identify themselves with their children's interest and activities' (1954:36). What was worth noting too was the accent on involvement, rather than discipline, which reflected another shift in the role of the father.

The Mazengarb committee was not alone in drawing attention to the father. In popular discourse, criticism of fathers often served as an effective counterweight to criticism of mothers. 'Bringing home the bacon is not enough', wrote 'Mum' in a letter to the Christchurch Star-Sun 'the man should not play the heavy father all the time, but mix a little affection with it. If they take their children and wives out to enjoy themselves they might be surprised to find that they enjoy themselves too' (12 Aug 1954). A Mrs Greenhill suggested that fathers were to blame for not 'taking their sons anywhere', going off to football and talking like 'big kids' to their pals while dodging their responsibility. One could hardly blame the 'poor overworked mother who to get herself a little peace will give them a shilling to take themselves off to the pictures' (Evening Post 25 Mar 1958). It was not so much about restoring paternal authority as finding a place for father, as an attentive playmate and companion within a new discourse of maternal security that by default gave the limelight to mothers.

The expansion of the mother's role, pushed along by overwhelming concerns about delinquency, in a way reversed the domestic hierarchy. Some were beginning to worry that fathers might in fact be crowded out. The case was made by no less than the chair of the School of Social Science at Victoria University College, and a former chief inspector of the London probation board, who warned that 'in the worry of present-day delinquency it was possible to over-emphasise the part of the mother so as almost to exclude [the] father from the family picture'. If fathers played their 'proper' role 'besides playing the part of breadwinner and holder of security of the family', Professor Minn argued, 'there would be less delinquency' (Dominion 2 Dec 1954). This widely reported speech was a prototype of the late twentieth century 'father-deprivation' argument, which will be discussed in 6.2.3, but in a radically different social context. Paradoxically, the 
superficial conformity to the 'traditional' gender regime appeared to have made it more difficult to guard against, in the professor's words, 'underground revolution' within the family structure.

Other intellectuals had a keener sense of present contradictions and irreversible changes. Robert Chapman, writing his influential essay on the New Zealand social pattern, thought fathers, having been 'driven from the bridge', were more likely to resort to the 'equalitarian comradely substitute for singular, hierarchical, patriarchal family life' in pubs and sportsclubs than working on their new emasculated role.

Father, increasingly a townsman, was a figure who departed for work in train or tram and returned at the children's bedtime. No longer did he teach the son by example in the bush or at the counter. The children went to school and the mother pointed to undone homework if much of the old participation was asked. Only in a depression and only on the farms did the family really return to that joint effort directed by father in his own sphere that had been a pioneering characteristic. Mother now had the children on her hand and in the home, which was her sphere, where she directed and where her work and management, so central to the family's position, could be observed and absorbed by the children, girl and boy (1953:83).

The last words contained a vague and perhaps subconscious fear about the gender disorder of future generations brought about by too much mothering. But Chapman's point was that it was brought about by an irrational adherence to the traditional familial norms for which the social context no longer existed.

\subsubsection{Class}

The familial ideology, in spite of its middle-class origin, was officially 'classless'. Some classed markers were indeed losing their salience. Overcrowding for one was no longer a coded word for moral concerns about working class families. Nonetheless, the headmaster of Hamilton East School still ranked the "chaotic housing situation ... fairly high in the causes of sex problems of young people' in his submission to the Mazengarb committee. He was convinced if court records were surveyed they 'would most likely show' that 'these young people had gone through a period of living in cramped and unsatisfactory quarters where they were compelled to sleep in 
the same room as adults or a number of children [sic] varying ages and sexes' (WSMC 1954). But as long as society refused to see the transit camps and the run-down cottages, such concerns could be set aside.

Working-class families nonetheless remained morally suspect to respectable society. Public scrutiny of 'parent examples' often revolved around the behaviours and habits of working class adults. Occasionally class stole the focus. The press in 1955 found in a Bluff police sergeant the conscientious social critic. His gripe was with the 'effects of the movement, general in the last few decades, towards the easy way of living', as the Christchuch Star-Sun paraphrased. In particular, the representative examples of bad parents were freezing workers, in many ways the vanguard of the New Zealand working class ${ }^{24}$, "who were always "broke", many of whom had not the money to pay their fare to their next working place, left a legacy of 2700 dozen empty bottles, representing a beer outlay of $£ 4050$ in six months'. The concerned editor wondered what was 'to be expected of children raised in such an environment' (Feb 22 1955). It was a way of life not 'peculiar' to freezing workers, and all the more disconcerting for that, but it clearly marked out one section of New Zealand families from the rest.

Even more frequently, public figures reminded New Zealand families of the virtues of poverty, even if these reminders jarred with the official commitment to social security. Many such sermons came, unsurprisingly, from the pulpit. The Reverend Gardener, writing for the Otago Daily Times, warned the readers that 'the prosperity of our country has made for relaxed oversight of the young. Prosperity destroys quicker than does poverty. Indeed it could be said that goodness thrives when living is hard' (31 Jul 1954). The president of the Mother's League was more direct. Attacking the working mothers, she was quoted as saying that 'New Zealand is said to have a higher standard of living than any other country. It would be better if we were a few rungs lower and ensured that our children were given a sound home atmosphere' (Evening Post 15 Jul 1954). The Wanganui Chronicle vigorously rebuked the confused logic of the welfare state:

The problem of bringing up youth in a desirable way of living is not to be solved by curing poverty, nor by providing housing on a scale not hitherto though possible. ... It is

${ }^{24}$ see Locke (2012:10;18-49) for an account of the freezing workers in the postwar years. 
probable that the discipline of poverty has done more good to young people than has the effortless demands of more affluent up-bringing.

Affluence was the apparent target, but the real enemy was welfare. It was 'manifestly impossible to carry everybody on the taxpayers' back', bemoaned the editor. 'Self discipline within the family' was the real answer, and without that, 'the provision of cheaper and better houses will not even touch the problem of juvenile misconduct' (June 2 1955).

Few issues brought out more clearly the deep-seated discontent, so often effaced in the subsequent genuflection to postwar 'golden weather', than the recent escape, via the welfare state, by those who had previously been subject to the virtuous discipline of poverty. In this way the discourse was implicitly and unambiguously class-coded. And it brought up the old question about the just desserts of the poor, sidelined by the universalist rhetoric of the welfare state which was supposedly the new consensus. Even the Mazengarb report could not resist making a dig at it. Although its recommendation of cutting the family benefits to delinquent parents came to nothing, it nonetheless aired its opinion:

The irony of the situation is that this slipping of parental responsibility has occurred contemporaneously with the granting of financial and other help to parents. Family allowances and State homes should be concomitants of an increased sense of responsibility. Despite all that the State has done, and is doing, for families, the moral standards of the community have somehow been undermined.

The press fondly remembered the past, when 'bad conduct brought its own harsh punishment', a punishment that went beyond moral and spiritual censuring: 'It could then, for example, as it cannot today when there is work for everyone, deprive young men of the opportunity to earn a good living'. And so the duty of parents to impose their own discipline was now greater than ever (Southland News 5 Feb 1955). Another editor bemoaned that the discipline in employment was almost a thing of the past. 'In a large measure' he contended, 'youth crime' was 'the price being paid for too long sustained over-employment and the restricted working week which gives youth too much leisure' (Manawatu Daily Times 2 Feb 1956). Unemployment or longer working hours, and low wages, might all be answers to idle hands. They were more bark than bite in an age of full employment and social security. 
For conservative taxpayers, welfare was reward for good behaviour, not an expectation to meet ever-expanding needs of families even in a time of prosperity. Indeed, such needs were part of the problem. The 'need' for a fridge or a motorcar among those families who until very recently were priced out of such things symbolised the rising tide of materialism, which drove mothers to work and teenagers to delinquency. Liberal commentators were easily drawn to this type of thinking, since they often had a different idea of what families should want. One complained too many 'wanted a home before they started, instead of gradually building it up over the years' and the easy credit for it had to be paid for by mothers' employment (NZ Parent \& Child July 1955:28). Meanwhile Warren Freer, a Labour MP, accused the working mother of putting the fridge, the washing machine and the motorcar before her family's welfare (NZPD 1954:1050). Conservative commentators were on home ground. It was plain selfish to want to 'keep up with the Jones'. 'Any father who let his wife go out working for a refrigerator', the chairman of the Mazengarb committee told an assembly of J.P.s, 'need not be at all surprised if his own son ended up in the "cooler" (Parent \& Child August 1956:6). The Mazengarb report itself, while acknowledging some mothers might 'need' to work, castigated many others who worked to 'provide a higher standard of living than can be enjoyed on the wages earned by their husbands', or preferred the office or factory to the kitchen sink. The bonus of the postwar boom, in the eyes of the Mazengarb committee, was strictly rationed, and not a universal entitlement, and 'going above one's station' in these supposedly egalitarian times was still a moral trespass.

It is interesting that these women and their families' pursuit of the suburban dream - after all, a house was the pinnacle of it - should be regarded by some as a case of moral failure rather than a reflection of their commitment to the 'conformist' social pattern. Clearly conformity was not a justification of everything, especially not for those who could not afford it in the first place.

\subsubsection{Ethnicity}

The issue of family and its discontent remained by and large a Pākehā concern. Problems of Māori youth were seen as part of the larger issue of Māori urbanization, and the underlying political dilemma of assimilation and integration, rather than a social problem of families and individuals. The priority, in other words, was to make Māori families look more like their Pākehā 
counterparts, to conform to the Pākehā ideal even if that ideal seemed fragile and in need of protection within Pākehā society itself.

This difference is reflected in the distinctive approach to Māori welfare illustrated by Bronwyn Labrum (2002; 2004; 2013). As Labrum (2002:167) argues 'the biggest and most persistent problems were material, and centred on housing, social security benefits, and other necessities of life, such as blankets and clothing'; problems, in other words, which officially no longer existed in the affluent Pākehā society. The distinctive approach was, of course, not about poverty per se, but the lack of necessary aspirations in a 'modern' consumerist society. What Māori must want, in the eyes of the state, was a 'good home' - 'a decent life centred on the house in the suburb'. Official propaganda patronized Māori families with a 1954 booklet that showed 'in simple story form ... the way a new home owner plans his home and grounds, furnishes, decorates, builds some simple improvements in the home, and meets his various new financial obligations, including some money laid by for future maintenance'. Welfare officers enthused about competitions for 'best kept Māori home with an emphasis on grounds and exterior homecraft' (quoted in Labrum 2013:73,76). Keeping an ornamental garden became a significant badge of civilized family life (2002:167-8). Such emphases sat in glaring contrast with the debates about Pākehā family life, examined above. While Pākehā parents were disciplined for having too much of this material suburban dream, and urged to get back to the moral and spiritual, as well as emotional aspects of the 'homely home', Māori families were chastised for not wanting enough of it, even at the expense of loosening family ties.

In spite of all its familial rhetoric, Pākehā society looked with remarkable indifference upon the extended family norms of Māori society which were arguably more cohesive than the emaciated nuclear model. But of course the latter was taken for granted as the norm. One Māori Welfare officer, writing for Te Ao Hou, asserted that 'it was wrong to allow grandmother to bring up the children'(July 1956). 'They should not be under the elders' control after a certain age when they must learn to face the outside world' wrote Officer Raureti. Pākehā grandparents were an entirely different category of being. Surely they were, as the Wellington Society for the Protection of Home and Family had it, 'without question ... an anchor for family affection and balance'. Too little consideration was given to providing for them, the society lamented, in the planning of housing areas and in the very design of modern homes (Evening Post 7 Aug 1958). 


\subsection{Conclusion}

This chapter argues that the conformity to the conventional ideal of domesticity in postwar debates about youth was illusory. 'Conformity' was in fact coded in classed, gendered and racial terms, and understood against the context of the welfare state that was deeply ambivalent about domesticity. It reflected paradoxically deep cracks within the social and political foundations of adult society.

The coming together of the welfare 'consensus' and the domestic ideology meant to anchor postwar society to its moral and political certainties. But the twin ideologies had a limited reach over new desires and also old divisions in class, gender and ethnic terms. Debates about the ideal family, sparked by concerns over youth, provided an opportunity for the postwar generation to articulate their discontents and imaginations that, while seldom confronting familial norms directly, went beyond the mere negation of them. The familial ideal, in this way, served not so much to enclose discourses as to link critically domestic norms, firstly with egalitarian aspirations, and then with diverse desires and divisions, so easily overlooked in the characterisation of postwar society as 'conformist'.

The welfare state did not so much contain such debates as adding fuel to it. Not only did it provide a focal point of scrutiny - what the state did, or failed to do, for families, conventional or otherwise. It also helped to centre the apparent contradiction between public egalitarianism and domestic inequality, and thus enabled critical reflection upon both. Young people, who were meant to be brought into the folds of familial conformity, was left to observe the adult anxieties about their public and domestic ideals. 



\section{Chapter 4 Youth and School 1950-1965}

It is easy to see youth and school in an antagonistic relationship and to conceive the latter as an institutionalised means of adult control. As this chapter will demonstrate, the debate about secondary education in the postwar era was far more complex.

To begin with, the postwar expansion of secondary education meant that school took on a distinctively positive role in the emergence of a new teenage culture, which was, in James Belich's words, 'so obvious that it is easily overlooked'. Secondary schooling had been a minority experience, according to Belich, until the early 1930s. Then it 'became a majority experience - an important and understudied watershed in social history':

for the first time most adolescents spent a substantial and significant chunk of their lives surrounded by other adolescents. Before this watershed, on leaving primary school, most adolescents returned to the family or went out to work - both sites dominated by adults. After it, they had the cultural site to become teenagers - once the word was invented (2001:506-7).

We can be more precise. There were more adolescents at school, because there were more adolescents. But schooling was by no means a universal experience for teenagers. The compulsory school leaving age at 15 remained a dividing line. Around half of teenagers finished their school life in the middle of adolescence. $50.3 \%$ in $1952-55$ and $44.4 \%$ in $1957-60$ respectively of teenagers did not continue to the third year of secondary schooling (Form 5). Many did not even make it to the second year at $15.2 \%$ and $12.8 \%$ respectively (Currie Commission 1962:204). The remaining half competed for the school certificate with increasing gusto, but only a quarter stayed to the end of the sixth form. These numbers did not tell the whole story either about how decisions to leave or stay were made. For the Currie Commission (1962:202), it was 'embarrassing' that young people could look upon themselves as 'fifteenyear-old leavers', able to leave school at the will of their parents on their fifteenth birthday, even 
if the school term had not quite finished. ${ }^{25}$ But 'staying on' with the slim chance of making it at school certificate and much less likely university entrance was a weighty decision administrative uniformity was neither here nor there - and potentially a point of conflict for many working class young people and their parents, particularly when jobs were apparently plentiful. The point of entry into work or adult domestic life was indeed postponed, but for many it was never far off. Even if many (though hardly 'most' ) postwar teenagers gained an extended lull in their sheltered school life, they continued to spend a substantial chunk of their adolescent life under the same pressures of home and work as did the previous generations.

Secondary schools did provide a crucial site of youth identity and social discipline in the postwar $\mathrm{era}^{26}$. And educational debates reflected the deeper anxieties about society as a whole as in broader debates over youth. Section 4.1.1 examines the continuing resistance to the idea/ideal of mass education. The notion of postwar schooling as a means of social discipline is examined in 4.1.2, followed by a critical discussion in section 4.1.3 of the debates about the place of competition vis-à-vis the liberal humanitarian ideal in education. The contradictions between the expanding meritocracy and egalitarian 'classless' ideal are explored in sections 4.2.1, 4.2.2 and 4.2.3 will look at the subtle changes and complexities beneath the overtly discriminatory schooling regime in relation to gender and ethnicity. The schooling regime, thus, could not be conceived as the imposition of a certain taken-for-granted 'liberal-humanist' orthodoxy, nor a thinly-disguised institution of authoritarian control. Rather it was a site where a variety of discourses contested the meanings of education, its role within the welfare state and the capitalist market and the future shape of society it was educating.

\footnotetext{
${ }^{25}$ The compulsory school leaving age during much of the postwar period was calculated by birthdays rather than school terms. At 15, most students nonetheless would have completed fourth form, or the second year of secondary schooling. Apprenticeship, as well as the skill-orientated technical colleges, provided another way out of the conventional secondary education before 15. Parents could also withdraw their children, by application to the headmasters, if they considered little benefit could be gained from staying on at secondary education, though this was made difficult by the 1964 Act (see 4.1.1 below).

26 Much has been written about secondary schooling by educational historians, though research effort seemed to taper off by the 1990s after a few rounds of myth-busting, the myth being the liberal humanist ideal (Openshaw, Lee \& Lee 1993; Openshaw 1995; Shuker 1987; also Lee \& Lee 2008; O'Neill 2004 for more recent overview). The findings have not been substantially revisited since. Opensaw \& Walshaw $(2010 ; 2013)$ 's recent articles on the literacy and numeracy debates from 1945 to 1962, focusing on primary education, cited below, is another valuable exception, closer to the approach of this thesis.
} 


\section{Part 1}

\subsubsection{Secondary Schooling for Some}

Not everyone in postwar New Zealand accepted without question the necessity of extending secondary education. The raising of the school age to 15 in 1944 remained controversial into the 1950s. Nor was 'staying-in-school' taken for granted, as is the case nowadays, as a panacea of youth problems. The report of the Mazengarb Committee made a sly, though hardly subtle, critique of the idea of universality when it argued that:

Post-primary principals ... appeared worried by the problems of conduct arising from the inability of pupils to leave school until they have reached fifteen years of age. ... The school leaving age is now 15, but there are obviously some pupils, in the upper forms of primary schools and the lower in post-primary, who, either through lack of ability or lack of interest, are not only not deriving 'appreciable benefit' from their further education, but are indeed unsettling and sometimes dangerous to other children $(1954: 24,26)$.

In fact, it went as far as recommending a more liberal reading of the exemption clause in the school leaving age regulation which would enable troublesome children to be taken out of school, and placed under state supervision, when they reached 14, the cut-off age between 1901 and 1944. It was Mazengarb himself who complained of the 'surplusage of students', rather than staffing shortage, to an audience of teachers in 1957. The 'effortless education' where students were automatically promoted and 'idle their time away unhappily at school until their $15^{\text {th }}$ birthday' was going too far (National Education 2 Sep 1957:301-2). And he returned to the subject again arguing that the 'play-way' education and 'promotion by age ... instead of by examination and merit' had produced a 'nerve crisis' in youth who had never got used to being failed (Evening Post 24 Sep 1960). Mazengarb's opinion was supported by heavy-weight commentators such as A G Davis, the Dean of Law at Auckland University College. In his submission to the inquiry, he emphatically did not understand 'why the competitive spirit should be maintained in the playfields and abolished in the class room'. And neither did he 'appreciate ... why the mere fact that a child [had] been so many years at a primary school should give that 
child the right (in legal language a privilege) to go to a secondary school'. The proficiency exam, abolished in 1936 by the first Labour government, at least excluded 'the lazy and the morons' from a free ride in state education (WSMC 1954). The professor never questioned, by contrast, the intellectual and moral desert of those whose parents could pay for their education.

For many others, less education and more hard discipline from the 'real' world was the answer to problems of schooling youth. A letter to the New Zealand Post-Primary Teachers' Association (NZPPTA) Journal complained of the 'excess of pupils who clog our post-primary schools', which were once 'meant for a selected and doubtfully [sic] lucky few'. The lowering of the leaving age to 14 , along with tougher teaching and stiffer testing of primary children, would solve not just the problem of the overtaxed secondary education, but also 'give to industry thousands of willing young workers whom it sorely needs', if not for 'political and trade union opposition' to it (NZPPTA Journal Nov 1 1955:8). A former president of the PPTA suggested in National Education that 'cutting the losses' by expelling the 'reluctant learners' - a euphemism for early leavers - may be the 'proper solution' (Nov 1959:447). The New Zealand Education Boards Association, no less, urged the government to make it easier to exempt those who it thought would be better off in employment than in school. The proposal was warmly received by the press. The Dominion quoted the opinion of the Commissioner of Works that 'too many young people were being encouraged to stay at school for too long, considering the class of work they would perform in after years' in the first of its editorials on the subject. Had those young people not been unduly encouraged, most of them, added the Dominion editor, would have 'necessarily entered into unskilled occupations but that is their wish and presumably it fits their capacity' (27; 28 Sep 1956). The Press, by contrast, warned that the 'abnormal' condition of 'over-full employment' might not last long, and while they were better off kept away from those more academically inclined, these unwilling school-children should nonetheless be trained better in one way or another (2 Oct 1956). There was then a strong opposition to the 'levelling' implications of mass education, even if it was meant to include more in the disciplinary apparatus of education.

These conservative opinions were challenged. 'World authorities and world tendencies', claimed one educationalist in Parent \& Child, were on the side of raising the school leaving age even further and not lowering it. And 'every right-thinking parent, 98 percent of them', he was certain, 
wished their children to stay at school just as long as possible (Oct 1956:14-15). This writer blamed the clamour for lowering the leaving age on 'small sections of industry ... starved for manpower ... or branches of the retail trade' as well as 'a few parents ... anxious to have their children working for the sake of their money'. Instead of addressing the criticism the argument simply dismissed the critics, and in this it echoed the perennial complaints from educationalists about 'selfish parents' and selfish capital (National Education Jul 3 1950). But the polemic in fact demonstrated the welfare consensus was not as strong as it was made out to be. Blaming a few 'selfish' parents eschewed all too obviously the economic pressures, which were supposed to be non-existent in an affluent society, on decision-making about education.

In these debates, the welfare 'consensus' was challenged precisely where it should have been the strongest, in the provision for the younger generation. Social divisions were again made explicit, which the expansion of education, paradoxically, was supposed to circumvent.

\subsubsection{Discipline or Development}

Postwar debates over discipline certainly revolved around the issue of corporal discipline (Marshall \& Marshall 1997:97) but that does not necessarily mean that corporal punishment was all that the debates were about. This reflex reveals as much about the past as our perception of it in the present. The point was in fact well understood by postwar society that discipline was not a thing, but a means of control that could be exercised not only physically but also psychologically, for social and not just educational purposes, inside as well as outside school, by coercion as well as by persuasion. For postwar society, school - without the hindsight of Foucaultian scholarship - was a disciplinary institution.

It would be a mistake then to accuse postwar educators, especially the liberal-humanists, of hypocrisy (see Marshall \& Marshall 1997:139-144; Spencer 2008:131. 156-9), since they never saw discipline and the liberal humanist ideal as mutually exclusive, or attempted to conceal the former under the latter. Discipline for its own sake, for example the school cadets, was rejected on idealistic and principled grounds by some. ${ }^{27}$ But the more complex question of school

\footnotetext{
${ }^{27}$ School cadets were certainly a venerable institution among secondary schools, more so in older establishments than newer (state) schools catering to the postwar mass. To do justice to the subject however would require a
} 
discipline, including corporal punishment, was not settled by abstract liberal impulses alone. From the start, the problem was never a choice between external discipline and individual freedom, but different kinds of disciplinary regime and their implications. What was also at stake was the balancing between disciplinary, 'developmental' and educational roles of schooling, not one or the other.

Nonetheless, corporal punishment in the postwar regime might still appear exceptionally harsh (though, I would argue, only because corporal punishment was an exception). To outsiders such as David Ausubel, an American psychologist and controversial author of the Fern and the Tiki, the adherence to an 'old fashioned, anachronistic, and authoritarian' tradition of discipline in post-primary schools was inexplicable, particularly considering the primary schools had almost caught up with, as he saw it, the more enlightened American practice (1960a:93-108). The secondary teachers' union, hardly a conservative bastion, did not hesitate to defend the teachers' right to use corporal punishment 'in loco parentis', even if it in principle preferred gentler means of education. It was either that or relax the compulsory leaving age and grant the schools the right to expel pupils. The denial of both could 'soon result in the kind of situation ... so well described in the Blackboard Jungle' (PPTA Journal 1 Apr 1956:1).

Conservative commentators nonetheless still saw only 'permissiveness'. Submitters to the Mazengarb committee, for example, made much out of 'free expression' and 'play-way education'. What was interesting, however, was that the Mazengarb report itself said very little about school discipline, apart from a note in passing about the alleged displacement in schools of 'traditional external discipline' by a 'concentration on the development of the personality of the child' in the submissions (1954:27). It might be that heightened anxiety about the home and parental responsibility inadvertently diverted attention away from schools. And moreover, whatever disciplinary power schools wielded over pupils, they did so in loco parentis (Marshall \& Marshall 1997:106-7).

It could also be that the barely established public system of 'mass' (secondary) education, which encroached upon the established sites of discipline - the home and the workplace - was in fact not so obvious a starting point for training young people in social conformity. Phoebe Meikle, a

more extensive discussion about the context of militarism and the Cold War, which is beyond the scope of this thesis. 
prominent educationalist and critic, rightly reminded her readers, as late as 1960, that it was only within the last twenty years, and with the raising of school leaving age and the 'social promotion' from primary school, that 'post-primary schools were asked to educate a nation' (Meikle 1961[1960]).

There were, of course, notable exceptions to the lack of focus on discipline. The ControllerGeneral of Police did muse about the British invention of 'attendance schools' on Saturdays as punishment for juvenile delinquents, though nothing came of it (Evening Post 14 Aug 1956). And one writer to the Evening Post, for instance, extolled the virtues of corporal punishment in the English public schools, such as Eton and Harrow, over 'mere' learning: character building could "not be accomplished without teaching the boys [that] the apostolic injunction to "endure harshness" and submission to caning when deserved is a necessary part of their education' (25 Mar 1958). But there was no strong evidence of such a virtue, with its distinctive upper-middleclass cachet, being passed down from above to the mass in postwar society.

Many more commentators in the postwar era saw corporal punishment as a necessary evil. And the necessity became greater - and discipline intensified - as the exclusion of the 'unruly mass' from secondary schools, and subjecting them to the discipline of the marketplace, became more difficult. The Currie Commission on education, for example, singled out two factors which brought about changes in disciplinary practices. The first was the increasing number of 'slow' and 'reluctant' learners in secondary schools, which demanded 'closer relationships characteristic of the primary school' rather than impersonal punishment. And the second was the increasing number of older students who stayed longer than previously (1962:299-300). The issues of discipline and academic 'underachievement' were conflated, and in turn further mixed up with demographic and policy changes. Similarly, the headmaster of Napier Boys' High School, writing in the Department of Education bulletin, saw discipline as a 'new' problem which resulted from the increasing roll. A young rebel 'formerly ... would have been allowed to leave at 14 from ... the primary school. Now, as a social promotion, he is a challenge and a threat' in the secondary school. It was 'their tragedy that in the interest of all they must be forced to conform so that they may not dilute the spirit which makes the world of the school the only hope for a rising standards in the world outside' (Education July 1961:178-9). The 'old 
authoritarianism', in the Commission's words, of secondary schools, was abandoned by necessity, not by choice.

Attitudes towards discipline changed nonetheless in other ways. Even hardened defenders of corporal punishment invariably framed it as a last resort. The school must be defended, protested one indignant master, against 'badly brought up' boys who 'force their teachers to give them corporal punishment.' (Parent \& Child Sep-Oct 1960:22). The prevailing opinion, as summed up by the Currie Commission, was equivocal. There was no support for the abolition of corporal punishment and it noted that teachers were 'unanimous in describing corporal punishment as a last resort' (although it did condemn the prefects system). How often this last resort was also the first response remains an open question. ${ }^{28}$ Nonetheless, it was not insignificant that authoritarian rule had to be justified in this way. Moreover the Currie Commission had 'no doubt that the long term policy of our education system should be for the disappearance of corporal punishment'. The Commission, tellingly, looked forward to the time when misbehaviours would be managed not by 'summary punishment according to a more or less recognized and accepted code, but ... means of discipline, ultimately more powerful and immediately more discriminating - prompt intervention by seniors skilled in guidance, prompt consultation with parents, and, in appropriate instances, even the practical operation of the responsible community of pupils' (1962:304-5). It noted earlier that heavy corporal punishment was itself a potential cause of delinquency and 'deviant sexuality' (1962:303). Not only did the authoritarian tone of corporal punishment jar with the aspirations of a welfare society, its retention on pragmatic grounds was increasingly unsecure.

Liberal educationists, too, justified the use of discipline on similar pragmatic grounds, though they saw wider inclusion not as a problem but an ideal. Elsie Locke, a prominent left-radical, for instance, could argue that the strap might be necessary to protect children 'whose parents have taught them decency from some who lack it' and 'in our school today, the strap is sometimes the quickest way out, and may be better than nagging'. Corporal punishment could be dispensed with in an ideal world where adults invariably set a good example, though 'in the community that we know, to give an occasional hiding may appear the lesser of two evils' (National

\footnotetext{
${ }^{28}$ We still know very little about the actual operation of corporal punishment in secondary schools during the postwar era (Marshall \& Marshall 1997:98-103; Grant 2003:115). As Grant points out, it was interesting that the Commission relied on anecdotal reports from schools themselves in its examination of the issue.
} 
Education Aug 1 1951:269). The New Zealand Education Institute similarly argued in its submission to the Mazengarb committee that while it was against use of corporal punishment for failure in school work, it ought to be retained as a last resort for misbehaviour. The submission reasoned that children could 'understand and appreciate righteous wrath' rather than 'unctuous righteousness'. In fact NZEI preferred the 'economical' discipline of corporal punishment to 'more burdensome alternatives' (WSMC 1954:4). And W J Scott, principal of Wellington Teachers' College and well-known civil rights activist, claimed that corporal punishment was sometimes 'the only workable choice that some parents and teachers are able to make at given moments, and it is certainly morally preferable to its possible alternatives - failure to control, futile upbraiding, lack of effort and attention on the part of their children, etc.'(Education 1961 [1955]:138).

Postwar educators such as Scott thus were not simply rejecting physical punishment because psychological discipline could be a more efficient - to borrow the Foucaultian term - technique of control. They were raising a different set of questions. Doubts about purportedly more liberal mechanisms of control were visible in the passages cited above, and they were fleshed out by Scott:

In the scars it leaves on the spirit, a thrashing is not to be compared with, for example, the relentless moral inquisition and censure to which some 'kindless [sic] villains' of parents and teachers subject children.... By persistently playing on the children's sense of guilt, the moral persecutor compels them to take part in their own condemnation, and thus both denies them the chance to enjoy a clear conscience and intensifies and prolongs their feelings of anger and hate (Education 1961[1955]:137).

This was as good a sketch of the Foucaultian 'technologies of the self' and their potentially more coercive, as well as insidious, effects on the individuals as any postmodern scholarship of later date. Scott saw corporal punishment as a necessary evil, an alternative to the 'cruel twisting of the moral life', for 'we ... are not ideal creatures in ideal situations but fallible ones in imperfect situations'. He was clear, however, that this must not be taken as a defence of it (op.cit.:138). If the pace of 'liberalization' of education was held back by an incipient fear of the future, its direction was also clouded by larger uncertainties. There were no unassailable notions of individual development to guide the 'hidden' course of discipline. Instead, in the New Zealand 85 
context at least, the disciplinary function of the schooling regime was made explicit through notions of 'character building,' which itself was tied up with contested claims about society and citizenship. Thus in 1955 the Director of Education could quote approvingly at length from the 1929 syllabus, still in force, specifically as a response to the Mazengarb report:

Character-training should not be regarded as a subject ... but rather as the principal function the State calls upon the teacher to perform. ... Every subject of instruction, and indeed every lesson, provides the teacher with opportunities for teaching right conduct and implanting such moral habits as honesty, modesty, perseverance. (AJHR 1955:E.1:9).

The importance of the moral dimension was reiterated in the 1944 Thomas report $^{29}$ on the postprimary curriculum, which linked individual moral character with new social and political aspirations even more explicitly. Secondary education would:

... aim, firstly, at the full development of the adolescent as a person; and secondly, at preparing him [sic] for an active place in our New Zealand society as worker, neighbour, homemaker, and citizen ... (The curriculum) represents what we consider is needed by the adolescent as an aid to growth and as a general preparation for life in a modern democratic community (Department of Education 1958 [1944]:4).

The vision for secondary education was clearly not one of individual consumers choosing the kind of educational goods he or she wanted. It implied a total immersion in the moral project of society at large, with the secondary schools as a microcosm of the ideal postwar society. It was significant that the idea of 'student government' in post-primary schools took root in this ostensibly authoritarian postwar atmosphere. Anton Vogt, a teacher and liberal commentator, pressed hard for the unspecified ideal: surely 'any school in a democracy is a failure, if its Fourth, Fifth, and Sixth Formers are treated as children, having little or no share in its government (or its purpose)' (Parent \& Child May 1956:26). Nor was this mere radical dreaming. The Currie Commission suggested 'pupil government' as an 'inevitable' alternative to

\footnotetext{
${ }^{29}$ The full title of the report, reprint by the Department of Education in 1958, is the Post-Primary School Curriculum. Report of the Committee Appointed by the Minister of Education in November 1942 (hereafter the Thomas report)
} 
the 'traditional' discipline of authority and obedience. It noted too that the recommendation was already made by the Thomas committee in 1944 (1962:300).

The trouble, as we have already seen in the previous chapter, was that adult society itself was often shown up by its flawed morality, since it was never as 'conformist' as it was presumed to be. That in itself placed a limit upon moral discipline. In the report cited above, the Director of Education argued that schools could not be

... expected to inculcate moral standards that are very far in advance of those commonly observed in the community as a whole. ... To do so in a public school system catering for the whole populace might be to drive a wedge between many of the pupils and their parents. If, for example, a teacher in twentieth century New Zealand were to condemn as immoral all forms of gambling or drinking, he would either fail to impress children in whose homes these were commonplace, or would leave them with the conviction that their parents were unregenerate sinners (AJHR 1955 E.1:8)

The apparently tongue-in-cheek comment nonetheless had a serious message that went beyond a dig at moral failing and hypocrisies of adult society. The outside world was 'not good enough to receive the children schools turns out', informed as they were by the ideals of citizenship inscribed in education, in other ways as one educator believed. In the 'rugged, ruthless, brutal rough and tumble' wider world, it was little wonder some of children went under, 'not because of the lack of sound teaching but because of the great contradiction between what they were taught the world should be like and the affairs [sic] as they really were' (National Education Sep 1957:292). Schools in the eyes of idealistic educators were a refuge from the 'unrealities of the real world' (Parent \& Child Sep/Oct 1957:20).

\subsubsection{The standards debate}

The perceived decline of standards in '3Rs' - reading, writing and arithmetic - was hotly debated in the postwar era. Moreover, such concerns about academic performance were often accompanied by misgivings about the broadening social curriculum and changing methods of pedagogy within the expanding apparatus of state education. As Openshaw \& Walshaw 
(2013:140 $)^{30}$ have recently argued, the postwar controversy over standards and curriculum revolved around a contradiction that rejected 'the competitive aspects of capitalism whilst accepting the material and other advantages capitalism provided'. As this section will demonstrate, however, not all embraced one set of contradictory beliefs about education that fitted nicely to the so-called welfare consensus or compromise. Many in fact placed themselves quite clearly on one side or the other of that contradiction.

Some submitters to the Mazengarb inquiry, for example, attributed juvenile delinquency to falling standards and the broadening of curriculum to include 'frills' over the 3Rs. But above all their concerns were about the apparent shift away from an emphasis on hard work to an indiscriminate egalitarian philosophy. These critics of the 'new' education included not just retired school mistress but eminent public figures such as E M Blaiklock, Professor of Classics at Auckland University College. Blaiklock found 'levelling ... at its most sinister and pernicious level', at the heart of the new education philosophy (1954:8N2). There was an 'exaggerated care taken to protect those of lesser ability from all knowledge of their condition', as well as 'the morally weak, the indolent, the rebellious, against the impact of their vicious attitude', at the expense of the more intelligent and 'those of greater potential usefulness', the professor wrote in his submission to the Mazengarb inquiry. The juvenile delinquent today was a product of this new educational regime, for 'perhaps no exacting task has ever taught them self-control, and no stiff programme of work and endeavour convinced them that life is earnest' (WSMC 1954). Such polemic exaggerated the 'levelling' effects of meritocracy. But Blaiklock was categorically rejecting the levelling philosophy itself; only hard work and natural talent would be rewarded, as was the case supposedly with a competitive market.

Concerns about the rejection of the competitive ethos within the classroom lingered and served to unsettle whatever 'consensus' there was about the wisdom of mass education, and the welfare state itself. Even within educational circles such concerns rippled the waters. A British educationalist, for example, argued provocatively that 'Educationalists Wrong to End Competition' in National Education. The popular idea that school children ought to be happy without the stress of competition was 'largely a political issue with social and moral overtones'.

\footnotetext{
${ }^{30}$ Openshaw \& Walshaw's timely contribution, which focuses particularly on primary education, has filled a gap in the literature. An earlier and more general treatment of the postwar controversy over standards and curriculum can be found in Openshaw (1997:49-99).
} 
For him schools were there simply to teach 'children in our society ... the habits of competitive striving and that the reward of perseverance and hard work is public recognition and prestige'. Educationalists were thinking too much about the 'backward and average child', and not enough about the clever and hardworking child. 'In a competitive system with rewards and incentives', anxiety and tension were not only 'necessarily' present, but also 'typically civilising forces'. 'If children are made anxious they will work the better for it and the price of some unhappiness may be worth paying' (May 1957:125). Such an opinion may seem conventional enough in retrospect, though in postwar New Zealand it touched on some raw nerves. One response labelled the article 'an appalling thing altogether ... so wholly negative, and such a pitch-patch of confused ideas'. Lynn's emphasis on 'competition' would 'have us promote the very anxiety, fear and tension that we ... are energetically experimenting to minimise'. 'Hanzup' would have 'success for all in happiness' and not 'success for a few under tyranny' (National Education July 1957:238).

That New Zealand's welfare politics seemingly stood in the way of good hard traditional education was hardly a secret, even in these supposedly conformist years. A national broadcast condemned 'recent' attempts to water down educational standards and drew a comparison between New Zealand and the United States. The latter was making education tougher and harder, while 'well-meaning' New Zealanders were questioning 'whether there was any real need for New Zealand children to sit up late at night studying'. And why should they be motivated differently, concluded the speaker Robert Gilmore, a well-known Auckland columnist:

In competitive societies such as the United States, or nearer home, Australia, there's a wide gap between the pay of the skilled and the unskilled. But one of the first consequences of the New Zealand tendency towards artificial equality between men is that the man who does not bother to acquire a skill often is paid nearly as much money as the man who does acquire a skill. Hence one of the primary traditional incentives to work as hard at school disappears in New Zealand. No longer can a child switch off the hit parade and get back to swot with the thought that those who swot will prosper and that those who loaf will starve. In New Zealand we have so ordered things that those who do not work hard and do not make themselves skilful will not lag far behind the others in money (Listener 14 March 1958:5). 
The discontent with the 'new' educational philosophy did not stay between the lines. Gilmore noted with glee the long waiting list for a newly opened Auckland private boys' school. The headmaster was reported to have said that he was not 'breeding boys for a soft welfare state atmosphere. He was breeding competitors and strugglers'.

Postwar debates about standards were practical as well as political and philosophical. Many of the criticisms about slipping standards came from the various Chambers of Commerce (Openshaw 1997:63, 85-6). The Wellington Chamber of Commerce, for example, complained that average New Zealand teenagers with their poor handwriting, bad spelling, inferior grammar and arithmetics were falling short of 'the standard we require in commerce today', and 'it's your job', as its spokesperson spelt it out, for educationalists 'to educate to that standard' (Evening Post 17 Apr 1958). Such bluntness was more than matched by opponents. An editorial in National Education was prepared to concede that the " $3 \mathrm{R}$ 's" might rise a little', but only 'by neglect of other subjects and some persistent hammering at the children'. And whether this would prove valuable to a prospective employer was quite 'beside the point in an educational objective ... aimed at the welfare of the child'. 'If employers' demands had always been acceded to, children would still be working twelve hours or more a day' (March 1950:1). The tone was militant. Debates about educational standards, then as now, were nearly always political. Underlying these disagreements was a deep divide about the uses of education, as well as competing claims of capitalism and citizenship.

The postwar era moved beyond neat penmanship, which had been a pre-war obsession, but both 'progress' and the demand of capital for new and better skills added to, rather than alleviated, the pressure on education to become even more competitive. This point is well illustrated by a widely publicised critique of New Zealand's education system by a visiting professor of physics, H Messel, of Sydney University in the wake of the Hasting Blossom Festival 'riots' ${ }^{31}$

'Playway', 'Deweyism' and 'Beebyism' might have been assailed by many critics over recent years, but 'seldom so devastatingly, or to such telling effects' as Messel's, gushed one editorial under the title 'Stripping the Hide of Our Education' (Dominion Sep 29 1960). Messel's acerbic

\footnotetext{
${ }^{31}$ The 'riots' played up by the paper were in fact a few cases of disorderly behaviours and public drunkenness occurred when the popular festival was cancelled as a result of bad weather. The disturbances were blamed on the influx of young people into the small town of Hastings from Wellington. Public anxiety about young people nonetheless was once again aroused.
} 
attack could not be caricatured as a mere 'backlash' against liberal education. For one thing Messel's liberal credentials were well established. He ridiculed the emphasis on sports, especially rugby, and decried the discrimination against girls' education, because he believed that, 'if democracy is to survive' in the Cold War technological race, it must 'use to the maximum the capacity of women' as well as men (Evening Post 28 Sep 1960). And it was perhaps a proof of his persuasiveness that the New Zealand press did not so much as bat an eyelash over the attacks on these sacred cows. Public opinion found instead much to agree with in his core message on the imperative of hard work. Hard work for Messel meant a six-day school week, like the Russians, though he was 'no communist'. But more conventionally it meant a 'hard core' of curriculum. Every student, in his opinion, should be 'forced' to take English, a foreign language, 'real' and not 'general' mathematics, history (so that they would not make the same mistakes as humanity did in the past), and science, which was not 'general science' but chemistry, astronomy, physics, biology and a little geology (NZ Herald 28 Sep 1960). There would be room, certainly, for music and arts, the professor conceded, but not in the 'hard core' for it would be 'absolutely ridiculous to see chemistry or mathematics or history or English replaced by such a subject as art or music' (Listener Nov 11 1960). The 'hard core' was a pointed differentiation from the 'soft core' of the New Zealand system, as laid down by the Thomas committee. The 'common core', as it was officially known, made it compulsory for schools to provide in theory, if not in practice, a range of choices in English, general science, elementary mathematics, social studies, music, craft, or fine arts for all secondary students.

Beneath the loaded metaphors of 'hard' and 'soft' cores, commentators had profoundly different visions of society and the place of the individual in it. Messel's society was a competitive one that discriminated sharply between the deserving brilliant and the undeserving mediocrity. An ambitious dustman could certainly become 'more than a dustman', said the professor halfjokingly in an interview, though he 'shouldn't become one of the great leaders in the community' (Listener Nov 11:1960:4-5). Yet everyone must play their allotted part unquestioningly in winning the 'Third World War', which had been 'raging for years in the classroom', as he told a packed lecture hall at Victoria University. It was a time of crisis that justified drastic measures such as six-day school weeks, and democracies such as New Zealand could not afford to be complacent (Evening Post 29 Sep 1960). In many ways his vision resembled much more closely the regimented, technocratic, dystopia that latter generations imagine postwar welfare states to 91 
be. It was all the more significant that contemporaries were much more likely to read such narratives as decisive blows against the welfare state.

The society envisioned by the Thomas committee, by contrast, was almost utopian. But it was not so much its progressive beliefs as the inherent ambiguities and idiosyncrasy that allowed the vision to escape the pressures of postwar reality. ${ }^{32}$ From the start the committee aimed to rescue 'personal needs and social needs ... all too often pushed into the background, especially by economic pressures' from the 'demand for attainments that can readily be marketed' (1959[1944]:5). It was disarmingly direct about the overriding emphasis on equality and consideration of those 'common needs of all future citizens'. The curriculum would cater for all adolescents without selection, and not just 'the intellectually bright minority', with the 'general principle that courses be preparatory to every life rather than to further schooling' (op.cit.6-10). The view, which was that of the 'educated layman rather than the academic or technical specialist' in the words of the committee, remained an officially-sanctioned aspiration. There could not be 'any other way [that the schools could] have borne the strains of handling 95 percent of the population within a framework devised originally to cater for a selected 10 percent', claimed the Director of Education (1958 E.1:9).

Outside the educational bureaucracy the humanist visions found few defenders other than liberal intellectuals like Monte Holcroft. 'Students are people', he cried, and people in a democracy 'could not be expected to work long hours and go in thousands to lectures' according to elitist standards:

Wastage in education is the price we pay, the necessary price, for believing that every human being is valuable, and must be given his chance - not in any perfunctory way, but generously. The aim of education is not to make some men efficient; it is to allow all men to fulfil themselves, within the limits of natural ability, as workers and citizens and indeed as simply human beings (Listener 11 Nov 1960:6).

\footnotetext{
32 The Thomas committee's prescribed aims for Social Studies - the flagship of its liberal vision - for instance, evoked not only an extremely wide definition of 'citizenship' which encompassed communal memberships as well as 'relationships with people of other nations and cultures'. It would not merely instruct pupils in social duties and responsibilities, but 'on the contrary', as the committee wrote hopefully, 'help to create individual interests of many kinds'. In fact the report went as far as linking specifically the curriculum with school practice: the task of Social Studies could not be 'at war with itself ... if for instance it tries to instil respect for democratic virtues in an environment which is heavily authoritarian' (1959 [1944]:27-8).
} 
These were strong words, if betraying doubt. Waste - a charge often made by critics - was conceded but excused. Furthermore, it relied fatally on an egalitarianism now under siege.

Messel, for example, unequivocally rejected the 'myth' of equality. Asked if his idea of selective education was 'bringing back the old idea of social stations and strata' in society, Messel said, quite plainly:

There's nothing wrong with social stations or social strata. I am completely and totally against the concept of socialisation and levelling everybody down to one common denominator. We were not born equal. ... if it was not mental capability that forms the stratification, what should? That is fair and equitable, and it's not a stratification which you and I decide, but the Almighty did (Listener 11 Nov 1960:4).

Newspaper editors seized upon this interpretation of 'equality'. The familiar ills of 'modern education' in New Zealand were once again paraded in the process. 'Less "playway" and greater emphasis on longer and more concentrated hours of study are a vital necessity if the country and its people are to get full value for the millions spent annually on education' (Evening Post 28 Sep 1960). The Dominion advocated "first and foremost ... the jettisoning of "social promotion", advancement by age instead of by merit, which has become a fetish of progressivism' Such easygoing progressivism failed to spur the 'laggards' or encourage the gifted (29 Sep 1960).

A second Evening Post editorial revealed the full implications. 'The free nations must be prepared to make big sacrifices' for a potential' Third World War', and more immediately to make up for the 'missile gap'. It meant not only 'a costly business which will call for changes in the operation of the Welfare State' but also the 'overthrow of the popular belief that Jack is as good as his master' (30 Sep 1960).

Mass education, then, became part and parcel of this larger political debate about welfare and egalitarianism, and not just a means to manage the influx of working class lads and lasses and their rising expectations. 


\section{Part 2}

\subsubsection{Class}

A meritocratic secondary education for all could not eliminate class differences. Nonetheless the accent on equality, even if naïve in hindsight, was an alternative to more explicit notions of social standing and stratification, which never entirely disappeared. Moreover, the ideal, if not the reality, was itself important in discursive and ideological terms. There were many who, as Dr Beeby reminded his audience of teachers, 'challenged the idea of equality even in its rudimentary form, and indeed considered it downright wicked' (Education Jun 1957:3). The appeal of the Beeby/Fraser vision, even if it was meant to be aspirational rather than practical, was plain ${ }^{33}$

The government's objective, broadly expressed, is that all persons, whatever their level of ability, whether they live in town or country, have a right as citizens to a free education of the kind for which they are best fitted and to the fullest extent of their powers.

The statement never promised equality in its fullest sense as an outcome of education. A contemporary lecturer in education, R S Adams, commenting a generation later, observed that it was 'clear of the taint of corrupted egalitarianism': it must not be misinterpreted either as 'identity of educational opportunity', or shortened into 'equality of education' (NZPPTA Journal May 1962:11). It never, in other words, pretended to be anything but wider and easier access to the educational ladder, or ladders, for the intellectually deserving upwardly-mobile pupils. Even judged by this modest objective, it failed. The expansion of free secondary education, far from reducing class divisions, reinforced the fallacy of classlessness (Nolan 2009).

The myth fed on postwar reticence about discussions of class. The controversy around New Zealand psychologist A A Congalton’s study 'Social Class Consciousness in Adolescence’ was a stark illustration of such aversion to class, at least in public discourse (Congalton 1952). ${ }^{34}$ Teenagers in Congalton's study were all well-versed in the material and cultural identifiers of

\footnotetext{
${ }^{33}$ The words were based on the idealistic motto of the New Education Fellowship conference in 1925. For Beeby, a free and generous education for all was an 'unattainable but approachable goal' (quoted in Clark 2004:6). ${ }^{34}$ The survey itself was conducted in the late 1940s based on a questionnaire given to some 100 students at Wellington Technical College, and met with fierce criticism even before the research had concluded, as Congalton recounted bitterly in the introduction to the monograph published subsequently (1952:n.p. also interview in Listener Jul 17 1953).
} 
social class. But it was the answer of one schoolboy that was particularly illuminating: 'there are no social classes in New Zealand; and if there are there shouldn't be'. The second half of the statement betrayed a subconscious and paradoxical awareness that the myth was important because it was not so much a fact but an aspiration.

In fact, perhaps no other social group was more blatantly reminded of inequality than postwar youth, given the prolific dichotomies - college and 'tech', academic and vocational, bright child and 'slow learner'. As adult society sweated over the implications of these terms, the swelling numbers of baby boomers became guinea pigs for ever more sophisticated means of mental testing, which 'streamed' them, as the contemporary euphemism had it, towards different stations in life, often on their entry to secondary schools. Meritocracy was the new sorting machine, though the destinations were the same: scholarship for the bright, labouring for the dull labourer, and clerks and typists the average and middling (Bell \& Carpenter 1994:126; Dale 2001:123). It would be superfluous to revisit the critique of the stratified curriculum and its shaky foundation in 'objective' measures of intelligence; that debate is long over (Olssen ed. 1988; Shuker 1987:170-90). Postwar proponents of IQ testing and streaming themselves recognised such limitations, even if they chose to ignore the implications 'The results of the examination of the school subjects are so dependent on the opportunities pupils have had both in home and in the school and vary so much', claimed one guidance on streaming, that these measures alone cannot be a basis for guidance or classification (National Education Feb 1957:32). The point was that the deprived pupils were classified in the same stream as the slowlearners regardless. Others unsurprisingly saw segregation as segregation, whether it was by 'intellect' or wealth. 'To segregate pupils by ability grouping is to foster class consciousness' argued one Auckland headmaster in an article aptly titled 'the Haves and the Have-nots'. 'Snobbery looks up and snobbery looks down, but whichever way it looks it sees intolerance, for it is like the man who does not need rose-coloured glasses but looks at the world through his bloodshot eyes'. By favouring the intellectually gifted, society was 'in great danger of producing human beings who are not truly human; of developing brains and skills to the detriment of social conscience' (National Education Aug 1951:243).

Postwar society was understandably anxious about its gifted young. As I have discussed before, conservative commentators fretted over the invidious effect of the levelling philosophy. The 
concern was shared by those of a more liberal persuasion, though the latter were more likely to place the emphasis not on the undeserving mediocre, but on the unfortunate bright child. 'Save the Bright Child' went the title of an article in National Education (Nov 1957). And the strength and weakness of this argument was paradoxically the same thing: it was not clear from whom the bright child should be saved. Another commentator, more conscious of the political and social implications, denied that special treatment of these bright children meant they would have more opportunity than others. But 'if we fail to make provision for their full development', he asked rhetorically, 'can we in all conscience subscribe to the ideal of equality of educational opportunity for all?' (Parent \& Child Dec 1960:12). In a context of teacher shortage and underresourcing, the idea that the bright pupil ought to receive 'more' equality than the dull one undercut the liberal rhetoric of equality.

The postwar schooling regime dodged, if only by accident, this vexing dilemma. The meritocratic institution of education was explicitly unequal, and as such it never attempted, to deliver fuller notions of equality in education. Quite the contrary; even at its most 'liberal' moment, the objective was precisely to 'deliver the goods' from something which was not more schooling as the postwar generation knew it, as the Thomas report had it. It led educationalists and others to explore other possibilities of equality outside the inherent limits of schooling. Not all were content that 'triage' was the answer. Some wanted to take the Thomas committee's incidental phrasing of 'full worth of education' at its face value and saw education not as an institution conferring worth upon the individuals but the other way around. In a speech on the effects of post-primary education for all, Dr W B Sutch, for instance, was optimistic that postprimary schooling had reduced 'snobbery':

The difference between older technical and secondary schools is being rapidly eliminated. Social tensions are lessened because of it. Even teachers are benefiting. The staff room of a post-primary school today contains experts of all sorts - carpenters, physical educationalists, art instructors, musicians, engineers, bookkeepers, and the rest and they are all teachers together. This increasing social cohesion is a symbol of New Zealand's changing society itself, the result, partly, of the all-purpose school (1957:12)

Dr Sutch was moving between educational equal opportunity and wider socio-economic egalitarianism, and blurring the boundaries in the process. 
The question was fudged still further because mass education had come to be regarded as a distinctive 'New Zealand' institution, as the Director of Education put it (1958:E1:10). The choice was not between equality of outcomes and equal opportunities, but between New Zealand's mass education and Britain's classed schools. Monte Holcroft for example encountered a confident British boy who told the audience he would be going to a public school, and later to Cambridge 'in a good clear voice, the vowels all given their true value'. Yet there were other boys who were 'more attractive than he, and perhaps more intelligent; but for them the future was guesswork and make-believe, with only daydream jobs to be visualized'. Unlike the scholarship boy, they were condemned to 'learn what they could in overcrowded classrooms and to follow paths marked out by circumstances ordained generations ago' (2 March 1962). Holcroft was adamant that New Zealand was not, and could not be, like that classed society.

Others however were more radical, and forthright in their critique of competition wherever it took place. If there was nothing more to life other than the 'fierce competitive struggle for what are considered to be the good things of life' then wrote one clergyman to the Listener, 'the less educated we are the better' (29 Jun 1951). There could be no satisfactory education system, in his opinion, 'before we have first evolved a social system in which every individual is ensured adequate food, clothing and shelter, whether he is working or not'. Similar radicalism found its way into the Department of Education bulletin. R G Munro, a secondary teacher, ridiculed the 'delightful absurdity' of school reports where:

with few exceptions, the top pupils are very good and good, the middle group is satisfactory or must work harder, and the bottom group is without exception 'poor' and 'weak' (Education Nov 1957:18).

Munro wished to abolish this 'unthinking ritual' of competition where 'the good are good because they work hard and the bad are bad because they are lazy'. This might be wild idealism, but it was argued in earnest. It was an attempt to find an alternative to a meritocratic logic which inexorably led back to competitive capitalism. These critics of capitalism were, nonetheless, a minority. 


\subsubsection{Gender}

Much has been written by feminist scholars about overt discrimination against women in education during the postwar era. ${ }^{35}$ Gendered inequality was sometimes deliberately and explicitly reproduced, not just passively copied, through the schooling regime itself. The egregious scaling mechanism of school certificate maintained a stereotyped bias by fiat: the system refused to factor in girls' longstanding competitive edge in subjects such as English (McGeorge 1987; McDonald 1992; Jones 2000). ${ }^{36}$ At the same time, however, the labour shortage driven by the demand of the state for its nurses and teachers, and commerce for its secretaries and typists, was making educational qualifications increasingly attractive to young women and encouraged their participation. (Nolan 2000:227; also May 1992:125). The widening opportunities for young women to become skilled workers, of course, did not in itself negate the gendered demand for women to be 'good' wives and mothers. And their work status after married life was still an open question, though the state and capital in their recruitment drives seldom confronted the vexed question of 'working mothers'. Still, the increasing value of education boosted already rising expectations further above what the traditional gender order could satisfy.

Similarly, one can appreciate the contradictions within the expectations of education. Scholars have been right to chastise the Thomas curriculum, in spite of its liberal rhetoric, for its stereotyping of girls as future 'homemakers'. Such an attitude was embodied by the very

\footnotetext{
${ }^{35}$ We know, however, relatively little about how (hegemonic) masculinity operated in its own right, especially in relation to other possible masculine identities, in postwar schooling, except what we can infer from the other side of gender relationship (but see below this section). One relatively recent contribution which claims to trace the 'genealogy' of the boys' achievement crisis, for example, includes no discussion of masculinity/gender in the context of postwar schooling (Spencer 2008:131-62). Discussion of masculinity is subsumed in analysis of moral panic and nuclear familial norms. Other notable New Zealand research on the New Zealand history of masculinity, such as Phillips (1996); Worth et al. eds. (2002), Kirkman \& Maloney eds. (2005) also make few references to postwar schooling.

${ }^{36}$ It had long been known that girls did better than boys in English and progressed faster than boys through primary schools since the early twentieth century (Jones:2000:85). The 'overachievement' of girls, however, was partly hidden by the scaling mechanism of school certificate based on a 'norm-referencing' system. At the risk of oversimplification, the system worked by lowering the weight of high grades in subjects such as English, particularly popular among female pupils, and increasing the weight of more male-orientated subject such as Latin as well as woodwork to maintain a superficial 'equity' between subjects.
} 
existence of 'home economics' as a virtually compulsory subject for girls. ${ }^{37}$ The low-status 'soft' subjects, and low expectations of girls' ability to achieve academically - the dichotomies 'hard' and 'soft', achievement and failure, moreover, were not self-evident - undoubtedly assumed women were inferior to men. But this was also sexism within an overarching discourse of equality where gains for girls, even if less than those of boys, were themselves reshaping the foundation of gender relations. Furthermore, the rhetoric of egalitarianism might overflow, even if it did not intend to. Gendered schooling did not go unchallenged in the postwar era. As Openshaw et al. (1993:265-6) point out, even in the early postwar years some female teachers and pupils took maths and science in their stride. And such transgressions raised no eyebrows. By the end of the 1950s, it had become difficult to keep girls out. Thus Dr W B Sutch, in his submission to the Currie Commission as the Secretary of Industries and Commerce, specifically rejected a gendered curriculum that channelled girls to commercial and 'home life' courses (Sutch's figures were 30.5\% and 18.8\% respectively). He argued that, in the new curriculum:

Our young women should have the same opportunity to be as knowledgeable about elementary physics and the internal combustion engine as our young men, and our young men should have the opportunity to learn about nutrition and house planning (1961:72).

Sutch's liberalism was still tinted with gender bias. He saw girls as 'mothers to be'. But there was, within the constraints of prejudice, room for resistance and subversion. In this light Sutch's embryonic idea that gender equality should affect changes both ways deserved sufficient credits. By this time, there was wide spread agreement about the necessity of better science teaching for girls even among those who did not necessarily accept liberal arguments for gender equality. The Currie Commission, despite its timidity and ambivalence, was unequivocal in encouraging more girls to study science and mathematics and urging the community and the state to pay special attention to the problem of the 'missing half' (1962:316-7).

Still, it was impossible to avoid the demeaning connotation of 'home economics', which could never rival Latin. The issue was partly symbolic, since 'bright' girls did Latin and the less bright picked other subjects such as commerce (fn.18). But Melanie Nolan (2001)'s skilful study of the early twentieth century New Zealand debate over the home curriculum shows that this archetypal

\footnotetext{
${ }^{37}$ Home economics was generally taken by girls in the lower forms of secondary school, though the number dropped sharply as they progressed (see Department of Education 1964)
} 
'feminine' subject was, from its inception, a contradictory being: 'home making' was not just the natural function of women but was a skill to be learned and taught. In the 1950s this pursuit of status took to new heights: pupils in cooking classes at Wellington Girls' College filled out a weekly spreadsheet that detailed the nutritional adequacy of each meal (Education Nov 1958:523). This did not mean the boys' subjects were an inherently more attractive alternative. The nonacademic girls, by 'following a course which their fathers took in the bad old days when mathematics and Latin were compulsory subjects for University Entrance', wrote the Principal of Wellington Girls' College, were just as much 'victims of social requirements' as their fathers had been, in a system which valued prestige over actual needs. There was a gendered antiintellectualism: 'differential calculus is not much help to a young mother with an ailing baby, nor can a husband be fed on Odes of Horace, or the theses of Cicero' (Education Jun 1956:23). Still it allowed for those girls who, 'encouraged' or not by adults, found more genuine contentment in pursuits other than Latin and arithmetic as well as for the boys who really enjoyed woodwork for reasons other than masculine status. And it gave some effects to the aspirations of liberalhumanists to cater for diverse social needs outside the constraints of meritocratic schooling.

The postwar school was not only an institution of knowledge transmission with a gendered curriculum, as today's schools are perceived to be, but also a gendered social institution of gender where learning as such was neither here nor there: a place where boys socialised with other boys and men, and where they met or were kept apart from girls.

Postwar schools undoubtedly promoted certain classical images of masculinity among boys, for example the school cadets marching in their khaki and playing soldiers, which were impossible to miss. But beyond such symbolic images, which offered anecdote and fragmented observations rather than a pattern, there were complexities and contradictions. The Governor-General, undoubtedly, had a good reason to remind some schoolboys that there was nothing 'effeminate' or 'sissy' about 'good English', and a 'witty address' shaped the world's destiny more than 'all the arrows, guns and rifles ever made' (Evening Post 17 Dec 1957). Thus expressed, nonetheless, the troubling contradictions between competitive meritocracy and rough masculinity was merely papered over. What then must one make of the clever boys streamed into the not-so-obviously masculine subjects of Latin and French, which opened doors to professional status and power? 
Furthermore, what passed for being 'manly' for a younger generation was not unquestioned. Even rugby could be challenged. Those from the right might question its utility for the space race (cf. 4.1.3). The left might object to rugby's exclusion of human values other than manliness. 'Manliness', for W J Scott, might include 'essential elements' other than physical courage, such as 'a capacity for tenderness', qualities easily overlooked in a highly physical and competitive game (Listener 5 Jun 1964:3). ${ }^{38}$ In other words, the visible privileges of manliness did not allow easy inference of a 'hegemonic' regime of masculinity in schooling.

Much of public anxiety, however, was not about masculinity as such but gender relations, and co-education was a perfect lighting-rod. ${ }^{39}$ The Mazengarb committee agonized over the 'propinquity' of sexes in schools, and post-primary schools in particular, but was not convinced it was a problem $(1954: 25,60)$.

Opposition to coeducational schools itself was deeply ambivalent. The superficial desire to shield adolescent boys from the corruptive influences of femininity could not hold water, not just because it was obviously impossible - no one was arguing for more single-sex boarding schools - but also because it sat uneasily with the necessary cultivation of masculinity. Some conservatives might hold that segregation of sexes in schools was nothing more or less than a God-ordained 'first principle', as the Director of Education of the Catholic Church put it (Listener Jun 23 1950). Yet even such first principles were not without intrinsic tension. In his submission to the Mazengarb committee, Father O’Neill, the Director of Catholic Social Services wrote that co-education, while 'not a fundamental cause', nonetheless contributed an 'added difficulty' by encouraging 'early company keeping'. The real problem as O'Neil saw it was 'the gap of almost ten years between physical puberty and normal marriage'. And with that aim of preparing adolescents for heterosexuality in mind, some 'innocent' company keeping was

\footnotetext{
${ }^{38}$ Scott's critique of rugby as a national 'institution' should be read against the mounting controversy around the racial politics of rugby since 1959 (Richards 1999:18-28). The gendered role of rugby is a comparatively well covered area in New Zealand research on masculinity (Andrewes 1998; Hokowhitu 2004; Pringle 2008). Pringle (2008:218-9) specifically emphasized the privileged place of rugby in contemporary schools. Yet postwar schooling has received little attention in this body of literature.

${ }^{39}$ There has been no study of the postwar controversy since Cocklin \& Battersby (1987). Their study concerns the proposal of establishing separate boys' and girls' schools in the Blenheim area, which had been served by a coeducational high school, and public debates around it from 1946 to 1958. They conclude that the debate was guided by a hidden agenda of gender differences - that girls were destined for domesticity and boys for paid work.
} 
acceptable even if it was driven fundamentally by sexual instinct (1954:3S4). It was a matter, then, of balance which stood in contrast against the categorical rejection of coeducation.

Some sought to circumvent this conundrum by pragmatic reasoning. It was much better to segregate sexes educationally, and make 'ample provision' for 'frequent mixing' on 'the purely social level', argued one commentator, than 'by collecting both sexes into one school and then imposing the restrictions e.g. boys and girls must not lunch together.' (Parent \& Child Mar-Apr 1958:35). The trouble was that such pragmatic justifications already conceded the principles of segregation. And not all even in the conservative establishment were convinced by them. The Press, for instance, gave short shrift to the moral merits of sexual segregation, and instead quoted approvingly the expert opinion ${ }^{40}$ that, if the aim of schooling was indeed 'social adjustment', then 'there could be no defensive ground for the segregation of boys and girls of adolescent age' (7 Feb 1956). Apart from such educational advantages, the Press was consistently in favour of coeducation also for its apparent economy and efficiency (31 Aug 1956). Expediency favoured the liberal approach, especially in the postwar context of school expansion and increased cost. The Currie Commission simply endorsed the Department of Education's self-professed 'resistance' to single-sex schools on grounds of staff and resource shortage (1962:222).

That is not to say that liberal advocates for co-education did not make principled stands for gender equality. Some such ideological arguments courted, paradoxically, fairly conservative constructs of gender. The argument went that the cruder method of segregation was unnecessary since heterosexual desires, once recognised, would disappear into the background because they were normal (e.g. Parent \& Child Mar 1957:35). Such thinking took defence of coeducation down some dark alleyways; it was worth noticing that some coeducational schools, a liberalminded headmaster R V Burton alleged, were 'deliberately founded in order to combat, if possible, the low standards of morality in some boys' boarding schools' (Parent \& Child SepOct 1957:30). Phoebe Meikle, another noted educator, argued along similar lines as late as 1964 (PPTA Journal June 1964:22). The limit of liberalism was clear; the freedom extended to 'normal' sexual attraction stopped well short of 'abnormal' homosexual desires, which it dared not even name.

\footnotetext{
${ }^{40}$ The expert here was an American professor affiliated with the New Education Foundation, the global advocate of the 'New Education'. This uncharacteristic receptiveness from the conservative Press is interesting in itself.
} 
Such a limitation did not, however, negate the conviction that advocacy for coeducation was correcting a historical wrong. Segregation, as Burton pointed out elsewhere, had its root historically in the inferior status of girls' education. And coeducation was only natural and right if we 'claim full growth and stature of every person - no less', not the least because it promoted mutual understanding over whatever gendered divisions that were there (Parent \& Child MarApr 1958:18-19). What was behind it all was the general philosophy behind the thought of 'Erasmus and Luther, Mary Wollstonecraft, the Society of Friends and Pestalozzi':

[In a co-educational school] boys grow less rough and aggressive and narrow-minded, girls less narrow and warped. ... Shall John be made more Johnish and Mary made more Maryish or shall each work with the other and merge into a larger society, both knowing and understanding each other well and naturally? (Parent \& Child Sep-Oct 1957:31)

This last point was purely rhetorical, of course. The idealistic humanism Burton was appealing to already eschewed gendered divisions as they really existed. Yet it nonetheless looked beyond gendered dichotomies for something more flexible.

\subsubsection{Māori}

Education debates, like other social issues during the postwar era, took on a different character when it came to indigenous people. The debates over the fundamental nature of education, the ones traced above, were addressed first and foremost to Pākehā society. Such discussions undoubtedly had implications for the education of Māori youth. Yet the latter issue in postwar discourse was framed very often not so much a youth problem as a problem of race and biculturalism.

For a postwar society which was only beginning to come to terms with the insidious inequalities under official 'racial harmony', education had a particular pertinence. Education was to deliver the goods of racial justice, and to do so in place of legal and political revolutions, and without addressing questions of socio-economic structure. In the words of the Hunn report, a key document on postwar race relations, education was 'the one thing, more than any other, that will pave the way to further progress in housing, health, employment and acculturation' (AJHR 1960:22). The prefabricated answer of meritocracy applied equally to race as it did to class and 
gender, except if anything more boldly. Thus F M Pinfold, an experienced Pākehā teacher of Māori schools, could claim that, with the formulation of a Māori educational policy:

the Pākehā community ... tacitly recognised as a duty of our superimposed Western society to give to the Māori, through our education service as well as in other ways, not only equality of opportunity, but an extra something based upon our sympathetic understanding of the handicaps suffered (National Education Jul 1957:208).

There was a whiff of Pākehā condescension about the backward race. But there was also a clear commitment to the ultimate goal of bilateral equality. Both undercut the contemporary 'consensus' on equal opportunity.

The same conflicted feelings underlined a 1962 appeal for the Māori Education Foundation by C M Bennett, a prominent Māori leader and New Zealand High Commissioner to Malaya. Bennett foresaw the objection against positive discrimination, for there would be some in the community who would argue that extra resources for one race, given the equality of opportunity in education, would be 'seemingly unnecessary and discriminatory'. But he argued one must 'distinguish between opportunities as such, and the effective utilization which really matters' and the gap was there. Admittedly, the Foundation, a statutory charity funded by government grants and private donation, was a curiosity in a supposedly universal welfare state. And it was perhaps not without a sense of bitter irony that Bennett compared the Foundation with the Colombo Plan: the tangata whenua cast as if strangers in their own land (Listener 25 May 1962). Nonetheless the idea that substantive social justice required 'an extra something' beyond formal equality of opportunity was significant; to utter such phrases in class or gender terms in the postwar context might have been considered positive heresy, even if they would have brought to the surface equally strong feelings.

Nor were such sentiments mere liberal utopianism. From a conservative standpoint, education, if it meant hard-work, was a legitimate vehicle for racial equality. The New Zealand Herald, for instance, saw education as key to Māori progress (Sep 19 1960). The emphasis, however, was not on needs but aspiration: 'too many young Māoris and their parents are still content with minimum standards'. Low aspiration was lowered further by the too easy welfare state. 'High wages in unskilled occupations, easy employment and all the assurance of "security" can play havoc with scholastic incentive'. Interestingly, the Herald had a penetrating observation about 
the classed implication of racial inequality. The 'predominant concerns of [young Māori] with one class of employment may well tend to create social barriers where none should exist'. It suggested that at least part of the appeal of social mobility through education was that it diffused the focus on visible markers of class.

Other contemporary opinions of racial disparity in education, by contrast, challenged rather than reinforced the myth of classlessness. Secondary teachers, claimed one teacher, were all familiar with the case of a promising Māori pupil who was instead

working in the freezing works, earning good money. Further study will reveal that he is one of a family of 12 , living in a cramped and poorly equipped home. His father, a heavy drinker, has never risen above the common labourer class. The boy has become a financial burden upon the family. ... The pressures of the present override future plans, and so a promising lad is lost prematurely to the labour market and he becomes another case to cite in support of the dictum, that 'a Māori lacks staying power' (Education Aug 1961:261).

Race as such was almost invisible in such a narrative, which was perhaps guilty of reading classed experience into lives shaped more powerfully by another category. But it nonetheless testified to the enduring economic pressures particularly on the minority in an apparent affluent society.

Many did not investigate along these lines. The prejudice had staying power because the education of Māori youth was thought about differently. The long-standing idea of a 'civilising' mission was current, at least in the early 50s. In almost every Māori school, reported Parent and Teacher in 1953, a definite pattern began with morning inspections of personal hygiene and 'the few who do not come up to it are sent away to make the necessary improvement' (June 1953:2). It epitomised the assimilative discipline of education, which gave scant regard to fancy notions of individual and varied development.

Others pressed claims for the recognition of Māori identity in education. A mere three years later in Parent and Teacher, Erik Schwimmer, editor of Te Ao Hou, was no longer content with knowledge 'alien and altogether separate from the warm and living reality of everyday things' which gave significance to Māori children in their community. He proposed an increase Māori 
content for Māori children. (Oct 1956:16). It was against such rising expectations the Currie Commission made its concession that 'a sense of belonging to a race of known and respected culture' must be included in the schooling of Māori children, on which basis scholastic achievement could be secured (1962:416). Cultural hegemony, in other words, was already weakening before these ideas were put into an 'identity politics' frame.

\subsection{Conclusion}

This chapter argues that postwar debates over mass schooling revealed complex undercurrents beneath the more obvious contest between liberal humanism and authoritarian attitude. Such debates must be read against the context of postwar society which remained under intense pressure from those sceptical of its officially egalitarian aims and those who had yet to receive what egalitarianism promised. The heated arguments about the means and ends of educational discipline were at the same time contests over the meaning of citizenship.

The postwar regime of schooling did not live up to its own egalitarian liberal-humanist aspirations. But from a strategic viewpoint, the postwar discourse of schooling with its refusal to reject discipline out of hand in fact, facilitated critical scrutiny upon the political and ideological implications of schooling. Moreover, it expanded the critical gaze upon education towards other forms of social control, and provided an ideal platform for public debates over the official commitment to egalitarianism, as well as hidden inequalities in class, gender and racial terms. Poswar discourses of schooling centred, rather than contained, larger debates about society. The welfare state agonised over how young people could be controlled through education, and for what ends. It did not find an easy answer. The pursuit of better, or more humanitarian, means of control, better aligned with its egalitarian philosophy, did not so much solve the problem of discipline as to reignite the political struggle over fundamental meanings of education and citizenship. Again, the attention is shifted away from youth and towards society as a whole. 



\section{Chapter 5 Youth and Society 1950-1965}

Issues of popular culture (more specifically, rock 'n' roll), changing sexual mores, and juvenile delinquency are explored in this chapter. These issues, which undoubtedly preoccupied postwar adult society, have been commonly regarded as classic episodes of 'moral panic'(e.g. Glazerbrook 1978; Soler 1988; Openshaw \& Shuker with Soler 1990; Yska 1993; also Laurie 2009 and Whitcher $2011^{41}$ ). But moments of panic, spectacular as they might be, are not an adequate lens with which to examine the complex social process which carried on as panics flowed and ebbed.

This chapter will examine the moral panics over youth/popular culture - comics and pop music sexuality and juvenile delinquency. In sections 5.1.1-3, it will show that concerns about these issues, while often misplaced, cannot be reduced to moral conservatism, or irrational fear, or elitist manipulation. Rather, adult discourses about these youth issues reflected uncertainties and complexities that lay beneath society's 'conformist' veneer. Further, these discourses made explicit class divisions that chafed against a 'materialistic' egalitarianism (section 5.2.1). They also reflected more subtle changes in the gendered regime and sexual norms than is captured by the notion of repression or liberation of (hetero) sexuality (section 5.2.2). Finally, in these discourses, issues about Māori youth were often overshadowed by cultural politics of assimilation/integration which highlighted the ambivalence about the taken-for-granted superiority of the dominant Pākehā culture (section 5.2.3).

'Moral panics', then, were not evidence of a homogenous social pattern. The articulation of the moral and social norms that were supposed to be 'unspoken' served, paradoxically, to disrupt the hold of those norms upon society. Instead of exploring possibilities of new strategies and mechanisms of social control, moments of 'panics' provided catalysts for wider debates that

\footnotetext{
${ }^{41}$ Guy Laurie (2009) took aim at the 'pejorative' labeling of panic. Laurie however was not disputing the moralist stance, but simply arguing that the anxieties of the moral guardians were in fact 'prescient' of social changes to come (2009:450). Whitcher (2011) by contrast focused on the anti-American sentiments and cultural elitism which united 'cultural guardians' both left and right in their battle against new imports of youth culture. The leitmotif was an intergenerational battle of tastes and mores, with the conformist adult society on the one side, and the rebellious young consumers on the other.
} 
illustrated the complexity and contradictions beneath an apparent 'consensus', the intricate links between the social pattern and the politics of the welfare state, as well as anxieties and uncertainties of adult society itself.

\section{Part 1}

\subsubsection{Rock 'n' Roll}

Rock ' $n$ ' roll was undoubtedly at the centre of mid-century youth culture, but comics have often been used as a foil to launch the larger thesis about moral panic over youth culture in previous research, and so we begin with them. The furore over comics was often, as Critcher (2008b:96) contends, 'not about comics at all' but about conceptions of children, society and nationhood. But comics themselves often were about these things. And the ideological undertone was exactly what caught the eyes of at least one New Zealand commentator. She reported one exchange: the 'American way of life', one American hero lectured his Chinese captors, meant 'truth' and 'freedom' under a 'free economic system' where 'every third American' had 'a car, a radio, a television set, electricity, a good job' (Landfall Mar 1955:52-3). Such propaganda might be incidental to the plot, but it was there.

It would have been stranger still if the left had had nothing to say about such propaganda than the fact that some on the left joined in an apparently conservative crusade. To be sure, such a crusade crossed the boundary between public politics and private fun (Whitcher 2011). This might look more serious than it was by an anachronistic $21^{\text {st }}$ century standard where the 'private' is off-limits. For contemporary observers, however, that line had already been crossed by what they saw as the commercialisation of childhood and even larger forces at play.

Much has been made, unsurprisingly, of this unlikely alliance between the political left and the moral right in the 'anti-comics' campaign in the conventional moral panic approach (There could perhaps be no better evidence of the strength of moral conservatism than the supposed fact that it managed to 'transcend' ideological differences). But the left and the right arrived at this converging point through very different routes, and with very different aims. That both sides shared certain cultural snobbery and pseudo-scientific arguments did not, therefore, cancel out the substantive differences. For the left, banning comics was never the whole point. Take, for 
instance, the Communist Party's attack on comics in its submission to the Mazengarb committee (WSMC 1954). It insisted on taking into consideration the 'overall atmosphere of war propaganda, of resort to violence'; in other words, the Cold War in which New Zealand was a complicit if not very active participant (It was not overlooked by the Communist Party that its focus on comics necessarily elbowed out other issues such as overcrowding and economic pressures that it had strong opinions on). Neither could it resist the temptation of drawing attention from beginning to the end of the party's submission to 'big business'.

The left did not have to speak about all this, if comics or even 'commercialisation' had been its overriding concerns. It would have been sufficient to duplicate the more respectable, if uncomfortably bourgeois, objections such as those made in American psychiatrist Fredrick Wertham's popular study of comics, which the left was perfectly capable of doing (Listener 3 Sep 1954:3; Here \& Now Jul 1952). But the Communist Party pushed the well-understood ideological buttons, so its moral campaign was as unpalatable as possible to its intended audience. That suggested a larger agenda than the banning of comics was at work.

In contrast to the Communist Party's moralising, the Mazengarb committee report was almost coolly rational (1954:18-20). The latter would have none of the naïveté about childish innocence. However 'pernicious', comics had little effect 'unless there were in the child, awaiting expression, an unhealthy degree of sexual emotionalism'. The committee thus shifted the onus to youth inherently 'at risk', and 'low mentality adults', rather than comics or external influences per se. No references were made to violence, let alone war propaganda. Instead, the committee was only interested in sex and saw no difference between crime stories and romance comics in 'exciting erotic feelings in children'. It had nothing to say against 'big business', or indeed businesses; the heavy-handed sanction fell only on a daring few who sold 'injurious' material 'with impunity'. Not a word either on the 'profit motive', that featured so prominently in the committee's critique of the 'materialistic' outlook of the welfare state and yet disappeared so completely in the attack on the comic publishing business.

As it transpired, there was no moral restoration through the banning of comics. The complexities and contradictions were masked by the rapid decline of the comic book itself as a medium. As moral panic over comics fizzled, a new front was opened up with the war on rock ' $n$ ' roll. 
Even here moral panic over rock 'n' roll was no sooner started than it was over. For all its supposed wowserism, the Communist Party had almost nothing to say about rock ' $n$ ' roll. This oversight would have been surprising if the party had lost all its senses in a wave of panic or capitulated all its principles to conservative morality. Or it might suggest that the ideological preoccupation with war and capitalism was better exemplified by comic books than by rock ' $n$ ' roll.

The crusade against 'undesirable' songs was spearheaded instead by the Catholic Women's League in its much-cited submission to the Mazengarb committee. Its extensive and annotated list covered jazz and blues classics such as 'I Get Ideas' and 'I'm in the Mood for Love', more than contemporary hits (WSMC 1954). It took the fight directly to popular taste, rather than to 'youth' music as such.

The committee members were unsettled enough to scrutinise their own music collections. But their report in fact downplayed the need for outright censorship. The screws were tightened considerably on the state broadcaster. The report said nothing, however, about the sale of records, which were repeatedly brought to its attention, nor about the menace of jukeboxes (1954:22-3). 'Suggestive' songs, like comic books and even semi-nude figures, would not 'incite a properly instructed adolescent to sexual misconduct' (1954:17). The emphasis on 'predisposing' factors already suggested responsibility fell largely on parents rather than, say, the recording industry. The anxiety dissipated into indifference. The songs, merely 'trashy', 'transitory in nature' (1954:22), constituted no more than a minor threat to 'juvenile morality'. Unsurprisingly, the recording industry was unperturbed. Indeed, New Zealand was, according to one music historian, the first country outside the US where rock ' $n$ ' roll recordings were released by the British multinational company HMV (Dix 2005:19). As Whitcher (2011:104-7)'s fairly comprehensive survey of public and journalistic reaction in New Zealand to 'Rock Around the Clock' shows, American pop culture had, by the mid-1950s, lost its ability to shock all but the 'cultural guardians'. Indeed, by Whitcher's own account, conservative opinion including not only the press but also the ministers of Child Affairs and Internal Affairs of the National government - those 'cultural guardians' with influence and capital - was quick to endorse rock ' $n$ ' roll and was easily convinced of the harmlessness of this profitable venture. There was no 
undifferentiated elitism, much less hegemonic consensus, as the blanket and pejorative term of 'cultural guardians' might imply.

Social attitudes cannot be imputed from the 'anti-establishmentarian' trope of rock 'n' roll and its retrospectively bestowed 'rebellious' reputation (cf. Mitchell 2013a; 2013b). Rock Around the Clock demanded, after all, only the right to rock. Moreover, as Mitchell (2013b) notes, not only did adults view rock 'n' roll as a passing 'craze', even its fans and stars saw rock 'n' roll as shortlived entertainment. 'It makes no pretence at lasting for more than a few weeks per song', protested one middle-class teenage devotee of rock ' $n$ ' roll (Listener 31 Jan 1964). In this way rock music fitted neatly into a limited script of generational rebellion, compared to more problematic acts of transgression such as 'hot' jazz/blues or the more political folk music, which cut across age groups. In other words, rock 'n' roll was just like adolescence itself; a stormy but ultimately transitory 'phase'. As one journalist for the Evening Post summed it up, it was 'an expression of an age ... destined to come and go' (13 Feb 1957). The 'crux of the whole pop song revolution', as another critic went, was 'a generation ... in revolt' (Listener 4 Aug 1961). The more substantive and subversive potential of rock ' $n$ ' roll was dissipated.

While some part of mainstream discourse increasingly regarded rock music as an acceptable, if not desirable, form of rebellion, others remained apprehensive. The liberal 'establishment' held out against rock 'n' roll. Dix (2005:57) for example singled out Holcroft, the Listener editor, for his barely disguised contempt for even the Beatles. As much as adults could tolerate 'a cry of affirmation that only the young can understand', it was 'our hope and indeed firm intention that having heard the Beatles once we shall not hear them again' (13 Dec 1963). The Beatles were certainly heard again and only a few months later with their triumphant tour of New Zealand. 'Good fun, clean fun, Beatle fun' ran the approving headline of Auckland Star. The plain 'suggestiveness' of the tour's top billing number 'Long Tall Sally' slipped quietly under the radar (Auckland Star June 25 1965). Even the Press was not so much alarmed about potential immorality as bemused at the prospect of riotous young girls, without whom 'thousands of staid citizens who take their pleasures vicariously' would be disappointed (27 Jun 1963). This apparent reversal of liberal/conservative attitudes pointed to the folly of reading cultural politics along dichotomous lines. 
The left had its own snobs. But the choice was not simply between high and low cultures. It was also between mass-produced consumerism and what leftists thought to be genuine authentic and un-coopted 'culture'. If Holcroft was wrong to dismiss the Beatles, he was certainly not so mistaken in his analysis of the 'cultural industry' in which 'any group with a passable voices and ample vitality can be groomed for success by the entrepreneurs, the big fellows in the background who go on making money when their "discoveries" have returned to obscurity'. What really puzzled Holcroft was the active hand of young people in their own 'seduction' by the disposable logic of cultural entrepreneurship. 'What a strange world has been discovered', exclaimed the editorial 'since teenagers began to earn enough money to dictate their own market requirements' (13 Dec 1963). They ought, it was implied, to have wanted better things.

This quandary was a consistent thread in the liberal left's response to popular music. The much quoted lines from Here and Now, often taken as proof of the left's superiority complex (Yska 1993:141; Whitcher 2011:105), were much more complicated. Rock music was dismissed as 'more monotonous than boogie-woogie'. But the point was that 'at worst' rock 'n' roll was a 'safety valve', a relatively harmless, if unproductive, outlet for teenage angst. What really irritated the author was that there was nothing on which 'youth could be invited to use its energy more significantly' (Here \& Now 1958:10). 'Rebellion' through mass entertainment, to the writer, was no real transgression; in fact it demanded conformity to the thoroughly consumerist logic of popularity. Neither did the 'straining for novelty' possess true creativity. There was almost an air of disappointment when Here \& Now commented that the opening of 'Rock Around the Clock' had passed with 'nothing more rowdy than some adolescent hand-clapping, some whistling and stamping, a little squealing in the rain after the show, and one charge of obstruction' (ibid.). It was clearly not, as Whitcher (2011:105) thought, a 'begrudging' admission of good behaviour on the part of young cinema-goers. If anything, it was a sarcastic swipe at the impotence of a 'consumption' rebellion, though without offering any better options.

\section{4}




\subsubsection{Sex and Sexuality}

Postwar New Zealand society for one well-known personality, Bob Jones, was a sexless place:

The general culture of course was that any sexual activity - or even thinking about it before marriage was just untenable, and there was certainly never any suggestion of contraception. And of course these were the pre-pill days as well, our sexual activity in those days was more wishful thinking. Oh look, I tell you it was Stalinist! (NZHistory Online/MCH 2012, n.p.)

Flippant though it was, the evocation of the suffocating horror of a totalitarian regime was not that distant a leap from the metaphoric 'tight' and sexually 'repressed' society in the more serious sort of historiography. The 'tight' society is usually a comparative construct offset against 'loose' youth. But we know relatively little about how adults themselves actually negotiated their own way through the cracks and fissures within the normative ideal of heterosexuality. This blank space stands out in contrast to the crowded field of New Zealand research in sexuality before this period ${ }^{42}$, much of which dispels puritanical myths. More recently scholars have begun to question seriously the 'tight society' thesis. Daley (2005:47-62) has briefly discussed the crucial years between the 'puritanical' pre-war era and the 'permissive' 1960s. Brickell (2012:94-114) makes a much more direct and sustained critique by reconstructing a 'queer' 1950s. A fortiori, rather than taking the 'tight' adult society for granted, it is useful to look closer at how postwar discourses of youth and sex constructed, as opposed to merely replicated, sexual norms.

The following image taken in the 1950s, which appears (among other places) in Browyn Dalley's discussion of postwar 'moral panic', was a useful illustration of the complexities and ambiguities often absent in the standard narratives of tight society and its moral panics.

\footnotetext{
${ }^{42}$ See Brown (2011) fn.45 and Brickell (2012:467-8) for a long list of literature, which barely touches upon the postwar years.
} 


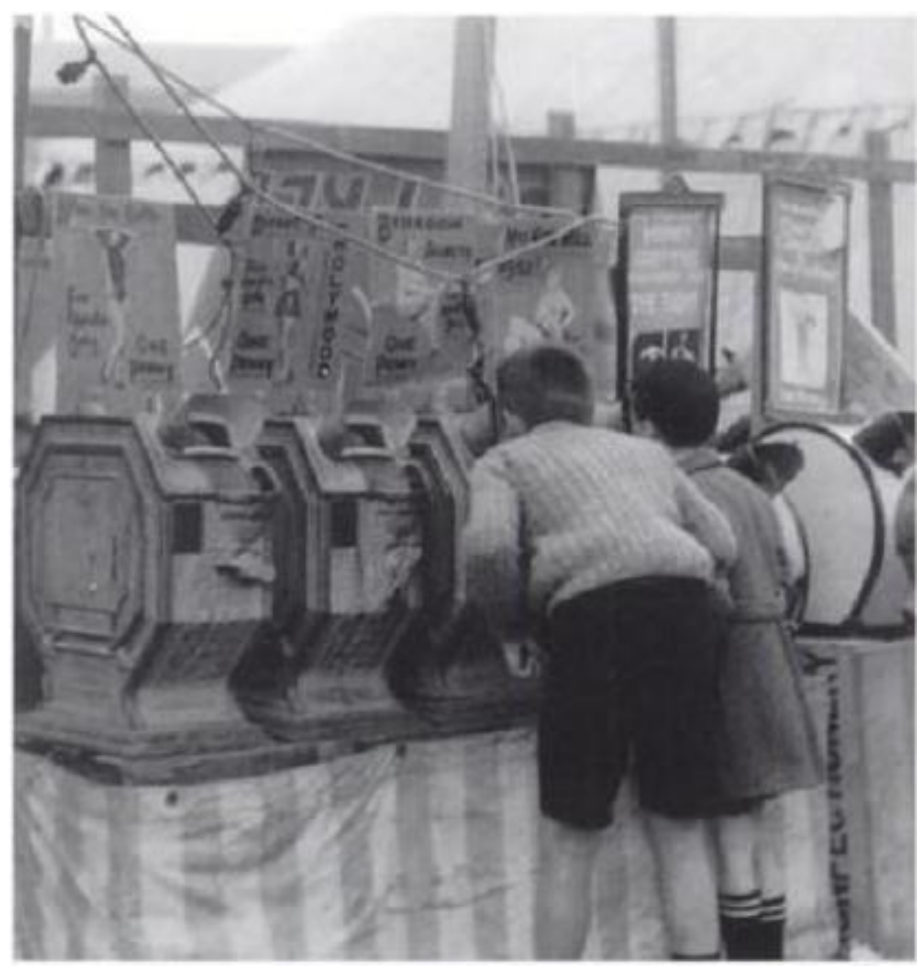

The text reads: 'salacious comics, along with films and peep shows, were among the amusements believed to be detrimentally affecting young minds in the 1950s and 1960s' (Dalley 1998:184). Yet the peepshow did not feature as a subject of postwar moral panic, in spite of all its subversions. The peepshow was no less sexually 'suggestive' than Elvis, and presumably that was what piqued the interest of the amateur photographer. And unlike pornography in late $20^{\text {th }}$ century, which was confined to the privileged private space, such sexuality could be flaunted in public, on the fairgrounds which were open to young and old, and where sexuality and other marginalised subjects had always had a central place. The two boys, in classic 1950s outfits, were perhaps only temporarily exempted from adult supervision, and yet their relaxed demeanour suggested an ordinariness where trespasses could be looked upon with amusement, rather than panic by adult observers. The act did not suddenly turn into an absolute taboo by the virtue of their age.

With this in mind one can now return to the stock illustrations of the 1950s in two major discursive sources. One clustered around the Mazengarb inquiry, and the second sex education. 
The Mazengarb inquiry is regarded by some as a futile attempt - whether it was a farce or a tragedy depends on one's convictions (e.g. Glazerbrook 1978; Guy 2009) - to stem the approaching tide of sexual liberation. But even the conservative-minded Mazengarb committee saw clearly that traditional mores could no longer be enforced by the double bind of repression and guilt, nor the discipline of poverty or state violence, as was supposedly the case in 'Victorian' times. All it could hope for was to regulate, rather than prohibit, sexual desires. And this paradox shaped its discourses.

To be sure the phrase used by the Mazengarb inquiry, 'sexual immorality', implied a certain aversion to sex, but it was still much less forceful and direct than what might still be read off a template of religious puritanism preoccupied with sins. The director of social services for the Catholic Church, Father O'Neill, for example, warned that many 'both highly educated and otherwise' now regarded sexual relation 'as a natural development in the growth of young people' (WSMC 1954). But following one's 'natural' instinct, sexual or otherwise, in the Church's opinion, 'logically leads to wholesale murder, theft and other similar things destructive to society and good human living'. Outside its 'proper' sphere of marriage, O'Neill was adamant that not only the 'full sex act' but also 'all acts leading directly towards it [were] wrong from every point of view - from the viewpoint of ethics, morals, the good of society, psychology, and human biology' (ibid.). The appeal to a broad consensus that deliberately downplayed religion could barely conceal the uncompromising doctrines which marked out the divisions. The lengthiest section of the submission was, unsurprisingly, on contraceptives. If contraception was permissible, then there could be "no serious argument against "free love" whether for the married or unmarried'; the use of contraceptives, even among the married, 'denaturalised' marriage by 'the direct exclusion of its primary biological function'. Unintentionally, O'Neill was making the case for those who challenged categorical injunctions against youthful sex on the ground of adult hypocrisy. At the same time he made clear the costs of real conformity.

But short of moral and social revolution, religious strictures had to compromise with social complexities. Even O'Neill's austere formulation of sexuality made room for 'instinctive' pleasure and emotional satisfaction, albeit subordinate to the biological necessity of reproduction. To work out the 'harmonious ordering' of these three functions, upon which morality depended, one had to look beyond scriptures about the primacy of reproduction to the 
indeterminable 'happiness and well-being of the individual and society' (ibid.). This nod to the contemporary norms of companionate marriage, and the rising expectation about sexual fulfilment ${ }^{43}$ might be reluctant; it was nonetheless a significant concession to the social, as opposed to religious, conceptualisation of sexuality.

In this way, moral conservatism was also forced to engage publicly with the social question of sexuality. That in turn fractured the apparent consensus on juvenile 'immorality'. One committee member and senior Department of Health official, Dr G L McLeod, reacted tersely to the insistence on reproduction and quipped, somewhat condescendingly, that there was 'more to the sex act than the appropriation [sic] of children' (1954:3S4). The snipe was met with an equivocal reply that pleasure may well be important in its own right so long as it remained secondary. The exact shape of the 'harmonious ordering' might appear tangential to the actual youth problem, though to McLeod, it was 'very much germane to juvenile delinquency'. The point was that such discourses made adult sexuality an issue.

In fact, not only could the centrality of reproduction be relaxed a little, the categorical injunction against youthful premarital sex was also negotiable. McLeod, for one, wondered if the ban on 'the full sex act and all acts leading directly to it' might exclude the 'healthy mixing between adolescent boys and girls' and the many 'little things' that would 'strictly speaking ... [lead] to the sex act'. O'Neill had to resort to pragmatism. A kiss outside the gate on the way home from the dance, wherever it led to eventually, was one thing. Long and passionate kisses by contrast were quite another. One could trust the 'agnostic from the University' to make such judgments 'without any religion at all', readily conceded the churchman, but what of 'the ordinary run of folk'(1954:3S4)? ${ }^{44}$ But this only made the dilemma clearer. Sex, after all, influenced almost 'the

\footnotetext{
${ }^{43}$ Szreter \& Fisher (2010:34-43)'s recent nuanced analysis challenges the generally held view that the norms of companionate marriage was well-established by mid-century and questions the reach of the ideal type in wider society (Szreter \& Fisher 2010:34-43). So here one might argue that conservative opinion, instead of being backward, was in fact jumping the gun somewhat. New Zealand studies on this subject remain rather sketchy, but a few sources support the hypothesis of a growth in companionate marriage with stronger emphasis on sexual fulfilment (Brown 2011:50-9; 206-12; Gooder 2010:28-9).

${ }^{44}$ Teenagers were perhaps more likely to turn to the popular press than clergymen for dating advice. Woman's Weekly began to offer regular columns on these issues during the 1950s (Evans 2005:115-8). Much of this new system of dating and courtship was concerned, of course, with controlling (female) sexuality and gender norms. Nonetheless it still signified social acceptance, and indeed normalization, of intimate involvement which might or might not lead to the 'full sex act' as an integral part of teenage lives. American scholars have scrutinized the postwar development of the institutionalized system of dating (Breines 2001:115-25), but similar research in the New Zealand context is still lacking.
} 
whole of our lives', said Reverend Jack Somerville, committee member and chairman of the Interchurch Council, and it went deeper and wider than 'that is completed in marriage'. Going to the pictures together might be innocent, but it was still plainly a 'sex attraction'. One could, he implied, hardly outlaw all these manifestations of sex, even if they all led in a way to that dreaded 'full sex act'. Concerns about sexual misbehaviour made an issue of these mundane facets of sexuality. The ever-widening gaze of moral concerns inevitably drew in richer and more intimate details of everyday life and detracted from the categorical injunction against teenage intercourse. Worse still, the endpoint in married life where all these preliminary acts of teenagers might lead to was itself shifting. Sexual fulfilment was increasingly part of the deal, if one were to consult, for example, sex and marriage guidance literature. The trend had been gathering force for some time. Two New Zealand authors by 1944 were advising young couples to try different sexual positions and different degrees of frequency to liven up their married lives (Cochran \& Cochran 1943). In the later postwar years even clergyman could speak openly about the importance of simultaneous orgasm without much stuttering (Blamire 1964 [1953]). And if without 'sexual harmony' there could be no firm foundation of marriage (National Council of Churches 1953:12), then there could really be no argument about keeping young people in ignorance. Increasingly sexual pleasure became constructed as desirable and even necessary in the marital context as a way of deflecting young people from premature consummation, and by implication, preparing them for a mature consummation.

This then afforded a role for postwar sex education, the other major plank in the construction of sexuality. Research on this subject often focuses on dismantling the misconception of sex education as 'progress' brought about by 'scientific' knowledge triumphing over religious and moralistic prejudice. Gooder's recent study, for example, concludes that 'the assumption that sex education was an uncomplicated call for sexual knowledge was not borne out in the New Zealand history of sex education in the $20^{\text {th }}$ century'. Sex education was not just, as Gooder rightly argues 'some form of enlightenment or empowerment' (2010:315-6). At the same time, there is no reason to regard this overlap between ostensible 'liberation' and social control of sexuality only in a negative light.

In the first place, as Brickell (2005:121) argues it was not until the 1950s that 'the heterosexual per se' came into existence in the context of sex education. And moreover, the reach and 
pervasiveness of the 'binarised calculus' of homo- and heterosexuality was questionable 'at any time before 1965 ' (op.cit.:122). ${ }^{45}$ In other words, the 'scientific' discourse of sex education was not just reinforcing the heterosexual norms that were already there; such norms had to be constructed partly through it. Moreover, one cannot assume contemporary moral and religious discourses necessarily led to some apparently foregone conclusion when they were in fact still being negotiated.

In this light, the shift in focus away from longstanding preoccupations with 'sexual hygiene' and 'venereal disease' to broader notions of social morality and citizenship in postwar sex education was significant (see Gooder 2010:27; 100). 'Venereal diseases', for example, occupied a single paragraph in the Health Department's 1955 sex education pamphlet with barely any elaboration of their potentially severe consequences. And instead of 'pathologising' homosexuality, a single line pointed out its illegality (Department of Health 1955a:7). The main concern of sex education was with the 'facts' of physiological changes as well as mechanisms of heterosexual intercourse and reproduction. Dull as it was, it was still not as dissuasive as an up-to-date catalogue of sexual pathologies or 'risks' could be (or should be, if sexual repression were its primary objective). In fact, it removed a few potential worries. A full page, out of eight, argued that there was "no truth whatsoever in old-fashioned beliefs that [masturbation] causes insanity, loss of manhood, pimples, or any other physical ill-effects' (Department of Health 1955c:7). The point was that this was more than what was needed to keep up the front of 'progressiveness', and rather less than what a 'scientific' discourse might achieve as a vehicle of discipline and control.

Furthermore, it was striking that, as contemporary critics of sex education noted, official discourse made few references to 'Christian' morality. This was no evidence of 'progress', but it did mean that conservative attitude had to find an alternative foundation in the changing social and secular context. Take, for instance, its advice to adolescent boys on sexual intercourse:

It should be an expression of deep love and affection between a man and a woman who are sharing their lives together in marriage to create a family. Sex can be a very beautiful thing, but it is very easily spoilt. It is only in the sanctity of marriage that it can be enjoyed freely, unashamedly and with the sanction of society. Sex indulged in for the

\footnotetext{
${ }^{45}$ The bulk of Brickell (2005)'s analysis is to draw out the implications of these points for the construction of homosexuality in New Zealand, as the title makes clear. On that front I agree entirely with Brickell's assessment and so it only remains for this thesis to cover other ground.
} 
sensation of the moment, and in the absence of deep love and affection between partners is almost inevitably disappointing. It creates under such circumstances so many problems that it is not worthwhile (Department of Health 1955a:5-6).

The strong insistence on the centrality of reproduction to sexuality came with a balancing act, mirroring the adult ideal of companionate marriage, which involved variables of fairness as well as pleasure, both in sexual and relational terms. The prohibition against premarital sex rested not so much on the aversion to sex per se as on pragmatic arguments based upon other social values. Sex thus constructed was not just a private matter of risk and morality but a social issue. This also helped to explain why postwar debates over sex education were often not about its content but about who was to deliver it. Social relations, particularly that between the family and the state, were not peripheral to 'sex'; they were at the very heart of the question about who should educate the young. On the face of it, the primacy of the home was confirmed. Parents' role in sex education, in the words of the Mazengarb report, 'should be a jealously guarded privilege' against outside intrusion, say, from the school (1954:27,39). Yet, as Gooder (2010:93-4, 114) astutely observes, this stress on the importance of the family at the same time highlighted its inadequacy in fulfilling the social expectations of its supposedly natural function in the delivery of sexual knowledge. This was, of course, not new in itself. But what was significant was the implication that the state was to pick up where families failed. Moreover, in this supporting task, the state no longer played second fiddle to medical and religious authority, in the context of sex education, which Gooder (2010:81) notes in passing. It attempted to articulate the regime of sexual norms consistent with its notions of citizenship. The content of sex education might have been less than revolutionary. But social change was reflected in the increasing role of the state, and the way it played this role, in the delivery of sex education.

\subsubsection{Juvenile Delinquency}

To postwar commentators, popular culture and sexual immorality were partly what were 'new' about the broader problem of juvenile delinquency, to which we can now turn. In fact the very notion of juvenile delinquency as distinct from adult criminality was still relatively new, as the Mazengarb committee noted, and certainly still contested, in fact, by the chairman himself a few years later. Such 'pretty names' for him were simply masking sin and crime (Evening Post 23 
Sep 1960). This section explores the construction of 'juvenile delinquency' and responses to its implications, processes which took place simultaneously across a number of distinctive discourses: medical-psychological, bureaucratic, conservative/religious and liberal. This complex process not only revealed some deep-seated contradictions within each discourse, but also undermined the coherence of a singular 'youth problem'.

Postwar medico-psychological discourses spoke of juvenile delinquency as a case of 'social maladjustment' that could be objectively diagnosed, or even 'cured' by ostensibly neutral expertise. This pathological model has been familiar to Foucaultian scholars, some of whom have been keen to cut off the king's head in political analysis and to replace that single repository of power with something else, like psy-knowledge. And yet, in such psychological analyses of society, the 'social' here was an appendage which refused to be cut off. And this was partly why 'psy' ${ }^{46}$ knowledge, although making considerable headway in postwar New Zealand society, did not manage to completely colonize the youth question ${ }^{47}$.

A E Manning's influential study of the 'Bodgie' (1958) illustrated this paradox of contemporary psy-discourses. Ostensibly a psychological analysis, though written explicitly for the popular market, the study trod a fine line between diagnosing a few 'abnormal' delinquents and exciting public discourses about wider society and its norms. But the gaze of the clinician often slipped, subconsciously as it were, from one to the other.

Occasionally the inconsistencies were apparent, for example, in Manning's histrionics against Mammon's grip on society, hardly a subject for 'scientific' study of individual pathology. Elsewhere the author was quite aware of the tension. He noted near the end of the book that the solution would require both 'the harmonious adjustment of each individual environment and the correcting of such environments that we, as a civilized people, know to be wrong' (1958:85). The silence on what was to be done about the latter - Manning had a lot to say about what was wrong - was made conspicuous.

\footnotetext{
${ }^{46}$ There were substantive and under-researched differences between disciplines of psychology and psychiatry in postwar era which fall under this term, and a matter for scrutiny elsewhere. Here both terms will be used interchangeably.

${ }^{47}$ Psychological knowledge did exercise significant influence on the welfare bureaucracy (Dalley 1998:183-4). Whether the influence was a result of expert power or correspondence with common sense about youthful misbehaviour was quite another question. At any rate, psychological expertise was by no means universally accepted in postwar New Zealand society. The Mazengarb committee, not for nothing, blamed the 'new psychologists' for the 'moral drift' (1954:24).
} 
It was this curious silence on social reformation and anxiety about what could not be fitted into diagnostic language, moreover, rather than the run-of-mill discussion about individual adjustment, that filled out the analysis. Manning did follow the form dutifully: each 'case' was classified and labelled by age, IQ, and alcohol or tobacco consumption of the delinquent. But the application was rudimentary and perfunctory. In fact, the clinical case was often closed before actual discussion began. The clinician's summary diagnosis contrasted with the excruciating attempt by the (self-identified) middle-class author to understand the unfamiliar social context of his subjects. 'Graham', a New Zealand lad aged '22 years and 5 months, I.Q. 125, alcohol from 17, smoking from 10' was an example (1958:52). The 'hysteric' delinquent, 'arrogant, selfopinionated and easily roused to bitter and violent anger', was a product of failed 'attachment' to the mother, according to the psychiatrist. Yet it was Graham's life story, which Manning recounted in great details that took up most of the space. The bright working class lad was bought up by a deserted mother who had 'no time for "sloppy sentiments'. The meritocracy which was supposed to reward his intelligence only brought him guilt about those classmates who 'used to try really hard [but were] ... trying without hope' because they were less intelligent than him (1958:53: italics original). The guilt became compounded, it was implied, when the impoverished mother had to take on work as a charwoman and washerwoman, 'even scrubbed to earn money'. Here Manning was shocked by Graham's 'cynical' remark about his mother's struggle: 'I guess there are lots of ways a beautiful woman can get money without scrubbing'. The long story had covered a page and a half. It screeched to a stop with a 'note': 'the youth was a hysteric'. The tension between diagnostic simplicity and the complexity of lived experiences was again made explicit, and left unresolved. In the process the diagnosis of the young patient became a monologue of the adult expert where themes of class, gender and occasionally race intruded. The inability to shut out these social 'noises' was shared by others within the same distinctive postwar genre of 'social psychology' such as Dorothy Crowther's Street Society in Christchurch, published in 1956. As Brickell (2013:68) rightly argues in his detailed examination, in her work Crowther had 'moved away ... from the diagnosis of a social "problem" ... to contextualize the life worlds of young people'. These life-worlds could barely be contained between the lines of 'scientific' observation.

In one place, Crowther's informant, a fifth-year psychological student, reported one conversation verbatim: 
First youth: 'What ar-ya-doin' tonight?' Second youth: 'Oh, a-dunno.' The first: 'Yi goin' ti the Māori Club?' The second: 'Oh, a-dunno.' The first: 'Ave-yi-gotta car? Couldja getta car? Yiv gotta car, haven't ya?' The second: 'Me, no, I smashed mine up.' The first: 'Wot about yer mother's?' The second: 'Don't be silly. Takes me all ma time to get hers any night, let alone a Sunday night.' The first: 'Couldn't ya get one then?' The second: 'No, I couldn't get one.' The first: 'Oh, ya' (1956:14)

It was a long and tedious way to make a point about bodgie 'aimlessness'. Yet the very length of the transcription itself, and the fastidiousness of noting variations of ya, yi, and yer and so on betrayed an uneasiness about the linguistic signifiers of class. ${ }^{48}$ Closer to the surface, moreover, the spectacle of aimless delinquents dissolved into mundane details of working class everyday life and its material constraints. By accident or by design, the porous 'social psychological' method took in more of society than it could decipher 'scientifically'.

Similarly, Crowther's observation of society shone a light upon both youth and adults, and their relationships. One teddy boy fell foul of an angry passer-by:

'I could twist your nose.' The boy looks a bit sick. The man says, 'You know what I mean?' He lectures the boy on manners, then drags him to his wife several chains down the street and makes him apologise (1956:7).

It may be the liberal sensibility talking through a contrived fact, though that did not appear to alter the author's otherwise unfavourable and occasionally condescending tone towards the 'teddy boys'. But the sharp attentiveness to what happened in the background tended to diffuse the focus on the young protagonists, and show up adults themselves as 'socially maladjusted' in the wider social context.

Political and social analysis did not always have to slip through the back door. Other psychoanalyses traced their genealogy to Freud through the Marxian Frankfurt school and the theory of the 'authoritarian personality'. 'Social maladjustment' for them meant first and foremost the trauma of adult society still reeling from authoritarianism. And it was explicitly a political and social critique.

\footnotetext{
${ }^{48}$ Scholarly analyses of class patterns in New Zealand English, especially ones which closely track their changes and variations, remain in short-supply, although such divisions are known to exist (Hay et al. 2008:101). For 'dropped-h' which took its cue from the British pattern, see MacLagan 1998.
} 
Harold Bourne, lecture in Psychiatry at Otago University, made the case at a conference organized by the Association for the Study of Childhood in 1958. In a long essay he argued that the 'defiant' and 'exhibitionist' behaviours of adolescent rebels were in fact a reaction produced by authoritarian adults clinging onto 'infantile omnipotence'. 'Forced submission to authority', said Bourne, dutifully quoting Theodore Frenkel-Brunswik, Adorno's colleague, 'produces only surface conformity countermanded by violent underlying destructiveness, dangerous to the very society to which there seems to be conformity' (1958:36). He warned about the 'campaign for war against the rights and freedoms of children' in New Zealand and was convinced that there were 'large, ugly, vicious social and political purposes served by all this'. What Bourne actually had to say about juvenile delinquents themselves was conventional. The point, though, was that, although Bourne was indeed guilty of reductionism, it was not reduction to a psychological 'science' that hid its normative prejudices, but reduction to an ideological critique of authoritarianism.

Of course it was not the social critique of 'psy' experts which made their knowledge useful to others, such as the bureaucracy, but its diagnostic and therapeutic potential. But this appropriation of knowledge was not all there was to the exercise of bureaucratic power. In fact it helped to reproduce the tension between the 'scientific' and the social in a different way.

A Child Welfare departmental directive, submitted as evidence to the Mazengarb inquiry, prescribed as many as 37 headings - which came with their own explanatory note - for its case file on juvenile delinquents (1954:E2-3). Under the group heading of 'family background', officers were advised, for example, to record any history of 'serious disease, mental subnormality or disorder, evidence of neuroses, emotional instability, or social inadequacy as shown, for instance, by chronic alcoholism or criminality' of the delinquent's family and other immediate relatives. As for the delinquent, nothing was allowed to escape the scrutiny of the bureaucrat. Behaviour symptoms and temperament included anything from sex and smoking to biting and screaming (WSMC 1954). The intense scrutiny of individual circumstances said little about society, except one fleeting reference to the 'cultural and economic aspects of family life ... dealt elsewhere'.

The logical end of this much 'pathologising', provided it did not collapse under its own weight, was clearly that the delinquent needed intensive treatment by psychiatric and medical experts, 
not the material and emotional help of the welfare state. And yet the latter was precisely what informed Peek's recommendations. Peek reminded his officers that they:

Must take into account the reasons for a delinquency and the satisfaction or the outlet it provides for the delinquent ... [Departmental actions] must be related to the needs, abilities and shortcomings of the delinquent and his family, and to the opportunities and limitations of his environment. They must provide him with possibilities for alternative and socially acceptable behaviour.

This language was paternalistic rather than diagnostic, and theoretical rather than prescriptive. There was a gap between the diagnosis of the 'problem' and the framing of possible solutions. It threw open again a whole new field of inquiry; once the maladjusted youth was thoroughly examined, what then was the delinquent to be adjusted to? Here, then, was an opening for the social engineer, however reluctant he might appear to be.

The same conundrum confronted bureaucrats as it did social psychologists. The bureaucratic discourse, couched in 'scientific' terms, often digressed into an eclectic mix of ideas. Case files supplied to the Mazengarb committee illustrated this where the desirability of housing often took up more space, in the bulging sections on 'Family Background', than, say, 'religious training'. The home of one delinquent, wrote the Christchurch superintendent, was 'materially ... an excellent one situated in a superior residential area'. The file was sterner on a 12 year old boy 'of the poorer working class type' who had been convicted of 'homosexual behaviour'. The home was nonetheless 'materially a good one ... giving evidence of conscientious attempts at a reasonable standard of housekeeping on the part of the mother who was in poor health'. The Auckland officer described a boy 'aged 16 ... below average intelligence. ... Normal range of interests. Parents rather dull, with little understanding of adolescent needs. A history of substandard housing, but now in State house' (WSMC 1954).

The discretionary nature of the postwar welfare regime (see Labrum 2004:153-73) might explain some of this highly idiosyncratic moralising. But the case files also spoke of the deeply entrenched notions of class and respectability in an ostensibly classless society that, like social psychologists, bureaucrats were struggling to articulate. Such notions, moreover, did not disappear behind the frame of individual pathology or the aspirations of welfare. 
Conservative opinions were no less conflicted than liberal ones. Appeals to morality and religion, like appeals to science, were supposed to frame juvenile delinquency in a way that bypassed social and political differences, and demonstrated the shared identity of adult society (Belich 2001:101; Guy 2009). What they actually did was to superimpose adult divisions over apparent consensus about youth.

Religion was a case in point. It might be a convenient justification for social control, often through the state, but the irony was that Christian morality was supposed to stand on its own, not be propped up by the state. Whether Mazengarb thought about the implications of disregarding a few polite, though long held, conventions in his strong appeal to religion we do not know. But others noticeably baulked at the dalliance between religion and the state. The Presbyterian Church, commenting on the appointment of the Mazengarb inquiry, hastened to declare that neither the school, nor cheap pornographic literature, were to blame for the outbreak of delinquency. The questions of 'goodness' and 'evil' were not decided by government expenditure or human benevolence. Legislation too was useless, since it 'cannot create morality', which was God's writ alone (Christchurch Star-Sun 16 July 1954) The church stopped short of explaining what should have been done, though it had called the bluff of all moral guardians, including itself.

What was significant is precisely that it was still possible to think about the issue of juvenile delinquency as immorality instead of a social problem. The Auckland Star for instance scorned the term 'juvenile delinquency' with its 'tinkling musicality' that was distracting from the point of moral transgression. This encouraged 'theyism', the great bogeyman which would blame everything else except the 'moral depravity of young folk not out of their teens'. The impulse to make these offenders 'conform either by force or elaborate social machinery' was, the readers were reminded a 'pagan' concept. Much better to leave it up to the 'supernatural sanctions', lest young folks without pious fear were to 'drift down the shallow, uncharted estuary of sensual impulse and confused desires, to [run a]ground upon shoals and rocks of moral ruins' (Auckland Star 2 July 1955).

This fluent use of morality to master social panic, although unusual in its forthrightness, was a reminder that 'conservative morality' was not merely about appearance; it also had a substantive point about individual responsibility. And after all there were other ways to the same end. In a 
conformist and 'conservative' society, private justice could be and ought to be swift, as alleged 'teddy boys' in Auckland found out when they were roughed up by a gang of uniformed servicemen (NZ Herald 5 Nov 1955). This campaign to 'clean up New Zealand' was short-lived, however. Liberal opinions recoiled at the apparent infringement of civil liberties (NZ Herald 1 Nov 1955; Listener 25 Nov 1955). It alienated not just radical opinion but also, as a contributor to Here \& Now (Mar 1956:15) observed, made conservative minds uneasy about empowering young roughs, whether in teddy-boys outfits or Queen's uniforms (Here \& Now March 1956:15).

The difficulty was that such 'conservative morality' required a laissez-faire social order prepared to let individuals themselves shoulder the full costs of their moral transgressions, which meant annulling the newly established welfarist regime. While religious figures might dodge the question of earthly social order, politicians and public figures could not but embroil themselves in debates over larger 'social delinquencies' which threatened to upstage juvenile delinquency. Governor-General Lord Cobham (1957-62), for example was convinced that a 'naughty society' was the problem. Some might have blamed delinquency on the insecurity of youth. But 'why on earth would it [sic] feel insecurity in a modern welfare state'? 'Is not the reverse nearer the truth', he asked, that the young people 'with nothing to fear and plenty of money to spend ... they simply do not know what to do with their leisure' (Press 3 August 1960)?

A softer version was put forward by the Mazengarb committee, which could not resist drawing a parallel between the problem of delinquency and the ideology of security:

Education, medical and hospital treatment, industrial insurance, sickness and age benefits, and other things are all provided by the State, when the need arises, without direct charge upon the individual. The virtues of thrift and self-denial have been disappearing. Incentive does not have the place in our economy which it used to have. The tendency has been to turn to the State for the supply of all material needs. By encouraging parents to rely upon the State their sense of responsibility for the upbringing of their children has been diminished (1954:45).

Juvenile delinquency here became an unambiguously ideological problem of the welfare state, and, because it was ideological, the message was open to political contest. And the argument cut both ways. The adults who were reminded that they themselves voted for age and sickness 
benefits rather than virtuous poverty, and thus contributed to juvenile delinquency, might stick to their 'hypocrisy' about youth, or they might change their prejudice.

The uncompromising critique, such as that of the Mazengarb report, however made the position of the 'hypocrite' uncomfortable, more so as the report did not, or could not, shy away from taking on even state housing, the symbolic pillar of postwar welfarism (1954:28). ${ }^{49}$ And this made concrete the choice between welfare and morality.

The difference was between the artificial 'mushroom growth' of planned suburbs - the characteristic expression of the welfare state - and the 'normal' development of communities with 'large family homes and smaller homes, grandparents, parents, uncles, aunts and children'. The latter was freely chosen 'either because their relatives or friends are there, because it is handy to the husband's work, because of "the view", or similar reasons'. By contrast in the planned developments "the people had not chosen to live there: a house has been "allotted" to them'. And more the pity since there was 'not a stratum of wealthy people in or near these settlements who might be benevolently inclined to help the district where they reside'. The images of community and people closely tracked each other. Except, of course, the former was not supposed to look like that. A wealthy 'substratum' with its 'grandparents, parents, uncles, aunts and children' in the larger homes, and the less well-off with their grandparents, parents, uncles, aunts and children crammed cozily into smaller homes could not be fitted easily into the compressed hierarchy of welfare ideology.

There were dissenting voices on the issues of juvenile delinquency from liberal and more radical quarters. Admittedly many took up the prop of psychology too readily and failed (if only by anachronistic standards) to make a principled stand for sexual and other liberties for the individual as such. 'Understanding' and 'treatment' were taken for granted as a better answer than punishment. In such ways the Listener made a plea for 'society's younger enemies' whose 'badness' may really be 'confusion', and confusion had 'causes which may be removed with studies and treatment' (Listener 21 Jul 1950). It seemed to have never occurred to the editor that adult society might be confused about its own standards of good and bad.

\footnotetext{
${ }^{49}$ The political left and the right by this time was no longer divided by state housing as such, but how to deliver it. The difference was between rented state houses and three-per cent mortgage (Schrader 2005:46-54).
} 
Others were more critical of society and its technicians. W J Scott, the well-respected educationalist and civil libertarian, warned about the 'priestly' role of psychologists and psychiatrists, attempting to master these 'more subtle, indirect and inner' ways of manipulating youth into conformities with existing social values, which might well be wrong, 'as I believe many of our present ones are' (Scott 1958:8).

It was characteristic of the liberal counter-discourse that this critical gaze did not 'excuse' young delinquents. Scott, for instance, was positively condescending about the teddy boys, bodgies and widgies, even as he was making a case for the 'non-conformists'. They were, he 'supposed', 'like criminals ... [who] tend to be not very intelligent individuals who have been not very intelligently treated by parents, teachers and other representatives of authority'. Their suggestible minds were too easily swayed by American 'modes of expression' which happened to be available. An unthinking moral conservatism, which bypassed politics, is a convenient explanation for this blinding prejudice.

But Scott was frustrated with New Zealand working class youth not because they rebelled, but that they did not rebel in a more sophisticated and better way like the 'angry young men' in Britain - 'upright', reputable', 'very intelligent', 'well-educated' and 'intensely uncritical' - as he wrote admiringly of them (1958:11). This sense of frustration was characteristic of an ideological rift between the working class and those thinkers and writers who thought themselves to be its spokespersons. Scott pointed to this rift when he said that 'under the welfare state, now supported by all parties, it is no longer a question of fighting against cruel inequality and injustice; the fight is against the moral and emotional quality of public and private life'. Now the working class seemed to have it all so good and all so easy on account of the welfare state, to which the 'left' had once lent at least moral support. They must want something better than this American trash.

Bill Pearson, in his influential essay on New Zealand character, 'Fretful Sleepers', also included a similar sketch of the 'milkbar cowboy' (Pearson 1952:222). The cowboy was a 'coward with a ready smile'; 'the youth reads double meanings into the most harmless quips on radio and film, keeps a store of dirty yarns, most of them without wit or fun' rather than making a bolder claim to sexual pleasure. Like Scott, Pearson thought this young rebel was simply not doing it right, and thus doomed to become as 'bored, doubtful, dissatisfied and afraid' as the adults against 
whom they rebel. Both were same part of the dull suburban life. It was from them he wished to save the sensitive and intelligent adolescent, the future intellectual. Pearson denounced the dream: 'everybody acts the same, receives the same amount of the world's goods, everyone moves in the same direction'. It also never occurred to Pearson, or Scott, that the second part of this dream remained an aspiration which had only been partially realized. The intellectuals could never quite work out that New Zealanders who had just got their backsides warm on the egalitarian bench might want to enjoy a little more comfort and leisure that they fought hard for, rather than flock to night classes. The intellectuals' ambivalence about the welfare state they had welcomed into being, rather than moral conservatism, underpinned their puzzling attitude towards juvenile delinquents.

All these complexities cannot be reduced to a simplistic explanation of mass delusion on the part of adult society about the moral standards it wished to impose upon the young. The older generation of New Zealand might not be 'very inspiring with respect to enterprise, efficiency, responsibility and self-denial', and was full of the vices that it condemned youth for, as David Ausubel complained (Ausubel 1960:108). But it did not delude itself into thinking that these values were unproblematic virtues. The debates over the young, as we saw, was one way that adult society attempted to come to terms with complex political and social questions about some of its most fundamental beliefs.

\section{Part 2}

\subsubsection{Class}

We may consider sex and sexuality first because the material with respect to class is limited. But the economic aspect of sex, which had class implications, was clearly at the back of the minds of some contributors to the Mazengarb inquiry. Was it not a deterrent to immorality, Mazengarb asked an unconvinced policeman after much persuasion, if boys do fear that 'if they had intercourse without the contraceptives something may result that will affect their pockets?' (1954:3B5). Even the Department of Health was not blind to the logic of economic incentives. Its pamphlet to adolescent boys warned them about the liability for child maintenance even if they did not marry the mother of their child (Department of Health 1955a:5). Such means of 
discipline, relying often on the collusion of the state, gave teeth to religious and moral condemnations of premarital sex which necessarily fell more heavily upon some than others.

At the same time one must consider these comments in the context of the postwar welfare state, which as Dalley (1998:217) argues, was increasingly unwilling to abandon the 'less deserving', for example, single mothers and their children. A larger number of young couples managed to evade such judgments on their sexual activities altogether by escaping, babies in tow, into Nappy Valley (Belich 2001:492-3, 505-6). But the point was that it was not just an escape from the moralising gaze of older generations. It was also an escape from actual classed mechanisms through which moral sanctions were carried out, and into relative material security and the whole package of respectability that not so long ago was available only to the well-off.

By contrast, the discourses around comics and rock ' $n$ ' roll were undoubtedly coloured by an implicit distinction between high and low cultures which in turn expressed classed prejudices. But the fit was loose. In fact, cultural distinctions often appeared secondary to classed prejudices, even where the lines between high and low cultures seemed clear. A conservative figure, thus, could endorse rock ' $n$ ' roll and escape criticism; a Labour politician could not.

The Minister of Child Welfare of the National government, Hilda Ross, for example, gave her endorsement to Rock Around the Clock, arguably a much more controversial event, without much fuss (Whitcher 2011:105). But her Labour successor, Mabel Howard was savagely satirized in the conservative press for taking essentially the same stance (NZ Herald 13 Jan 1959; Press 13 Jan 1959). One letterwriter deplored her lack of decorum as a cabinet minister and, perhaps as a snipe at her social security portfolio, added that 'social security is [as much] gained by a decent, orderly way of life as by a monthly security check'. Another, a 'cruelly overtaxed' bachelor, asked for his money back from the Labour government for the 'untold thousands of pounds involved in the education of Mr J Devlin ... and his screaming admirers'(Press $21 \mathrm{Jan}$ 1959). The controversy showed a ready interoperability between cultural and political judgments.

Moments like these were rare, though. Before the turning point of the Vietnam war, rock 'n' roll was preoccupied with love and not war, let alone ideological imaginings, in spite of its working class audience and self-proclaimed working class 'roots'. Elvis' pelvis did upset some adults, not the least because it invoked the sexuality of the racial and class 'other'. But the threadbare 
phrase 'I want you/I need you/I love you' and the monotonous beat paled by comparison to the sexual appeal and political potency of, say, the blues standard 'I Get Ideas' which belonged to an older generation. Even love had become, over time, less a corporeal practice than a respectable, and all embracing, notion of romance. It might be tempting to see this trend as 'cooptation', but that would be missing the point. It did not matter whether 'Lawdy Miss Clawdy' was sung by Lloyd Price from black New Orleans in 1952, or the white working class Elvis Presley in 1956, or New Zealand's own Pākehā bank-clerk-cum-rock-star Johnny Devlin in 1958. This pursuit of popularity might be anathema to the used-and-abused trope of 'authenticity', but it was precisely by its refusal to commit to any specific external context that rock ' $n$ ' roll remained steadfastly true to its own identity, above all as popular music. In this way the discourse of rock ' $n$ ' roll was not dissimilar to the discourse of youth, which strove to dissolve the national, racial, and class boundaries, out of which it was made.

Both identities were made possible by changing socio-economic conditions which they rendered invisible. Songs about love spoke louder when other noises of everyday life had for a moment ceased to be overwhelming. And leisure consumption could shape identity precisely because the opportunities to consume were much more widely available. This contradiction was central to understanding the ambivalence, both in the politics of rock ' $n$ ' roll itself and adult reaction to it. So while rock ' $n$ ' roll might be morally challenging for some, to others, its economic appeal was as plain as the ubiquitous sight of undergarment models as an advertising trope in mid-century New Zealand media. One billboard for Johnny Devlin, 'New Zealand's own king of rock 'n' roll', on his tour sponsored by New Zealand's largest chain cinema, Kerridge-Odeon, featured the fresh-faced young man holding up the iconic American commodity. 'After a solid session I dig a Coke. Dad ... that flavour's real cool', he said (Dix 2005:27). There was not a shadow of reservation about its crudeness nor any backlash against 'Americanisation'. Capital understood what sold, even if it sneered at the consumers. Working people, and their politicians, were not completely opposed to commodified affluence either, nor did they see it only in moral or utilitarian terms. Rather they clearly understood it was about their entitlement to a share in the consumerist society and thus must be vigorously defended. Youth culture was part and parcel of this entitlement in the eyes of Mabel Howard, among others, who also saw no necessary contradiction between the right to have fun and the ethics of hard work, as Brickell (2005:146-7) observed. Of course, within this discourse of entitlement, young people were still likely to be 
treated somewhat differently than adults. But the Labour party which had made an election pledge for more cigarettes and nylons for the parents (cited in Brickell 2005:143) could hardly deny their offspring access to rock 'n' roll. In short, class politics did not intervene in any straightforward fashion in the consumerist culture of the young, but it did structure how that culture was produced and consumed.

Class as such was seldom mentioned in public discourse on juvenile delinquency. Imprecise euphemisms - 'materially good homes', for example - denoted class positions, but only to explain them away. Paradoxically, the cruder measure of class in economic terms of rising wages and employment security, of which working class youth were often the most conspicuous beneficiaries, often invoked stronger antagonisms.

Complaints about the high wages paid to adolescents were regularly heard from letter writers as well as editorials (Christchurch Star-Sun 29 Jul 1954). The Mazengarb report too found 'high wages' a factor in juvenile delinquency. It made a not so subtle attempt to pit working mothers against working teenagers: there was certainly something wrong when mothers worked to increase the family income while youth earning 'nearly as much' as their parents were free to spend it on 'expensive luxuries'. Yet it soon turned on both: these affluent teenagers without the requisite habit of 'thrift' would be joining those complaining about the affordability of housing in a few years (1954:36-7). Neither were such complaints about high wages exclusively from the right. Liberals too felt a sense of unease about the indiscriminate spread of material wealth. 'Easy money and motorbikes don't bring security', cautioned Monte Holcroft, and added that 'understanding did not come from big fat paychecks' in a Listener editorial that went on to denounce the 'downright hypocrisies' of adult society (19 Aug 1960).

Not all young people had it so good at the age of fifteen. The sons and daughters of the betteroff, staying on at school, had to do without the temptation of 'high wages'. And adult society was no more interested in their pocket money than their future earnings or inheritance. Working class boys and girls on the shop and factory floors, by contrast, could be earning adult wages for their equally unskilled labour. Apprentices whose earnings were pegged to skilled or semiskilled tradesmen might, with a stretch, be included in this group of 'affluent teenagers', which was the main target of criticism from the right. 
'Again and again', pondered the Listener, 'we noticed the occupations [of young offenders] with good wages but no prospects', the 'familiar dreary list' of 'van boys, assistant porter, builder's labourers' (29 May 1964). Whether or not the list was accurate is beside the point. It hinted that good wages which were supposed to prop up the egalitarian myth that 'Jack', prospect or no prospect, was as good as his master were in fact not enough to compensate for the 'dead-end jobs'. So it was difficult to press the point. If young people were frustrated by their lack of prospects, what did it say about their parents who were trapped in the same position?

The welfare state, however, seemed as if it could well afford to conceal such contradictions. The full amplification was not drawn out until a few years later. Mazengarb argued in a feature piece:

The very concept of a Welfare State is a materialistic concept operating to the prejudice of thrift and other moral virtues. Instead of a religious faith that 'the Lord will provide,' the present generation has inherited a carefree and careless notion that the State should provide all their needs. ... Material desires can be realised by, or through the State only because, when sufficiently pressed to do so, a Government can turn the handle of a printing machine or allowed trading banks to create more money at the cost of a drop of ink. ... That is why our $£$ continues to buy less and less every year. That is why some young people are unsettled through having too much easy money to spend. That is why bodgies and widgies and milkbar cowboys are able to move about in gangs and become a threat to manners, morality and peace (Evening Post 27 Sep 1960).

The 'gaining of money', Mazengarb worried, was 'taking precedence over the development of character'. He was indignant that wealth appeared to have been taken away through inflation induced by high wages and easy credit, and conferred on those who instead should have been content with virtuous poverty. Mazengarb here was translating the supposedly 'new' problems of juvenile immorality back into the old problem of class relations. Such a translation, however, pointed not so much to a moral consensus as social divisions. 


\subsubsection{Gender}

Rock ' $n$ ' roll, with its preoccupation about sexual and intimate relationships, could hardly avoid gender politics. But it was not until the second half of the 1960s, when the Rolling Stones played the soundtrack to the ostensible liberation of sexuality, that there appeared a certain affinity between these two discourses. Rock ' $n$ ' roll in its early years might have been an affront to a Victorian code of silence, if there was ever such a thing, but it seldom ventured too far outside heterosexual norms. There was perhaps, as one critic believed, 'often ... a more honest expression of sex' in its version of teenage romance. Yet it did not escape the critic that there was also a 'realist attitude to sexual destiny', by which was meant 'married love' (Listener 4 August 1961:5). That 'destiny' of heteronormative marriage might be postponed by the trials and tribulations in search of 'true' love, but it was never seriously questioned as an aspiration and a necessity. In fact, it was 'ordinary' adults, rather than youthful pop stars, who were continuing to chip away at the foundations of heterosexual institutions. ${ }^{50}$ Moreover, as sexuality became more and more encapsulated within the leisurely frame of adolescent romance, as it was extricated from more complicated social relationships, rock music also became less threatening compared to say early blues, which were one of its precursors. 'Shake, Rattle and Roll' which Presley introduced to white teenagers, might have been sexually 'suggestive'. But it was not a direct invocation of sexual pleasure as part and parcel of everyday life, alongside its practical needs and worries, such as Bessie Smith's 'Empty Bed Blues'. 51

Sex and romance were only a part of the gender regime. The representation of the latter in rock 'n' roll was much more problematic than an oversimplified motif of rebellion. In the first place, as a long line of critical scholarship has shown, the gender politics of rock ' $n$ ' roll was often dominated by the conventional desires of (young) men, and frequently served to intensify the aggressive side of masculine norms. If it pushed the boundaries, it was often because of its disregard for the convenient façade of respectability, rather than on account of any critique of masculinity as such (e.g. Frith \& McRobbie 1978; Martin 1995; Bertrand 2004). At the extreme, Bertrand claims that rock music was defined by a 'patriarchal ethos [that] typically manifested

\footnotetext{
50 More recent research has only just begun to revise the impression of postwar New Zealand adult society as sexually repressed. See Daley (2003; 2005:47-62) and Brickell (2012:94-114).

${ }^{51}$ Bessie Smith's bestselling record, released in 1928, weaved a glut of overt sexual double entrendres into domestic scenes. Smith's longing for a man, among other things, to 'grind' her coffee and put the 'bacon' in her 'overflowing' pot, upset at least one leftist puritan as late as 1954 (Whitcher 2011:fn.91).
} 
itself in the form of a physical presence that exuded self-assertiveness, aggressiveness and competitiveness' (2004:66). Such qualities were perhaps best embodied by Presley, or rather his thrusting pelvis. Young women's part in these performances of masculine rebellion was primarily, if not solely, to make their emotions and sexuality available. In fact, they appeared more frequently as mere audience: the 'hysteric' female fans - almost never male - that resonated with older prejudices. 'He's a Rebel' as the song went; the protagonist was never a $\operatorname{girl}^{52}$

To take rock ' $n$ ' roll's gender subversion seriously, analysis must be disentangled from the cultural myth of intergenerational revolution. The postwar generation of youth, like adults, had to work with the possibilities within the heteronormative gender regime itself. Even the hypermasculine image of 'the King' was not closed to alternative readings (e.g. Zemke-White 2008:194-201). But what often escapes attention is that this kind of negotiation was not the privilege of the young. Adults too were seeking out opportunities within the cracks of masculine hegemony. The mid-century masculine ideal, as Jock Phillips (1996:266) described, was incredibly tough physically, shockingly crude in their language and behavior, fond of their yarning and boozing, but terrified and contemptuous of urban society and appallingly misogynic [sic].

Adult men no less than adolescent boys dreamed of escape from and subversion of the same suburban life they shared. The former fantasized about 'frontier men' of a bygone era when the living was tough while the latter looked to milkbar cowboys. It was not just young people who were pushing the masculine norms towards their breaking point.

Changing gender relationships also shaped postwar discourses about adolescent sexuality. Some feminist scholars have pointed to a 'backlash' against the 'loosening' of female sexuality. Gooder (2010:95, 271-2), for instance, finds in the Mazengarb inquiry and sex education discourse a paradoxical image of female sexuality (2010:95, 271-2). On the one hand, girls were

\footnotetext{
${ }^{52}$ Young women and girls were in fact beginning to assert their desires, backed by their spending power on records. The monopoly of masculine rebellion gave away, briefly, to softer 'teenybop' idols such as Cliff Richard or Tommy Steele, towards the end of the 1950s. Popular girls' groups and singers both overseas and in New Zealand, also emerged, though they were still often overlooked in pop music history (Keightley 2001:117-8). It was some years before a new wave of feminism opened up cultural and leisure consumption, along with other aspects of the personal' to political scrutiny.
} 
assumed to be sexually passive and vulnerable. On the other, it was their responsibility to control their own sexuality as well as the 'natural' sexual urges in boys. In such ways girls' sexual misconduct became doubly deviant, and the blames fell often on girls themselves. This was explicit in the Mazengarb inquiry, which set particular store on the 'new' threat of 'precocious' girls (1954:18-19). The fact that a boy's sexual misconduct was necessarily caught up by law and the girl's would not worried the committee chairman (1954:F2). And its lengthy discussion on law and morality was almost exclusively about the advocacy for imposing legal punishment for girls who 'tempted' boys and older men (1954:46-50). And this contrasted with the charitable view - or even double standards - of boys' transgressions. It was not 'chivalrous' for a man or boy to inform on the girl, Mazengarb contended on one occasion, and it was a 'well known fact' that they did not (1954:4X2). On the one hand, this view reflected an uncritical approach to masculine privilege. 'hegemonic' masculinity. On the other, to shift the blame away from oversexed boys to 'precocious' girls also, in a sense, inverted the hegemonic power of masculinity, whose need for protection entailed an admission of its essential vulnerability, and even passivity. Control of young people's sexuality, in other words, did not necessarily replicate the exact contours of gender regime.

Gendered constructions themselves complicated the matter even further. Boys, because their sexuality was assumed to be more active, and more central, by implication, faced greater difficulty than girls in controlling it, which in turn made boys rather than girls the more problematic subjects of intervention. This was reflected in the subtle difference in sex education pamphlets, about how boys and girls should prepare for their respective 'sex roles'(Gooder 2010:269-70). Girls were told that they were 'not nearly ready to take the responsibility of marriage, home-making and the care of children'. Boys by contrast were reminded that, as they were 'soon to become a man', there were 'new kinds of problems that [they] have to cope with', including, for example, troubling relations to one's own sexual body - erections, wet dreams, masturbation - which did not appear at all in the advice to girls (Department of Health 1955a:3$4 ; 1955 b)$. For girls, the control of sexuality submerged in the adjustment to social roles which were themselves changing. For boys, it remained a constant struggle with dangers inherent in their very own identity. Sex and gender, once again, were in complicated relation to each other. 
While concerns about sexual misbehaviour often turned their gaze to girls, discussions about juvenile delinquency as such, by contrast, readily assumed the adolescent male as its subject (Spencer 2008:120). Much less, however, was said on this subject, and thus only partial observation can be made. The Director of Education, for instance, reported to Parliament in 1957 that juvenile delinquency was 'predominantly a boy's problem', with a ten to one ratio of court appearances if minor offences such as theft and property damages were counted (AJHR 1957:E1:43). This was reinforced by more general observations. The matron of one Burwood girls' home observed, for instance, that 'boys tend to express difficulties through violence'. Girls on the other hand tend to 'take it out on themselves ... Their crime is mainly against themselves' (Listener September 28 1956). Such distinctions were certainly consistent with a traditional gender regime which emphasized boys' active and public role. Whether the distinctions were a paradoxical result of gendered conformity by these 'non-conformists', or they were at least partly skewed by adult perception of what troubles young people of each gender ought to make, is a debatable question. Nonetheless, it does not contradict what has been discussed about the changes to the gender regime which lay underneath the insistence on gendered sexual morality.

\subsubsection{Ethnicity}

The problem of sexuality, whether in terms of social norms or 'juvenile delinquency', was defined primarily from the Pākehā viewpoint. The Mazengarb committee made one fleeting reference to the unavailability of statistics regarding sexual delinquency of Māori youth and little more. The series of sex education pamphlets published by the Department of Health, for instance, featured not a single brown face, as Gooder (2010:285-6) notes. 'Whiteness' was represented only implicitly in 'respectable', middle-class, images which by no means included all Pākehā. Nonetheless, the invisibility of the sexualities of other ethnicities could legitimately be interpreted as a reflection of the dominance of colonizing culture.

But possibilities of alternative discourses might be preserved by their very exclusion. There was evidence, for example, that Māori communities remained accepting about premarital relationships between young people, even when they faced pressure to conform to Pākehā sexual 
norms in their new urban environment (Labrum 2004:461). ${ }^{53}$ It was striking that the ethnic 'other', convenient though it was, did not become a scapegoat for public anxiety in the way that 'youth' supposedly was and instead was overshadowed, like other aspects of Māori youth problems, by the larger issue of urbanization. The reach of the 'conformist' Pākehā society was thus perhaps more limited than it seemed. Among other things, it could not so easily displace its own uncertainties and confusions around sexuality onto others.

If sex did not make ethnicity an issue, neither did rock 'n' roll, in spite of its obvious potentials. It would certainly be problematic to take rock ' $n$ ' roll's origin myth at face value, and see its appropriation of black culture as progressive race politics (Daniel 2000:174-5; Wald 2009:171). Nonetheless, the emergence of rock ' $n$ ' roll coincided with the rising tide of the Civil Rights movement in the US (Altschuler 2003:38-66; Bertrand 2000). For contemporary observers, including New Zealanders, rock ' $n$ ' roll and race were inseparable. Letter-writers often grumbled about its 'negro' origin and denigrated its 'jungle' rhythm. Even the more respectable commentators were sometimes seemingly oblivious of the coded prejudice. One Wellington critic and jazz connoisseur saw in Elvis 'whose raw uninhibited jungle singing blitzes his audiences ... the primitive side of the current Rock and Roll craze'. Rock ' $n$ ' roll, he told the radio audience, was essentially 'Negro rhythm and blues whitewashed, with the emphasis on the white', which had its root in the type of 'crude' jazz known as 'race music' (Listener Nov 9 1956). It was possible, however, to interpret 'race music' in exactly the opposite direction, as did the editor of the Listener, for example. The 'simple and primitive' rhythms of the 'descendants of African slaves' was precisely what western youth with 'a pulse in [their] veins wide open for living' wanted. 'And what a wry-mouthed joke it makes of the colour bar' (Listener Oct 10 1958). The crumbling of moribund civilization in the face of robust primitivism of the young and the 'racial' other did not seem such a bad thing. It pointed to a sense of uncertainty about the superiority of the dominant, Pākehā, adult culture.

However, very little of this reflection on the cultural politics of rock ' $n$ ' roll addressed local debate over relations between Māori and Pākehā. This was especially odd given the popularity of

\footnotetext{
${ }^{53}$ Only a 'veneer' of information, in Hutchings \& Aspin's words (2007: Introduction) about same sex attractions among indigenous people, has been passed down in historical records. Even less is available concerning the postwar era. Still, Te Taite Cooper, who was a teenager in the 50s, can still declare that 'at no time have I ever lived in a closet' (Cooper in Hutchings \& Aspin 2007:141).
} 
rock ' $n$ ' roll among Māori community, which had perhaps always been less resistant than middleclass Pākehā audiences to American cultures (Bourke 2010:251-7). Whitcher insists that this 'shared enjoyment' of Pākehā and Māori youth 'illustrated the potential American music had for shaping racial sensibilities' (2011:102). Rock 'n' roll may well have circumvented the 'colour bar' in its making. It talked past, however, a whole host of dilemmas around assimilation and biculturalism that began to emerge locally. And it was not the only attempt by indigenous culture to recover its colonised voice: country, 'South seas' rhythms, music hall and cabaret were other examples (Bourke 214-20; 246-7; 328-40). These were forgotten, not the least because they proved to be less amenable to the demand of the cultural industry, for which racial sensibility was necessarily secondary to the marketable appeal of youth in rebellion. Rock ' $n$ ' roll was in that sense not so much blind as indifferent to race.

Public discourse on juvenile delinquency, too, seemed strikingly inattentive to race. Officials and Māori communities already noted the 'over-representation' of young Māori delinquents, pivotal to today's discussion about juvenile delinquency. Dalley (1998:193) observes, however, that it barely registered throughout much of the 1950s. This relative inattention was even more conspicuous given the demographic of Māori urbanization. Many of the new-comers to the city were young, 'a group of "young unmarrieds' bent on asserting their independence"' in the words of Joan Metge (Metge 1963:199; also King 2004:576-8). For them, the task of 'adjustment' meant not only growing up but becoming more like Pākehā; both were fraught with conflicts. It might seem surprising then that the 'moral panic' around juvenile delinquency did not have ethnicity as a central thread, convenient a scapegoat as it was.

The explanation partly lies in the incoherence within the prevailing racial ideology which was making the transition from assimilation to integration. Upon this haphazard terrain, new attitudes often overlapped with, and sometimes served to conceal, old prejudices. When asked for comments on the disproportionate rate of 'Māoris and half caste' youth offending by the New Zealand Herald, one magistrate, for example, responded that he believed 'environment counts for everything', and 'as their accommodation improves, I feel the matter will begin to right itself'. And yet he added that it was 'a retrograde step to allow Māori women such free access'in other words, the same access as Pākehā mothers - 'to hotel bars and to let them take liquor away' (22 Aug 1953). It appeared that heredity, rather than environment, justified this 
benevolent discrimination. The contradiction was characteristically swept away by a confident belief in the promise of equality and progress.

Progress and equality, though, were not universal values among Pākehā society, and the fact that Māori had neither, by virtue of their dispossession and exclusion, appeared sometimes almost a blessing in disguise. Māori culture in spite (or rather because) of its 'backwardness' could be made an approximation of the timeless communitarian and familial virtues which Pākehā society had lost. 'The Māoris could teach us a lot about community spirit' commented another district welfare officer in the Daily Telegraph on recent statistics of juvenile delinquency. 'In the social functions attached to the pa, the family goes as a whole. Everybody joins in the activities'. Pākehā families were 'in many cases' exactly the opposite where 'dad goes off to the club, or some sporting fixture, mum has her work and her women's organisations to attend, and junior is left to find his own entertainment' (13 Jun 1951). It was not only the Pākehā who felt that way. 'Influential Māoris', reported the Press, had 'drawn comparison between events at Hastings during blossom festival and at Waiwhetu', where an extremely well-behaved 25000 attended the dedication of a marae, with many young visitors in 'bodgie and widgie dress'. All thanks to 'the Māori Way' (19 Sep 1960). Being Māori was positively constructed in these frames, and yet it was no more than a pale reflection of Pākehā nostalgia.

Underlying this was still a persistent notion of the Māori as the other, which, instead of becoming seamlessly embedded within a discourse of Māori juvenile delinquency, was bringing the racial politics to the surface while simultaneously drawing attention away from universal explanations of adolescent turbulence. And this sometimes disrupted even the most conventional narrative of juvenile delinquency. It allowed the conservative-minded Auckland Star to insert an uncharacteristic demand for better housing for Māori youth when so many of them 'were forced to [live in] semi-slums' in-between its persistent calls for short and sharp punishments for young hooligans (September 17 1960). Māori youth, in other words, were constructed as part of a collective 'them' outside Pākehā society, and just like Māori adults, as passive though perhaps necessary victims of modern times, and whose problems were 'largely distinct from those affecting Pākehā' (Dalley 1998:193). ${ }^{54}$

\footnotetext{
${ }^{54}$ Psychologists contributed a potential alternative lens. Ausubel's thesis of 'acculturative stress', supported by local research such as Beaglehole \& Ritchie (1958), Mulligan (1957), might have been used to locate the problem in
} 


\subsection{Conclusion}

This chapter argues that while the postwar society failed to respond adequately to issues of youth culture, sexuality and delinquency, this inadequacy cannot be explained in terms of 'panic'. Rather it resulted from deep-seated uncertainties within adult society about its own norms which young people were supposed to conform to. Such anxieties brought to surface not only the ambivalence about moral and political 'consensus' but also the deeply embedded class, gender and racial divides.

As postwar society scrambled for responses to perceived new threats from youth, as if in a panic, it became clear that it lacked the strategic means to overcome oppositions and distractions. Talks of music, sex and delinquency were not just about these particular subjects, rather they offered new vantage point from which new visions of society could be articulated. The discourses of the welfare consensus and moral conservatism could never encompass the entire range of such discursive possibilities. The debates revolving around them, instead, revealed instead subtle but critical differences in values, beliefs and experiences that fractured ostensibly unquestioned norms. They also served to bring to the front political implications of social conformity.

The welfare state was pushed and pulled into debates about youthful leisure, sexuality and delinquency beyond its comfort zone. It had few alternatives but to rely, as a starting point, on moral conservatism which was not only increasingly challenged by adult non-conformers, but also chafed against its egalitarian aspirations. The welfare state highlighted, perhaps in spite of itself, the political dimensions of these social issues. It also meant that concerns about consumerism, as well as the class, gender and ethnicity code of moral norms could not be so easily overlooked. What began as an attempt to control young people ended up a collective introspection of adult society itself.

individual psychological adjustment than social change. Yet here the psychologists - as David Ausubel exemplifies often did not hesitate to draw out the ideological implications and articulate their own views on cultural politics. 



\section{Chapter 6 Family and Youth 1990-2005}

The notion of the family remained central to public discourse in the 1990s and early 2000s. The fact that the National government's proposed Code of Social and Family Responsibility, like the Mazengarb report, was distributed to every household in New Zealand in 1998 affirmed that centrality. But the meaning of the family's centrality had changed radically. It was telling that the Mazengarb report had come with the payment of family benefit; the new Code with a denunciation of welfare dependency in favour of more responsible parenting.

In this chapter I will trace this change, which was enabled by a broader shift from the welfare state to neoliberalism, from a top-down familial-domestic ideology actively supported by welfare to a 'bottom-up' discourse of parental function that emphasized individual responsibility. This change cannot be explained away by demographic shifts in family composition. Nor can the apparent liberalisation of attitudes account for the change.

Families did become more diverse in their forms by the 1990s, as a cursory glance at censuses and surveys will show. But demographic changes were themselves complex and open to different interpretations. First, in spite of heightened public anxieties about single parents, only a minority of young people were likely to grow up in single-parent households. The incidence was particularly low, for example, for middle to upper income Pākehā families. Many more experienced the 'reconstituted' family, but in conventional heterosexual forms. And the vast majority of young people, especially Pākehā, were still likely to grow up with their biological parents (Pool et al. 2007:306). Second, the majority of young people were increasingly economically dependent upon their families, even if they were ostensibly freer consumers. An early escape into the Nappy Valley, once within the reach of working class teenagers with the help of the 'Nanny State', was no longer a possibility as the state reorganised its priorities. The family now seemed far closer to the 'traditional' ideal of home as a refuge from the cruel, insecure world outside, than it ever was during the postwar years. In short, there was no straightforward trend that led inevitably to 'new' discourses of family. 
Nor is the apparent liberalisation of social attitudes towards alternative forms of families selfexplanatory. Such an oversimplified narrative of 'progress' captures only the impression of radical change. Not only the tone but the subject of discourses had certainly changed: single mothers on benefits, rather than working mothers, were subjects of public anxiety. All the more reason not to lose sight of underlying shifts in political logic and social context that set limits to tolerance and diversity.

Governments both left and right, under the watchful eyes of the free market, would no longer, for example, force the carrots of family wages and family allowances down the throats of their citizens. They would no longer attempt to reinforce gender norms at the expense of economic rationale; waged work was an equal right and equal obligation that trumped the value of motherhood. But against the backdrop of this (neo)liberalisation of political ideology, the liberalising of familial ideology was much less striking than it might have been on the grounds of equality alone. Labour's Minister of Social Service and Employment could declare boldly that 'it was time to acknowledge that the days of the nuclear, European-styled family unit had gone' and that his government would not attempt its 'restoration'. But new forms of families were expected to provide 'love, discipline and sound nurturing' (16 May 2000). ${ }^{55}$ They must, in other words, be deserving of tolerance.

Greater tolerance of alternative family forms then did not preclude intervention in families by other means. In fact, since ensuring conformity to the nuclear form was no longer the sole method of intervention, the new interventions, targeted at 'bad parents', were potentially more pervasive and intensive, and more efficient. This was made possible, as this chapter will show, by a highly individualistic logic that underlined the discursive reconstruction of the family through the notion of parenting function (6.1.1), as distinct from familial norms, with an increasing emphasis on the self-directed cultivation of parenting skills (6.1.2). Both served to reinforce individual responsibility for 'failed' parenting which in turn helped to explain away

\footnotetext{
${ }^{55}$ Even this watered-down version of tolerance did not go unchallenged. In 1997 the Governor-General lamented publicly the 'disintegration' of permanent wedlock between husband and wife, and called for the return of traditional Christian values (Hardie-Boys 1997:n.p.). A book-length attack, penned by Patricia Morgan and published by the influential New Zealand Business Roundtable, bemoaned the decline of the 'traditional family based on marriage', a decline which, she alleged on the evidence of the Christchurch Longitudinal Study, was detrimental to the upbringing and socialisation of adolescents (2004:154). For Morgan, the welfare state which once propped up the postwar ideal she subscribed to was not the solution but the problem because it undermined the self-sufficiency of the 'traditional' family.
} 
social problems, for example youth suicide, as individual deficiencies (6.1.3). Moreover, this discourse functioned specifically to rule out socio-economic class as an alternative explanation of youth 'problems' and instead blamed 'under-parented' stratum of youth, the products of an underclass (6.2.1). It helped to align the emerging indigenous discourse of whanau with the dominant logic of individual responsibility (6.2.2). The same logic, working through the discourse of 'fatherlessness', rearticulated traditional masculine norms in the new language of neoliberal individualism (6.2.3).

\section{Part 1}

\subsubsection{The Ideology of Parenting}

The discursive shift was reflected in the way the state talked about families. While the state no longer expected all families to look the same, it wanted them to produce the same results. The Minister of Social Services, for example, this time announcing the establishment of the Families Commission in 2003, said that:

we do not want the Families Commission to be established to begin an argument about a certain kind of family; we want it to ask what the functions are we expect from every family. We expect families to nurture and support young people. We expect them to provide consistent love for children and consistent boundaries for their behaviour (NZPD 9 Dec 2003).

Apart from the rhetoric of diversity, such pronouncements resembled statements by the conservative National Prime Minister Jenny Shipley as, for example, shortly before the launch of the proposed Code of Social and Family Responsibility:

We must find consensus on what Government can do, on behalf of the taxpayer, and what New Zealanders and their families can and must do for themselves to solve these problems ... the Government, on behalf of the taxpayer, cannot continue to increase funding of programmes that seek to solve problems when the answer lies elsewhere in the 
complex areas of personal and family relationships, responsibilities, and self-discipline (NZPD 17 Feb 1998).

The first seven out of the eleven items of the code concerned the ways families should look after children and young people. Indeed, as contemporary observers noted, the code intended to mobilize families as a solution to 'state dependency' (Angus in Davey 2000:146-7; Larner 2000:256; Worth 2003); a renunciation in other words of the postwar pact between the family and the welfare state. The starting point was no longer what the state could do for families with their complex needs so that they might fulfil social expectations, but what parents must do for society, without imposing on the state, by taking care of the younger generation.

This new perspective led inwards rather than outwards. As Dutch scholar Nancy Vansielegm argues, the contemporary way of bringing up children was no longer 'something the parent comes to understand in relation to social and cultural norms, but ... a process [of selfactualization] in which they must invest', one that calls for expert advice in coping with permanent uncertainties and risks $(2010: 343 ; 351-3)$. In this way, the focus on the family was no longer distracted by the fragility of external social norms which families were expected to conform to, as was the case discussed above with the postwar ideal of domesticity.

Moreover, this individualising perspective relegated the state and society to the margin. While the state was free to emphasize the importance of good parenting, it was no longer its role to articulate the social norms that defined what counted as good, or take over responsibility for parents to find it out for themselves. Ironically, the Code of Social and Family Responsibility, reminding all parents on such matters as vaccination, crossed this line. It irked even the Director of the New Zealand Business Roundtable, a bulwark of the New Right, who vehemently rejected the perceived intrusion into private decisions of families (Independent 20 May 1998). The state could only have a residual role (though this role was by no means any less coercive). It had to be ready to take over from 'failed' families in order to secure individual responsibility. And when it concerned teenagers, it addressed their individual responsibility too, not just that of their parents. 
This may help to explain why, while a plethora of parenting programmes were set up as a means of state intervention, very few concerned teenagers. ${ }^{56}$

Scholarly literature, including officially commissioned research, might have been, alongside the state, another potential source of the rules of good parenting. But there was little. A New Zealand bibliography in 1994 could only list five sources with only one New Zealand journal article specifically dealing with adolescents (Burgoyne 1994). There was a longer and up-to-date list, though again with only a small proportion of New Zealand literature, in the Government commissioned Youth Development Literature Review (McLaren 2002). The review, which focused almost entirely on one theory of 'parenting styles', was more than adequate for policy makers; whether it was useful for parents was another matter. ${ }^{57}$ The large body of rigorous research from two New Zealand longitudinal studies, similarly, focused upon empirical testing of various 'risk factors', with an overwhelming emphasis on early childhood. Little, if any, research before 2005 addressed the relationship between adolescents and their parents in its own terms. ${ }^{58}$ Andrew et al. (2002)'s monograph on parents and their teenage sons was a valuable exception. 'Comparatively little', they argued, was known about 'their daily lives and the ways they interact within family/whanau'.

The remarkable paucity of literature means we must look elsewhere, as parents themselves had to, for clues to the new norms of good parenting. A burgeoning private industry of parenting advice catered for such needs. The significance of this industry might be seen in its size and

\footnotetext{
${ }^{56}$ The Review of Parenting Programme conducted by the Families Commission in 2005 had one line in passing about 'the ongoing need for parenting programmes beyond those targeting pre-schoolers' (2005:6). Another broad overview of parenting programmes in academic literature also mostly targeted young children only (Shulruf 2005:84)

${ }^{57}$ For a critical review of competing models of parenting, see Kerr et al (2003; 2008). McLaren's review interestingly focuses entirely on the parenting style theory, which divided different styles into 'authoritative (nurturing)'; 'authoritarian'; 'permissive'; and 'neglectful'.

${ }^{58}$ The title of one much cited article from the Christchurch Longitudinal Study offered a clue to its concerns: Show Me a Child at Seven: The Consequences of Conduct Problem in Childhood for Psychological Functioning in Adulthood (Fergusson et al. 2005). Beals (2006:50-100; 113) has argued, quite rightly, that the singular focus on the longitudinal correlation and 'causations' in this body of research risks constructing young people as pathological subjects of developmental knowledge while at the same time downplaying the importance of social and political context, especially given the prestige these studies enjoy in the wider public sphere. It is worth noting too that a focus on the adolescent-parent relationship in its own right is conspicuously absent in the voluminous outputs of the two longitudinal studies. Among the 146 publications (to 2010) related to parents and parenting in the Dunedin multi-disciplinary study, six examine this subject, two of which were published after 2005. Young people appears in these studies almost as if they were mere 'outcomes' of early childhood adversities or 'strengths', rather than active agents.
} 
popularity, compared to the sparse and little-read academic and policy literature discussed above. Local reprints of Australian bestsellers were commonplace (e.g. Biddulph 1998; Carr-Greg \& Shale 2002), and some UK and American titles (Figes 2002; Coloroso 1996) were also widely available. ${ }^{59}$ Local gurus, some well-known media personalities, others popular psychologists and psychiatrists also published prolifically (Birch \& Mafi 1996; Cowan \& Grant 1998; Grant 1998; Lashlie 2005; Marris 1996; MacDonald et al. 2009). Half a dozen full-length paperbacks, many of them certified bestsellers, made for a boom given New Zealand's relatively small size. The parenting advice industry reached beyond printed material; media publicity, workshops and seminars were all important and popular spin-offs. One bestseller, John Cowan and Ian Grant's The White Water Rafting Years: A Common-sense Guide to Parenting Teenagers, for instance, was only a small part of the bustling business Parents Inc., which claimed to have put 150,000 parents through its faith-based parenting programme.

The influence of parenting self-help literature in these years cannot be underestimated, and it provided a wealth of resources on the parenting discourse that were as yet under-studied. In the following discussion I will make extensive use of this body of literature, but first, some caveats. Parents as consumers were free to choose the advice offered. One must be careful not to exaggerate the difference in this respect (we also know very little about what postwar parents actually did with the Mazengarb report or if they read it at all). Nonetheless self-help literature was by definition not imposed from above. In this way, it was entirely consistent with the dominant ethos of neoliberalism where the imperative of individual responsibility necessitated the exercise of 'free' choice, even if only among the market's offerings.

The advice offered by parenting experts was fundamentally different from advice prescribed for families in the postwar era. For one thing, given that the notion of 'teenagers' no longer induced anxiety, nor provoked wider discussions about society itself, the new parenting literature in the 1990s began upon the secure foundation of developmental presumptions about adolescence. The claim, for example, that 'the secret to great parenting' was 'having an understanding of the developmental psychology of adolescence’ (Carr-Gregg \& Shale 2002:216) was more of a sales pitch than a secret. Moreover the 1990s saw the intensification of the 'science' of adolescence.

\footnotetext{
59 The focus of this thesis is on New Zealand writers, the content of which overlaps considerably with overseas bestsellers which are outside the scope of this thesis.
} 
New claims of 'hard' neuro-scientific evidence reinforced popular notions of 'teenage brains' (e.g. Grant \& Cowan 1999:139).

Crucially the development discourse was orientated towards an adulthood that was rational, responsible and above all autonomous, rather than anchored in a childhood and its problems from which young people had emerged. Adolescence was, in Grant \& Cowan (1999:64)'s words, a 'dress rehearsal for adult life'. The emphasis was on independence rather than conformity. Carr-Gregg and Shale (2002:72-89) offered a variation on the same theme. The most important task for young people was to arrive 'at a point of self-understanding and self-acceptance'. This was followed by the goals of '[achieving] independence from adult carers and parents, [establishing] love objects outside the family', and '[finding] a place in the world by establishing career directions and economic independence'. Indeed it was an 'absolute need', as Marris advised teenagers, 'to separate from your family system'. The ideal teenager was 'selfdetermining, autonomous, effective, and self-responsible.' (1996:16) It was perhaps no simple accident that such adjectives could be applied equally to the neoliberal individual par excellence. This change in emphasis aligned the developmental narrative with the imperative of neoliberalism, in which, as Kelly (2006) argues, even adults themselves were increasingly subject to the pressures of 'becoming' better, more enterprising, individuals. There was no secure template for young people.

Autonomy was favoured, and so was risk. Although 'at-risk' youth still posed grave social problems, risk-taking paradoxically was constructed as a necessary task of becoming adult, and not just an immature impulse to be tolerated and controlled. 'Healthy risk-taking is a positive tool in an adolescent's life for discovering, developing and consolidating identity' advised one pair of psychologists (Carr-Gregg \& Shale 2002:45), for 'learning how to assess risks is a process we work on throughout our lives', without which 'our sons and daughters would never get on their bicycle, or take that first plunge into water'. Risk-taking was a 'normal part of adolescence', according to MacDonald et al. (1999:2-4); in fact teenagers 'need to take these kinds of risks [which might be unacceptable to parents] as part of sorting out their identity'. The 'whole point' was 'doing something that parents wouldn't do' (MacDonald et al. 1999:3). If the 'too good teenagers' were already looking vaguely suspicious in the conformist 1950s (cf. 3.1.3), they were positively abnormal in the era of risk-taking. Marris (1996:26-7) for instance warned 
parents against teenagers who were 'always willing to conform to the norms of the family system and who goes through their teenage and early adult years hardly setting a foot wrong'. Marris informed parents, based on his 'clinical experience', that these compliant adolescents often developed 'antisocial and sometimes criminal lifestyles'.

This emphasis on necessary risk-taking was not, however, an open-ended endorsement of adolescent experimentation. There were certainly differences between 'healthy' and 'unhealthy' risks, but what mattered was the process, in which teenagers must learn to choose, rather than the outcomes. And parenting experts were usually confident that the self-choosing individuals would ultimately make the right choice. 'The more willing we are to let go, the more likely they are to make choices we can approve of, and the more quickly they will come to decisions that work for them', readers were assured by Birch \& Mafi (1996:22). It was good that young people should 'try on independence', or try out 'the garment of values that you have handed on to them' to see if they fit (Cowan \& Grant 1999:50, 55-6). The metaphor of clothes-shopping, convoluted though it was, evidently resonated with Carr-Gregg \& Shale (2002:36). 'Playing with various identities', they stressed, 'is completely normal'; teenagers would 'try on one mask after another to find one that fits'. Narratives such as this belied a central paradox of neoliberalism where the seemingly open-ended 'choices' inexorably led to the lack of choice, not the least because neoliberalism refused to acknowledge financial constraints upon the exercise of these choices.

These narratives of self-making included not just teenagers but parents, in the never-ending process of 'self-growth', a metaphor frequently employed by self-help authors, including parenting experts (Birch \& Mafi 1996:23; Grant \& Cowan 1999:182; MacDonald et al. 1999:181). Parents were also enjoined to take risks and make choices, to see parenting as, for example, an analogue of the extreme sport of white water-rafting, as in Grant \& Cowan (1999)'s somewhat over-laboured metaphor in their eponymous book. In this adventure, adults could never be sure about what they had achieved. MacDonald et al. (1999:147) for example devoted a whole chapter to advising parents how to deal with their 'middlescence' problem. Even that was only a 'drop in the ocean', as the authors warned; parents should go back to the bookshop for self-help books that had been written on all kinds of subjects. And there was always the possibility of failing one's self that was at the bottom of bad parenting. Ian Grant, for instance, closed his book to fathers of teenage boys with an ominous quote purportedly from Death of a 
Salesman: 'the trouble with Dad was he didn't know who he really was' (Grant 1998:197). ${ }^{60}$ The great American tragedy was turned on its head, regressed from a social critique to a parenting problem explained by the father's lack of self-esteem.

It was possible to argue, in spite of all the pressures being loaded onto parents, that parenting as learning and 'self-growth' was incomparably more 'liberating' than parenting as control. Learning was, by definition, a self-reflexive task, and thus necessarily an act of autonomy. More importantly perhaps it did not subtract from the individual responsibility of young people themselves. What good parents wanted for their children was not 'blind obedience' but young people who could learn and exercise skills (Birch \& Mafi 1996:7) and 'the most useful skill of all [is] asking "what is likely to happen if I do that?"'. MacDonald et al. (1999:34-6) pointed out that 'one of the most important tasks' of adolescence was 'that of developing skills and confidence to take responsibility for their own lives'. And certainly teenagers would not 'learn as much about a skill when someone else does it for them'. The properly brought up teenager would 'realise they have options, can think through to consequences' (Grant \& Cowan 1999:23-4). 'Dumb and stupid things' must be tolerated, not because one should refrain from judging, but because they were 'significant learning opportunities' (op.cit.:63-4). 'Let the situation teach them the responsibilities and the consequences' of adulthood (op.cit.:38, italics original). By sleight of hand, learning skills and taking responsibility, that is accepting blame and punishment beyond the shelter of the family, became synonymous. It never occurred to the authors that the 'situation' might not be the anthropomorphic teacher but a complicated, and often inequitable, social process.

The dilemma here was not so much to balance the discipline and care, but to balance between short term [youth] and long term [adults] effectiveness of discipline. A refinement of roles was necessary and the world of business provided a ready set of rules about how to resolve such conflicts without undermining individual autonomy and responsibility. It was necessary, for Birch \& Mafi (1996:54), to establish who 'owns the problem' to begin with. 'Non-owners would only get in the way and prevent the owner starting work'. Teenagers, in fact, 'need their problems in order to mature'; parents would play the role of 'consultants and contract partners' instead. 'Contracts' provided one way that 'parenting-at-a-distance' might work. Some parenting

${ }^{60}$ It was likely a misquote. The line does not appear in the text of the play itself. 
authors took it seriously. Birch \& Mafi, for instance, wrote a whole chapter on 'how to make a deal that works for us all'. They insisted, among other things, the 'ritual' of writing it down and making it clear that you have entered into an arrangement seriously and in good faith' (1996:63). Grant (1998:149) was enthusiastic. The author defined contracts as an agreement made 'in return for your supplying [or allowing] certain things your teenager wants'. And he detailed a success story. In one case a young man's curfew was set by a 'contract'; so surprised was he about its effectiveness that the lad subsequently got used to setting his own curfews. It was all very uplifting, though one presumes that contracts could not be openly tendered; that their drafting was not up to the enforceable standards; and that such 'contracts' were not made by equal parties but meant as an instrument of inculcating work ethics in young people. As Lambeir \& Ramaekers (2007:95-107) point out these contracts often risk alienating family members, but alienated workers, contracting from a distance, were precisely the ideal sort of individuals a market society demanded.

\subsubsection{Skills of Parenting}

Not only was parenting in popular discourse now aligned with a new set of individualistic selforientated norms, it also became more instrumental. This depoliticized instrumentality was reflected in the heavy reliance on expert advice in the construction of good parenting. It would be too easy to draw a facile parallel between the popular parenting experts of the late 20th century, and the psychologists and psychiatrists who supposedly dominated the postwar welfare bureaucracy. This would however both underestimate the complexity of the past, and obscure the distinctively new ways through which expertise was deployed in parenting advice.

Scientific expertise, especially psychological/psychiatric expertise, still had immense value in the new self-help literature, of course. No self-help author would neglect to display his or her clinical/professional credentials on their book-covers (Birch \& Mafi 1996; MacDonald et al. 1999). Even qualifications as vague as 'hospital scientist, youth worker, media producer, minister, writer and communication' had publicity value (Grant \& Cowan 1996). Academic research was routinely mobilized, if somewhat selectively, to support specific claims. Appeal to scientific authority, however, was apparently counter-intuitive, given the heavy emphasis on parenting as a private, individual, family responsibility. This contradiction was partly pre-empted

\section{4}


by the explicit 'self-help' orientation of the discourse. More specifically, the expertise self-help authors were offering - not just limited to the subgenre of parenting - was not substantive rules about what parents or young people should or should not do, but rather techniques of selfmastery which supposedly left individual autonomy intact (Hazleden 2009; McGee 2005; Philip 2009; Rimke 2000). Expert advice was specifically not meant to be a set of directives from above, but what readers themselves must internalise and deploy creatively.

Self-help literature tended in fact to construct expertise not as specialized knowledge, but rather as immensely practical and perfectly ordinary 'common sense', which was ostensibly accessible to anyone willing to work on it. Characteristically, as Hazleden (2009: n.p.) observes, self-help authors employed the trope of the self-deprecating expert to stop their advice from appearing too sophisticated. MacDonald and the other three psychologists bemoaned the fact that 'these days' there was 'no shortage of experts - writing books, speaking on television and radio or chatting over the back fence - telling you how to raise your children'. Their own book was different, because it encouraged 'you', the reader, to be the 'expert of your own family' (1999:12). Another psychologist told the story of 'Margie' who came to him as a troubled teenager (Marris 1996:23). 'Margie' had 'shopped around several other psychologists, psychiatrists and counsellors over the years' and 'undergone years of therapy ... learned all the rules of the psychological game'. The breakthrough came when the author had broken away from his own professional training by simply 'haranguing' Margie until he had 'run out of steam', 'as nontherapeutic as one could imagine'. One certainly did not have to be a psychologist or psychiatrist to harangue, he implied.

The sense of ordinariness was further reinforced by the emphasis on personal, practical, experience. The family backgrounds of the writers were often included as a sort of 'credential'. 'Mothers of two sons' who could draw on experiences of 'our own families' could be as persuasive a label as professional counsellor (e.g. MacDonald et al. 1999). 'Real life' cases and anecdotes or stories were frequently used as a rhetorical device to construct an intimate, rather than professional, rapport between the reader and author, who ostensibly was just like 'you', a real parent. Other writers such as Grant and Cowan (1999) made more direct appeals to 'common sense' itself as ordinary and inarticulate knowledge, unavailable from abstract and unduly 'sophisticated' expertise. Psychological knowledge, in other words, no longer functioned 
as a self-sufficient disciplinary mechanism in classical Foucaultian terms. Rather it was increasingly reliant upon the mobilization of the intimate and private 'common sense' of individuals themselves to carry out the imperative task of self-governance. This was consistent with the increasing blurring of boundaries between formal expertise and 'folk knowledge' in the broader context of contemporary societies (Epstein 1995). Experts, in this guise, posed no threat to parental independence. No matter how extensive therapeutic expert advice was, parents still had to work upon themselves and their families. Self-mastery was not only guaranteed, it was part of the programme.

Regardless of whether that ideal of self-growth through parenthood was achievable in practice, with or without expert guidance, the development of 'good' parenting skills was not optional. The very notion of parenting 'skills', as distinctive from parenting itself, implied a sort of universality independent of whatever substantive values or identities were cultivated in the younger generation by parents. In such a skill-based discourse, parenting increasingly looked like skilled employment. Business metaphors casually framed parenting as a 'job', a 'challenging task', or even 'a most important investment opportunity' with barely any thought about the distinctive kind of labour parents performed, or the sort of personal as opposed to contractual relationship they had with young people. And the discourses usually provided very little clue about the optimal 'work-life' balance. New job titles had to be invented for the previously unskilled position of mere parent. The White Water Rafting Years fittingly urged 'every parent to become a parent-coach', who worked ‘to make every family member a real part of the team'. A good 'coach' saw his 'team' not as 'an enemy to be conquered but a resource to be worked'. It even came with a complete game-plan, with bullet points such as 'assume the responsibility of office', 'understand your job' and 'your team', and 'coach skills and values'. The distinctive brand of 'team talk' could easily have been written for a book on management, rather than parenting. These business-like rhetorical devices often conveyed little more than a vague impression, but within this vagueness there was an effective and consistent message to parents about the need for self-directed improvement of (parenting) skills. This echoes Cherry's (2008:346-7) argument that self-help literature operates within a distinctively paradoxical ontology. If the prescribed interventions were completely successful, then they must be redundant. Self-help literature relies upon their readers to go beyond what has been written, and claims credits for their efforts, even when the readers must necessarily depart from vague advice 
in complex situations. It co-opts them, in other words, in making those parenting interventions work.

The improvement of skills sometimes seemed to become its own end. Ways to become more effective were frequently mundane, though no less onerous for that. Birch and Mafi, for example, set out their advice in the general format of a workbook and told readers to "work through as many of the exercises as you can, just for practice', for 'nothing improves skill like practice'(1996:8). Another offered 'user-friendly, bite-sized strategies' which could be practised 'even on your busiest days' (Grant 1999:9; 16). At the end of most chapters in Carr-Gregg \& Shale (2002) there was a multi-choice 'crunch-time' exercise waiting to be completed by parents, followed by the authors' own opinion of their relative merits. There was, of course, little risk of parents making the wrong choices. The questions hardly touched on complex moral and ethical dilemmas. The exercise was not imposing certain norms, but about parents becoming skilled at making choices.

Parenting skills might be, in theory, discursively 'empty categories' seemingly more plastic than say gendered norms of a conformist society. In practice they had stable and meaningful patterns, arising from the wider social context. It was to be expected, for example, that communication skills should be privileged by parenting self-help experts. For one book communication was the beginning and the end of parenting The 'domestic community' was built upon 'negotiation and communication', argued a chapter on communication in Birch \& Mafi's book (1996:39-54). Communication, and thus the community, broke down when parents or children misbehaved and yet, misbehaviour could only be addressed by 'trying to keep talking, and more importantly, listening', in other words, better communication. Elsewhere the advice was more straightforward. A 'recipe for parents of adolescents' suggested 'a big helping of communication (above all, listening), mix gently with sensitive negotiation, frequent demonstration of interest in your adolescent's interest, and then the final ingredient, lots of love!' (Carr-Gregg \& Shale 2002:113). It may be mere coincidence that the premium skill of 'communication' in every parent's home looked suspiciously identical to the so-called 'soft' skill touted in the new world of work by the turn of the $21^{\text {st }}$ century (Cameron 2000; McGee 2005). Both were now matters of skilful self-mastery. 
The implication of such juxtaposition was nowhere clearer than in the idiosyncratic phrase 'life skills', a common term in self-help literature. This linking of life and skills, awkward though it was, captured succinctly its 'catch-all' nature, including everything from communication to negotiation, relationship management, and 'team work' to the more esoteric 'self-esteem'. The reach of this discursive device was perhaps best illustrated by Grant \& Cowan (1996:57)'s advice to parents that they should 'adopt a lilt in your voice when giving instructions ... like the Welsh and the Irish'. Such advice might seem trivial, but by targeting a deeply personal characteristic such as the tone of one's voice, it touched at the very core of individual identity. It offered an important explanation to the ideological meaning and appeal of self-help advice, not limited to parenting, that is, such advice demanded nothing more or less than skilful mastery of one's own life (and Italian philosopher Giorgio Agamben's phrase 'bare life' was apt, cf. Vansielegm 2010:353-4). It was perhaps easier than trying to conform to the postwar society's often self-contradictory articulation of norms. But at the same time it carried a greater risk, or perhaps a threat. To fail at parenting was to fail at life, and the fault would be entirely the individual's own.

\subsubsection{Parenting as a Solution}

This skill-based discourse of parenting needs to be considered in relation to the social problems which good parenting itself was now expected to solve. There was nothing new in this construction of parenting as a 'solution' to social ills, except the fact that the demarcation of responsibility now became much clearer. The inflation of the 'natural' responsibility of parents for their children into the state's responsibility towards its citizens was always a precarious one, even during the heyday of the 'Nanny State'. Now it was simply an incongruity.

This point is perhaps best illustrated with a brief case study on the subject of youth suicide in parenting literature. Youth suicide had been a focus of public concern since the 1990s, not least because of the apparent correlation between the high suicide rate and the tough economic times, especially for young men. ${ }^{61}$ Yet in the official discourse of youth suicide prevention, as one

\footnotetext{
${ }^{61}$ New Zealand was alleged to have one of the highest rate of youth suicides in the 1990s, a revelation which generated considerable anxiety in popular and policy discourse. The claim of correlation between this and the high rate of male youth unemployment was noted in the media, and became a subject of scrutiny by academic researchers (Atwool 1999:384-5; Blakey et al. 2003; Chapman et al 2005; Weaver \& Munro 2013, among a large
} 
contemporary critic observed, parenting responsibility, not social responsibility for these acknowledged 'risk factors', was a dominant theme, alongside the education of young people themselves (Atwool 1999:385).

The opportunity for expert intervention could hardly be passed up in parenting literature itself. Unsurprisingly, depression and suicide were by and large framed in pathological terms, even though social and economic factors were often acknowledged. Carr-Gregg \& Shale (2002:157) for example, saw such issues as a 'diagnosable and treatable illness'. Grant \& Cowan by contrast defined suicide as a 'measurable mental disorder', which was said to reflect 'mood disorders, substance-use disorders and social disorders'. There was, moreover, an 'absolutely imperative' 'ethical obligation' on parents to seek help for these young people, even if it meant 'protecting young people from themselves' (Marris 1996:259). Grant \& Cowan (1999:165) could only think of one potential objection to professional help, namely, affordability, but of course 'you can't afford not to' either, readers were told. Carr-Gregg \& Shale, similarly, chose to highlight the risk of failure on the parents' part to make the right 'work/life choice': 'while the demands of the working world can be incredibly draining, nothing is more important than the mental health of young people' (2002:165). The emphasis on the distinctive roles of young people and parents in such scenarios, one in need of help, the other obligated to buy it, gave no recognition to the fact that not only young people but parents - or indeed any individual - might be under stress in such extraordinary times. Such discourse pre-empted the need to choose between parental responsibility and social intervention. It helped perhaps that the psychological profession was no longer so closely associated with the state, but instead offered its authority in an open, and presumably free market. The crucial idea, however, was that parents and young people themselves were the makers of their own problems, and could and should be the active 'choosers' of appropriate treatments. Seeking help was not an expression of vulnerability, but a courageous and assertive move (Birch \& Mafi 1996:86; Marris 1996:261).

The emphasis on the necessity of parents 'choosing' expert treatment for their children did not diminish the importance of choice on the part of young people for their own welfare. Choice

body of New Zealand literature on the subject). Weaver \& Munro (2013:764-9) also linked economic recession experienced by young men to the increase in sexual and other freedoms for young people 'since the 1960s and 70s' (768). Youth suicide, for Weaver and Munro, was explained not so much by specific factors as by the passing of an era when wages were high and premarital sexual urges were supposedly lower. 
indeed became both the problem and the solution, and the choosing individual became the only possible subject. 'Whatever the circumstances', stated MacDonald et al. (1999:115) authoritatively, 'teenage suicide is a result of choices made by the individual adolescents over which others may have had little or no control'. The choice was a misguided one, of course, a case perhaps of 'sulking mentality taken to an extreme' (Grant \& Cowan 1999:166-7).

The right choice parents must make was painfully plain. It was nothing more than helping young people to build the sort of individual capacity that contemporary society might demand of, say, a good worker. The most effective strategies, according to one book, were those that developed 'characteristics and skills' in the 'social and emotional competencies of young people such as problem solving, decision making, anger management, conflict resolution and assertive communications'. It was the responsibility of parents and schools to teach these skills if they wished to reduce youth suicide rates (Carr-Gregg \& Shale 2002:162). It might be a truism that 'problem solving' was the universal panacea to social and individual problems. It was nonetheless an effective discursive ploy. Grant \& Cowan (1999:173) urged parents of moody teenagers to 'give your teenagers the tools to solve their own problems'; the 'ability to problem solve' was a necessary attribute of 'tough people' who will stare down the challenges of living. Conversely the emphasis on such 'life skills' reinforced the framing of suicide and depression as a life choice. Marris (1996:255) put the problem down to the fact that young people 'tragically ... underestimate the danger of their actions and their distress signals' and naturally one might expect them to make better choices if they were made 'aware of the risks that are involved [in suicide and other "attention seeking gestures"]'. The explanation of suicidal behaviours, in other words, was not structural factors such as poverty or homophobia, but wrong 'choices' made by uninformed individuals.

Parents took on the heavy responsibility of helping young people to cultivate these skills. In order to take the risks of suicide seriously, they must become amateur counsellors. Carr-Gregg \& Shale (2002:158-9) for example, provided a condensed and simplified form of diagnostic questionnaire, based upon a standardized screening test used by professionals, against which parents could score depressive symptoms. MacDonald et al (1999:114) similarly offered a series of structured questions on depression to help parents to 'bring it out in the open'. Psychological expertise here was no longer an inaccessible mastery. It was an ordinary kit of skills which could 
be, however awkward for parents running down a list of pre-formulated questions, incorporated into everyday interactions. Even though, in practice, such interventions carried out by parents themselves who lacked power or resource meant little more than surveillance and monitoring of young people, the expectation that they should be actively intervening was firmly established.

These positionings of parents and young people rendered these structural issues such as unemployment invisible. Marris (1996)'s guide to parents contained nothing on the subject. A chapter on 'finance' was concerned exclusively with allowances and saving habits. Other writers had more to say, however. Birch \& Mafi (1996:109)'s advice to the parents of unemployed youth was to keep them busy. 'Having an unemployed and increasingly apathetic youth hanging around the house', 'reluctant' to leave home, was 'no fun for every one'. Parents ought to encourage these young people to 'maintain a purpose in life [though things] such as training courses, active job hunting, physical fitness', and 'never make an over-generous agreement' to support them. 'Unemployment' here was a moral marker, not a social-economic and structural problem. And parental love, unlimited in other aspects, must be carefully controlled lest it undermine economic logic. Grant \& Cowan (1999:176) similarly warned parents about 'allowing' young people to be an 'idle leisure class' and '[robbing] them of vital training and significance'. 'All that prepares them for is a life time of welfare dependency or marriage into the royal family'. Youngsters should instead be encouraged to take 'any job', even if it comes with minimum pay, few opportunities and even lower satisfaction 'working for the clown with big yellow shoes'. A family's support for their young people in such a trying time had paradoxically become a luxury, which had to be carefully rationed. The dilemma between love and control took on a whole new dimension.

What made such responsibilities even more taxing, ironically, was the commonplace insistence in self-help literature that the work of parenting was both necessary and simultaneously effortless. As McGee (2005:145-6) argues, this rhetoric of 'effortless realization' was a central strategy in the broader regime of work upon the self, as exemplified by self-help literature, which offered 'effortless effort, passive activity, endless work imagined as effortless exertion'. It assumed that parents could draw on the inexhaustible supply of emotional resources, and thus invalidated any 'excuses' on the part of materially deprived parents. And this assumption in turn was reinforced by framing parenting in terms of 'learning', 'self-growth' or 'love', terms which 
were vague and intuitive, one step removed from the day-to-day reality of family relationships. All 'you' needed was love, was the common mantra. For Grant \& Cowan (1999:57) love was apparently spelled 'T-I-M-E'. It was interesting, so the authors found, that 'dysfunctional families' often tended to lack those 'commodities' that 'don't really cost money, just time'. Put in such terms there could only be one choice. 'If it comes down to a choice' between work and parenting, 'go for the time [unless] your hourly payrate is better than the charge-out rate [of a psychologist] to straighten out your kids'. Words strung together like this not only refused to acknowledge the material burden of parenting, they also implied that parents who failed were deficient in basic human qualities. Moreover, such a frame glossed over the fact that the 'work/life' - and parenting - balance was not solely up to parents themselves, but rather determined by conditions of paid work. The unconditional love from the parent, then, was no longer something which deserved social compensation, say in the form of a family wage, for the material sacrifice which it embodied. Because the costs of love remained invisible, it became an ethical obligation to exploit one's own 'free' love for the good of young people, society and oneself.

\section{Part 2}

\subsubsection{Class}

In the passages discussed above, a more general contradiction loomed. It was precisely because material and structural constraints were not irrelevant that the transcending power of emotional labour was invoked. Had those constraints not existed in the first place, there would be nothing to overcome. Social inequality was simultaneously effaced and normalised.

Individual attitudes had to change so that problems could be willed into challenges. The message was often implicit but the occasional expositions rose easily to a terrific pitch. Poverty, war and crime, if Carr-Gregg and Shale (2002:211) were to be believed, were no real obstacles to good upbringing, so long as young people had 'access to charismatic adults', 'perseverance and ability to learn from mistakes', a belief in the meaning and purpose of their lives, and knowledge that they were 'good at something'. Resilience was one panacea and positive thinking was another. 
There were 'choices', according to another parenting expert, if children were taught the virtue of compliance, to 'choose to be happy' and not to 'blame, complain or criticise' about the lack of things to be happy about (Grant 1999:38-9). In fact, what 'every parent should teach every child', according to the authors, was that 'life is not fair'. Thus the quintessential 'life lesson' was that 'in spite of what happens to us, we can always choose how we respond'; teenagers learnt that success was determined more by 'attitudes and character than by circumstances' (Grant \& Cowan 1999:73-4, italics original). These were not merely feel-good stories for troubled young people and their parents; they expressed the ethical imperatives of a neoliberal society where those who were most disadvantaged must, paradoxically, learn to embrace and take responsibility for what was beyond their control.

Even so, the link between class and family dysfunction was not hidden. And now there was more than prejudice to prove it, in the form of rigorous quantitative analysis. The Christchurch Longitudinal Studies, for example, found a 'clear and significant' link between family socioeconomic disadvantage and poor adult outcomes. Other risk factors included 'family stability/conflict; parental adjustment problems ${ }^{62}$; child abuse exposure; and childhood behaviour problems' (Fergusson \& Horwood 2003). A government-commissioned report identified poverty alongside single parenthood and teenage pregnancy as risk factors for family functioning and child development (Kalil 2003:38-41).

Isolating poverty as a 'risk', not a cause or a context, preserved scope for individual responsibility in its management, and avoided questions about broader social and political factors. These authors had little to say about a competitive economic structure in which, by definition, some had to be of a lower socio-economic status than others and therefore exposed to greater risks (cf. Beals 2006:123). And they provided few alternatives other than the seemingly obvious implication that additional efforts by parents themselves were needed. Structural changes were seldom proposed as a necessary remedy. Instead, commentators seemed determined to cast their eyes elsewhere. Kalil (2003:27;71), for example, implored policy makers to make use of religion, a 'somewhat neglected' area of research by the author's own admission, as a way to enhance family resilience. The faith in good parenting as a way of compensating for

${ }^{62}$ alcohol/drug use and criminal history 
social and economic disadvantages was a good fit with the secular neoliberal faith in improvement by individual efforts.

Structural causation was abandoned. The correlation between poverty and bad parenting, however, became stronger. The 'underclass' and bad parents did not produce each other, for they were both produced by irresponsible individuals who failed to choose wisely. In this way, the class/dysfunction link was sustained, and helped to sustain, not just simple prejudices against the disadvantaged families, but rather the neoliberal logic itself.

Unsurprisingly, some commentators attacked rather than preached at such individuals. One wellknown conservative personality, Michael Laws, commenting on recent child abuse statistics, wondered whether 'eugenics wouldn't be such a bad thing at all'.

we have now created such a grossly dysfunctional underclass that it might not [sic] just be best to rescue and remove the children now, sterilise the parents and hope their genetic stock is forever purged ... Our underclass is here to stay and it can't and won't help itself. If it could, then it wouldn't be an underclass (Sunday Star-Times 16 Nov 2003)

Laws intended to shock, certainly. Yet he was not alone. Michael Bassett, a minister of the fourth Labour Government, opined that the first thing to tackle about the 'cycle of child abuse' was the 'excessive number of children born to those with little or no interest in their upbringing'. It was 'ridiculous', to him, in an era of free contraception and relatively easy access to abortion. The fundamental problem, Bassett argued predictably, was the welfare system which 'encouraged those caught in the welfare trap to breed': 'pay them to breed, then accept the responsibility to care for their offspring, and they'll oblige with more' (NZ Herald 17 Nov 2003). The taboo subject of eugenics was, in a sense, mere flourish. The real argument was that individual irresponsibility produced social inequality and its problems, as Laws' quote made clear, not the other way around.

\subsubsection{Ethnicity}

The ubiquitous juxtaposition of 'family/whanau' in public discourse was a signpost of how far whanau had travelled from outside the monocultural ideology of domesticity into the very heart of bicultural politics. There had been significant movement towards 'inclusiveness'. But it was 
not necessarily easier to evaluate the changes. Exclusion had its advantages, as I have argued above, because it created a vantage point to explore outwards larger questions about racial politics of assimilation/integration, and reflect inwards upon the contradictions within the domestic ideology itself. Being included, on the other hand, brought competing ideals of family, rather than the ideological limits of diversity, to the fore.

The recognition of whanau did not entail a fundamental rethinking about young people, their intimate relationships and wider communities. The boundaries of the pluralistic family were rarely tested. The exception was the almost-forgotten debate about the Child, Youth and Welfare Act 1989, the first (and last) piece of legislation which granted extensive recognition to the bicultural family/whanau model. It was a foregone conclusion that the child-centred approach carried the day, despite its contradiction with indigenous norms which centred on the whanau as a whole. ${ }^{63}$ There lay lost an opportunity: we might think of conflicting interests of children and adults not as a matter for triage, but signalling the merits of enhanced support so that they could be reconciled. If whanau was the answer the question was clearly not how Pākehā institutions divided along public/private lines might be rethought in view of the different ways whanau, hapu and iwi interacted with each other. Neither was it whether the socialization of the young should be an exclusive function of parenting, rather than part of some larger equation about the collective interest and welfare of the community. The question was simply whether or not whanau could live up to what was demanded of Pākehā parents.

Even in this restricted sense, recognition was a highly uneven process. The popular discourse on parenting surveyed in this chapter, for example, made virtually no reference to Māori youth and their whanau. A couple of scholarly texts on contemporary Māori parenting were hardly an adequate counterweight (e.g. Herbert 2001; also Herbert 2012), leaving aside the question of whether the notion of parenting was the most useful starting point in a discourse about whanau. Substantive discussions about whanau, in fact, were to be found almost exclusively in the academic and policy texts. And here, little research existed that drew out the implications of whanau norms and practices for youth, although much was written, and developed into parenting

\footnotetext{
${ }^{63}$ Metge (1995:141), for example, could argue that while whanau did value children, they were not 'child-centred'. For commentaries on the perceived conflicts see Atkin (1990;1991).
} 
programmes, about young children. ${ }^{64}$ The imbalance was consistent with the prevailing concerns about Māori overrepresentation in child abuse statistics, where Māori parents were perceived as lacking in the bare minimum of child-rearing skills. ${ }^{65}$ It also reflected the contemporary focus on early intervention, as an answer to youth problems, as opposed to the 'normal' troubles of adolescence, that underlined the growing interests in whanau as a social institution. Discourses about whanau that developed in this context were inevitably addressed to public concerns and anxieties, and seldom catered to the mere needs of parents themselves. Finally, recognition of responsibilities tended to be granted more swiftly than that of rights and entitlements. It was no coincidence that inclusion of this kind made significant inroads, not in income or welfare legislation, but in the Child, Youth and Family Act 1989 which recognized whanau's responsibility for care of vulnerable children, and the discipline of young offenders (through the Family Group Conference model, see Ch8).

What emerged from these spaces, moreover, was often an affirmative, positive, discourse about the ideal of whanau, constructed in direct opposition to 'deficit thinking'. In such discourses whanau was not merely a protean social institution, but the necessary vehicle, if not the very embodiment, of aroha, mana, and other values central to Māoridom (Cunningham et al 2005:60; Durie 2003a; Metge 1995:83-101). And moreover, as one report had it, it was whanau, and not hapu or iwi which had 'withstood both colonization and urbanization' in spite of their damaging effects and thus was an obvious choice as a vehicle of collective empowerment (Cunningham et al. 2005:13). Whanaunatanga, that is, 'strengthening the bonds of family unity' argues Gagne (2013:179, italics original) recently, 'appeared to be the important value for Māori to make them strong, individually and collectively'. The proliferation of positive images of whanau posed an all too obvious risk that the whanau might fall into the same essentialist trap as the family. However, not much can be gained from rehearsing the familiar argument against essentialism here, which champions of whanau were well aware of, ${ }^{66}$ nor from assertions about the 'real'

\footnotetext{
${ }^{64}$ The gap remains largely overlooked. Edwards et al. (2007) is an exception which notes explicitly the paucity of research related to the experience of young people and whanau. This of course was not necessarily a bad thing, if it meant that the culturally coded notion of adolescence had not yet taken over other ways of thinking about young people.

${ }^{65}$ A more recent commentary observes that any discussion on Maori parenting remains forced to deal with discipline issues in the context of child abuse (Eketone 2012). This focus certainly intensified after 2005 with a number of high profile cases. Nothing prior though contradicts this general impression.

${ }^{66}$ See Metge (2001:22-4).
} 
issues that a discourse of whanau ought to address. To go down those tracks distracts us further from the underlying political logic of the 1990s which operated through the family/whanau model as it did through issues about young people and their families.

Yet the insistence on the 'positive' was nonetheless necessary. Rearguard actions had to be fought on an extended front wherever Māori youth and their parents were 'overrepresented'. This included issues of educational underachievement, teenage pregnancy and youth crime, all discussed in this thesis. These problems of 'over-representation' were linked, moreover, by researchers back to family dysfunction (see Pryor \& Woodward 1996; Fergusson 2003; also Marie et al. 2009). Statistical analysis such as these, however rigorous, could not protect themselves from misinterpretations. Preoccupations with cross-ethnic comparison, in addition, in themselves reinforced an (unintended) impression that ethnicity was an intrinsically meaningful variable. Correlation easily slipped back to causation outside the academia, especially when alternative causes received less attention and publicity. It was still imperative for whanau to prove itself to be worthy of recognition by others, instead of asserting its own claims on its own terms. For this purpose, appeals to essentialised values which resonated outside the specific cultural and political contexts of whanau were both expedient and necessary. It was not simply a theoretical error that replayed the same mistakes of essentialism. Given persistent inequality, the ideal of whanau provided indispensable political leverage for Māori, channelling support and resources where more combative claims of, say tino rangatiratanga [self-government], might have fallen upon deaf ears.

This strategy could be costly, however. The more whanau aspirations were articulated in terms of innate strengths and everlasting values, the more plausible it was to suggest that they could be achieved through individual efforts alone, and the more acceptable it was to insist that the 'is' could imply an 'ought'. If the ideal of whanau somehow transcended politics itself, then there could be no necessary contradiction between it and the neoliberal regime of responsibility.

This slippery logic reinforced the contemporary construct of the dysfunctional whanau. The Minister for Youth and Māori Affairs John Tamihere thus could appeal to the ideal of the whanau, while dismissing the 'whanau mantra' as a myth for many Māori. The ideal was not the target. 'In the ideal world whanau is nurturing, supporting, loving, protecting, teaching, guiding, sharing and strengthening' and yet 'in the real world', according to Tamihere: 
Too many whanau in New Zealand are dysfunctional. Rather than reaping the rewards that a whanau should give them, too many Māori children live among whanau where the lessons they learn from their whanau are the lessons of violence, neglect, drug and alcohol abuse, lack of aspiration and responsibility, and welfare dependency (NZ Herald 10 Dec 2003).

The underlying message was one of self-reliance and individual responsibility in line with what neoliberalism demanded of Pakeha and Māori. Tamihere did not shy away from invoking even more 'myths' to get his myth-busting message across. The once-were-warrior myth was one. 'As Alan Duff puts it, so much better than I can', Tamihere explained, 'we were once warriors, not whingers'. The heterosexual nuclear family was another which singled out the father: 'where are the caring and supportive fathers in our idyllic whanau'? The possibility that care and support of whanau, and even wider community, might do away with this anxiety about single parents altogether was not considered. The self-enclosed, privatized, unit of responsibility remained the only thing that made sense.

The rise of the whanau as an ideal was thus a Pyrrhic victory. The real battle was no longer fought over competing ideals. Within a neoliberal regime, pressures upon the whanau no longer needed to be exerted through a cultural hegemony of 'domesticity'. Such pressures could be applied by mediating the gap between realities and aspirations. Moreover, it was possible to distance these pressures from simple prejudices, even if they were mutually reinforcing. The familiar logic of necessity was all that was required. This discursive strategy was employed skilfully by Tamihere. The dichotomy between the reality and the ideal was mobilised in his argument. Whatever there was in the immemorial past or the distant future, for the here and now, there was still no alternative but to 'work with the reality and not the myth', in Tamihere's words, and only then 'the reality will start to look in reality more like the myth that we aspire to'. Within the context of neoliberal politics, then, the ideal of whanau could amount to little more than adding a new locus of responsibility away from the state where the ordinary mechanisms of parental responsibility had failed. 


\subsubsection{Gender}

In contrast to class and ethnicity, popular parenting literature discussed gender issues extensively. In fact, it constituted a sub-genre exemplified among others by two self-help bestsellers Biddulph (1998)'s Raising Boys and Lashlie (2005)'s Growing Gorgeous Boys into Good Men (also Grant 1999). This was supplemented by more specific texts on 'fatherless sons' (McCann 1999; Pudney \& Cotterell 1998). The concerns articulated in these texts echoed contemporary anxieties about masculinity and single parenthood, and in some instances fed directly into policy and academic works (Barwick/MYD 2004; Birks \& Callister 1999 also Brickell/Commissioner for Children 1997; 1998; Birks 2005). Similar concerns about the alleged crisis of masculinity were played out differently in the boys' underachievement debate, which will be discussed in Chapter Seven (see 7.2.1). Much of the discussion around the explicitly gendered notion of 'fatherhood' and the derivative notion of boyhood had a distinctly conservative bent: in spite of a rhetoric of difference and equality, it was not far from a simple reassertion of traditional gender norms. In fact there was an apparent reversal of focus, if not substance, from keeping women out of the public sphere to placing men inside the family circle. It was no longer sufficient for fathers to be the invisible figures of authority. They had to carry out their responsibility in a much more active and self-conscious manner.

Behind all these efforts to fashion a discourse of fathering was a new formulation of masculinity, aiming not so much to break it down as to make it more genuinely masculine. As McCann (1999:34; italics original) puts it: the old fashioned 'Fifties father' would not cut it anymore because they could only 'show their son how to act like a man, but not how to be like a man'. And it was these inappropriate acts, rather than the masculine essence, which were to blame for the problems of the past. Consistently, the basis of masculinity was to be found not in social norms, but rather innate, individualised, difference. Again McCann (1999:13) summed it up nicely: the 'zeitgeist' was 'not one of women against men and their power structure [but] one of shifting the location of ultimate authority from a public "out there" to a personal "in here", to be discovered by those spiritual or mystical rites of passages that self-help authors enthused over (e.g. Biddulph 1998:21-3; Lashlie 2005:20-1). Such responses did not so much engage with feminist critiques of unequal gender relations as relegate these critiques to the margin along with the redundant parts of the traditional gender order. They were also effective strategies to decouple the centrality of the same heterosexual masculine norms from the marginalization of 
other possibilities. It was much easier to make room for individualized differences, especially given the presumption that individual freedom of choice, rather than its scope and costs, was the issue, than to scrutinize unequal gender structures. A brief acknowledgment that some boys did not conform to the pattern might paradoxically buttress claims that most boys supposedly did.

Diversity then existed only as exceptions outside the life of the 'average' boy favoured by parenting authors (Riggs 2008:191-3). There was little diversity within what was 'average'. Boys in such texts were invariably tough, risk-loving, action-orientated. The defining experience of a typical boyhood was always some kind of rough-and-tumble play (Biddulph 1998:66-7;70-1; Grant 1999:110-6; Lashlie 2005:46-7; McCann 1999:54). Indeed gender was still very much destiny. 'Even boys who have not watched any [sic] TV suddenly want to play with swords, wear Superman capes, fight and wrestle and make lots of noises', as Biddulph (1998:11) observed. Such behaviours, moreover, were ultimately driven by. in Biddulph (1998:44)'s words, 'cranial urges', that revolved around heterosexual desires (cf. Riggs 2008:194).

These characteristics were in-built and universal, which could, as Biddulph (1998:32-3) believed, be explained by a range of theories such as evolutionary biology, 'natural' division of labour (in hunter-gatherer societies), hormonal changes and 'brain science'. Interestingly no authors mentioned religion or morality as a justification of gender difference. But perhaps 'real gender differences', as Biddulph suggested, were the ones which were 'so obvious that it's amazing they were overlooked' (op.cit:33), or in other words, plain common sense. Among others, according to Biddulph, the average boy has 30 percent more muscle bulk than the average girl'. Of course such 'facts', as he warned, did not mean saying 'every boy must ...' or 'every girl must ...'; 'after all some girls are stronger and more physical than most boys'. But the allowance made for these exceptional cases said nothing about what the implicit norms were.

Even those who were more aware of the decades-old critique of essentialism seemed inexorably drawn to the same common-sense conception of gender difference. A commissioned review of literature and 'best evidence' about 'strength-based' and 'male-focused' approach to youth development claimed that:

...being male is not just the gender into which some are born, but is about a set of characteristics, activities, preferences and forms of expression that we associate with it. Male-focused approaches respond to the fact boys are different from girls, both in 
gender-related traits and preferences and in the expectations society places on them.

Some of the challenges boys face as they move towards adulthood are different and need different responses (Barwick/MYD 2004:6).

This passage stood social constructivist arguments on its head. The revelation that gender was constructed by society led not to consideration of social change but acceptance of society's expectations.

In this light, the new masculinity promoted by boys' parenting experts did not differ very significantly, in its essentialising tendencies, from the age-old assumption about men. There was less talk about what boys and men should do, and more about what they were, but there was the same confusion between normative assertions and empirical statements. What was different however was that this masculinity, although 'natural', now required cultivation. This was precisely where fathers might be brought back into the family picture. The message was not always consistent. 'Boys don't just grow up in a smooth and even way' argued Biddulph (1998:5) who then proceeded to chart 'three stages of boyhood' which were 'timeless and universal', as if they were not contingent upon human intervention and social context. And yet the 'fact' that boys must grow into men was precisely, as Biddulph saw it, why they need fathers. The contradiction between these two beliefs however was glossed over.

Fathers were needed less for what they could do than what they stood for, the role model of heterosexual masculinity. Indeed, for McCann, a biological father had an almost magical ability to 'demonstrate merely through his presence that sexuality is OK and that there is a way to stand as a sexual man in relation to the mother and all women' (1999:74; also Grant 1999:159). The variety of father-son activities were limited and predictable. Grant (1999:112) listed 'fishing, camping, fixing things, and sport' and other activities involving 'genuine responsibility'. As for daughters, the authors suggested that fathers need to 'flatter and admire' them, for 'our daughters need to practice conversation and mutual admiration with a safe male' (op.cit.:106). And singleparent families, regardless of their parenting abilities, were necessarily lacking in these masculine influences. Boys with single mothers, argued McCann (1999:73), had only 'limited models of how a man can be in an intimate relationship with women'. Grant and Cowan (1999:123) advised single mothers to 'seek out other families where there are mothers and fathers'. These authors, to be sure, were not necessarily prejudiced against mothers and their 
parenting abilities, but by privileging masculinity and fatherhood, they inevitably produced the same result.

In one aspect the new dads in parenting literature were distinctively different from the traditional authority father-figure. They had to be more emotionally-engaged, more demonstrative and communicative, all traditionally presented as feminine traits. This might be put down to the loosening of rigid gender stereotypes. But it might also mean an intensification of the work of masculinity, which could no longer be secured simply by an outward display of strength, but also mastery of one's own emotional self. All this of course was entirely consistent with the new demands of a neoliberal economy. Biddulph (1998:62) for example called on fathers and sons to become 'a new kind of man', for

The world no longer needs men who can wrestle with buffalos. In the modern world, where manual or mechanical labour is less and less important, we need to take that masculine ability and energy and redirect it to another kind of heroic effort. This means adding language and feelings skills to the thinking and doing skills of boys - making a kind of superboy who is flexible across all kinds of skill areas.

There was no return to the inefficient division of labour of the past, which had to be shored up by support from the state. In spite of the rhetoric about the new man, however, the emphasis on competitiveness, hard work and possession of useful skills simply reproduced a privileged version of masculinity which was more capable of sustaining itself than by brute strength.

\subsection{Conclusion}

This chapter discusses the shift from a collective discourse of the family to a privatised one of parenting during the 1990s. It argues that this new discourse of parenting was steeped in neoliberal ideology. This discourse was not about challenging conservative norms of domesticity, rather it was about the reproduction of responsible individuals and the discipline of 'dysfunctional' parents whose differing degrees of 'functioning' and normality were now to be measured by market rather than moral standards

The new discourse of parenting no longer committed itself to a single ideal of familial form, at the expanse of its other uses. It was consciously depoliticised and privatised, sidestepping the 
larger question about the relationship between the family and society and its political implications. The ideological imperative, instead of being imposed from above by a somewhat reluctant welfare state, was diffused and infused into everyday discourse of parenting via seductive calls of self-help. Class, gender and ethnic inequalities were just below the surface of the social, and yet the articulations of parenting norms seldom 'spilled over' to these larger issues, let alone unsettling the ideological regime. As such, the scope of public debate over families was increasingly limited, and the reach of the neoliberal logic was extended.

Under the neoliberal regime, the apparent retreat of the state from meddling in family's affairs turned out to intensify its hold over the ideology of the family. The family appeared not so much a social unit, as a site for intervention on individual skills (for parents) and behaviour (for young people) shielded from public, and political, scrutiny. Through this discourse of parenting, moreover, social problems confronting families in an increasingly unequal society were placed squared at the feet of parents and young people themselves. 



\section{Chapter 7 Youth and School 1990-2005}

Schools in the 1990s, like the family, appeared more progressively liberal than in the 1950s. Fairness in matters of gender and race, while suffering backlashes and setbacks, seemed much more secure, though less was heard of class. At the same time, the postwar humanist-egalitarian impulse was no more. Schooling without selection was out, and competition was back. The return of the market appeared to have a silver lining. Schools seemed less concerned about enforcing authoritarian controls, as the more market-orientated reformers of education might have imagined, than providing useful services to their willing 'customers'. This pattern of change was entirely consistent with the shift to a neoliberal regime.

This shift to neoliberalism has been a subject of much academic discussion, which usually focuses on policy and administrative reforms in the 1990s. The literature is too voluminous to cite, but it is adequately represented in a number of edited works (Codd et al. eds. 2005; Marshall et al. eds. 2000; Thrupp ed. 1999; Thrupp \& Irwin eds. 2010). Some have brought Foucaultian insights about the changing ways of governing, as opposed to the retreat of government, to bear on changes in New Zealand's education system (Olssen 1999; Peters \& Marshall 1996; Peters \& Besley 2005). Other studies have explored the changes in particular aspects of schooling, for example, in curriculum, in this changing context (e.g. Bernarde 2011; Fernandez et al.2008; Roberts 1998; 2003; Sheehan 2011; Tremewan 2005; Wood \& Sheehan 2012). And their findings largely reinforce the point about neoliberalism's deep penetration of New Zealand education.

Recent scholarship has continued to grapple with the impact of neoliberalism, although with somewhat different emphases. Some argue that existing critiques were inadequate. Elizabeth Rata, for instance, laments 'the seductive appeal of postmodernism' and the heavy emphasis on

identity and culture which obscures the universal structural inequalities in the neoliberal regime of education (Rata 2012:36). For others, however, the critical task has been shifted from unearthing the neoliberal colonization of education, to working the 'spaces' within the regime (Nairn \& Higgin 2007; McMaster 2013). A recent article from two researchers who have been 
deeply critical of the neoliberal vision of education even made an appeal to go 'beyond ideology' in the matter of social class and educational achievement (Snook \& O’Neill 2009).

In this chapter I will take policy reforms as a starting point, given the abundance of material there. However, I will focus on the notion of education itself (as opposed to policy questions such as the respective merits of public or private funding of education, or what actually 'works' to improve student achievement). Section 7.1 discusses how schooling was transformed, in Michael Peters' words, from being 'centrally related to welfare' to being 'a subsector of the economy - perhaps even one of the leading sectors of the "knowledge economy" (2000:63). I will then discuss the issue of 'boys' achievement' in some detail, as a specific, gendered permutation of this ideological shift, rather than a mere conservative 'backlash' (7.2.1). The paradoxical and complex effects upon Māori, caught in the changing Pākehā discourse of education will be examined (7.2.2). 7.2.3 looks at the classed logic of the discourse around the so-called 'NEET' youth at the limits of 'social inclusion'.

\section{Part 1}

\subsubsection{Educating Capital}

The schooling regime of the 1990s no longer appealed to grand 'myths' such as the Beeby/Fraser vision (Clark 2004). If a vision had to be found, it was to be found in the catchphrases of 'human capital ${ }^{67}$ and the need for public 'investment' in education which appealed less to a mythical ideal, ostensibly, than the 'reality' of a market society. The problem, as Fitzsimons sees it, was that over recent decades, and in spite of the apparent roll-back of neoliberalism post-1999, education increasingly became a device that defined people in terms of capital, that is, a set of marketable skills (2010:215). Individuals were increasingly compelled, Hughes \& Lauder (1991:35)'s apt words, to 'become capital', 'not from the diffusion of ownership of corporate

\footnotetext{
${ }^{67}$ The theory of human capital could have been applied differently (and the application of the formal theory was more thorough-going in the tertiary sector than elsewhere) (see Eagle \& De Bruin 2000:5-7). My concern here is with the roles of such notions as 'human capital' and 'investment' in the discursive positioning of education, as they played out within a neoliberal regime.
} 
stock, as folk lore would have it, but from the acquisition of knowledge and skills that have economic value' (also Feher 2009:26).

This 'human capital' vision of education was far removed from the postwar liberal dream about 'humanism'. The former was in some ways obviously more attuned to certain human needs than the latter. No longer were young people fitted by adult society to pre-determined social roles, as workers, neighbours, homemakers and citizens, to borrow the words of the Thomas Report. It implicitly acknowledged the right of individuals to shape their own economic destiny through meritocratic education of their choosing, or in practice, their parents' choosing.

This freedom of choice in educational investment, however, came at the expense of fewer alternatives to the market logic. The postwar ideal of liberal education, although it never managed to escape economic and political pressures, let alone achieve its egalitarian aspirations, nonetheless disrupted the competitive logic (cf. 4.1). Moreover, the resulting contradictions and inconsistencies made room for individual and collective negotiation. It followed, in the 1990s, that the humanist and egalitarian visions could not be left unfulfilled and unfulfillable; instead they had to be excised from official discourse. This was explicit during the early 1990s when the real or imagined economic crises made a 'choice' between economy and society plausible. The clear priority, as the Minister of Education of the National government announced in a pamphlet on official policy in 1991, was 'to enhance educational achievement and skill development to meet the needs of a highly competitive, modern economy'. From this angle, the problem was among other things exemplified by 'an excessive focus on social issues and poor preparation for the competitive world' (Smith 1991:1). In fact, the title of the pamphlet itself - 'Investing in People: Our Greatest Asset' - was a clear signal; social issues, unlike marketable knowledge or skills, could not yield the ready returns required for sound investment. The implication for the education system was also spelt out. It would be 'responsive to change and to community and curriculum needs; efficient in its use of resources; able to produce the generic and specific skills required by the workforce of the future; attuned to the economic restraint within which all government activities must operate' (op.cit.:32-3).

The emphasis on the responsibility of schools and the educational system to meet the needs of the market was reiterated in the 1993 curriculum framework. 'Substantial overhaul' of the curriculum as set down by the Thomas report was necessary, and schools must adapt, wrote the 
Secretary of Education, 'if we wish to progress as a nation, and to enjoy a healthy prosperity in today and tomorrow's competitive world economy', to the need for a 'highly skilled' and 'adaptable' workforce (Ministry of Education 1994:1). It is true that concessions to gender equality and biculturalism/multiculturalism came, not without resistance, as part of the package, but the overall thrust was towards the market. National Prime Minister Jim Bolger succinctly summed up the alternative to the liberal-humanist interpretation of 'Education for All':

In an economy which is integrated and growing - in an inclusive economy - there must be a place for everyone. And education is the key to participation. (quoted in Ministry of Education 1994)

Notions of equality and inclusiveness were placed within the confines of the market, and education was to put young people in their proper places within its competitive order, without the illusion of egalitarianism.

Such arguments worked partly because they made strong appeal to the global 'economy' as a force in itself so that radical change to satisfy its needs was not only necessary, but inevitable. Smith explained the idea perfectly:

Over recent years the word 'competition' has disappeared from the vocabulary of educationalists. Yet, the world is a competitive place. Our standard of living as a nation now depends on our competing successfully in the international environment. We do our young people a grave disservice if we shield them from that reality and if the curriculum ignores it ... the imperatives of the modern world require a new culture of enterprise and competition in our curriculum (Smith 1991:2)

In other words, it was exactly the opposite of the postwar idealism which sought explicitly to give young people a measure of equality, through the state sponsored expansion of mass schooling, even if equality was at the expense of efficiency and economy (cf. Ch 4).

While economic pressures - real or perceived - markedly lessened by the end of the 1990s, the commitment to the priority of economic foundation in education hardened. Changing political tides brought a shift in rhetoric but not substance. While the early 1990s discourse, as discussed above, emphasized the inevitable subjugation of education to the competitive economy, third- 
way politicians talked up the positive use of education for a changing economy by appealing to notions of human capital. The 1999 Speech from the Throne explained that:

Central to the new information-based economy which is emerging is the growth of human capital. We need to improve substantially both the quality and the nature of the skills that our people possess (NZPD 21 Dec 1999).

The Labour Government upon its re-election in 2002 announced that 'increasing the quality and quantity of our human capital is the highest priority' (NZPD 27 Aug 2002).

Positive rhetoric of this kind allowed more flexibility than talk of welfare retrenchment, and permitted even a generous nod to the postwar 'Beeby vision', as Labour's Associate Minister of Education Steve Maharey did in a 2003 speech. He went so far as to proclaim the government's commitment to 'rebuild ... education as a public good', as opposed to a mere private 'commodity'. This broad appeal to the Beeby legacy, however, served only to confine it to a past which, as the speech laboriously made out, was irrevocably lost. The distinctive expectations and aspirations of Māori, Pacific Islanders and new migrants were mentioned, but much more ink was spilled on the 'very different' kind of economy and society which New Zealand found itself in. New technologies, 'information age', 'global', 'creative' and 'innovative' were some of the predictable tags, a 'far cry' in short as Maharey saw it from the 'low skill, low wage, commodity producing economy' of Beeby's day. Education thus now provided 'multiple pathways', instead of 'a series of barriers designed to sort people out'. It was assumed rather than explained that these pathways would be equally smooth and rewarding for all (Maharey 2003b).

This juxtaposition of 'then' and 'now' was banal and yet illuminating. It conveniently masked the fact that the postwar era was also a time of radical demographic change, when issues of biculturalism were already present, and when competitive pressures were equally intense. 'Sputnik' was no less a challenge than 'global economy'. Moreover, this selective comparison of past and present served to conceal the ideological choices. This new rhetoric talked of equality but in fact surreptitiously replaced it with a presumptively inclusive notion of development. Elsewhere Maharey distinguished development, as 'the extension of economic opportunity' and the redistribution of wealth as central to the difference between the new 'Third-way' politics, and the old welfarism (Maharey 2003a). It refused to contemplate that redistribution politics, implicit 
within the ideal of a broad and generous education, was meant as a solution to competitive pressures and social changes.

There was never any doubt that economic demands, rather than social needs, came first, even at the widest point of the Third-way revival of social democracy. Labour's Prime Minister came closest to a 'humanist' as opposed to economic definition of education when she spoke of its role in producing

well rounded, highly literate, well informed New Zealanders, who are aware of the world around us, of history, of cultural heritage, and of the great ideas and philosophies which have driven humankind. Education can never be reduced to a mere economic input. ... Its focus must be broad and empowering, not narrow and confining.

All this, however, came with the proviso that 'inevitably future strategies for education [will] have a strong and necessary focus on how to drive a stronger, up-market economy'. 'The pace of economic growth is still outstripping our ability to supply enough relevant skills, and we are racing to catch up' she said, and 'that is a top priority for the government' (Clark 2002). The question of prioritization was tackled explicitly in an official statement on Educational Priorities for New Zealand, which opened with a tribute to Beeby's vision of a 'broad and generous education'. The document talked of the need for a high-skilled workforce and 'national development', explicitly indexed to the OECD league table, and underlined the importance of upskilling and 'lifting achievement' (Ministry of Education 2003:4-6). As Codd (2005:xiv) observes, the emphasis was on delivering 'results' that could be measured on national indicators relevant to economic performance, and not on notions such as 'social inclusiveness', 'democratic citizenship' or 'moral responsibility'. The 'Third-way' appropriation of a liberal-humanist legacy thus did not provided an alternative to the neoliberal discourse of economic imperatives. Rather, it subsumed the former in the latter.

\subsubsection{Skill and Knowledge}

If education secured its niche as a 'capital asset' in the national 'infrastructure' of a market economy, schools came under increasing pressure from the more immediate needs of the market itself. The 'intrinsic' value of education, once understood in lofty terms of citizenship, had been 
rather incidental to the labour it sought to 'round off'. Now it was explicitly subordinate to its instrumental value for a 'knowledge economy'. Debates raged over whether education should be, as will be discussed in this chapter, about 'skills' or 'knowledge', but these disagreements did not so much challenge the primacy of the market as reflected different opinions about how education could best serve market needs.

It is unsurprising, then, that concerns about unemployed youth, which reached a peak in the mid90s, should have intensified the focus on schools. What could easily be overlooked though was that the emphasis on schooling itself reflected, in Higgins (1997; 2002)'s words, the 'closure' of the employment debate. To see education as the answer to the alleged collapse of a traditional, unskilled, working class labour market was to accept that structural changes were to be explained in terms of technological changes, rather than distributive politics. Yet even those on the left proved susceptible to the seductive, depoliticised, imagery of post-industrial or even 'post-work' society. Gerry Evans, a waterside unionist, lamented the 'chilling ring of truth' in the 'theory' of 'technological unemployment' he attributed to Keynes. The 'rapid pace of technology', he believed, was 'producing ever greater income inequality' than in the past when

New Zealand had a safety net for those without a university education. Manual workers with some skills could make a good living, as could watersiders, freezing workers, miners, seamen and some production workers. Their wages made an important contribution to the economy at all levels. More importantly, those occupation were open to those who failed in the education system ... They are now dinosaurs (Independent 1 Nov 1996).

Evans was oblivious of the contradictions in this argument: the technological determinism which rendered the politics of welfare redundant in the 1990s had not had that effect in the 1950s (say, keeping the wages of these low-skilled manual workers down). The mainstream press, by contrast, did not allow nostalgia to wreck a good argument. 'Jobs only for the skilled', wrote the Dominion, 'in today's world, there is no such thing as an unskilled job'. And yet, the possession of skills was no guarantee of jobs. The 'message teenagers need to hear repeatedly in 1995', added the editor, was that: young people 'must not be put off by stories of how, during the recession, many people with skills found it hard to find a job' (11 Jan 1995). It was young people themselves who must shoulder the costs of the apparent contradictions of the market. 
Low skilled jobs, in fact, refused to become extinct: the market by the new millennium wanted more rather than less of service and sales workers. (Spoonley \& Davidson 2004:33). Labour politicians now in power adjusted their buzzwords of ' $21^{\text {st }}$ century skills' to the reality of a booming, profitable, low-skilled economy. Maharey, speaking as associate Minister of Education, observed cryptically that whereas the 'old' labour market resembled a pyramid with 'a broad low-skilled base tapering up to a high-skill, high-knowledge apex', the 'new' labour market was more like a 'triangle'. Whatever the difference, gone were the days of his youth in the postwar era when young people could always expect a job when they left school. It was evident to him that 'the labour market could not readily absorb the present volume of low skilled school leavers' (Maharey 2002). The self-willed appetite of the market relieved the state and society of any responsibility towards those who necessarily occupied the lower rungs of the skills ladder, as the ladder was pulled upwards for the high-skilled climber to reach even further.

The problem of the knowledge economy and 'technological unemployment' was thus framed ideologically. Schooling had to sit within that ideological frame. The humanist-liberal regime of citizenship training might expand knowledge but it was hard to place in a knowledge economy. 'Hard' science and technology, by contrast, attracted a premium, especially in the form of the information and communication technology emblematic of the new 'information age'. ${ }^{68}$ That these technicians were in short supply assumed, for the Dominion, the proportions of a 'crisis' in schools. Educators and lobbyists interviewed were unanimous that IT was 'the most important tool in the modern teacher's repertoire' (27 Feb 1995). Governments responded to popular demands by extra funding (to the tune of $\$ 50$ million in 1999) and a number of expert investigations . The Minister of Education in a National-led government declared that he intended to 'make information technology as common as school books' and personally lectured principals about the ‘information-technology revolution' (Press 10 Jun 1999).

Computers had lost some of their cachet by the new millennium, as they trickled down into even disadvantaged schools. But the high-tech rhetoric was inherited by the new Labour government

\footnotetext{
${ }^{68}$ The insertion of 'Technology' as a separate section into the national curriculum also reflected, as Marshall (in Marshall et al. 2000:194) argues, 'instrumental, if not outright economic' principles of contemporary education (see also Davis, J 1998; Davis. R 2007:35). Yet the principles allowed some ambiguities: the technology curriculum also included subjects such as woodwork and home economics.
} 
It spoke a broader, esoteric and 'techno-futurist' language about 'knowledge waves' (Stephenson 2003, also Grewal 2008:159-193).

Such metaphors said nothing of the undercurrents of an entrepreneurial, 'innovation-based', 'techno-capitalism' (Sturm \& Turner 2011; also Wood \& Sheeham 2012:17-30). Instead, the waves were meant to be irresistible. 'Nation must choose to surf knowledge wave or sink', claimed the Auckland University vice-chancellor at the much-hyped 'Catching the Knowledge Wave' conference (NZ Herald 28 Feb 2001). 'The challenge', observed Fran O'Sullivan, a business journalist, was 'ensuring that once New Zealand gets up on the knowledge wave surf board, it stays there' (NZ Herald Aug 1 2001). Some were determined to exploit the 'hip' metaphor of 'Catching the Knowledge Wave' for all it was worth. The choice to link a national policy with a surfing subculture may be accidental, though the link was deeper. They were both high-risk and high return activities compatible with the competitive entrepreneurial ethos of neoliberalism.

The conference did not say much about those who were washed out to sea by economic tides, let alone by the Knowledge Wave. Neither could it offer much to those who did not fancy the heartstopping thrill of surfing the knowledge waves. Dissent could be heard, nonetheless. Green's MP Sue Bradford argued that, 'New Zealand must have more ordinary jobs for ordinary people, not just focus on 'centres of excellence' and the IT industry. Chris Trotter, a left-leaning commentator, castigated those riding high on the knowledge wave for refusing to recognize the crucial contribution ordinary Kiwis made to the New Zealand economy and their roles in any further economic restructure (Independent 09 Aug 2001). And one young schoolgirl at the conference optimistically called upon the powerful not to fixate their sight on the wave, but also look into 'the eyes of those in need' (NZ Herald 04 Aug 2001). The argument over the knowledge economy was a pale reflection of the debates over the market economy of the 1990s; 'sink or swim' was another way of articulating the imperative of competition.

The burden of the competitive imperative was in fact more likely to be felt by those at the lowerend of the real economy, than the ones riding high on the metaphoric 'knowledge wave'. This was an economy that having developed a certain taste for advanced technology, could afford to be picky about those young people who would fill the kind of low-skilled and low-paid jobs that 
had not completely disappeared. And it was as vocal about the shortfall in such basic supplies as the lack of cutting-edge scientific or creative talents.

The allegedly declining standards of '3Rs' in the information age, thus, unsurprisingly remained a cause of discontent for businesses, as it had been forty years ago. The Wellington Manufacturers' Association complained in 1994 that 'many job applicants lacked primary school basics' and campaigned for a return to the 3Rs (Dominion 13 Jan 1993). A Canterbury electronics mogul warned, eight years later, that the country's economic future was 'jeopardised by abysmal standards of literacy displayed by students and university graduates' by which he meant 'punctuation, grammar, spelling, and sentence construction'. At his insistence, the University of Canterbury Council, of which he was a member, called upon the government to fix the 'fundamentals' (Press 28 Sep 2001). Universities were also irked by the perceived decline of 3Rs, sometimes without the prompting from business, even if no longitudinal studies of undergraduate standards in such matters existed. The University of Canterbury had been deploring the 'declining' writing and math skills of its intakes for many years (Press 4 Oct 1994). And Victoria University's Commerce Department lamented that 'many' of its students 'cannot write a coherent sentence or do simple mental arithmetic', to a chorus of agreement from employers and officials (Dominion Post 11 Nov 2003). The press took notice of the grumbling of bosses and professors and added its own complaints. One sharp-tongued columnist laid into the 'fluff-headed' state secondary education, where young people learnt 'all about Colin McCahon, global warming, Shortland Street, gay and lesbian rights, Jonah Lomu, the Internet and the Treaty of Waitangi but they can't do arithmetic or put a sentence together' (Sunday Star Times 25 Oct 1998).

Occasionally, more charitable views were voiced. It was true, wrote David Hill, a writer and columnist, that 'the lack of correctly sloping letters, rote knowledge of Longfellow, and third declension verbs' left gaps in young people's education today. He wondered nonetheless why New Zealanders could not 'lament the decline in our $20^{\text {th }}$ century priorities a little less' and approve a little more of schools' efforts in teaching new forms of literacy and numeracy (Dominion Post Jan 1 2005). Such opinions, however, were exceptions.

The question was of course not about the intrinsic values of skills and knowledge. Some thinkers on the right were clear that the demarcation should not be allowed to obscure the larger 
ideological point, that is, the primacy of market. The concern was that an ostensibly 'marketorientated' skill discourse might still give leeway to subversion. An exclusionary, detached, meritocracy appeared thus superior. The director of the New Zealand Business Roundtable, Roger Kerr, for instance, assaulted the 'crass' utilitarianism of the 'social engineering' kind. The substitution of new skills for old-fashioned 'knowledge' whether or not dressed up in the language of the market, was a disguise for the 'post-modern', 'socio-critical', agenda of biculturalism and other forms of 'political correctness' (Kerr/NZBR 1999:221). A submission on the English curriculum penned for the NZBR by the lionised writer, C K Stead preached the gospel of grammar, punctuation and apostrophes, and railed, analogously with Kerr, against misguided efforts designed to 'foster social accommodation and melioration rather than excellence' (1994:1). Most remarkable was Stead's attempt to place such critiques in a longer history of struggle. He quoted from a 1962 article in Landfall, by Margaret Dalziel, a professor of English that:

'Education for citizenship' is likely to be a dangerous thing, dangerous in proportion to the rigidity with which the term 'good citizen' is defined. ... The concept of the good citizen seems to me of little value to the teacher faced with the class that has to be taught 'English'.... [Schools] have a special duty to those who will be specially responsible for guarding and transmitting the culture which the schools themselves represent (op.cit.:21)

To argue that education should be about 'apolitical' knowledge rather than notions such as citizenship was, however, itself making a political point. And beneath their shared emphasis on English as an 'apolitical' subject, there was a gulf of difference in political logic. Dalziel was protesting for the cultural guardians against the masses who threatened to take over education for themselves (instead of being 'improved' by it), with the complicit support of postwar egalitarianism and the humanist-liberal educational 'establishment'. Stead was weeding out what had sprouted when citizenship had been uprooted by market forces.

The market-orientated skill discourse, as promulgated by officials, did not satisfy those on the right. The concern that serious knowledge might be replaced by mere generic, and worse-still 
'student/activity-centred' skills was examined in some detail, for example, in a report on the 1993 curriculum from the NZBR $(1994)^{69}$ :

The description of the language and languages learning area is almost entirely about the language skills and their relevance to personal growth, social skills, or New Zealand's economic development. ... there is little to suggest that the development of aesthetic skills is desirable by, for example, exposing young people to the best of their cultural heritage, or to what Matthew Arnold referred to as 'the best that has been known and thought in the world' (1994:15-6).

Roger Kerr was more forthright: the 'current obsession with skills', was to him 'part of officialdom's aversion to any "givens" in education, that is, to knowledge that has to be learnt and acquired with hard work and concentration and not simply invented by the child as and when he or she sees fit' (Kerr/NZBR 1999:212).

The market, though, felt no need to be consistent about what it wanted. Even a prestigious subject like law was not exempt from the scrutiny of an increasingly demanding market, notwithstanding a few platitudes about the non-utilitarian benefit of education. Throughout the 1990s, the perception that the education system was churning out too many lawyers, and not enough real 'wealth creators', was a recurring theme (NZ Herald 15 Jun 1992; Independent 23 May 1997; 24 Nov 1997). A 'high-skill high-wage entrepreneurial-culture' rhetoric itself was disposable when the market changed its mind. As the enthusiasm for all things IT subsided in the new millennium, the popular press was filled with renewed anxieties about the 'real' skill shortages. 'Not every school leaver is cut out to be an economist or website designer,' declared the Dominion Post, though the editor at least conceded the difficulty of getting young people trained to fix 'leaky roofs and seized car engines' when 'he reads of e-commerce entrepreneurs making their first million-dollars aged 19' (Dominion Post 22 May 2003). 'Jobs of the future', Sunday Star-Times counselled young people and their parents, would be 'only low to medium skilled jobs': jobs in 'flipping your burger, making your latte, doing your gardening and providing home security' (15 Feb 2004). Too many young people were 'defaulting to universities', echoed the Minister for Tertiary Education (NZ Herald 13 Jul 2003). Good

\footnotetext{
${ }^{69}$ In fact, public controversy was still going strong in the second decade of the 21st century (Rata 2012; NZ Herald 7 Sep 2013; 17 Sep 2013) around the relative importance of low-status skills and high-status knowledge. The issue was still about access to the latter. Few talked about what counted as social justice for those with low skills.
} 
education was simply what market wanted, whatever that may be, and it was up to young people themselves to manage the consequences of its capriciousness.

\subsubsection{The Discipline of Skills}

The state was as ever needed to ensure that the market got what it wanted, a labour force equipped not just in terms of specific standards or skills of young people, but more importantly the attitudes - flexibility, work ethics, and 'employability' - that would willingly adapt itself, at its own costs, to the fickle demand of the market.

Against this imperative of market discipline, the old debate over school discipline and its traditional preoccupations was increasingly irrelevant. Corporal punishment, which dogged the postwar debates, dwindled into a non-issue after it was banned in 1990. Competitive pressure, however, was no less forceful than the cane. There was no longer a consolation prize of rough and ready egalitarianism, for the 'non-academic' or the not-so-competitive who had no other capital but what they could hope to gain from meritocracy. The state - or rather the economy expected them to work even harder to make up for their inadequacies, but no longer admitted to any responsibility for the lives of those who failed, whatever their 'innate' potential, in the academic race or any other sort of competition. Discipline no longer needed the visible hand of the school master; the psychological pressures upon young people who were shown their precarious future, if they did not succeed, were motivation enough.

This regime required young people to know the precariousness of their own conditions. And this still required some efforts in the early 1990s. One prescient columnist read a link between the alarming unemployment rate and the 'decline' in literacy standards, in 1993, even though available international surveys at the time indicated otherwise ${ }^{70}$ :

New Zealand society has changed radically in the last two decades. The warm blanket of state provision for essentials like health and education is being lifted and the unskilled, uneducated are feeling the chill most. Responsibility for these services is devolving to the community and to take part, or simply to cope, individuals must become self-sufficient.

\footnotetext{
${ }^{70}$ Subsequent international benchmarks, International Adult Literacy Survey (1996) and Adult Literacy Life Skill (2006) confirmed the suspicion of 'declining' standards, or to be more precisely growing gaps within the population.
} 
Self-sufficiency requires, at the very minimum, basic education skills such as literacy and numeracy (North \& South June 1993).

This message no longer needed to be elaborated by the end of the decade. Official and public discourses could talk in more positive terms about the imperative of basic skills, and the necessity of participation in the 'knowledge economy', not the least because the costs of failures and exclusions were self-evident. The official slogan that 'every child' should be able to 'read, write and do sums for success' hid the fact that literacy and numeracy skills were valued not so much for their own sake - as the debates over declining educational standards might seem to imply - but as signals of 'employability', that is, readiness for the market.

Here, as Hamilton \& Pitt (2011) recently argue in the British context, learning the 'basics' was no longer a matter of rights but an obligation upon those who were 'excluded'. As such, it had a more pervasive and intensive effect than sporadic exercise of physical punishment within the schooling regime. Being able to read, write (in English) and do sums opened doors in a capitalist society. But the mastery of such skills guaranteed no success, either in educational or economic terms; it meant no more, and less, than that young people were now included in the orbit of market discipline. Nor did it offer any certainty; in fact, the point was to prepare them for the uncertainty of unrelenting demands for upskilling and reskilling. The risks of failure were still there. It was only that young people could now understand them better.

This disciplinary mechanism should be distinguished from traditional regimentation of schooling. It is true that for the majority of young people, literacy and numeracy meant, as the old '3Rs' for their forebears, not the ability to read Longfellow or do long divisions, but the ability to fill out time-sheets and incident logs and follow other rules of the workplace. But the new discourses of literacy and numeracy laid a much stronger emphasis of a self-driven process of learning, rather than simply following the rules imposed from the outside. In this way, education was about active rather than passive discipline. In the new millennium officials and politicians began to talk about 'foundation skills'. The Minister of Social Development spelt out the content:

Developed economies continue to face on-going structural changes and people are going to need skills that can be adapted to a number of jobs. Foundation skills are ... a key to adaptability. These foundation skills range from literacy, numeracy and presentation 
skills to learning how to learn. Such skills also underpin individuals' sense of self-worth. Attitudes and behaviours, such as self-motivation, are also essential to the development of foundation skills (Maharey 2003c).

Bureaucrats concurred. One definition of 'foundation skills' included 'technological literacy, communications skills, team work, "learning to learn" and self-confidence skills' besides numeracy and literacy (Ministry of Education 2002:36). Another stressed 'communication, adaptability, self-confidence, resilience and group effectiveness' (Ministry of Education 2002:23). Such terms as 'self-confidence' might be banal and thus unobjectionable, though they were hallmarks of the 'post-industrial' society. They stepped into the shoes of 'obedience' and 'conformity' to provide a new 'hidden curriculum' for young people, fully compatible with the characteristic demands for emotional labour. The focus shifted from social order to individual attributes. The subject changed from the distribution of knowledge to the self-sufficient cultivation of a work ethic. And there was a new imperative too for young people themselves; not to resist, but to accept 'structural changes' and their own precariousness as natural. Moreover, all these were to be understood positively as skills rather than negatively as discipline. All young people were supposed to learn these skills. But it was those at the bottom of the academic ladder who were most likely to suffer the repercussions through the lack of them, if only because literacy and numeracy, being easily measurable, made those at the bottom more visible targets of intervention. This connection allows one to probe deeper into the problem of 'underachievement', and to better appreciate the discursive change. The new terminology was not just another name for the 'slow' or the 'reluctant' learners of the postwar era. Yet both groups so labelled were drafted from more or less the same milieu: the working class, the ethnic 'other', albeit with more boys among the ranks of underachievers in the 1990s than in the 1950s. Both attempted to articulate inequalities which were purportedly non-existent: in one case because equality seemed already achieved; in another because it was irrelevant. The point, however, is that in the 1990s these young people were positioned differently. The postwar regime, as we saw, excluded them from its meritocratic hierarchy and yet attempted to cater to their needs as workers and citizens within an ostensibly egalitarian economic order. The new system by contrast offered only one route to economic and social security. Inclusion was imperative. 
The paradox of this 'inclusionary' paradigm, however, was that it produced the very stratification it purported to eliminate. While the discourse of 'achievement' promised limitless upwards mobility, it produced quite a different effect upon young people who were most 'at risk'. To escape from the vicious cycle of underachievement simply plunged individuals into another struggle with no exit. To become adaptable, flexible, and resilient meant also to accept the 'reality' of changes as outside their control, rather than to challenge it. It meant that the acquisition of minimum qualification and basic skills could be no more than a temporary reprieve from their precarious existence. It meant accepting the fact that they would still be less protected than their educational betters from the next round of upskilling, and the only way out was to try even harder. All this, of course, was entirely compatible with the new ethos of a competitive, entrepreneurial, society which regarded its 'failures' as disposable. That ethos in turn held the key to understanding the sorts of discourses aimed at rescuing 'underachievers'.

\section{Part 2}

The discourse of underachievement then entailed a vigorous disciplinary regime. But the trouble was that 'underachievement' was often reduced to a self-evident 'problem' which was to be fixed, self-evidently, by lifting achievement (Smith 2010:41-2). This precluded scrutiny of its possible ambiguities, let alone the disciplinary effects. Moreover, 'underachievement' could not but proliferate in a competitive system (Gilbert 2010:25). This was a circular and self-reinforcing logic which perpetually opened up 'gaps' that needed closing. These gaps themselves, measured by ethnic, and alleged gender disparities, directed attention away from the underlying structure of a capitalist economy and crowded out alternative explanations.

\subsubsection{Gender}

Gender issues in schooling in the 1990s were overshadowed by a perceived 'crisis' in 'boys' achievement' (Jones 2000:97). The general impression was that New Zealand was now on the other side of the gendered school regime of the postwar era. The prevailing opinion was summed up in the authoritative statement, by now much quoted, from the Christchurch Longitudinal 
Study: 'by the mid-1990s, any female educational disadvantage (up to the point of school leaving) has largely disappeared and has been replaced by an emergent male educational disadvantage' (Fergusson \& Horwood 1997:19). The authors laid the blame squarely on the misplaced emphasis over the past decade upon the disadvantages faced by girls.

Neither the veracity nor the predictive power of analysis is at issue here. The question was how the results came to be interpreted as a crisis in boys' achievement. For one thing, the crisis could not be read off directly from statistical disparity. After all, girls had been outperforming boys in certain subjects, if one disregards artificial equalizing of scores, in key subjects such as English even during the postwar era (see $\mathrm{Ch} 4 \mathrm{fn} .17$ ). And one might even argue that boys had improved, or at least performed just as well, if historical trends and international benchmarks were taken into account. Nor did the statistics of standardized test results say much about the operation of the broader gender regime, say the changing fortune of boys (or not) when they entered the work force.

Critical literature on the issue has often pointed to a swing back to conservative attitudes, a moral panic no less. A different strategy is employed here. First I examine the construction of crisis and achievement, two of the key words in the boys' underachievement crisis, within a neoliberal discourse. Second, I look at how this reformulation supported a re-conceptualization of essential gender difference. And finally I wish to highlight the classed nature of the boys' underachievement debate.

The effect of the 'crisis' framing in garnering public attention needs little elaboration. It took a little longer in New Zealand, however. ${ }^{71}$ Although the Christchurch Longitudinal Study had already unearthed the 'problem', it was not until a few years and several official reports later that it became a full-blown crisis. John Langley, the principal of Auckland College of Education, warned in 2003 that boys' underachievement was 'a social tragedy of considerable proportion'. 'We males,' he lamented, 'are fast becoming an endangered species'. The 'gradual and insidious decline in the fortunes and the welfare of our young boys and young men has almost gone unnoticed' (NZ Herald 12 Jun 2003). But this time it did not go unnoticed. Langley was joined among others by the celebrity parenting author Celia Lashlie (cf.ch6). The media took note of

\footnotetext{
${ }^{71}$ For a review of earlier debates see Kenway (1996), for Australia, Epstein et al. 1998 for UK. In the case of the US, there was no obvious target in the form of a comparable 'liberal' bureaucratic state, though conservative and antifeminist sentiments were by no means absent (Weaver-High Tower 2009).
} 
her work for the 'Good Man' project generously funded and supported by some of New Zealand top boys' schools, united in their perceived 'marginalisation'. Her report on the project, the only book-length contribution to the subject, became a best-seller, which also brought together the influences from parenting discourses on 'fatherless sons' (Lashlie 2005; also cf.6.2.3). ${ }^{72}$ This framing of a gendered crisis paradoxically helped to bury the complexity of gender issues.

'Either we deconstruct masculinity for a few more years, or we use what we know today to make schools better places for boys tomorrow' said one conservative commentator (NZ Herald 26 Nov 2003). Crisis, as usual, allowed no alternative.

The debate, however, was not just about recovering past gendered roles, even if conservative commentators frequently slipped into nostalgia. It was also about the remaking of masculinity for the new economy and this was encoded in the construct of 'achievement' which often escaped attention.

Here it was not so much boys or masculinity, but these 'macho-types' who let the side down by being underachieving and in crisis. These macho boys were further distinguished from the general male population by the connotation of class. Such connotation was less explicit in New Zealand, than say the UK, though it was still discernible. ${ }^{73}$ The rector of Southland Boys' High, and appointee to the ministerial inquiry into boys education, for example, summed up the 'macho' types as 'a Mazda 323, a boot full of beer and a rugby game' (Southland Times 5 April 2003). The 'macho' type was rejected not because it hyped masculinity, but rather because the structural changes in the economy - a change which must not be reversed - had decreed it redundant. ${ }^{74}$ Or, as the rector put it succinctly, 'beef and brawn don't get your jobs any more. All that macho stereotype', the principal of Shirley Boys' High and vocal advocate for boys' education John Laurensen declared, 'is just nonsense'. The days when boys 'left schools at 15, got a job, had a house with a mortgage, and cut grass at the weekend,' were long gone, he warned. (Press 23 Apr 2001). In a similar vein, the 'muscle-bound, tongue-tied' traditional masculinity was found to be 'useless' by another teacher. This teacher went further however.

\footnotetext{
72 Lashlie's book included references to 'boys's parenting' experts such as Biddulph (1995; 1997); Gurian (1996; 1998 2001); Kindlon \& Thompson (1999); Pollack (1999). The American conservative writer Christina Sommers' The War Against Boys, a key influence of the conservative backlash, was also quoted in her report (2004:38). ${ }^{73}$ In Britain the debate over the boys' crisis was joined up by an attack on 'anti-learning', 'laddish' and 'chav' working class culture, spearheaded by the New Labour government (see Francis \& Skelton 2005; Francis 2006; Jackson 2006).

${ }^{74}$ For a thorough discussion of the notion of 'redundant masculinity' in the UK context, see McDowell (2003).
} 
'Should we train our boys to behave more like women' who were 'assertive, competitive, and independent', or in other words, 'had learnt to behave like men'? (Press 23 Sep 2003). Gender boundaries were blurred somewhat here. The message was not. The successful woman and the 'post-macho' 'real' man was the same gender-less entrepreneurial individual.

The fact that certain expressions of masculinity became redundant in a neoliberal context did not mean a fundamental shift in the gender hierarchy. On the contrary, the innate differences between genders were often reiterated, and the claims of masculine superiority, although never asserted categorically and unequivocally, were often implied. One prominent professor of education, for example, ventured the opinion that based on his forty years of classroom experience boys' poor performance in reading had something to do with the fact that 'children were brought up by their mothers' (Press 6 Dec 2001). Such an upbringing turned boys off learning. The same line of thought underpinned numerous campaigns for male 'role models' of educational achievement in teachers and fathers. Lashlie (2005:149) was one woman who willingly stepped aside from her son's 'journey to manhood' because 'I wasn't a man'. And the headmaster of Christchurch Boys' High was apparently so convinced by Lashlie's argument that he instructed staff to tell parents that they 'prefer' to deal with fathers rather than mothers' (The Press 12 Mar 2004). ${ }^{75}$ It was also reflected in attempts to reassert some traditional male privileges, or 'rights' against girls and other boys. Lashlie (2005:110) for example took issue with the fact that 'boys saw girls as the ones who called the shots: he asked, she said no and thus [the] parameters of their friendship were defined'. Consent from girls bruised male ego, and that was not a good thing, in Lashlie's eyes. Elsewhere she suggested that boys simply could not resist flicking 'anyone within arm's reach with a ruler or [moving] past a fellow student without hitting him'. Although they did need to manage their boisterousness for the sake of learning, this 'maleness' was not to be suppressed. Perhaps they should be allowed to 'stand up every ten minutes and put someone in a headlock' (Lashlie 2005:43-4). This may be an attempt at humour, yet it seemed thoughtless of those who were hit or being put in headlocks.

The reinvention of a 'traditional' gender construct was also reflected in attempts to explain behaviour and achievement difference by certain innate qualities. Boys were 'hardwired' for numeracy and 'scientific thoughts', and girls were 'hardwired' for linguistics, according to one

\footnotetext{
${ }^{75}$ Lashlie's report, upon which the book was based, had been released in 2004.
} 
feature article in NZ Herald (15 Jul 2004). Common sense assertions worked just as well as appeals to hard science. The ERO report on boys' achievement had the following quotes from its UK equivalent:

Girls are more attentive in class and more willing to learn. They do better than boys on sustained tasks that are open ended, process-based, related to realistic situations, and that require pupils to think for themselves.

Boys show greater adaptability to more traditional approaches to learning which require memorizing abstract, unambiguous facts and rules that have to be acquired quickly. They also appear to be more willing to sacrifice deep understanding, which required sustained effort, for correct answers achieved at speed.

New Zealand bureaucrats could think of nothing more to add than that 'girls tend to prefer narrative reading, while boys prefer non-fiction' (ERO 1999:8-9). Celia Lashlie had a more intuitive grasp: The boy

...wants to be able to run and play, to live in the moment, and to enjoy the fact that for now he's exactly where he needs to be and there's nowhere he needs to go. ... [The girl, by contrast ] today she's going to be a flight attendant, tomorrow an astrophysicist, the next day a vet ... then it's back to the flight attendant (2005:77-8).

In these narratives the acknowledgment of girls' achievement, a concession to the principle of gender equality, was framed in such a way that modified rather than discarded older prejudices. Girls were better when the subject required emotional labour, or when hard work, as opposed to intelligence and creativity, was in itself sufficient. By contrast boys were active, rational, goaldriven. They were capable of spectacular successes or spectacular failures, and not just mediocrity. And these were the very same values upon which men had been distinguished historically from the passive, chattering and fickle-minded 'other'. And moreover in this construction of masculinity, boys were the competitive and risk-taking neoliberal subject par excellence, even if their masculine superiority was no longer guaranteed: the promise of entrepreneurial individualism was a double-edged sword.

In this light, then, construction of failed masculinity and successful masculinity, vis-à-vis femininity, both had an implicit class script. Masculinity needed hard work, like everything else 
in a world without welfare. And this called for traditional forms of discipline and self-control, as common sense might suggest. 'Boys need more help than girls', argued Paul Baker, head of the Boys' Schools Association, 'they need more direction, they need more discipline, they need more boundaries'. And 'not only do they need it', he stressed 'they'll take it' (Sunday Star Times 15 Jun 2003). John Morris, headmaster of Auckland Grammar, was convinced that the erosion of the 'old fashioned' trinity of 'competition, discipline and structure' was at the bottom of boys' underachievement (NZ Herald 21 Jan 2000). The traditionalists, in other words, were calling for the return of something which had been perceived to be under threat already in postwar society, as we have seen.

Boys who went to Waitaki Boys' High or Auckland Grammar might certainly expect that kind of discipline so they would not fall short of their potential. That was one sense of 'underachievement'. At the other end, 'underachievement' meant simply the risk of failing, and discipline became more plainly a matter of control. And 'boys underachievement' here was better understood in the broader context that:

Our boys and young men account for over 80 percent of those defined as behaviour problems at school, 75 per cent of those stood down or suspended from school, over 80 percent of those who appear in the criminal justice system, represent most of those who develop serious mental health conditions and tragically those who end their lives prematurely through suicide (NZ Herald 12 Jun 2003).

While it was not stated explicitly, the 'underachievers' described in such paragraphs were much less likely to come from decile 10 schools such as Auckland grammar. In fact, among the betteroff young people, the gender disparity in achievement was smaller, and even reversed in some instances (Alton-Lee \& Praat 2000:14). Middle-class boys then, while they might benefit indirectly from the attention to boys in general, were less likely to be subjected to more punitive interventions aimed at arresting this particular kind of 'underachievement' of the underclass. It was not merely a coincidence that Lashlie, the foremost popular authority on the subject, was also an ex-manager of a man's prison, a fact which undoubtedly lent credibility to her discussions of education.

Yet the construction of 'boys' underachievement' served to divert attention from the classed kinds of underachievement to a seemingly classless crisis of masculinity. Lashlie for example 
managed her emphasis well. Even the students at Wanganui Collegiate, a leading exclusive private boys' school, received the same message about staying at school. 'Every month a boys' school manages to keep a student' according to her calculation 'regardless of the family and socio-economic background of the student ... the school reduces the chances of the student arriving at a prison gate by at least one if not several percent'. Eight and a half year of schooling would eliminate the risk of prison altogether (Lashlie 2004:36 italics added). The burden of socio-economic inequality was conveniently erased.

\subsubsection{Ethnicity}

In spite of the seemingly intractable problem of 'Māori underachievement', the combined forces of biculturalism and neoliberal reforms ${ }^{76}$ appeared to offer new opportunities for Māori education which the old liberal-humanist orthodoxy did not. Even for those who were (and still are) highly critical of these new ideologies, there was a sense that Māori 'could not do worse' than the liberal humanist orthodoxy which had yet to deliver the goods of substantive equality (Smith 1991; 2003). And the achievement could be seen in the strong growth of Māori educational institutions: the kohanga reo, kura kaupapa (primary) and whare kura (secondary) in spite of economic pressures and backlashes. This apparent breakthrough in the direction of greater equality was, however, at bottom illusory.

Much has been written about the limits of cultural/identity politics operating within a neoliberal context in terms of delivering socially just outcomes for Māori (Poata-Smith 1996; Rata 2000; 2012). Others have attempted to locate the 'real', and perhaps easier to quantify, causes of underachievement in factors other than the indefinite 'culture' (e.g. Nash 2001). But a critique of 'tribal capitalism', for example, is unhelpful if it were to divert attention from 'capitalism' to 'tribal' and end up an apology for non-tribal capitalism that it accuses cultural politics of failing to resist, or an endorsement of the culture of western capitalism that identity politics challenges. And a 'social realist' alternative to cultural politics is equally less useful if it simply serves to legitimise the reality of monocultural hegemony. Moreover, the bicultural accommodation of

\footnotetext{
${ }^{76}$ See Openshaw (2010) for a detailed account about 'how neoliberals and biculturalists drew upon each other's discourses to successfully challenge existing bureaucratic structures and the postwar liberal ideology that traditionally underpinned them (2010:5). Openshaw's focus was on the 1988 Picot Report and the 1987 Treasury briefing on the education system, which strongly influenced subsequent reforms.
} 
neoliberalism was by no means a historical or theoretical necessity. Many indigenous scholars have consistently argued for Kaupapa Māori and against neoliberalism (Smith 2003; Penetito 2010:230-1). And Māori educationalists had long warned that the goal of cultural selfdetermination on its own could easily became co-opted into a neoliberal moral imperative of self-reliance, which only served to entrench structural inequalities (Smith \& Smith 1996:232). In fact, it is necessary to qualify the extent of actual concession made to indigenous aspirations in the form of official biculturalism. The ascendance of biculturalism in official educational discourse was certainly impressive, and might seem to overcome even conservative aversion to cultural politics. The conservative National government in the early 90s, for instance, rejected the imposition of equity requirements upon individual schools, but it did not shy away from thoroughly 'biculturalising' its strategic and curriculum policies. The government's strategy promised not just equal access to mainstream education, but also a Māori medium education that would ensure the revitalization of the Māori language. Its curriculum document went even further. Not only was it an exercise in bicultural design: each heading was annotated in Māori (subsequent curricula were published in both Māori and English, and some were in fact developed separately). It explicitly acknowledged that all students should have 'the opportunity to acquire some knowledge of Māori language and culture' and the 'opportunity to learn through te reo [Māori language] and nga tikanga Māori [Māori customs]' (Ministry of Education 1993:7, 10). All this, however, did not necessarily contradict the overall ideological frame of 'choice': Māori education would be no more than an option (cf. Appleby 2002:114-5). It was supposed to be read against the overarching imperative of competiveness within a 'global marketspace'. The preservation of indigenous culture was contingent upon actually yielding a hard competitive edge. Bicultural approaches, in other words, did not so much challenge the dominant regime as fill out its interstices.

We may state the case more positively. There was undoubtedly potential to exploit the 'spaces' within a neoliberal regime. And it would be unreasonable to hold cultural politics solely responsible for failing to provide a radical alternative. All the more important then that we need to scrutinise the potential and the risks of working within a neoliberal regime.

One may take as an example the speeches from Mason Durie, a prominent Māori leader and the 'guardian' of the then Labour Government's secondary schooling policy initiative, at the Hui 
Taumata Matauranga (Māori Education Summit) in 2004. ${ }^{77}$ The 'apparent irony' that 'Māori were able to assert demands for an education that supported Māori values within a market driven environment' did not escape Durie, even if what made this ironic remained implicit (Durie 2004:8). Neither was there a thorough-going apology for neoliberalism and its 'trickled-down' benefits; concerns about persistent inequalities could only be read between the lines (Durie 2003a:222-3). Beyond these fleeting references there was barely a sense of the radical potential of Kaupapa Māori as formulated, its collective accent echoing strongly working class notions of community, as an alternative 'worldview' to market-driven neoliberalism. It also lost much of the imagination and vitality. The suggestion from Graham Smith that Ako Māori would 'logically' move towards Pacific/Asian cultures and languages, its Austronesian cousins, would have gone completely over the head of conventional visions of Māori education such as Durie's (Smith 1991:21).

Instead, there was the same platitude about 'globalization' spinning firmly around the western financial capitals, as propounded by Pākehā prophets. The 'shrinking globe', in Durie's words, 'would bring the cultures of other lands and communities to Turangi and Taupo, and in turn those towns will be only a stone's throw from London and New York'. 'Māori advancement' would come to rest upon access, through education to 'music, sport, travel, and the international discipline of commerce, law and science'(Durie 2001:3). Durie demanded that education must prepare Māori youth for te ao Māori, a world of 'Māori language, culture, marae, resources such as land, tikanga, whanau, kaimoana'. The tension between globalisation and indigenous society, both in cultural and socio-economic terms, lay unrecognised. And not a word was said about the difficulties of making it through local structures of cultural and socio-economic inequalities, let alone the double burden of juggling one's ethnic and 'global' identities (op.cit.:4). Instead, social mobility through meritocracy was assumed. 'Educational achievement correlates directly with employment, income levels, standards of living, and quality of life'.

This appeal to globalization then meant that the concrete problems were eschewed. It simply reinforced the intolerance of 'failures'. And Durie spoke of ‘60,000 young Māori', who were

\footnotetext{
${ }^{77}$ Durie's influence might be seen in one strategic document from the Ministry of Education on its priority of lifting Maori educational achievement. The stated 'goals were almost exact replicate of Durie's own: 'to live as Maori', 'to participate as global citizens' and 'to enjoy high standards of living and good health'.(Ministry of Education 2004:15; Durie 2003a:199-200).
} 
'trapped in lifestyles that were essentially incompatible with healthy growth and development and would struggle to participate in either te ao Māori or the wider global community' (op.cit.:6). Durie blamed the 'system' for the lack of success (the prescription was 'cross-sectoral cooperation', the vogue policy jargon). But this said nothing about responsibilities for those who had already 'failed', except to place them in the same trope of 'circle of dependency' used so successfully by the right. And here the concrete burden was more likely to fall on the shoulder of young people themselves and their whanau, than the abstract system.

This peculiar version of Kaupapa Māori schooling, in other words, was not so much an alternative to a Pākehā system of competitive meritocracy as a brown-tinted mirror of it. But it lent itself to the perception that cultural politics had gone too far. The conundrum though was that cultural politics had to go further to make up for socio-economic disadvantages which it refused to acknowledge. Durie, for example, acknowledged candidly that the emphasis on indigenous achievement might conflict with notions of democratic citizenship. Māori should aim not for mere parity with Pākehā, Durie urged, but to become 'better, different, or even markedly superior'. The suggestion anticipated a potential 'backlash' about 'Pākehā underachievement', while denying itself any support for equality. The uncritical acceptance of the logic of competition, paradoxically, gave legitimacy to already existing inequalities. The concession to market imperatives, moreover, depoliticised cultural politics in its own terms. 'Empowerment' was reduced to having access to indigenous knowledge without ever changing the power relationships that governed how knowledge could be put to use as cultural identities were lived. Such a simplistic reasoning was captured neatly in an official slogan: 'Te Ihi, Te Mana, Te Matauranga: Empowering Education' (quoted in Jenkins \& Jones 2000:139). The fact that indigenous leaders had bought into a clichéd western aphorism of empowerment through knowledge did not make it better.

In addition, cultural politics of this kind ran the risk of reversing the problematic dominance of socio-economic explanations of structural inequalities and thus reinforcing the individualistic logic of neoliberalism. Worse still, it rebooted futile debates over the primacy of class, ethnicity, or gender in explaining educational inequalities, which only served to conceal the inequalities that they were supposed to be explaining. Bishop and Glynn (2003:69-70) for example took issue with the 'structuralist' approach to Māori underachievement, and thought it insulting that Māori 
should be included in an 'Anglo-Māori working class subculture'. Yet the impassioned critique of cultural reductionism missed the target. The literature they cited (Chapple et al. 1997; Nash 1993 ) in fact rejected quite emphatically class structure in favour of 'classed' behavior and family influence. There was 'very little evidence', concluded a group of economists under contract from the Ministry of Education, 'that Māori students put pressure on each other not to succeed at school. ... But some research shows that working class boys, both Māori and nonMāori, back each other up in doing badly at school' (Chapple et al. 1997:14). Cultural explanations proved here to be more amenable to a discourse of individual responsibility. And it was possible to talk up lifting Māori achievement while carrying on the assault upon the slovenly 'anti-learning' working class. The brown working class youth and their communities were still likely to bear the brunt, whether such an assault was delivered in class or race terms. The same confusion was at play, with the debates around Labour's ill-fated flagship policy 'Closing the Gap'. While the opposition and mainstream media cried foul over 'separatism' and 'preferential' treatment, for some, the policy focused too much on socio-economic disparities and not enough on ethnic ones (Humpage 2002:142-5; also Humpage 2006; Elizabeth \& Larner 2009:145). The false dichotomy between class and ethnicity satisfied no one and was misleading itself. The real limit of the rhetoric of social inclusion and investment was not so much the barriers of exclusion, but its economic logic. As the Minister of Social Development put it to those sceptical about the policy: ‘just think of your superannuation' (NZ Herald 9 Aug 2005). There was no ground for redistributive justice across either racial, or class lines. 


\subsubsection{Class}

As I have discussed above in (7.2.1), the contemporary regime of schooling itself had increasingly become infused with a distinctively classed competitive ethos. In the postwar era, as discussed in Chapter 4, class compromise was delivered not so much through the meritocratic regime of schooling in itself, but in the grey zone where education, full employment, and social citizenship overlapped. This grey area had disappeared by the 1990 s, with serious consequences for working class young people. Social mobility through meritocratic schooling was now once again their only hope for a better life.

The New Zealand case shared much with similar trajectories overseas, even though on the surface it would appear to confirm some of the long-held illusions about a classless tradition. There had not been the same visible 'moral censoring', as was the case in the UK, as exemplified by the frontal assault on working class 'anti-learning' by the Conservative and New Labour governments (Mac an Ghaill \& Haywood 2011:735; also Jones 2010:90; McDowell 2012:99; Reay 2010). Nonetheless, the state in New Zealand made it abundantly clear to working class young people and their parents that opting out of the lower rungs of the meritocratic ladder was no longer an option, whether or not they actually could attain a place in the 'high skill high wage' economy.

The rise of 'NEET', a terminology invented by British New Labour for 'young people Not in Education, Employment or Training', in New Zealand discourse by the end of the period was an excellent illustration of this changing understanding about young people and their education.

NEET has been extensively critiqued in the UK (Chadderton \& Colley 2012; MacDonald 2011; Thompson 2011; Yates \& Payne 2006). In New Zealand it has yet to be examined thoroughly. In policy terms NEET encompassed a complex range of issues. Indeed, as Nudzor (2012) points out, the acronym made little sense if one takes social complexity into consideration. Hayward \& Williams (2011:175) argue rightly, however, that the invention of the NEET had significant 'symbolic and political meanings', even if its 'sociological' meaning was 'questionable'. It is these ideological meanings that I wish to sketch. 
What was hidden, but in plain sight, in the first place, was the seemingly innocuous conflation of education, work, and training. The use of an acronym served to attenuate the substantive meaning even further. What made this particularly important was its apparent contradiction with the meritocratic rhetoric of a new 'knowledge economy', within which further education was supposed to equate to higher status and income, and not just the equivalent of a ready job upon leaving school. Instead, education, employment and training were simply conceptualized as interchangeable 'activities' which served not so much to bestow social status on young people as students, workers or apprentices, but merely to keep them occupied. From there, it was a short step towards the so-called 'active labour market policies' which were a hallmark of neoliberal workfare programmes (Larner 2000:13). Such programmes suggested that young people could be 'activated', without having to specify what young people could be active in. The weight of scrutiny was instead thrown upon young people themselves, while the question of who was responsible for youth unemployment, inadequate schooling, and the lack of training all disappeared into the enigmatic acronym. Lateral thinking could run wild. The Ministry of Social Development, for example, suggested that NEET was synonymous with 'inactive', 'economically inactive', 'disengaged', 'disconnected' (MSD 2003b:2).

Moreover, 'NEET' connected seamlessly with the risk pathology of unemployed and undereducated youth. This was the case even though research was thin on the ground. In spite of the much-touted longitudinal reviews, there was 'not a lot of good data in this area' according to one official review (McLaren 2003:2). Convenient risk indicators such as 'early school leaving' and 'lack of qualification' were simply taken for granted as meaningful because 'young people who left school early without qualifications are seen as at high risk of inactivity generally' (op.cit.:2-3). Such indicators subtly directed the gaze of the reader. There was no need, after all, to look too closely at those young people who might just be 'backpacking around the world', as the author suggested, nor to look too closely at those destined for a life of leisure once suitably credentialed. It was the potential claimants of social welfare and their pathologies who were worth dissecting. 'Inactive - by definition less successful', the researcher blurted out. This narrowing of common sense was strategically important, because one was soon told that 'inactivity' in itself - pre-existing conditions or unmeasured factors could all be ruled out notwithstanding the limits of 'not a lot of good data' - led to grave consequences such as crime. Worse still, 'evidence' indicated that they were likely to create 'a cycle of generations who fail 
to contribute to society to their full potential' (ibid.). There was little which differentiated all this, in spite of an apparent change of political ideology and the exhortation of evidence-based policy making, from the early 90 s crusade against 'welfare dependency'.

Third-way politicians were loath to talk about morality, yet the discourse of NEET was inevitably an individualizing and moralizing one. Demanding that 'at risk' young people get a job might increasingly look unrealistic, or even unreasonable, given jobs were in short supply. But to prevent young people from becoming 'inactive' or 'disconnected' implied an immanent reasonableness; it seemed to ask no more than a small measure of self-respecting virtue. In contrast to the traditional notions of unemployment or school drop-outs which pointed immediately to social problems, the idea of 'inactivity' was a generic one which might apply just as well to the lack of physical exercise and an unhealthy lifestyle. 'Lifestyle', of course, was a familiar word to working class young people and their families in neoliberal times. It insinuated a certain moral defect about the way young people were living, rather than what they could or could not achieve. In fact, it seemed like a throw-back to an even earlier era, where the line between the 'deserving' and 'undeserving' poor was starkly drawn. That line was never completely erased, even by the welfare state, but a market economy reinvigorated it. The unnamed 'opportunities' within the realistic reach of these young people, were likely to be poorly paid and 'flexible'. Such jobs were not much better than unemployment so that the difference could and had to be located in individual morality. Interventions including schooling which 'activated' these young people did just that; they did not promise them a good job, much less a good life (cf. Jordan \& Strathdee 2001). In contrast to this pathological class of young people waiting to be saved from idleness, the moral worth of those young people who could afford leisure was never questioned. A place in the meritocratic trajectory was an added virtue in itself, whatever one actually did. It was, in the moral economy of 'activity', superior to whatever else the working class NEET must do to eke out an existence. Class, here, operated at its full strength.

To 'activate' young people within this frame precluded a return to welfarism. This 'common sense' was implicitly affirmed by McLaren's research; alleviation of poverty was not mentioned at all in the numerous principles she identified for effective intervention (2003:16-20). Yet McLaren could cite nearly a score of articles attesting that young people were less likely to 
become 'inactive' where family income was higher, and parents were in higher status occupations with higher qualifications, and with good parenting skills. In other words, not the working class (op.cit.:7).

There were tried and true solutions to the age-old problem of class indolence. In this case, McLaren gave her stamp of approval to the US programme Upward Bound, targeted at teenagers from 'low income families whose parents have not gone to tertiary study to attend university etc. [sic]'. It offered extra instruction, 'usually after school and on Saturdays', in 'mathematics, laboratory science, foreign languages, English and composition'. There was also 'instruction in study skills, academic or personal counselling, exposed [sic] to cultural events, tutorial services, information on financial assistance ... and career options'. Whether or not such measures served an educational purpose was beside the point; the primary purpose was to expose young people to the better things in life and to drill them in the necessary basics.

It is difficult to say whether the experiences of 'underachievers' within the school system was markedly different from those who were explicitly excluded. One way that schools conveyed the message of class was through the education market opened up by neoliberal reforms. Thrupp $(2007: 77,79)$ labels it an 'inconvenient truth' that New Zealand's schooling system, as a result of the reforms, accrued 'persistent advantage to the middle class'. The truth was ignored, not the least because structural class inequalities in education were often overshadowed by gender and ethnicity issues in late twentieth century New Zealand. More importantly, Thrupp argues that such advantages were exercised by the New Zealand middle class 'positionally' which in turn actively reproduced and inscribed class inequalities (ibid. \& 2009). Thrupp's specific focus was on the issue of school zoning. As Thrupp demonstrates, the increasing inequality in housing, which reflected also enlarging income inequality, meant school zoning served to demarcate the rich and the poor, the well-educated and the 'at-risk' or underachievers. Auckland Grammar was singled out by Thrupp as an example of a high-decile school which guarded its selectivity jealousy, among other things by conducting dawn raids on suspect enrolment 'cheats'. 78 'The Labour Government's decision to cling doggedly to educational egalitarianism' said Grammar's principal John Morris, 'and to the globally discredited belief that all differentiation is bad and that it is better for everyone to suffer mediocrity than for some to do better than others is

\footnotetext{
${ }^{78}$ The zoning policy meant schools were obliged to accept students living within their zones, which as Thrupp points out were determined by schools themselves.
} 
anathema to us ... The essence of effective education is surely continuous improvement rather than equalisation' (North \& South Aug 2000). Morris could, in a way that his postwar predecessor could not, trust to the 1990s orthodoxy that, whatever the Labour government might think, egalitarianism was discredited. ${ }^{79}$

\subsection{Conclusion}

This chapter contends that changes in education between 1990 and 2005 were not about the demise of the schools' role as institutions of social control, but the return of competitive meritocracy, updated in terms of the new market economy, as the core philosophy of education. It is this reorientation that underlined schools' changing focus and approach of discipline, and their responses to class, gender and ethnic inequalities in education.

The neoliberal discourse of education did not talk much about what young people should be educated for; the market society was the beginning and the end. Education, in this new political context, was no longer defined in relation to substantive notions of citizenship. Instead it was talked about increasingly as a commodity, the value and meaning of which was to be dictated by market demands, and thus not open to public debate. At the same time the neoliberal discourse of education was capable of exerting greater pressure, both by feeding off pervasive anxieties within a highly competitive society, and by naturalising the logic of meritocracy as a necessity for skilful living. This individualising frame sidestepped structural inequalities in class, gender and ethnic terms, and foreclosed the articulation of alternative visions of society through debates about education.

The neoliberal regime did not regard schooling as simple means of social control. Rather it sought to remake schooling in such a way that allows freer and more effective circulation of market forces. It also left young people who wished to escape its structural inequalities with no choice but to learn its meritocratic lessons. In such ways, discipline no longer needed the birch, but it was far more intensive when carried by the double helix of meritocracy and market forces, and less forgiving towards those deemed to have failed not just society but themselves.

\footnotetext{
${ }^{79}$ Similar words were uttered forty years-odd ago about the same Auckland school (cf. 4.1.3). It was an officially egalitarian society then; it was not in 2000.
} 
206 


\section{Chapter 8 Youth and Society 1990-2005}

By the 1990s, the freedom to rebel in style, and through consumption, no longer faced serious challenges from conservative forces in society. As young people's social life became increasingly fragmented and diversified, there were certainly more options, which at the same time seemed to defy efforts to maintain control. But changes, as this chapter will show, could not be reduced to a necessary trend of 'liberalisation'. In 8.1, I trace how the focus of social control in 1990s and early 2000s shifted away from matters of leisure and sexuality, as reflected by changing discourses around hip hop and sex education, but tightened around youth crime. Both shifts, however, highlighted the ideological imperative of individual responsibility consistently. Furthermore, as 8.2 will discuss, while the changing discourses around cultural consumption and sexual pleasures did not, in themselves, produce class, gender, and ethnic divisions, they nonetheless helped to mask structural inequalities and reinforced the individualising logic already at work in the wider social context. Discourses about youth crime, by contrast, actively produced a moralising notion of individual responsibility that served to entrench further class, gender and ethnic inequalities.

\section{Part 1}

\subsubsection{Hip Hop}

Hip hop, hailed by Time magazine as the 'most important youth culture on the planet', was the 1990s successor to rock ' $n$ ' roll in New Zealand. ${ }^{80}$ Adult society to be sure tolerated rather than embraced hip hop. But it was remarkable that, while NZ Herald (14 Dec 2002) claimed it 'makes for moral panic', hip hop did not in fact produce such a reaction. Its often deliberate amplification of sex, addiction and violence baited adult society, and yet little came of it, not even a commission of inquiry.

\footnotetext{
${ }^{80}$ Time Sept 22 2000. By 2004, it made up 70\% of songs on the pop charts, and one album sold as much as 45,000 copies (NZ Herald Jun 11 2004; also Shute 2004:126).
} 
It would be a mistake certainly to confuse hip hop with its spoken tropes. It was no more wedded to gratuitous violence, or radical politics, than rock 'n' roll was to sex and revolution. Likewise, its affronts to adult sensibility were often the most expedient way to mark out the authenticity of a new generation, rather than say a conscious political project to reform society. A more 'tolerant' adult society, conversely, provided too easy targets. And it was harder in a field already plundered by generations before it, to find new ways of 'keeping it real'. Moreover, this relentless pursuit of authenticity now dovetailed with the ideological imperative of selfimprovement/self-making in other spheres of life. It could not but reinforce the individualistic logic of neoliberalism, even in its attempt to assert a different kind of authenticity. This paradox was best illustrated in the contradictory and often ambiguous deployment of hip hop's core symbol: 'the hood' (the neighbourhood). The 'ineluctable' centrality of 'the hood' in hip hop needed no elaboration (Forman 2014:300; also Forman 2002). 'The hood' hypostatized an indelible, if not immanent, sense of collective identity rooted not in the larger abstraction of class or community, but in the immediate reality of a place. As a spatial trope, it was the exact opposite of the suburbia that postwar teenagers were eager to break out of. And unlike young love and teenage angst which romanticized a universal sensibility, the hood was meant to denote a grittier existence. This emphasis on concrete and specific 'realness', paradoxically, was what allowed hip hop to invest new 'hoods', for example South Auckland, with a sense of belonging analogous to the original 'hood' of Bronx (Sigler \& Balaji 2013:337; Zemke-White 2004).

Knowing what was real in the hood was one thing; 'keeping it real' out there in the alienating world, and in spite of its hostile forces, was another. Hip hop artists were not oblivious to the particular challenges it posed. Some captured the sense of paradox rather elegantly. Hip hop was 'about community being powerful within a powerless world', said one 'hip hop writer and aficionado'. Another remarked 'the most important thing is people without much doing lots' (NZ Herald 18 Dec 2003). This curious disjunction between 'empowerment' within and dispossession without revealed, and at the same time, validated, the contradiction between the authenticity of the hood, and the imperative of self-made success. If the scholarship boy was always at the friction point between two cultures, the hip hop artist was free to explore the world of the other because 'the hood' could never be taken out of him or her. Loyalty to the hood was fiercely proclaimed, and literally 'performed', and yet there was a tacit recognition that 'representing the hood' was only possible from the outside. 'If it wasn't for music I'd probably 
be still in the gang life' admitted one local 'gangsta rapper' signed by major record label BMI (Dominion Post 22 Jul 2005). If he hadn't picked up a microphone, reflected Scribe, he would probably be 'either in jail or selling drugs or just being a bum and getting wasted all the time' (Dominion Post 14 Nov 2003). 'The hood' was all the more real because there seemed to be few ways of escaping this destiny.

The irony was that in this uncompromising negativity hip hop reproduced, through the magic power of music and representation, the mirror image of what it must take to make it in the outside world. Self-identity was the only capital available. Success had to come from making the right choice, having the right skills, and the matching entrepreneurial spirit. In his song 'Dreaming', Scribe told of his struggle to 'be everything I can be', in a groove in which many self-made men and women would no doubt find resonance. 'I didn't care about pay/I sacrificed late nights and going out with my friends/Just to stay home alone with my pad and my pen/Had my eyes on my prize, my mind on my goal/As I carved these rhymes out with my heart and my soul'. Young people who aspired to 'making it' in the 'creative industry' related easily to this in their workaday reality of low-paid menial day jobs. And this must be read in the broader picture of a talent-led economy with its offer of 'a deeply individualised dream of affluence based on sheer effort and without the resources of welfare' (McRobbie 2002:104). This was where many young people were now herded by the New Zealand state (Scott 2013; Shuker 2008). Yet this precarious space was, for many, the only space left where they could still dream of a future, even if more often than not their dreams were to be broken.

With so much at stake, it was not surprising that hip hop became an extremely competitive site. There were always new and better ways of representing and identity-making and being more real. Nor was it surprising that hip hop placed a high premium on 'battling' as both a style and practice. The 'whole aspect' of battle, as one practitioner explained, was about 'being the best, eliminating the opposition'; 'you're taking out your opponent and ... lyrically destroying your opponent' (Evening Post 11 Apr 2002). This aggressive swagger was not meant to be taken seriously. It was achieved not through 'real' violence but through the individual command of words, rhyme and wit, which were deeply personal and creative, and by their nature, offered no guarantee of permanent superiority. And this meant a constant demand for ever more skilled and individualised performances. Moreover, it required individuals to draw heavily on their 
emotional capital. 'You've got to latch on to anything you see ... They might have a big nose, a high voice, wack clothes or they might remind you of a rapper who sucks. You can't hold back. ... If you can't handle being ridiculed, don't battle', advised an organiser (NZ Herald 28 Mar 2003).

Given this context, it was unsurprising that violent images and sexual bragging, as well as misogynous and homophobic slurs, were routinely used in 'battling' to 'diss' one's opponents (Shute 2004:1). Hip hop artists and followers were certainly implicated in broader issues of racism, sexism and other forms of oppression. But the discursive deployment of violence was also itself important. It could be seen, as Couldry (2008:3) says of reality TV, as 'a secret theatre of neoliberalism', where the social reality of violence and inequality was 'translated ... into ritual that enacts as "play" an acceptable version of the values and compulsions' of the social order. Hip hop might have once invoked those forms of 'unacceptable' violence, say against the police, as 'a cri de coeur from the disadvantaged asking for the redress of a socio-economic injustice' (Evening Post May 30 1997). ${ }^{81}$ This history though was not what its stars remembered now: 'if you really know about the history [of hip hop/battling] it's the thing young men would do so they wouldn't go and shoot each other'. To 'battle' was to 'to get that aggressive, negative energy out, allowing you to go up against someone and both of you would be physically okay at the end', said $\mathrm{Che} \mathrm{Fu}$, a key figure of New Zealand hip hop. It was cultivating a competitive ethos that was hardly anti-establishment, or in Che Fu's own words, it was just like the Renaissance, 'when Michelangelo and all those other cats were trying to outdo each other' (NZ Herald Sep 10 2005). Hip hop in this way became similar to other acceptable outlets of (masculine) violence - boxing, hunting, boot camps - frequently suggested as 'solutions' to youth problems, domesticated within and indeed useful for a competitive order.

\subsubsection{Sex and Sexuality}

Similarly, the overt 'liberalisation' of sex and sexuality obscured the complexities of the changes. Sexual freedom might be seemingly impossible to repress, but it raised new contradictions as well as possibilities of more effective and insidious means of discipline. A case

\footnotetext{
${ }^{81}$ The reference was to Ice-T's 'Cop Killer'. The New Zealand police attempted unsuccessfully to pressure the censor to ban it in the 1990s. The comments were made by Bill Hastings, later to become chief censor.
} 
in point was pornography. The perennial anxiety about pornography, echoing the wider 'sexualisation' of youth debate ${ }^{82}$, suggested a trade-off between adult freedom on the one hand, and youthful 'innocence' on the other. At the same time greater 'liberalisation', whatever adults thought of its consequences, appeared almost a foregone conclusion, not least because of the apparent technological impossibility of regulating cyber-space, not to mention powerful forces of commercialisation. It was an open secret (though still relatively under-researched), for example, that many young men took their cues on sex from mainstream pornography (Allen 2004:17-18; 2005:395; also 2006). The debate about youth and pornography was implicitly framed around young people's access to what adults considered acceptable, if not desirable, themselves, rather than the content or the context. What lay beyond the age barrier was valorized as the secret. But what young people found, when they vaulted over-elaborated barriers erected by adults - in the form of ever more sophisticated surveillance software - was really what adults did and adults wanted, and no less importantly what sold to adult consumers. Pornography, because it appeared as 'transgressive' of the age boundary, simply served to entrench adult norms. The debate might be stretched as far as the recognition of sexual pleasure for young people themselves in their furtive demand for pornography. But it still left no room to ask questions, for instance, about the underlying ethics of sexual relationships that might allow an explicit discourse about sexual pleasure appropriate for both adults and young people.

This subtle change of subject, from sex to age, also implied a changed objective of adult control, and this is reflected clearly, as I will show below, in the discursive construction of sex education. Here, the problem was no longer with sex and sexuality as such, but rather the management of risks associated with youth. And this provided, in turn, a necessary link that connected educational discourses about sex and young people with the larger discursive regime of a neoliberal 'risk society'.

One characteristic of these discourses was that they were often hopelessly dull. One awardwinning sex education publication, still widely used, advised teachers to provide clear descriptions of sexual intercourse in the following terms:

When a man and a woman have strong feelings for each other they may want to show their feelings by being close. They may feel like hugging, cuddling, touching and kissing.

${ }^{82}$ For a brief review of the debate see Lumby, Catharine \& Albury, Kath (2010) 
They may feel like getting their bodies as close as possible. This may mean taking off their clothes. As people take part in close body touching, they may choose for the man's erect penis to go into the woman's moist vagina. This is called sexual intercourse. It is one way of being able to express strong sexual feelings (FPA 1994:34).

It also suggested it could be 'very helpful to use anatomy pictures'. Young men and women might as well picture themselves as wildlife through the impassive gaze of documentary makers. This dryness was often characteristic, however, of a liberal discourse of sexual pleasures that continued to define itself against religious and moral discourses (Rasmussen 2010; 2012). This false dichotomy was also of little help in understanding what contemporary debates over sex education were actually about.

Contemporary debates, for example, over 'abstinence only' or 'safer sex' certainly boiled down to ideological and moral differences. But they also spoke to the same discourse of risk management; what abstinence-only offered was a categorical certainty that eliminated all risks associated with sex. Conversely this overarching risk discourse allowed liberal discourses to appropriate some conservative tropes. A 'sex crisis', for example, need not necessarily imply a moral collapse, and the appeal to 'crisis' could be made by the conventionally liberal Family Planning Association as well as conservative moral entrepreneurs (Dominion Post 25 Nov 2000). A crisis here was justification enough for the new, rational, liberal approach that workedconsider the contemporary policy mantra of 'what works' - as opposed to the old, moral, and conservative prohibition which did not work. In this case, compulsory sex(uality) education was introduced soon afterwards.

This pragmatic frame in turn limited how far sex(uality) education could go beyond teaching the same facts about heterosexual reproduction (cf. Diorio \& Elliot 2005:597; Jackson \& Wetherall 2010:49). This was the case despite official endorsement of the notion of 'sexuality education' which was differentiated from the old 'sex education' precisely because it was meant to be 'holistic', that is, taking into account 'social, mental and emotional, and spiritual' dimensions of 'wellbeing' and 'hauora [well-being]' (Ministry of Education 1999:8). The lofty objective 
translated in practice to a dogged insistence on 'knowledge', 'skills' and 'understanding ${ }^{83}$, which did not in fact leave much room for social and political conceptualisation of sexuality issues that could not be phrased in these instrumental terms. It was however compatible with an emerging neoliberal discourse which saw sex as work that required constant up-skilling (cf Harvey \& Gill 2011b:56).

In one aspect, however, contemporary sexuality education discourse did go considerably further, and that is, in the emphasis on self-management of emotions. The fundamental idea was that 'manning oneself against the many risks to one's sexual health requires cultivating the emotional self' (Moore 2012:35). This was clearly not about sex education, as Moore points out, because it reflected the broader imperative of the 'risk society', which revolved around making choices and taking responsibility for oneself. This deeply-embedded neoliberal logic was reflected in New Zealand discourses on sex education, in spite their often liberal and socially conscious orientations. A sexuality education module for 10 to 12 year olds, for example, framed its overarching objective as being to 'enhance each student's self-image, build up their sense of selfworth, and help them to manage the changes as they occur (Learning Media/Ministry of Education 2002:1). Another emphasized the importance of self-awareness and being 'in control' (FPA 2000 n.p.; also FPA 1997). After the usual warning that love was more than 'just sex', it argued that young people must 'be honest with themselves and each other about what it is that they really want' (FPA 2000:10; 12-14; 16). This served to orientate discussion towards an essential truth about the self, theoretically waiting to be discovered, rather than a complex and ever-changing social context which shaped what one 'really' wants. The focus on the self naturally led to the imperative of choice (the pamphlet was titled Your Choice). The choice of whether to have sex, and how to have sex, the pamphlet advised young people in capital letters, 'IS ALWAYS YOUR DECISION. No one else should make it for you ... YOU ALWAYS HAVE THE RIGHT TO CHOOSE' (FPA 2000:7). The role of sex education was thus reduced to providing information which would help young people make the kinds of relatively straightforward choices that rational individuals were supposed to be making. The whole matter was really 'a battle within yourself' (ibid.).

\footnotetext{
${ }^{83}$ Very often these materials do include some references to the social dimension of gender, in critiques of caricaturised gender stereotypes, for example. One exception is Tasker \& Aldrige (2000) of Christchurch College of Education which provided an extensive resource on social and ethical issues for teachers of Year $12 \& 13$ pupils.
} 
It was plausible to argue that this focus on individuals and their choices nonetheless allowed sex education to be more focused on what young people (supposedly) wanted, rather than what adult society expected, especially if young people were allowed to speak themselves. This argument would appear to be partially borne out, if one looks at those 'youth voices' which filled the side bars of Your Choice. Many of them, unsurprisingly, reinforced official emphases on safe sex. But others broke through. One young person for example offered a sound-bite on ' $g o o d$ sex ... when everything flows, and all of me is there, like I am not out of it or anything'. And to provide contrast, a bad experience was quoted in capital letters:

He was only on top of me for two minutes, I couldn't even feel it, then he pulled out and that was it. So I'm asking them "So what did you do it for" and it's like 'I don't know' (FPA 2000:17-18).

The point was that while these youthful discourses might have rejected adult emphases on sexual safety, they did not in fact go much beyond the conventional adult view that sexual pleasure was a private, and therefore free, affair, there for the taking if one wanted it and knew how to get it. The official discourse, however much it affirmed sex as a valid choice, said nothing about the possibility that sexual pleasure itself might already been structured by social and cultural meanings: the fear about early withdrawal might have as much to do with sexual pleasure as it had to do with a particularly narrow construct of masculine prowess.

Far from being emancipatory, a discourse about self and choice had a critical impotence. It might fit a conservative attitude just as well as, if no better than, a liberal one. This could be demonstrated, for instance, with Sex with Attitude, a widely circulated pamphlet produced with a controversial $\$ 94000$ funding from the National Government in 1996 (Sunday Star Times 6 Oct 1996). Sex with Attitude made no secret about its 'traditional values', especially on issues such as abortion, celibacy and marriage. But for the most part, its brand of sexual conservatism was couched in a positive and individualistic language, much like its liberal counterparts.

In fact, Sex with Attitude could almost be accused of laying on too thick its upbeat message about sex, illustrated, among other things, by its cover image of a confident young woman practicing martial arts moves. 'Sex is great', concluded the pamphlet; 'a powerful source that can enhance life, build character, add to romance, and be a wonder sauce to an already good relationship'.

\section{4}


Equally significantly, 'bad' sex was defined in the terms of pleasure, rather than morality, for it 'reduces the chance of ultimately having a fulfilling sex life' (Cowan 2005:30).

This may be a replay on the same theme of 'delayed gratification'. But the message was delivered in the main through a self-sufficient felicitous calculus, rather than old-fashioned catechism. 'The important thing', Sex with Attitude advised young people on premarital sex was 'not to wreck the million dollar future dream, with a \$2.95 cheap thrill now' (Cowan 2005:6). And 'guys', the pamphlet pointed out specifically, 'you may be liable to pay child support for the next 16 years'. What made premarital sex undesirable was then not necessarily that it was morally wrong, but it was evidently unprofitable. And for the author, abstinence was not about repressing one's sexual desires. Rather it was 'like choosing a designer label'. It led to 'better sex' because it 'lasts longer and is far safer'. 'Designer sex', as the author put it, promised a far superior commodity than 'Bargain Basement [sic] sex' (Cowan 2005:17).

Young people thus ought to behave like any rational consumer would; they should, in a phrase, buy quality. 'When you want Designer anything, what do you do', asks the pamphlet. 'You find out what you want, you save for it. You wait for it. You dream what it will be like to have it. That's what Designer sex is' (ibid. capital original). What choices young people actually had, or how social context shaped these choices, were not discussed in Sex with Attitude. It was still a 'battle within yourself', to borrow a phrase quoted earlier, entire of itself. Or to quote from Sex with Attitude: 'You are the director, script writer and star of your own show... Take control of your life, and write a script for yourself' (ibid.). Here the measure was not conformity to external morality, but the performance of self-regulation.

We may now rethink the difference or rather similarity between liberal and conservative discourses. They both appealed to a notion of a true self, though they disagreed about what that might be. They both deployed the useful device of rationality, but differed as to whether scientific rationality (in a narrower sense of biological and medical knowledge about the true risks of sex) or market rationality was better suited to a discourse about sex. These in themselves generated new and interesting paradoxes; for example, regarding non-heterosexual identities where the liberal narrative resorted to predetermined sexual identity and conservative commentators claimed merely having same sex crushes was no impediment to changing one's mind latter and making the 'right' choice (FPA 1994; 1995; Cowan 2005:28). Such differences, 
however, could be settled on their own terms. Both eschewed rather than confronted their ideological differences regarding sex which were effaced by the claims they were making. Both, consciously or not, served to naturalise the broader discourses of choice and self-responsibility.

\subsubsection{Delinquency and Crime}

Resurgent calls for tougher punishment for youth crime, culminating in the aftermath of the Kurariki case ${ }^{84}$, appeared to be at odds with an apparently more liberal social attitude towards youth in their music choices and sexual decisions. As this chapter will show, however, these seemingly divergent movements were underpinned by the same individualising logic of neoliberalism. Using the Kurariki case as a key example, this section seeks to re-examine the socalled the so-called 'punitive turn' in youth justice, which has already been rightly linked by other scholars to the neoliberal strategy of offloading collective responsibility onto young people individually. ${ }^{85}$ Here my argument is that more attention should be paid to the prior 'agentification' process, where the departure from the traditional repressive mode of social control is most visible. This locates, moreover, a dark side of agency which is commonly constructed as inherently positive in youth studies (against structure cf. 1.1.1).

The lack of agency was partly why the postwar idea of juvenile delinquency was ultimately flawed as a mechanism of control, as I have discussed before. Talking about young people as immoral, or psychologically abnormal and socially maladjusted, was certainly one way to justify external compulsion, but it also directed one's gaze to external influences and inadequacies. By contrast, to see young criminals as fundamentally normal, rational, individuals meant they could take the blame themselves. Furthermore, there could be fewer excuses about their behaviour which was no longer seen to be determined by external factors. The whole point was that these young people needed no saving or correcting. The law could do without condescending niceties, and get on with the business of punishment.

\footnotetext{
${ }^{84}$ Bailey Junior Kurariki was convicted of manslaughter in 2002. At the time of the crime he was 12 years old and his young age provided a catalyst for widespread attention to the issue of youth offending.

${ }^{85}$ See Muncie (2008) for general commentaries on the 'punitive turn' and Lynch $(2012 ; 2013)$ on the New Zealand case and its apparent lag with global trend regarding youth justice. The Kurariki case has been examined using discourse analysis similar to mine by Beals (2006) and Wright (2010), with focuses on construction of youth deviance and moral panic respectively.
} 
The portrayal of Kurariki demonstrated this crucial discursive intervention. His young age, and by extension the apparent incongruity between childish innocence and cold killing, was at the very centre of public concern. It was not a vulnerable minor seen by newspaper readers or television viewers but almost a hardened criminal, who showed a perverse power of control over others. It was on this point the prosecution made its case, and the media seized upon it. Thus the New Zealand Herald, writing about his previous offending, described in graphic detail the way 'the small boy with a cherubic face lingered in a Papakura alley, waiting for his victim to pass on the way to school'. Kurariki 'stalked his quarry', the journalist added 'pounced, punching him repeatedly in the head and left him cut and bloodied on the ground'. He became 'feared by children across South Auckland', no small feat for one young boy in an under-15 population in the tens of thousands (26 Aug 2002).

It was the 'system', rather than the child, which was 'powerless', the article implied, referring to the inability of police to lay charges for his previous offences. The powerlessness was amplified, in another article, which pointedly challenged the age of criminal liability. Celia Lashlie, a parenting expert discussed in previous chapters, was quoted on the matter. 'We', she complained, 'were caught in this view that children aren't capable of this [murder] but we've got an extraordinary level of sophistication among some of these youngsters that belies their age' (Press 29 Nov 2003). She recommended the age of criminal liability be lowered to $11 .{ }^{86}$ The fear of the system being manipulated by a few youthful criminal masterminds was enough to invert the presumption of childhood innocence.

Moreover, other possible explanations which might have mitigated this implied responsibility were vigorously contested. Kurariki's intelligence, for example, was the only point dwelt upon in Justice Fisher's judgment in the case. Fisher was keen to scotch one psychologist's suggestion that Kurariki was deficient in his IQ. Such a label, he insisted, would be 'unfair' even to the defendant. Reduced verbal skills and comprehension were 'simply one aspect' of IQ, which 'may well have something to do' with his lack of schooling. Instead he referred to the defendant's headmaster, among others, having testified that the boy was 'street-smart'. A more likely explanation was to be found, in Fisher's opinion in his lack of 'self-esteem' and his 'need

\footnotetext{
${ }^{86}$ Children aged between 11 and 13 could be charged with manslaughter and murder under the New Zealand system at the time of the article, as an exception to the general age limitation. The article was in fact suggesting an expansion of the scope, as the practical effect would be to capture lesser offences committed by others.
} 
to impress others' ${ }^{87}$ The suggestion that poor educational achievement might be made up by 'street smartness' or self-esteem was certainly not meant to be generalised; all the more significant that it was asserted as rigorous legal reasoning, which provided in turn a convenient foundation for assigning individual responsibility. And the point was well-understood by journalists, vying to hold the criminal to account. Reports on Fisher's judgment across several major dailies all drew attention to these comments on IQ, rather than to the other 107 paragraphs (Press 17 Sep 2002; NZ Herald 17 Sep 2002; Dominion Post 17 Sep 2002). This stood in sharp contrast to the older attitude which fell sometimes for the easy explanation of psychological abnormality, as in the postwar era, or the even older presumption about children and young people's irrationality, which undermined their responsibility as free agents.

Other social factors were received with varying degrees of suspicion by the public. Poverty was rarely mentioned. TV violence, with specific reference to hip hop music videos, was blamed by at least one well-known criminologist, Greg Newbold (Press 22 Aug 2002). The state, or more immediately the CYFS bureaucracy, was blamed more often. And yet, when Kurariki's mother sought to do the same, she was sternly told off. As one editorial sneered, the suggestion was 'not surprising but wrong' since after all 'the state cannot and should not be a parent'. Rather the responsibility must be placed squarely on the underclass themselves (Dominion Post 18 Sep 2002; cf. 8.2.1 below). Individual responsibility was the bottom line that needed to be secured, and not even the favourite sport of bureaucracy bashing was allowed to distract from this point. Framing the question as the inability to make responsible decisions led to predictable solutions. One article in Investigate, a leading publication on the moral right, spoke approvingly of similar ideas in its only feature length article on the Kurariki case. The recipe for youth offending, according to the article, was not just punishment but more schooling, though schooling in this context meant something entirely different from meritocratic education: 'what we really need to do is [to] teach law and living - the consequences of law and living - even before they teach them math or English (Sep 2002.:52). This appeared exactly what was prescribed for Kurariki in a tailored rehabilitation programme which aimed to teach him 'social and communication skills, problem solving, and victim empathy' (Press 30 August 2002). It was no different from those 'life skills' that parents and schools were supposed to be teaching to 'at risk' youth. The

\footnotetext{
${ }^{87}$ R v Rawiri HC Auckland T0140174 at 108-12
} 
'problems' and the 'solutions' collapsed into a single imperative of self-improvement, while social inequalities remained invisible.

This emphasis on individual choices and responsibility should be considered, moreover, within the dominant risk discourse of youth crime. Much has been said about the latter (France 2007; Goldson \& Muncie 2006; Gray 2009; Turnbull \& Spence 2011; for New Zealand, Beals 2006:101-19). A key point in this now extensive body of literature is that the risk frame has the potential to 'pathologise' young people. Terms such as essentialism and positivism tend to be used liberally in such accounts. Some have argued that this risk discourse denies the agency of young people in their negotiation of 'risk factors', positing them instead as passive subjects of intervention (Mahony 2009). In the vulgarized rendition and with headlines such as 'Born Bad', certainly, this did often degenerate into the old nature/nurture debate (Sunday Star Times 1 September 2002; Listener 21 May 2005). But what sustained more sophisticated arguments in academic and policy discourse was not this sterile biological determinism, but rather an attempt to make risk discourse operate through the deployment of agency, rather than against it.

Perhaps the most representative example could be found in a report from the Otago Longitudinal Study, which came on the heels of the Kurariki case. This groundbreaking and much-cited article identified a link between a 'low-MAOA genotype' and criminal offending (Caspi et al. 2002), which came to be known somewhat misleadingly in popular discourse as the 'Warrior gene' hypothesis. Beals (2006:103) is scathing about the 'bogus objectivity' implied by 'rational and scientific rhetoric ... looking at what industrial society once referred to as danger'. Elsewhere her assessment is more qualified, and perhaps closer to the mark. Beals notes that the authors emphasized in fact not the predisposition to crime, but genetic 'resilience' to influences likely to cause crime (2006:52). It might be more appropriate in fact, though no closer to the truth, to accuse the authors of having essentialised a part of agency - the argument still left room for individuals with low genetic resilience to build their resistance in other ways - against essentialised risks. The real problem is clearer if we look at the earlier work of one of the coauthors of Caspi et al. (2002). For Moffitt (1993) who arrived at the same point through the route of neuropsychology, rather than genetics, it was 'immaterial whether the difference arises from shared genes or shared homes'. Yet, such a difference was politically important. Genetic disadvantage might serve to underline the legitimacy of additional support, whereas the 
dysfunctional family invited external discipline. The one-sided scrutiny of agency and genes risked overlooking the politics of the relationships between risk factors and social structures.

The problem was worse outside academia where agency risked becoming a feel-good label, while 'risk factors' simply solidified into indiscriminate 'facts' that concealed social structures. 'Risk factors', in policy discourses were far less discriminating. McLaren (2000:36-7) identified twelve, which ranged from 'being low in popularity' to 'living in a neighbourhood that was poor, disorganized, with high rates of crime and violence'. This was replicated, for example, in the Government's Youth Offending Strategy, when it identified the family as a key site of intervention. The 'strongest predictors of youth offending', it argued, were to be found in 'inadequate or inappropriate parenting, child abuse and neglect, early childhood cognitive or behaviour problems, and family poverty’ (Ministerial Taskforce on Youth Offending 2002:26). 'It is vital that these key risk factors are addressed early to prevent them from accumulating and interacting cumulatively, and to inhibit a child's progression towards offending and other poor outcomes' (ibid.). This conceptualisation of criminal risks was naturally amenable to the paradigm of 'early' intervention, which focused precisely upon those basic 'problem solving' or life skills seemingly independent of social context. It also concealed the trade-off between the positive 'development' of these capacities and the negative discipline in other parts of the lived experiences of young people and their families. The improvement of one's numeracy and literacy skills undoubtedly improved one's chances of making the right choice. It said nothing, however, about the constraints faced, and the need to overcome them, in making such choices, and the relative value of that improved life-chance compared to the diminishing return on the choices they could afford to make. The calculation of these 'at-risk' youth, given the declining fortune of their families and wider community in which they would become adults, was hardly likely to be the same as the official 'balance-sheet' approach that refused to acknowledge structural constraints in the first place. This was not simply the state offloading responsibility onto young people and their families. Rather it was consciously preparing young people to think that they were exercising agency or were empowered when they actively accepted more responsibility. 


\section{Part 2}

\subsubsection{Class}

The idea of class, in the form of certain structured relationships of production, might seem a little out of place in an individualistic conceptualization of youth culture and crime. It was a chickenand-egg question, however, whether the disappearance of traditional class or communal cultures had led to the 'democratisation' of lifestyle preferences, substance uses, and sexual freedom, or vice versa. Although it is less often suggested, it may also be argued that the disappearance of class also implied a certain 'democratisation' of crime, which has now shed even the last scrap of association with inequality. The point here, however, is not to suggest a causal relationship, but rather that the process of 'democratisation' had produced as a necessary and crucial side effect our inability to 'see' class, let alone analyze how it worked or had ceased to work.

Hip hop music might have exemplified a certain upward 'democratisation' of tastes, if one were to measure it by the commercial success of mainstream rap. Yet on the other hand, hip hop remained attached to a certain class aesthetics, owing a mythical allegiance to the original experience of socio-economic deprivation by its pioneers. And this link endured, even though classed experience made up only a very small proportion of music content, as one chronicle of New Zealand hip hop music found (Shute 2004:142).

This is not to deny that one could still find potent tracks, for example, in the unassuming lines of Mareko's chart-topping 'Cityline': 'I reach in my pocket and gather up all my coins/And bought a chicken pie/But my ass couldn't afford the sauce'. Such gems have to be unearthed, however, from 90 odd lines littered with coarse epithets aimed at a female bus driver ('that fat brontosaurus') as the singer narrates his journey stop-by-stop from South Auckland to the slicker Newmarket. Mainstream critics lavished praise on the number, found 'something evocative about life', and left it at that ambiguous place (NZ Herald 14 Aug 2003; Press 16 August 2003; Sunday Star Times 20 Jul 2003). It was by no means clear, even between the explicit lines, that New Zealand hip hop music did live up to Zemke-White (2005)'s glittering generalization that a unique attribute of the genre was that its practitioners 'decry the exigencies of their own poorer [sic] community'. The problem was that classed experience was conceptualized as no more and no less than a part of what was real about 'the hood' so that retelling of every-day life 'like it is' 
must inevitably throw up titbits of classed imagery. And like 'the hood', it became a necessary backdrop for the performance of individual authenticity. The relentless and sometimes valorized 'realism' in turn overshadowed and undermined the message of class and communal belonging. 'Truths' about urban deprivation hardened into 'facts' of life, among which misogyny as much as poverty carried weight as a badge of individual authenticity.

The symbolic meaning of class, like that of 'the hood', was thus built upon shaky ground and frequently the feelings were ambivalent, if not outright contradictory. Interviewed about his experience growing up with poverty, an acclaimed rapper showed a keen awareness of how 'fortunate' he was to move to Christchurch on a scholarship 'before I got locked into the South Auckland mentality of not expecting much. If I hadn't got that ... I know I probably would be at

a freezing works or working at the Warehouse or whatever - that's just reality because there's no opportunities [sic] there'. He insisted nonetheless that he had 'got the best of both worlds' (Shute 2004:170). The pejorative label of false consciousness was clearly inadequate here. Unlike the deceived suburban workers, the cultural vanguards of South Auckland did not in fact believe in the myth of universal social mobility. The classed reality was not only accepted but embraced as a fact of life, and even in a vague sense as a part of one's intrinsic identity. And yet this led not to a desire to change the reality, but rather a belief that one could only rise above it by exceptional means, in this case a scholarship, or in more general terms, high aspiration and hard work which were open only to a few. This was an interesting subversion of class loyalty, and a very effective one.

Social class entered into conversations about young people's sexuality too, though only in a roundabout way, as this or that 'factor' and 'consequence' to the larger question of sexual rights and responsibilities. Yet sexual decision-making was also an integral part of everyday experiences shaped by social and economic pressures which also shaped the very person making the decisions. Such pressures did not cease to be overwhelming when it came to sex. . The narrow focus on questions such as safe sex and unwanted pregnancy made it immensely difficult to take in such experiences as a whole. And as a consequence the markers of classed differences were too easily buried. But an emerging body of international research has indicated that 
contemporary young working class women ${ }^{88}$ continued to view their body and their sexuality in profoundly different ways from their middle-class counterparts. As Kehily (2012:265 italics original) notes, for example, sexuality has 'always been a calling card for them [working class women] en route to somewhere else' other than their limited life circumstances. It provided a source of personal capital in place of, say, the educational qualifications which middle-class girls could rely upon. Such capital in turn paved the way to 'alternative careers' as intimate partners and mothers within their families and local communities. Decisions along these paths were seldom articulated, but they were carefully and consciously worked out by young working class women themselves (Thomson et al. 2003; Walkerdine et al. 2001:193-6).

Studies like Kehily's and others cited above were still in short supply, particularly in New Zealand. It was virtually impossible to uncover from popular and policy discourses the intricate intersections between class and sexuality. If class was mentioned at all, it was only so that young people could be helped to circumvent the classed barriers to the same goal of self-discovery and freedom. Paradoxically, however, this 'classless' space of sexuality sharpened social divisions in other ways. Some young people, especially those of the working class, might find themselves in a double bind. Few were likely to live up to the respectable ideals of conservative morality, particularly when the state no longer compensated them for their conformity (McDowell 2003:30). Few, moreover, had much opportunity to exercise their 'free' choices about economic, political and social matters in their day-to-day life. And, when it came to sex, it was up to them, and them alone, supposedly to make the final decision.. Indeed, the presumptive liberation of sexuality only served to show them up as inadequate, even despicable, subjects who failed to use their sexual freedom responsibly and thus did not deserve it (Skeggs 2004:105; 2005).

The liberation of sex, like the liberation of cultural styles, 'worked' in a sense to free structural inequalities from too much attention. That sexual mores were no longer imposed, or seen to be imposed, by blunt force of moral conservatism meant they could no longer be seen as part and parcel of classed oppression from above. That particular line of reductionist reasoning might be

\footnotetext{
${ }^{88}$ Much of the empirical evidence comes from young women rather than young men. We do not know much about how and to what extent the differing socio-economic circumstances intruded upon young men's sexual lives. It is interesting, for example, that while the less-than-respectable sexist and homophobic masculinities are often associated with a 'traditional' working class culture, the supposed demise of that culture passed without much comment in public discourse, nor has consideration been given to what had replaced it (see Paap 2006 for a discussion on the US working class).
} 
mistaken, but it still arrived at the issues of class. By making agency the starting point of discourses about teenage sexuality, however, the connections between sex and class were severed. In this way, sexual (as cultural) freedom appeared to be an attainable goal in spite of deeply entrenched structural inequality. But it could only be attained by young people becoming rational choosers and thus rising above their disadvantaged positions.

Classed mechanisms worked in a different way in issues of youth crime. Social class, as one local commentator argues, is 'often neglected in accounts of youth crime and desistance' (Carpenter 2011:38). Yet less precise, though more evocative, signs of class were not hard to find. News media from time to time made clear the otherwise unspoken connections. One editorial on the Kurariki case, referred to previously, talked about the 'underclass of nonachievers, drug-takers and drunkards, people without work living in relative poverty and taking little responsibility for their own plight and that of their families'. The cure, 'putting the family back around the table', invoked the time-honoured virtue of the middle class (Dominion Post 18 Sep 2002). The same paper a few months earlier went with the headline 'the Underclass of Young Crims' (Dominion Post 2 Apr 2002). These were vintage words of contempt reserved for the strange and frightening 'other': the young 'louts', the 'thuggish children and their families', and the underclass of 'dysfunctional homes, often headed by sole parents, with little discipline'. 'Poverty' made a single appearance, and it appeared not so much a structural problem as a moral condition. Such a malaise was to be cured by 'education and work ethics' and emphatically not by a further handout of 'welfare'.

Such epithets of class warfare were unlikely to be found in more respectable circles. Scholars and policymakers had more polite categories to describe the persistent link between social class and youth crime. Class itself was seldom named. What appeared more frequently were blander variants such as 'socio-economic status' or 'disadvantages'. Such themes certainly survived in the long tradition of critical/classical criminology and sociology within university departments. But thanks to leading scientific research, for example, the internationally renowned Christchurch and Dunedin longitudinal studies, the class-crime link had a continuing public profile (e.g. Fergusson et al. 2004; Wright et al. 1999). Robust statistics and clinical precision were hard to argue with, especially when findings appear to confirm what popular opinion instinctively knew 
to exist. The fact that such research was highly influential in policy and public discourse about young people ensured that class, even though it comprised only a small portion of research, nonetheless found its way back into official statements.

Yet, although researchers were often attentive to classical political and social theories of crime and class, the gravity almost invariably shifted subtly towards 'scientific' paradigms of diagnosis and intervention. The 'science' here was not the issue, and at any rate it was often deliberately kept in perennial neutrality. The new evidence of a class-crime link 'provided no strong discrimination' between major theoretical frameworks (Fergusson et al. 2004:963). The voluminous literature, ranging from Mertonian strain theory to social learning and social control, which the authors had meticulously summarized, came to an end with a few standardized hedging lines. Notwithstanding all that, such findings 'clearly imply that effective policies to address linkages between SES [socio-economic status] and crime will require interventions that: 'a) reduce the exposure of low SES children to adverse family environments; b) intervene early to address the development of early conduct problems; and c) act to mitigate the effects of exposure to deviant peer groups’ (2004:964). The list was long. But apart from a passing reference to 'population level factors' such as unemployment, any need to tackle structural inequality itself was eschewed. The recognition of class as a risk factor, then, did not so much underline its significance as bury it under other risk factors. The potentially explosive politics of social class were thus neutralized and turned into useful fodder for 'evidence based' policy.

Other studies were similarly crafted. Another influential article from the Dunedin study, for example, left its reader in no doubt about the causal relationship between crime and social class. But this finding contrasted sharply with the authors' own policy recommendations. It might be 'efficacious', they suggested, for policies to differentiate those from different social economic backgrounds. Programmes would be 'most successful' if, in the 'lower social classes', prevention were 'to reduce the level of aggression and alienation while increasing educational and occupational aspirations'. Conversely, 'in the higher social classes, conventional values and the risks of crime' might be 'emphasized' (Wright et al. 1999:191). The 'importance' of class, which otherwise rang loudly through the article, fell silent in these closing words, which left an impression not of class relations, but differences in rank and station. Moral persuasion was good 
enough for some, so it seemed. Much stronger medicine was needed for others who could not be expected to control their pathological flaws.

The policy transcriptions of such scientific truths were often rather less scrupulous with qualifications, though the result could be more telling. 'Social economic status', or poverty, was begrudgingly conceded as a 'plausible', 'second-ranked risk factor' in one commissioned review (McLaren 2000:29-31). And as such it must be understood as part of an 'epidemic model' which explained that youth crime was a result of various other pathogens of poor parental supervision, antisocial peers, and child neglect, all of which, unlike structural inequalities, were responsive to individual 'treatments' and interventions. In such a discourse, class was not only buried; the suggestion was that it could explained away as a symptom of deeper causes in individuals themselves, or at the very least as 'caused' by their inaction and their failure to become 'resilient' in spite of their deprivation. In this light, it did not look so different from the popular caricature of the underclass.

Relational structures and experiences of class thus remained hidden by the new political logic. Yet, unlike the approach which sought to single out 'delinquents' paradoxically from an officially 'classless' society, class division was being reconstituted in ever more explicit manners through images of criminality. The 'othering' gaze of disgust and moral judgment directed at one's fellow members of society often found in its sight the criminal, an indisputable other. And in a climate where the patronising civility of welfare was stripped away, the stare fell upon the figure of the 'young offender'. This process often operated through the apparatus of 'early intervention', which was undoubtedly a dominant policy paradigm of youth offending in New Zealand. In the British case, McCarthy demonstrates how, under the overarching logic of crime prevention, knowledge of deficits in every aspect of young people and their families' lives is sought after by professionals in seeking effective points of intervention. As such knowledge grows, a moral regime takes shape, no longer simply on the basis of actual offence, but grounded in comprehensive information about how they live (2011:512-3). In turn, it makes possible differential classifications and treatments. Such moral judgments as the author shows are often formed out of everyday experiences - the 'state of their homes', their 'abilities to parent', their 'dirty appearances', and their "“lack" of willingness to deal with their own problems'. This last 
'lack' is key. And as McCarthy rightly notes, it plays a significant role in the 'continuing classification of white working classes as a distinct group in need of correction' (2011:511).

\subsubsection{Gender}

Gender politics occupied somewhat of a blind spot in hip hop culture, in contrast to its explicit alignment to certain themes of progressive politics of ethnicities (see below 8.2.3) and much less frequently of class. Indeed practices and cultures of hyper-masculinity, and the misogyny and homophobia often associated with it, remained highly visible in hip hop, particularly in the popular gangsta rap genre (Jefferies 2010). New Zealand was no exception, as local commentators and industry insiders noted (Shute 2004:164-5; Tamati 2004:41-3).

Necessary qualifications, however, had to be made, and such qualifications were in some ways more telling than the too obvious 'lack' of a progressive gender agenda within hip hop culture. Criticisms of gender inequalities could be problematic when they ignored the social class and ethnic context to which hyper-masculine behaviour partially responded (Tinsley et al. 92; 93-94). It would also certainly be counter-productive to measure hip hop as a subculture against simplistic universal standards of gender equality - or in bell hooks (1994)' words, 'bourgeois' sexism with 'no rawness, no vulgarity' - especially when gender injustice was by no means erased from the 'mainstream' society. It is true, or perhaps rather a truism, as Iskasen (2011:155) argues that disadvantaged boys and young men must by necessity seek out alternative scripts of masculinity than those adopted by the more privileged, which in her words 'is itself a metaphor of possibility'. The exaltation of the abundant and essentially progressive possibilities inherent in hip hop, however, seemed only to underline the unexplained contradiction with the actual conventional masculine script it frequently adopts. The answer may be to acknowledge that hip hop, like other subcultural forms, was not a political or ideological abstraction, but a complex social phenomenon. It was just as likely to reflect hegemonic ideas of gender as transgressive ones.

None of this, however, should exempt hip hop music from critique. On the contrary, a useful starting point is to place the gendered politics of hip hop within the broader ideological context of neoliberalism. Here what is important is not so much to locate the 'root' of hypermasculinity in a certain subculture, but to explain its persistence. There is some truth in the conventional 
wisdom that commercialization and objectification of feminine sexuality went hand in hand together. There might also be a deeper connection. Jefferies (2010:160) for example links the performance of hyper-masculinity to the idea of authenticity, aligned to the ideology of neoliberal individualism. Moreover, this pursuit of authenticity was carried out in a complex context which Jefferies' correspondents inadvertently made explicit. For one young man, the 'typical white teenage girls' who bought a CD and thought they were 'like down now' were simply fakes. In his eyes they were 'like got a Lexus from their daddy, haven't worked for a dime in their life'. And therefore they could not 'get' rap, which was 'basically a giant struggle to make it out, have, no, like thought of a struggle '. What seemed like a tangential explanation for sexist attitudes revealed class and morality rather than gender. It highlighted the absolute centrality of work as the basis of entitlement, even if (white) teenage girls could hardly be expected to be financially independent. In fact, frequently the precarious existence of many young urban men of colour was characterized precisely by a state of dependence: on their employers, on their families and communities, on the shadow economy of crime, and on the ever-shrinking welfare. They had no other resources with which to demonstrate their hard work, than what they had got, their own body and sexuality. And what better route to show off their control over their own body and sexuality than by adopting an expressive, even aggressive, stance.

\section{$* * *$}

The relationship between notions of gender and discourses about sexuality was similarly complex. A few findings might nonetheless be extrapolated from previous discussions on sexuality. The acknowledgement of young people's sexual agency and diversity in both liberal and conservative discourses of sexuality education, however limited, remained a challenge to the (adult) male-centred and hetero-normative script of sexual behaviours. At the same time, this script was reproduced and made explicit, literally, in all its dramatic details through pornographic and sexualized discourses which were predominantly heterosexual, frequently sexist, implicitly homophobic and unapologetically exploitative. It was no secret, however, that many young men found pornography far more accessible, if not appealing, than the bland 'reality' represented in sexuality education. Unlike the postwar era, gender equality was no 
longer transgressive, or 'sexy'. It was no longer what the adult society sought to repress. Pornography, on the other hand, still was.

The reactionary posturing of some young men was clearly unsettling, but it was less perplexing if the notion of gender equality was itself placed in a wider social context. Discourses around gender and sexuality did not operate on their own; they were almost always 'mediated', to borrow Harvey \& Gill (2011a:488)'s phrase, by other discourses which spoke too about the notion of equality and the place of gender in relation to other social structures. It would have been odd in fact if young men had adopted an egalitarian, caring and open ethics in their intimate relationships when they were being inculcated with public virtues of competition and assertiveness. The flatly equal code of the new sexual contract had to be squared somehow with the 'unspeakable inequities' that operated not through gender itself, but through the social and economic order (cf. Gill 2011:62-3) and one could hardly blame young people for problems adults themselves had yet to confront.

The inability of liberal discourse on sexuality to deal with these broader structural mediations meant a self-reinforcing narrowing of focus upon sex and sexual violence, in spite of its attempts to talk about sexuality and gender. This stood in a curious contrast with the postwar 'moral guardians', as we see in 5.1.2, whose reticence about the 'full sex act' nonetheless did not prevent them from exploring possibilities in changing social relationships that ushered in the act. Liberal discourse however was tethered by its own 'progressiveness' to the one area where that it could have an unambiguous view: the right (or rather choice) to say no. It offered little to young people whose sexual decisions could not be separated from their everyday lives, where their social and economic rights were constantly under threat and had to be constantly negotiated. And rather than challenging the dominant and potentially oppressive gender regime, liberal discourse, intentionally or not, placed a heavy responsibility on young people themselves to manage the damaging effects. The rise of a liberal discourse of sexuality then perhaps demonstrated not so much a changing sexual regime but, as Allen (2007:148-9) rightly argues, the very 'flexibility' and 'stability' of the hegemonic practices; young men must now 'be sensitive and real macho all at the same time'. 
The gender dimension was often implicit though easily overlooked in the construction of youth crime. There was no longer a clear demarcation between boys' and girls' crime, though the boundary-crossing by girls into the masculine territory of violence still had a certain shock value. In one editorial, the main narrative was clearly structured by the gender code:

Police have got a problem. Boys on the rampage are committing more serious crimes than they used to, and now girls are taking up criminal career paths ... There is a surprise emergence of an aspiring sisterhood, specialising in violent offences ... 'We have young women from disadvantaged backgrounds, who have been taught to be assertive,' says $\mathrm{Mr}$ Roper [police constable]. "Sadly, many of these young women don't have the maturity and life skills to work out the difference between being assertive and aggressive" (Press 25 Apr 2001).

Such skills were also what some young men lacked which, in turn, led them into violence rather than 'real' manhood. 'A picture emerges [in South Auckland] of the bad land of Los Angeles, where smart-alec, undisciplined boys posing as men ruled what is known as the "projects"' so went one reporter. 'The tragedy today, however, is not the influence of James Dean on the motorbike but of unguided missiles raging with testosterone on impressionable hangers-on' (Dominion Post 26 Oct 2005).

Official discourse was less sensational, though equally gendered in a subtle way. Government reports casually ranked 'being male' as a 'risk factor' and 'being female' as a 'protective factor' in youth crime alongside other factors such as intelligence (McLaren/MYD 2000:22; Ministerial Taskforce on Youth Offending 2002:12). Other reports talked of crime as 'largely a male issue' while echoing the popular concerns about the 'growing' problem of violent offending by young women (Barwick/MYD 2004:32).

The repeated highlighting of the gender of criminal youth can be read, to follow Beals (2006:556)'s analysis of a similar case, as one way in which criminality became associated 'naturally' with masculinity and in turn reproduced femininity as meek and inoffensive. This construction, evident in the two excerpts above, was not entirely straightforward however. On the surface, there was an obvious link between biological drives, masculine power and violent crimes. But a few carefully placed qualifiers alerted readers to the fact that the real target was not masculinity as such, but the failed, inauthentic, performance by certain 'boys posing as men' [italics added]: 
the 'unguided', 'impressionable', and 'undisciplined' misuse of masculine power. It was further specified by its 'race' and class associations; 'the bad land of Los Angeles' and the 'Projects' were overloaded symbols. Thus, the cryptically didactic notion of 'our young men' morphed effortlessly into 'smart-alec, undisciplined boys' whose exaggerated performance of masculine conventions, to paraphrase Connell (2005:111), was never going to be recognized by polite society anyway.

Similarly, one may take from the first press excerpt what many feminists have noted about recent moral panics over girls' offending, that girls are 'doubly condemned: once because violence is generally abhorred and again because such behaviour is seen as "unfeminine" (Burman \& Batchelor 2009:271; Hine \& Welford 2011:157; Dekeseredy 2010:241-54: Gelthorpe \& Worrell 2009). This was precisely the element of surprise which the journalist purported to uncover. It could be drawn out further, however. Like the second excerpt, what emerged as problematic was not the institutions of masculinity or femininity as such. The problem was quite clearly that some of the girls, as the quote emphasized, were from 'disadvantaged backgrounds'. And just like their criminal brothers, the underachieving sisters who lacked 'maturity' and 'life skills' failed to make proper use of their supposedly liberated femininity. The difference was in the subtle implications. While masculinity could not be held entirely responsible for the failed boys, liberated femininity had to answer for its failure to bring benefits.

Taking these together, one can argue that the issue here was not merely the unthinking acceptance of outdated gender presumptions. Rather, the appeal of popular discourses about girls' and boys' violent offending lay precisely in its complex engagement with a changing gender regime, in line with new expectations of self-control, entrepreneurship and authenticity. Whether or not young people's performance of gender roles conformed to these expectations was as important as, if not more than the roles they were supposed to be reproducing.

\subsubsection{Ethnicity}

The construct of ethnicity played a prominent role in the discourses around hip hop and youth crime. This was not the case, however, with discussion about young people's sexuality, which 
nonetheless merits a brief discussion. ${ }^{89}$ In practice, much of public attention to the implications of ethnicity remained framed by the notion of 'over-representation' and confined to the issues of teenage pregnancy and sexual health/safety, understood within a risk discourse.

The implication of inserting ethnicity (or more specifically 'Māori') as a risk factor into official discourse is captured by Green (2011:66-8):

In current sexual and reproductive health policy a body of discursive statements exist about Māori, yet these statements, what they represent, and the meanings they produce are not immediately apparent. Statements such as 'rangatahi Māori continue to experience significantly higher rates of STIs' and 'Māori teenage pregnancy' are more than an arrangement of words in a linguistic sequence: they are densely populated fields of meaning which produce particular representations of Māori, and importantly, of nonMāori.... In sexual and reproductive health policy in New Zealand there is hardly ever any discourse about Māori sexual and reproductive health that is for itself.

The discourse actively constructed specifically young Māori parents as the 'other' which was then made available to surveillance and intervention. Green though still has very little to say about the intersections between an indigenous model of sexual well-being, and the realities of class and gender disadvantages. Virtually nothing was written about Māori working class young men's pattern of sexual behaviours. And rather than challenging Pākehā norms as an alternative system of sexual ethics in its own right, ${ }^{90}$ authentic indigenous sexuality was presented as already fully consistent with the liberal western ideal of sexual diversity.

It was indeed no coincidence that the discursive construction of ethnic identity, especially Māori, found some of its most potent and popular expressions through channels which were in a sense literally carnivalesque. The subversive display of hip hop, which still identified with a 'brown' image in spite of its mainstream consumer profile, had a certain resonance with the protest

\footnotetext{
${ }^{89}$ While there has been some interest in the study of indigenous sexuality more recently (e.g. Aspin \& Hutchings 2007), it has not realised its potential as an alternative framework to the 'western' heteronormative regime. ${ }^{90}$ An exception is Pihema (2009) which argues that Maori society did not necessarily view 'underage' pregnancy as a problem in itself.
} 
politics of ethnic identity. One was constantly reminded of its origin in the radical black movements of the 1970s which shared many objectives and discourses with Māori.

Nonetheless, the connection was not uncontested. Some early commentators saw in this adaptation the danger of cultural imperialism and the evisceration of indigenous forms of resistance (Wilcox 1996). That caution had been long forgotten in more recent claims, for example, that some of hip hop's 'essential ideology' was its 'community base', 'educational empowerment of marginalized peoples', and its 'vigorous opposition to hegemonic racist and colonizing forces' (Zemke-White 2004:205; also Zemke-White 2005; Mitchell 2001:280-302 \& Shuker 2004:226-229, all of which were highly positive assessments). But the final word must go to Harvey (2000) who cautioned that hip hop as political critique could 'only exist alongside its opposite in a marketplace'. This opposite was the hostile hegemony of neoliberalism, which severely constrained political challenge through expressive means (Jeffs 2005 also Spence 2011 on American hip hop).

The point though is that hip hop did not need to politicize ethnicity. Rather it could sidestep the conflict. Harvey (2000) for example continued that hip hop was 'representative of ... the global post-modern'. In spite of its necessary confrontation (and compromise) with consumerism, hip hop she claimed acted 'as a critique of mainstream society', and 'a voice for dispossessed people everywhere'. It was time in other words for peaceful co-existence between resistance and hegemony, between the freedom of the creative consumer, and the powerlessness of the disposed. There was no conflict, and therefore no politics.

Hip hop was not completely 'co-opted' by its mainstream Pākehā demographics. There was a poignant portrayal of the legacy of colonialism in, for example, King Kapsi's 'Screems from tha Old Plantation', the title of which was revealing enough. Articulating one's 'roots' with a stylistic tongue could be an intensely political experience still, because it pointed to voices lost in history written by the privileged other. Yet in practice it often simply resorted to a pedagogical insistence on the essence of the past. In the lyrics of 'AEIOU', one of the first indigenous adaptations of rap to break into the mainstream, the rangatahi were urged to 'learn about yourself, your history, know where you come from, where you want to be'. History here appeared as forgotten destiny, simply waiting to be discovered. But more than that 'it's a global thing, been happening for a while, because we choose to learn about ourselves'. The call for self- 
willed empowerment fused the politics of decolonization with the neoliberal order of individualism by choice.

This limited, 'essentialising', construct of ethnicity could barely stand on its own. Indeed more often it fell back into the soothing arms of national, rather than ethnic, identities. Here indigeneity was less a political rallying cry than reassuring sense of security which could be, in the hip hop lingo, 'sampled' for the benefit of 'Brand New Zealand'. It was not surprising then that little came of the scream from the plantation. For the artist, the critic, and the popular media which embraced it, the questions of who won and lost in that round of cultural globalization, and whose political identity it now served to underline were simply never asked. What was left was the sharing of the past, against the more distant 'others'. 'I am not from Africa or America. I'm from the island of Samoa ... I represent for all Pacific peoples from Hawaii to Aoteaoroa'.

If an impoverished account of indigeneity was one side of this national identity, then its obverse, paradoxically, was stamped sharply with the force of globalization. Again there were simply no contradictions, since they were both flattened imageries. In a way hip hop might be read as an allegory of the search for anchored belonging in the context of fluid global forces, a crucial question of identity for young people. Hip hop then served a vehicle for such 'post-modern' articulations. The call for New Zealand hip hop to 'stand the fuck up' against unspecified bullies, as one best selling and multi-award winning number had it, became by no accident 'the sound of young New Zealand' in 2003 in the word of the NZ Herald (18 Oct 2003). The bullies were unnamed, but for one scholar at least, it was clearly 'the assertion of the current state of New Zealand hip hop, coming to a cultural, creative, political and economic maturity ... especially in its resistance to detractors and American hegemony' (Zemke-White 2005). It was difficult to tell whether this was meant to be a metaphor of hip hop, or international relations, or the development trajectory of young people. Perhaps it was all these. What disappeared into this mix, however, was any substantive notion of contradictions, or rather such contradictions were explained away. The broader forces of commodification and global capitalism, upon whose wings hip hop travelled across the globe, were hardly reckoned with. And the impressive effigy of 'American hegemony' still stood, represented in its simplest form by the dogged adherence to a highly stylistic genre, in spite of its supposed diversity. 
Crucially, the formidable challenges of globalization were now presented as a matter of individual skills, which put together cultural artefacts as if they were lego blocks. They were simply found to be compatible, and 'all we can do is to inject our own culture into it. Kia Kaha' in a casual response to weighty questions (Pavement Feb 1994:50). Even national identity melted down into unrecognizable shapes. New Zealand's hip hop national anthem 'Stand Up' served as a B-side to the now schoolground fixture of 'Not Many If Any'. The unabashedly self-laudatory lines were 'how many dudes do you know roll like this, not many, if any'. A claim to national identity then was bundled up with the skilful performance of individuality. It was with good reason that Zemke-White (2005), who wrote prolifically on New Zealand hip hop, chose these lines in her article on New Zealand hip hop. It was perhaps a little too explicit when she called upon hip hop artists to stay 'true' to their (national) identity by using hip hop as 'springboards for self-esteem, cultural affirmation and creative initiative ... in spite of local power structures of class, culture and race' (Zemke-White 2004:225). If one were to find an 'authentic' identity outside the power structures of class, ethnicity and gender, one might as well look to mythical roots, or to the larger indescribable feelings of national pride.

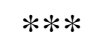

Issues of ethnicity were ever-present in more recent discussions about youth justice, even if they sometimes depended more upon 'rigorous assertion' than 'rigorous research', as one commentator put it (Stenning 2005). A substantial body of very solid evidence, nonetheless, had been steadily accumulating on one small point of correlation, that is, the 'overrepresentation' of Māori (and Pasifika) young people in crime statistics over this period (Ferguson et al. 1993; 2003). What was uncovered presented, as one expert rightly commented, 'the end of a long-term historical process' (Fergusson et al. 2003). But while ethnicity as an end product of that history could be converted into a single variable, and subjected to robust verification, thus adding weight to its own significance, the historical process itself was much less amenable. What could be drawn from the relative abundance of evidence on the one side, and the paucity of it on the other, was illuminating though necessarily limited. Yet these provisional 'truths' could hardly be prevented, by the mere strength of academic footnotes, from entering into the wider circulation of public discourse as a form of hard currency, against which credit might be borrowed for some other claims. 
This economy was at work in popular discourse, for example, in media reporting of young crime which made frequent reference to the numbers, and not much reference at all, to the history. Journalists and others were, of course, allowed more speculative latitude than academics so that the shred of quantitative truth could be made into a fuller figure by padding it with common sense and creative prose. Some of this dramatization could be charged with prejudice (Matheson 2007; Nairn et al. 2012; Wall 1997; Walker 2002). But usually the feelings were subtle and ambiguous, and often expressed only indirectly.

Courtrooms provided perfect settings for such staging, for example. One representative sketch was offered by a reporter for the NZ Herald with strikingly generous provision of column inches:

Out at Manukau the aggro, confusion and examples of messy families ratchet up. This is problem country. Demographics spell a young, brown population. ... Families, when they turn up, are often heavily tattooed, fathers frequently absent. Many mothers have babes in arms, plus toddlers. A sibling sports a large purple bruise on her cheekbone. A father asks the judge, who bans his son from alcohol because of violence problems, if he can drink with him while at home on bail. ... A mother, whose son had been picked up by police at 2 am, cannot see the point of a curfew (10 Mar 2001).

Whatever this had to do with the delinquent boy in question ('hooded sweatshirt, battered Nikes, outsize jeans hanging on skinny hips, baseball cap clutched in his hands') it was not necessary to make explicit. It was a stock number meant to be understood. Condensed judgments were pressed upon individuals and their families, through a narrative which moved seamlessly from generic differences (of 'messy families' and 'young brown population') to specific trespasses (the suspicious bruise and impertinent replies). The point was that while ethnicity made only a brief appearance it provided a convenient motif around which other tunes could be mixed nicely. In fact, one could choose instead to regard such snapshots as a kind of 'theatrical truth', whose values lay not so much in the falsifiability as in their ability to convey more than what could be spelt out. On the Kurariki case, Wright (2010:149-50) observes, that although very little press coverage made explicit references to his part-Rarotongan heritage, the widely circulated photograph already framed "him as the 'other' child: his name - Kurariki - clearly denoting he is of the other descent". Attention was drawn, elsewhere, to the imagery of Kurariki's mother 'adorned with elaborate Māori-styled carvings BJ [Kurariki] made', that prepared the readers for 
an interview in the NZ Herald (26 August 2002). One Pasifika journalist was blunter when she observed that 'Most Pākehā see only the face of Bailey Kurariki, who was, yes, part Cook Islander, when they think of merciless little killers' (NZ Herald 30 Oct 2002). Though one might suggest that it was not so much the actual face they saw as an interchangeable mask.

These examples confirmed among other things indigenous scholars' long-standing critique of mainstream media where nearly always 'Māori news is bad news', and no news otherwise (Walker 2002; Nairn et al 2012). The well-argued points here do not need to be rehearsed. To pursue this line of inquiry would lead one ultimately to the ongoing, and sometimes acrimonious debates about historical injustice and its redress, the nature of state-sponsored biculturalism, and the more recent politics of 'backlash', which sometimes turn to the area of Māori youth justice (Bradley et al 2006; Marie 2010; Quince 2007; Tauri 2013). The following discussion will take as a starting point that socio-economic disadvantage, including the disproportionate youth crime rates, were deeply entangled in the legacy of colonialism. What warrants caution here, however, is that neither the structure of disadvantages nor the construct of ethnicities is stationary. And the changing nature of this entanglement and its implications, not the least in its discursive manifestations, must be taken into account.

One can apply this lens to the 'dominant' official discourse about Māori youth offending, centred around the notions and practices of restorative justice, which came under sustained attack from both ends. For some indigenous scholars, it was merely a simplistic discourse which surrounds the continuing co-optation of indigenous cultural symbolism by the neo-colonial state with various 'myths' (Tauri 1999b). Indeed, 'demythologising' continues to be a preferred strategy for critical engagement with official versions of restorative justice (Bradley et al 2006; Tauri 2013). Others took aim at the 'mythical true story' relying on the origin myth of ethnicity, which was not the 'real story' on the ground (Daly 2002:71; Marie 2010:284-6). Whatever their disagreement, there was one point of consensus: that the current regime of restorative (youth) justice was simply not real justice.

To tell an alternative story one might begin by dispensing with the 'Pākehā' discourse which privileged the 'real' over the symbolic along with the obsession with 'what works' since cultural symbolism was important in its own right. It was necessary to give adequate recognition to the 
elaborate cultural performance that advocates envisaged in its earlier incarnations, which was vividly illustrated in case histories in one account:

This FGC [family group conference] took place in the home of the young person's auntie. Although it was not held on a marae, formal Māori protocol was observed. This was made possible by the presence of two kaumatua, both men of standing in the local community, and by the presence of various aunties, uncles and cousins from the young people's family ... There were eighteen family members present, and kaupapa Māori prevailed. ... Whaikorare, waiata, and karakia opened the FGC (Olsen, Maxwell \& Morris 1995:53-4, italics original).

To be sure, this setting had more warmth and safety, and thus less alienating, than the courthouse. But it was still authorised by the state whose judgements and punishments were to be imposed. The role given to whanau risked internalising these judgements and punishments in young people and their communities by obscuring the presence of the state legal system, a jarring contradiction to which the narrators were almost impervious.

This contradiction could not be resolved easily by appealing to some transcendental forces beyond culture and political economy. . Richards (2011:95-6) for instance argues that what enabled the unlikely marriage of neoliberalism and restorative justice was the widespread acceptance of the 'invisible' discourse of 'empowerment' which possessed the ability to 'transverse effortlessly political boundaries'. Citing New Zealand examples, he argues that the concept of 'empowerment' was in turn 'directly linked to the engagement, participation and activity of its key subjects - victims, offenders, parents, families and communities'. This implied, one may add, the relative 'inactivities' of the state, in the care of victims, in the rehabilitation of offenders, and in the support for parents, families, and communities, and the withdrawal of the state from its social responsibilities. Moreover, it glossed over the relational nature of power; for example, between the offender and the victim, or among communities, and thus eschewed responsibility for its unequal distribution and unjust exercise in the first place. This was fully consistent with the individualizing and responsibilizing logic of neoliberalism (Cuneen 2010; Muncie 2005).

However, as Richards (2011:99) quite rightly emphasizes, “"empowerment” was not something forced on participants in restorative justice process'. It was also something which was 'thinkable 
and practicable'. If one could speak of, for example, an equal 'treaty partnership' between Māori and Pākehā, then the individualized and responsibilised process of 'restorative justice' was not obviously inadequate as a means of redress for historical wrongs visited upon one anthropomorphic party by another. It was sufficient to speak of equality in terms of equal right to speak for oneself, even if this meant simply a different strategy of individualization and responsiblization; instead of 'only individuals and their families', one simply substituted individuals and their whanau. Certainly young people and their families, both Māori and Pākehā, had legitimate interests in this bottom-up empowerment of their collective, ethnic, identities. In this sense, there was a natural overlap between neoliberalism and 'treaty' justice in the case of restorative justice, which would not have been possible under the 'assimilationist' ethos of the welfare state. This is so even if the collective spirit of the latter was more conducive to the formulation of broader solidarity than the fragmenting drives of the former; the politics of identities did not always fall neatly into the pigeon holes of political economy.

Nonetheless, young people and their families were subjects of that political economy too. They had an interest not only in sovereignty over the process of justice, but also the mundane business of restoration. And in this complex structure of deeply unequal power relationships, it was difficult to see the point of a dichotomous balancing of power. Neither the hegemonic order of neoliberalism, nor the 'authorised' and unauthorized versions of bicultural politics, afforded adequate expression for the differing circumstances in which young people found themselves in, regardless of which treaty partner controlled the process of justice.

In this aspect, Marie (2010:286-9) is right to point out the limitations of the shift from class to ethnicity in the New Zealand model of youth justice. The shift to ethnicity produced precisely that false dichotomy between 'subjective' culture and 'objective' evidence which undermined cultural approaches. The 'cultural' explanation of Māori offending as primarily an issue of identity and discrimination (Owen 2001:181) could have nothing to say about the correlation with socio-economic disparities, given that it eschewed both critical reflections on the materiality of cultural discourse, and the play of subjective judgments in quantitative research. 


\subsection{Conclusion}

This chapter argues that we must read together the seemingly divergent responses to youth culture and sexuality on the one hand, and youth crime on the other in order to see beyond the apparent liberalisation of social attitude during the 1990s and 2000s. This apparent liberalisation did not change the fact that social responses to youth culture sexuality and crime were just as deeply inscribed by class, gender and ethnic inequalities as the apparent 'panic'. The discordant shifts, moreover, were not to be explained in terms of changing balance between control and freedom, but rather different logics of power.

The apparent liberalisation also masked the fact that the neoliberal responses to 'new' problems of youth culture, sexuality and crime were carefully measured. There was no hint of panic. The arbitrary line between the public and the private was deftly managed in a way that contained youthful acts of transgression, effaced structural inequalities in class, gender and racial terms and staved off deeper critique of social and political structures. At the same time, it became possible to disseminate the neoliberal logic widely and efficiently, not just as structural hegemony, but as cultural practice of self-making that siphoned off individual energy and creativity so that it too would diversify and multiply alongside attempts at transgression.

In this light, the neoliberal regime was at its most intensive when it appeared least bent upon the imposition of control. There was no singular pressure to conform to a template of norms which tended to fall apart by their own accord, and no single focus of anxiety. The imperative of individual choice and responsibility could now be encoded more effectively and consistently into as diverse a range of youth issues ranging from hip hop to sex education to violent crime, not the least because it circumvented critical reflections of larger social, economic and political forces that acted not just upon youth but society as a whole. Conformity could be cultivated in young people's pursuit, and increasingly their performance, of cultural and sexual freedom. Conformity must be enforced by increasing punitiveness towards youthful criminals behaving irresponsibility. All the same, it was unquestioned conformity to a regime that not only limited, but increasingly prescribed, freedom. 


\section{Chapter 9 Conclusion}

What happened when the discourses of the welfare state and neoliberalism circulated through youth issues in the post-war and near-contemporary periods? The internal contradictions and uncertainties of the postwar welfarist regime were amplified and refracted by public debates over youth. The neoliberal regime, although contested, successfully managed the youth question. We can now trace, to return to the metaphor of windbreak in Chapter Two, the different ways power travelled through intertwined relationships that structured young people's lives in these two periods, engendering oppositions or diffusing tensions in the process. The way that the governors and the governed of the welfare regime employed power exposed cracks in ideological and social consensus. . But what can appear to political philosophers a 'misunderstanding' of power was what made the actual exercise of power more dynamic and interesting than might otherwise have been the case. So while the postwar generation did not think too much about the nature of power, other than as a necessary means of coercion, they debated vigorously over how control could be exercised, for example, over young people. The attempt to impose adult norms upon youth thus subjected these very norms themselves to critical scrutiny in the process. The neoliberal regime, by contrast, was better at managing such cracks because it had more means of control at its disposal, some less apparently coercive than others, and a clearer emphasis on efficiency when it came to how power is used. Compared to the welfare state, it was far more capable of localising the implications of the youth question, and of naturalising its own political logic in new territories. .

In Chapters Three to Five this thesis re-examined postwar discourses about young people between 1950 and 1965. The discussion has demonstrated that the 'conformist' thesis of postwar society underestimates its complexity (and by implication exaggerates the contrast with the more recent period). The governors and the governed of the welfarist regime did take social conformism seriously. But, as they did not understand how power 'really' works, in their attempts to translate imagined homogeneous patterns into reality, the complexities and divisions of postwar society, as well as alternative values and aspirations, even if only to be denied, were constantly made visible. These two sides of a productive dialectic served to unravel the fragile accommodation between conservative morality on the one hand, and welfare politics on the 
other. In this way, moral questions became at once social and political, which in turn undermined the efforts to impose conformity.

In Part 1 of each Chapters Three, Four, and Five, I explored this dynamic in the construction of the youth question in relation to family, school and society respectively. As this thesis argues it was at least partly because postwar society arrived so swiftly at a vague and all-encompassing ideal of domesticity that it was immediately confronted with domesticity's social and political complications, particularly in relation to the welfare state. The very attempt by some to impose moral norms upon young people through parental control exposed just how far adult society had departed from the same norms. It also made explicit the disjunction between moral certainty and material security, the latter of which brought to the fore the responsibility of the state. The competing emphasis on care and discipline in parenting practices mirrored these other dilemmas of adult society. Schooling too became a debate about society and not just education. Vehement disagreements over the expansion of secondary education exposed the deep cracks in a supposedly egalitarian and liberal humanist consensus about educating youth. The discourses around discipline revealed not just more or less liberal attitudes towards schoolchildren reduced to a single issue of physical punishment, but also a more complex and sophisticated reflection about social control. The means and ends of social control, moreover, were subjected to vigorous contest by some who intended to bring schools in line with the disciplinary regime of a competitive marketplace rather than with an egalitarian society, though it was not until the 1990s the former triumphed completely over the latter. Similarly, when various parts of postwar adult society scrutinised the behaviours of juvenile delinquents, their gaze was inevitably drawn towards the broader social context. The 'social maladjustment' of the young often lurched into uncertainties about the society to which they were supposed to adjust. Such uncertainties were exemplified moreover by a changing attitude towards sexuality, and changing social relations around sexuality, which were hampered from finding adequate expression by a language of repression. Concerns about popular music (and briefly comics) equally showed not so much adult (elitist) aversion to youthful fun as apprehension about the larger forces of mass consumerism already deeply ingrained in adult society and the impotence, rather than the threat, of commercialised 'revolt' through style. 
The construction of the youth question as a problem of the social also served to highlight the class, gender and racial divisions in postwar society which some preferred to ignore. These implications were examined in Part 2 in each of Chapters Three, Four and Five. The myth of classlessness, especially, was repeatedly punctured. The 'moral panic' over 'working mothers' as enemies of ideal domesticity often exposed deeper discontents about working class families while rallying others to the defence of those who had to work, and the responsibility the state and society owed to them for this supposedly necessary trade-off between work and life. Attempts to subjugate egalitarian principles to meritocratic competition by conservative opponents to mass education, and efforts by liberal educators to balance egalitarianism and meritocracy, made clear that the class division would not be abolished. Some saw education as part and parcel of a right to welfare of those excluded from the competitive social order. Others saw it as a privilege. And the same disagreement were also reflected in debates about juvenile delinquency. A roundabout attack on 'affluence' or high-wages, though, often placed the attackers in the uncomfortable position right against the seemingly immovable bottom line of class compromise. And it was exactly this bottom line, the spreading of 'affluence', which took much of the sting out of judgments upon young people's sexual behaviour or aesthetic taste. Wages, unlike charity, could not be taken away easily as punishment for 'immorality'. And they could be spent more freely upon the leisure and pleasure already enjoyed by the better-off.

These discourses about class, among other things, mean that a narrative of postwar society focusing entirely upon the apparent correlation between welfare egalitarianism and gender inequality is problematic. The latter in fact was itself shifting, as we can see in discourses about youth, in a similarly indirect manner that encoded ambiguities and complexities in adult attitudes as discussions of class. Postwar society did not question the idea of heterosexual marriage as destiny. But it reconsidered the changing social relationships between men and women, boys and girls that no longer took for granted religious and moral constructs of femininity and masculinity. Mothers for example could no longer be kept in the kitchen as a matter of course; such a position had to be justified, even if ultimately raising doubts about justifications in the name of child welfare or public interest. And men no longer escaped scrutiny over their role as fathers. Debates over the schooling of boys and girls also reflected this paradox as education took on the role of a social, if not a welfarist, institution. The deeply gendered discourses around curriculum and coeducation did not pre-empt attempts to make its inadequate constructs work towards the 
aspiration of equality, or in line with the new ethics of intimate relationships. The latter pointed to the larger shift in social norms often obscured by the smaller point of whether or not young people were allowed to have sex. Adult society thought long and hard, with an eye to its own conduct and its ideals of egalitarianism, about what kinds of sex and intimate relationships young people would be having. It was, curiously, much less reflexive when it came to the juvenile delinquents. Nonetheless such complex undercurrents in public and official attitudes towards gender contrasted with the 'suggestive' discourses of rock 'n' roll, which did not so much challenge the limits of sex and sexuality as display heterosexual norms in highly commercialised forms.

Ethnicity, unlike class and gender, was indeed a blind-spot. But it was not because postwar New Zealand society refused to recognise the ethnic 'other' in its discourse about youth. This invisibility owed much to the impasse about the larger 'race' question as Pākehā society oscillated between older assimilationist policies and newer attempts at 'integration', while Māori society was beginning to articulate its own futures. Discourses about youth accentuated the inherent ambivalence: the problems of Māori youth were often explained away as an inevitable consequence of urbanisation and modernisation, which in turn often made them an issue of welfare. In this narrative the unquestioned belief that Māori youth must be integrated into Pākehā society sat incongruously alongside the critiques of the same Pākehā society.

In spite, or rather because, of its lack of 'permissiveness', and more broadly a 'governmentality' that would manage rather than suppress freedom, the postwar welfarist regime had been able to push the discursive boundaries beyond its official 'classless', gender-discriminatory, and ethnically blind ideology.

The neoliberal regime changed all that, and Chapters Six, Seven, and Eight (Part 1) discussed the changing discourses about the youth question and the connections to this ideological shift in the 1990-2005 period. Youth remained a social problem, but the 'social' was increasingly supplanted by an individualist discourse. Instead of diverting its resources to defending prescriptive social norms that might overflow into a protean social reality, the neoliberal ideology was tightly focused on the imperative of individual responsibility and remarkably efficient in its management, as opposed to suppression, of individual freedom. It managed to transform domestic norms into an individualistic, functional, discourse of parenting orientated towards the 
cultivation of private responsibility. Young people, and their families, moreover were increasingly seen as responsible for 'managing' their own 'human capital' - or the lack of it - in line with market demand for skills in a schooling regime where competition was once again imperative. And although this discourse of individualism entailed some relaxation towards 'private' matters of leisure consumption and sexual pleasure, it opened up new routes of inculcating an ethic of self-responsibility in both areas. This was entirely consistent with the 'punitive' turn in youth crime which, both in its articulation of the 'problems' and 'solutions' of youth crime, reinforced the importance of taking responsibility for oneself.

Class in this new discursive regime was effaced and reconstructed. Unlike 'classless' postwar society which was self-conscious about its internal divisions, and required the state to mediate the contradictions, neoliberal society talked about the underclass explicitly as the 'other' whose motives and behaviours were simply beyond the pale of 'normal' responsible individuals. The 'underclass' was shown to be inadequate to the basic task of parenting its own children, which required supposedly little more than instinctive love and responsibility. These 'underparented' young people, moreover, were said to be excluded, and indeed to be excluding themselves, from the competitive educational race. The most problematic of them, the 'NEETs', necessitated state intervention not so much through education as such, but the inculcation of entrepreneurial virtues and ethics which were expected to break the generational vice of 'dependency'. The individualising and moralising logic implicit in these interventions in parents and young people found cultural reinforcement. It served to manufacture a new consciousness in young people, as reflected in hip hop tropes, that both naturalised the 'facts' of classed inequality, indeed as part of their very own identity, and compelled them to work harder not to end inequality but to raise themselves, as individuals, one or two rungs higher in the ladder of that inequality. It reminded these disadvantaged young people that they were constantly at risk of making wrong choices about sex and sexuality and yet refused to acknowledge the classed constraints upon their lives of which sex and sexuality were only a part. And while it insisted that disadvantaged young people must take full responsibility for crimes and would face ever severer punishment, criminality at the same time was encoded into the construction of the underclass, as a risk that these young people simply had no hope of escaping. 
Part 2 in Chapters Six, Seven, Eight showed that while class was further marginalised, gender and ethnicity became highly visible in the discourses about youth. Contemporary discourses no longer believed that women and girls were limited to domestic labour. And the idea, already passé even in the postwar era, that schooling should prepare them for such limited gender roles, was now unthinkable. The gendered regime appeared to be shifting not just over public roles but the private and personal as well. 'Precocious' girls no longer seemed an overwhelming anxiety. And conventional discourses, as exemplified by sex education discourse, spoke an overt language of equality, or more specifically, equality in making responsible sexual choices. Yet the insistence of equalities and choices did not so much challenge the hetero-normative and sometimes openly sexist culture, nor the underlying social and economic forces - reflected, among other things, in hip hop's misogyny - as simply dismissed them altogether. Young people themselves had to negotiate the ideals and the reality. At the same time, the disappearance of discriminatory practices served to conceal the reinvention of gendered prejudice, not as social norms but as individual 'differences', which again shifted responsibility onto young people themselves. It is in this context that we may read the concerns about 'fatherlessness', for example, not as a mere backlash but as a reorganisation of traditional gender order, in a world which, among other things, was growing anxious about 'failed' masculinity in an increasingly competitive society. Such a reorganisation allowed discourses about youth crime to be subtly gendered, explaining crime partly in terms of the misuse of feminine empowerment and masculine force. It was more explicit in the discursive construction of 'boys' underachievement', which highlighted not just a stubborn attachment to masculine privilege, but also an imperative to align masculine norms to new market conditions.

The construction of ethnicity posed a different paradox. The neoliberal regime did not simply coopt indigenous aspirations. The language of choice and individual responsibility, which sometimes borrowed the terminologies of cultures and identities, was one possible way to articulate the demands for indigenous self-determination. Nonetheless the neoliberal logic in such ways became the organising principle of cultural politics, foreclosing other possibilities of articulating cultural, along with socio-economic and political aspirations. The emerging discourses of whanau, and of Māori education, had thus limited effects on the new political regime which sustained inequalities not through blatant racial discrimination, but rather through global socio-economic mechanisms. The growing visibility of culture amounted to little more 
than a conspicuous representation, including through the popular medium of hip hop. It provided no substantive alternative to the dominant sexual discourse. And neither did it challenge discriminatory discourses institutionalised not simply along racial lines but within an interlocking cultural and socio-economic grid.

There is no reason that we should accept the liberal-humanist impulse of postwar society and its aspirations of 'welfare' as necessary progress. By the same token, however, it is important not to confuse political and ideological changes, and certainly not to regard them as necessary tradeoffs, with the inevitable passing of a supposedly 'conformist' society. The liberal, humanist and egalitarian ideals of post-war welfarism might turn out to be illusionary and contradictory. But the neoliberal regime that succeeded the welfarist society, with its intensification of power and control, made these ideals even more distant. 



\section{Bibliography}

\section{Books Articles and Speeches}

Allen, L. (2004). "Beyond the birds and the bees: Constituting a discourse of erotics in sexuality education." Gender and Education 16(2): 151-167.

Allen, L. (2005). "'Say everything': Exploring young people's suggestions for improving sexuality education." Sex Education 5(4): 389-404.

Allen, L. (2006). "“Looking at the Real Thing": Young men, pornography, and sexuality education." Discourse: studies in the cultural politics of education 27(1): 69-83.

Allen, L. (2007). "“Sensitive and Real Macho All at the Same Time" Young Heterosexual Men and Romance." Men and Masculinities 10(2): 137-152.

Alton-Lee, A. and A. Praat (2000). Explaining and addressing gender differences in the New Zealand compulsory school sector: A literature review, Research Division, Ministry of Education.

Altschuler, G. C. (2003). All Shook Up: How Rock'n'Roll Changed America: How Rock'n'Roll Changed America. New York, Oxford University Press.

Andrew, A., J Sanders, et al. (2002). Windows on family life: Report 1, Teenage sons. Palmerston North, Massey University, School of Sociology, Social Policy, and Social Work.

Andrewes, F. (1998). "Demonstrable virility: images of masculinity in the 1956 Springbok rugby tour of New Zealand." The International Journal of the History of Sport 15(2): 119-136.

Angus, J. (2000). Social and Family Responsibility as a Family Policy Initiative. Another New Zealand Experiment: A Code of Social and Family Responsibility. J. Davey. Wellington, Institute of Policy Studies, Victoria University.

Anthias, F. (2013). "Intersectional what? Social divisions, intersectionality and levels of analysis." Ethnicities 13(1): 3-19.

Appleby, P. (2002). "Kura Kaupapa Māori: tomorrow's schools and beyond." New Zealand Annual Review of Education 11: 105-121.

Atkin, B. (1991). "New Zealand: Families, Children and Ethnicity." J. Fam. L. 30: 357.

Atkin, B. (1990). "Courts and Child Protection-Aspects of the Children, Young Persons, 
and Their Families Act 1989." Victoria U. Wellington L. Rev. 20: 319.

Atkinson, W., S. Roberts, et al., Eds. (2012). Class Inequality in Austerity Britain: Power, Difference and Suffering. Basingstoke, Palgrave Macmillan.

Atwool, N. (1999). "New Zealand children in the 1990s: Beneficiaries of new right economic policy?" Children \& society 13(5): 380-393.

Ausubel, D. (1960). The Fern and the Tiki: An American View of New Zealand National Character, Social Attitudes and Race Relations. Sydney, Angus \& Roberts.

Bacchi, C. and J. Bonham (2014). "Reclaiming discursive practices as an analytic focus: Political implications." Foucault Studies(17): 179-192.

Baker, J. (2008). The ideology of choice. Overstating progress and hiding injustice in the lives of young women: Findings from a study in North Queensland, Australia. Women's Studies International Forum, Elsevier.

Bannister, M. (2008). "Where's Morningside? Locating bro'Town in the ethnic genealogy of New Zealand/Aotearoa." New Zealand Journal of Media Studies 11(1).

Barwick, H. (2004). Young Males: Strengths-based and male-focused approaches. Ministry of Youth Development. Wellington.

Beaglehole, E. and J. E. Ritchie (1958). "The Rakau Māori Studies." The Journal of the Polynesian Society: 132-154.

Beals, F. M. (2006). Reading between the lines: Representations and constructions of youth and crime in Aotearoa/New Zealand. Education. Wellington, Victoria University. PhD.

Becroft, A. J. (2003). "Māori Youth Offending." Journal of Public Administration 62(3): 65-73.

Behrent, M. C. (2009). "Liberalism without humanism: Michel Foucault and the freemarket creed, 1976-1979." Modern Intellectual History 6(03): 539-568.

Belich, J. (2001). Paradise reforged: A History of the New Zealanders from the 1880 s to the Year 2000. Auckland, Allen Lane:Penguin

Bell, A. (2004). Relating Māori and Pākehā : the politics of indigenous and settler identities. School of Sociology, Social Policy and Social Work. Palmerston North, Massey University.

Bell, A. and V. Carpenter (1994). Education's role in (re) producing social class in Aotearoa. The politics of learning and teaching in Aotearoa New Zealand. E. Coxon. 
Palmerston North, Dunmore Press: 112-147.

Benadé, L. W. (2011). From technicians to teachers: the New Zealand curriculum and the development of ethical teacher professionality. Education. Auckland, University of Auckland.

Bertram, G. (2000). The New Zealand Economy, 1900-2000. The New Oxford History of New Zealand. G. Byrnes. Melbourne, Oxford University Press.

Bertrand, M. (2004). I don't think Hank done it that way: Elvis, country music and the reconstruction of southern masculinity. A boy named Sue: Gender and country music. M Bertrand, KM McCusker and D. Pecknold, University of Mississipi Press: 59-85.

Bertrand, M. T. (2000). Race, rock, and Elvis, University of Illinois Press.

Besley, T. (2006). Counseling youth, Sense Publishers.

Besley, T. and M. A. Peters (2007). Subjectivity \& truth: Foucault, education, and the culture of self, Peter Lang.

Biddulph, S. (1998). Raising Boys. Sydney, Finch Publishing.

Birch, K. and S. Mafi (1996). Parenting teenagers: a self-help guide for New Zealand parents / Kate Birch \& Sue Mafi. Auckland, Cedar New Zealand.

Birks, S. (2005). Proceedings-Men's Issues: Summits 2005, Centre for Public Policy Evaluation, Massey University.

Bishop, R. and T. Glynn (2003). Culture counts: Changing power relations in education, Zed Books.

Blakely, T., S. Collings, et al. (2003). "Unemployment and suicide. Evidence for a causal association?" Journal of Epidemiology and Community Health 57(8): 594-600.

Blamire, E. P. (1964 [1953]). The Husband Fulfilling His Role. Auckland, E P Blamire.

Bolger, J. (1993). State of the Nation. Wellington.

Bourke, C. (2010). Blue smoke: The lost dawn of New Zealand popular music 19181964. Auckland, Auckland University Press.

Bourne, H. (1958). The Use and Abuse of Authority. Conformity and Individuality: the 1958 Lectures, Wellington, Association for the Study of Childhood.

Bradley, T., J. Tauri, et al. (2006). Demythologising youth justice in Aotearoa/New Zealand. Comparative Youth Justice. J. M. B. Goldson. London, Sage. 
Brady, A. (2012). "The transgendered Kiwi: Homosocial desire and 'New Zealand identity'." Sexualities 15(3-4): 355-372.

Bragg, S., D. Buckingham, et al. (2011). "Too much, too soon? Children, 'sexualization' and consumer culture." Sex Education 11(3): 279-292.

Bray, A. (2011). "Merciless Doctrines: Child Pornography, Censorship, and Late Capitalism." Signs 37(1): 133-158.

Breines, W. (2001). Young, White, and Miserable: Growing Up Female in the Fifties. Chicago, Chicago University Press.

Brickell, C. (2005). "Sex instruction and the construction of homosexuality in New Zealand, 1920-1965." Sex Education 5(2): 119-136.

Brickell, C. (2007). "Those "Other Sociologists": Social Analysis Before Sociology." New Zealand Sociology 22(2): 195.

Brickell, C. (2009). Sexuality, morality and society. The New Oxford history of New Zealand. G. Byrnes. Melbourne, Oxford University Press: 465-486.

Brickell, C. (2012). Moral Panic or Critical Mass?: The Queer Contradictions of 1950s New Zealand. Queer 1950s: Rethinking Sexuality in the Postwar Years. H. Bauer and M. Cook. Basingstoke, Palgrave.

Brickell, C. (2013). "On the Case of Youth: Case Files, Case Studies, and the Social Construction of Adolescence." The Journal of the History of Childhood and Youth 6(1): 50-80.

Brickell, J. (1999). Fathers Who Care: Partners in Parenting - An Overview of Parenting Programmes for Fathers. Wellington, Commissioner for Children.

Brookes, B. (1997). "Nostalgia for 'innocent homely pleasures': The 1964 New Zealand Controversy over Washday at the Pa." Gender \& History 9(2): 242-261.

Brown, H. (2011). Loosening the Marriage Bond: Divorce in New Zealand, c. 1890s-c. 1950s. History. Wellington, Victoria University. PhD.

Brown, W. (2003). "Neo-liberalism and the end of liberal democracy." Theory \& Event 7(1).

Bryder, L. (2003). A Voice for Mothers: The Plunket Society and Infant Welfare. Auckland, Auckland University Press.

Bull, S. (2009). "Changing the broken record: New theory and data on Māori offending." 
Paper delivered at the Institute of Policy Studies,'Addressing the underlying causes of offending: What is the evidence.

Burgoyne, D. (1994). Parent education programmes: bibliography of publications held in New Zealand libraries. Wellington, Ministry of Education.

Burman, M. and S. A. Batchelor (2009). "Between two stools? Responding to young women who offend." Youth Justice 9(3): 270-285.

Butler, J. (1997). Excitable Speech: A Politics of the Performative. New York, Routledge.

Callister, P. and S. Birks (1999). Perspectives on Fathering, Palmerston North, Centre for Public Policy Evaluation, Massey University, April 1999.

Cameron, D. (2000). Good to talk?: Living and working in a communication culture. London, Sage.

Carlyon, J. and D. Morrow (2013). Changing Times: A History of New Zealand Since 1945. Auckland, Auckland University Press.

Carpenter, C. (2011). Young People and Desistance from Crime. Criminology. Wellington, Victoria University. MA.

Carr-Gregg, M. and S. Shale (2002). Adolescence : a guide for parents. Sydney, Finch Publishers.

Caspi, A., J. McClay, et al. (2002). "Role of genotype in the cycle of violence in maltreated children." Science 297(5582): 851-854.

Chapman, R. (1953). "Fiction and the Social Pattern: Some Implications of Recent New Zealand Writing." Landfall 7(1).

Chapple, S., R. Jefferies, et al. (1997). Māori Participation and Performance in Education. Wellington, NZIER/Ministry of Education.

Cherry, S. (2008). "The ontology of a self-help book: A paradox of its own existence." Social Semiotics 18(3): 337-348.

Cho, S., K. W. Crenshaw, et al. (2013). "Toward a field of intersectionality studies:

Theory, applications, and praxis." Signs 38(4): 785-810.

Clark, H. (2002). Launch of the Tertiary Education Commission. Wellington.

Clark, J. (2004). "Education Myths as a Framework fo education Policy: Towards a New Myth." New Zealand Annual Review of Education 13: 5-19. 
Cochran, J. and B. Cochran (1943). Sex, love and marriage. Wellington, Reed.

Cocklin, B. and D. Battersby (1987). "Gender, the hidden agenda: A case study in educational decision-making." New Zealand Journal of Educational Studies.

Codd, J. (2005). Is there a "third way" for education policy. Education policy directions in Aotearoa New Zealand. J. Codd and K. Sullivan. Melbourne, Thomson.

Codd, J. and K. Sullivan, Eds. (2005). Education policy directions in Aotearoa New Zealand. Melbourne, Thomson.

Coffey, J. and D. Farrugia (2014). "Unpacking the black box: the problem of agency in the sociology of youth." Journal of Youth Studies 17(4): 461-474.

Coney, S. and M. Thompson (1993). Signs of Rebellion against the Back-to the-Home Movement of the 1950s: Housewife or Human Being? Standing in the Sunshine. A History of New Zealand Women since They Won the Vote. S. Coney. Auckland, Penguin: 80-81.

Congalton, A. A. (1952). Social Class Consciousness in Adolescents. Wellington, Department of Psychology, Victoria University College.

Connell, R. (2005). Masculinities. Berkeley LA, University of California Press.

Côté, J. E. (2014). "Towards a new political economy of youth." Journal of Youth Studies 17(4): 527-543.

Couldry, N. (2008). "Reality TV, or The Secret Theater of Neoliberalism." Review of Education, Pedagogy, and Cultural Studies 30(1): 3-13.

Cowan, J. (2005). Sex with Attitude. Auckland, Parenting with Confidence.

Cram, F. and S. Pitama (1998). Ko toku whanau, ko toku mana. The Family in Aotearoa New Zealand. V. A. R. Nixon. Auckland, LongmanPaul.

Critcher, C. (2008a). "Moral panic analysis: Past, present and future." Sociology Compass 2(4): 1127-1144.

Critcher, C. (2008b). Making waves: Historical aspects of public debates about children and mass media. The International Handbook of Children, Media and Culture. K. Drotner and S. Livingstone. Los Angeles, Sage: 91-104.

Critcher, C. (2009). "Widening the focus moral panics as moral regulation." British journal of criminology 49(1): 17-34. 
Crompton, R. (2010). "Class and employment." Work, Employment \& Society 24(1): 926.

Crothers, C. (2013). "Editorial: social class and inequality in New Zealand and Overseas: introduction to special issue."

Crowther, D. M. (1956). Street society in Christchurch, Department of Psychology, Canterbury University College.

Cuervo, H. and J. Wyn (2011). Rethinking youth transitions in Australia: A historical and multidimensional approach, Youth Research Centre, Melbourne Graduate School of Education, University of Melbourne.

Cuervo, H. and J. Wyn (2014). "Reflections on the use of spatial and relational metaphors in youth studies." Journal of Youth Studies(ahead-of-print): 1-15.

Cunneen, C. (2010). The Limitations of Restorative Justice. Debating Restorative Justice. C. Cuneen and C. Hoyle. Oxford, Hart Publishing: 182-194.

Cunningham, C., B Stevenson, et al. (2005). Analysis of the Characteristics of Whānau in New Zealand. Wellington, Ministry of Education.

Currie Commission (Commission on Education in New Zealand) (1962). Report of the Commission on Education in New Zealand. 1962, Government Printer.

D, H. and H. Lauder (1991). "Human Capital Theory and the Wastage of Talent in New Zealand." New Zealand Journal of Educational Studies 26(1): 5-20.

Dale, R. (2001). Social class and education in Aotearoa/New Zealand. Politics, Policy, Pedagogy: Education in Aotearoa/New Zealand. J Marshall, E. Coxon, K. Jenkins and A. Jones. Palmerston North, Dunmore Press: 107-137.

Dalley, B. (1998). Family matters: child welfare in twentieth-century New Zealand, Auckland University Press Auckland.

Dalley, B. and G. McLean (2005). Frontier of dreams: The story of New Zealand. Auckland, Hodder Moa Beckett.

Daly, C. (2003). Leisure and Pleasure: Reshaping and Revealing the New Zealand Body 1900-1960. Auckland, Auckland University Press.

Daly, C. (2005). Puritans and Pleasure Seekers. Dunedin, Otago University Press.

Daly, K. (2002). "Restorative justice: The real story." Punishment \& Society 4(1): 55-79.

Daniel, P. (2000). Lost Revolutions: the South in the 1950s. Chapel Hill, NC, Univ of 
North Carolina Press.

Davey, A. (2000). Another New Zealand Experiment: A Code of Social and Family Reponsibility. Wellington, Institute of Policy Studies: VUW.

Davies, J. (1998). "Constructing technology education: Questions of purpose and fit." New Zealand Annual Review of Education 119: 146.

Davis, R. (2007). "Whose education is it anyway?": Why it is important that teachers understand and question the broader contexts shaping the curriculum." New Zealand Journal of Teachers' Work 4(1): 32-38.

Dean, J. (2008). "Enjoying neoliberalism." Cultural politics 4(1): 47-72.

Dekeseredy, W. (2010). Moral Panics, Violence, and the Policing of Girls. Fighting for girls: New perspectives on gender and violence. M. Chesney-Lind and N. Jones. New York, SUNY Press.

Department of Education (1955a). Sex and the Adolescent Boy. Wellington, Government Printer.

Department of Education (1955b). Sex and the adolescent girl. Wellington, Department of Education.

Department of Education (1955c). Sex and the Parent. Wellington, Department of Health.

Department of Education (1958 [1944]). The Thomas Report: The Post-Primary School Curriculum Report of the Committee Appointed by the Minister of Education in November 1942. Wellington, Government Printer.

Department of Education (1964). Education Statistics of New Zealand. Wellington.

Diorio, J. and K. Elliot (2005). Teaching of Sexualities in New Zealand. Youth, Education, and Sexualities: An International Encyclopedia. J. Sears. Connecticut, Greenwood.

Dix, J. (2005). Stranded in Paradise. Auckland, Penguin.

Durie, M. (2001). "A framework for considering Māori educational advancement." Opening Address. Hui Taumata Matauranga, Turangi.

Durie, M. (2003a). Nga kahui pou: Launching Māori futures, Huia Publishers.

Durie, M. (2003b). "Māori Educational Advancement At the Interface Between Te Ao Māori and Te Ao Whänui." 
Durie, M. (2004). "Māori achievement: Anticipating the learning environment." Hui Taumata IV Conference. Palmerston North, NZ: Massey University.

Eagle, L. and A. DeBruin (2000). "Ideological and Theoretical Underpinnings of the New Zealand Education Reforms." ACCESS 19(1): 1-17.

Easton, B. (2013). "Economic inequality In New Zealand: A user's guide." New Zealand Sociology 28(3): 19.

Edwards, S., T. McCreanor, et al. (2007). "Māori family culture: a context of youth development in Counties/Manukau." Kōtuitui: New Zealand Journal of Social Sciences Online 2(1): 1-15.

Eisenbichler, K. (2002). The Premodern Teenager: Youth in Society, 1150-1650. Toronto, Centre for Reformation and Renaissance Studies.

Eketone, A. (2012). "Māori parenting, from deficit to strength." Aotearoa New Zealand Social Work 24(3/4): 75.

Eley, G. and K. Nield (2007). The future of class in history: What's left of the social? Ann Arbor, University of Michigan Press.

Elizabeth, V. and W. Larner (2009). "Racializing the "social development" state: investing in children in Aotearoa/New Zealand." Social Politics: International Studies in Gender, State \& Society 16(1): 132-158.

Epstein, D., J. Elwood, et al., Eds. (1998). Failing boys? Issues in gender and achievement. Buckingham, Open University Press.

Epstein, S. (1995). "The construction of lay expertise: AIDS activism and the forging of credibility in the reform of clinical trials." Science, Technology \& Human Values 20(4): 408-437.

Evans, C. (2005). Not Aunt Daisy: Ambivalence in the Representation of Womanhood in Postwar New Zealand. History. Auckland, University of Auckland. MA.

Fairclough, N. (2013). Critical discourse analysis: The critical study of language. London, Routledge.

Families Commission. (2005). Review of Parenting Programmes. Wellington.

Family Planning Association (1994). Challenges and change: a sexuality education programme for adolescents.

Family Planning Association (1995). The Rush. Bancroft, A. Auckland. 
Family Planning Association (1997). The Word. Wellington.

Family Planning Association (2000). Your Choice. Wellington.

Farrugia, D. (2013). "Young people and structural inequality: Beyond the middle ground." Journal of Youth Studies 16(5): 679-693.

Feher, M. (2009). "Self-appreciation; or, the aspirations of human capital." Public Culture 21(1): 21-41.

Ferguson, J. (2010). "The uses of neoliberalism." Antipode 41(s1): 166-184.

Fergusson, D. (2003). Ethnicity and Interpersonal Violence in a New Zealand Birth Cohort. Violence Crimes: Assessing Race and Ethnic Differences. D. F. Hawkins.

Fergusson, D., L. Horwood, et al. (1993). "Ethnicity, Social Backgroud and Young Offending: A 14-Year Longitudinal Study." Australian \& New Zealand Journal of Criminology 26(2): 155-170.

Fergusson, D., L. Horwood, et al. (2003). "Ethnicity and criminal convictions: results of a 21-year longitudinal study." Australian \& New Zealand Journal of Criminology 36(3): 354-367.

Fergusson, D., N. Swain-Campbell, et al. (2004). "How does childhood economic disadvantage lead to crime?" Journal of Child Psychology and Psychiatry 45(5): 956966.

Fergusson, D. M. (1998). "The Christchurch Health and Development Study: An overview and some key findings." Social Policy Journal of New Zealand: 154-176.

Fergusson, D. M. and L. J. Horwood (1997). "Gender differences in educational achievement in a New Zealand birth cohort." New Zealand Journal of Educational Studies 32: 83-96.

Fergusson, D. M. and L. J. Horwood (2003). "Resilience to childhood adversity: Results of a 21-year study." Resilience and vulnerability: Adaptation in the context of childhood adversities: 130-155.

Fergusson, D. M., L. John Horwood, et al. (2005). "Show me the child at seven: the consequences of conduct problems in childhood for psychosocial functioning in adulthood." Journal of child psychology and psychiatry 46(8): 837-849.

Fernandez, T., G. Ritchie, et al. (2008). "A sociocultural analysis of mandated curriculum change: the implementation of a new senior physics curriculum in New Zealand schools." Journal of Curriculum Studies 40(2): 187-213. 
Fitzsimons, P. (2010). Education - A Capital Idea! Another decade of New Zealand Education Policy: Where to Now? M. Thrupp and R. Irwin. Hamilton, Wilf Malcolm Institute of Education Research.

Fitzsimons, P. and G. Smith (2000). "Philosophy and indigenous cultural transformation." Educational Philosophy and Theory 32(1): 25-41.

Flew, T. (2012). "Michel Foucault's The Birth of Biopolitics and contemporary neoliberalism debates." Thesis Eleven 108(1): 44-65.

Flood, M. (2010). Young men using pornography. Everyday Pornography. K. Boyle. London, Routledge: 164-178.

Flynn, T. (2005). Sartre, Foucault, and Historical Reason, Volume 2: A Poststructuralist Mapping of History. Chicago, University of Chicago Press.

Forman, M. (2002). The Hood Comes First: Race, Space, and Place in Rap and Hiphop. Middletown CT, Wesleyan University Press.

Forman, M. (2014). "Visualizing place, representing age in hip-hop: converging themes in Scarface's 'My Block'." Continuum 28(3): 300-313.

Foucault, M. (1980a). The History of Sexuality. Vol. 1, An Introduction. New York, Vintage.

Foucault, M. (1980b). Power/Knowledge: Selected Writings and Other Interviews. Brighton, Harvestor Press.

Foucault, M. (1995). Discipline \& Punish: the Birth of the Prison. New York, Vintage.

Foucault, M. (1998). Aesthetics, method, and epistemology. New York, The New Press.

Foucault, M. (2002a). Archaeology of Knowledge London, Routledge.

Foucault, M. (2002b). Power. London, Penguin Books.

Foucault, M. (2003). Society Must Be Defended. New York, Picador Eribon.

Foucault, M. (2007). Security, Territory, Population. Basingstoke, Palgrave MacMillan.

Foucault, M. (2008). The Birth of Biopolitics. Translated by Graham Burchell. New ork, Palgrave Macmillan.

France, A. (2007). Understanding youth in late modernity, McGraw-Hill International. 
France, A. (2008). "Risk factor analysis and the youth question." Journal of youth studies 11(1): 1-15.

France, A. (2012). "'It's all in the brain'science and the'new'construction of the youth problem in New Zealand." New Zealand Sociology 27(2): 76.

France, A., D. Bottrell, et al. (2012). "Managing everyday life: the conceptualisation and value of cultural capital in navigating everyday life for working-class youth." Journal of youth studies: 1-15.

France, A. and S. Roberts (2014). "The problem of social generations: a critique of the new emerging orthodoxy in youth studies." Journal of Youth Studies: 1-16.

Francis, B. (2006). "Heroes or zeroes? The discursive positioning of 'underachieving boys' in English neo-liberal education policy." Journal of Education Policy 21(2): 187200.

Francis, B. and C. Skelton (2005). Reassessing gender and achievement: Questioning contemporary key debates. London, Routledge.

Frith, S. and A. McRobbie (1978). "Rock and Sexuality." Screen education.

Furlong, A., D. Woodman, et al. (2011). "Changing times, changing perspectives: reconciling 'transition'and 'cultural'perspectives on youth and young adulthood." Journal of sociology 47(4): 355-370.

Gabriel, F. (2013). Deconstructing Youth: Youth Discourses at the Limits of Sense, Palgrave Macmillan.

Gagné, N. (2013). Being Māori in the City: Indigenous Everyday Life in Auckland. Toronto, University of Toronto Press.

Gelsthorpe, L. and A. Worrall (2009). "Looking for trouble: A recent history of girls, young women and youth justice." Youth Justice 9(3): 209-223.

Gilbert, J. (2001). "Science and its 'Other': Looking underneath 'woman' and 'science' for new directions in research on gender and science education." Gender and Education 13(3): 291-305.

Gilbert, J. (2010). Are we there yet? Sixty Years of Education Sociology and Equality in Aoteaoroa/New Zealand. Looking back from the Centre: A Snapshot of Contemporary New Zealand Education. J. Kidman and K. Stevens. Wellington, NZCER.

Gill, R. (2011). "Sexism Reloaded, or, it's Time to get Angry Again!" Feminist Media Studies 11(1): 61-71. 
Glazebrook, S. (1978). The Mazengarb Report, 1954: Impotent Victorianism. History. Auckland, University of Auckland. MA.

Gleason, M. (1997). "Psychology and the construction of the'normal'family in postwar Canada, 1945-60." Canadian Historical Review 78(3): 442-477.

Gleason, M. L. (1999). Normalizing the ideal: Psychology, schooling, and the family in postwar Canada. Toronto, University of Toronto Press.

Goldson, B. (2011). "'Time for a Fresh Start', but is this it? A Critical Assessment of The Report of the Independent Commission on Youth Crime and Antisocial Behaviour." Youth Justice 11(1): 3-27.

Goldson, B. and J. Muncie (2006). "Rethinking youth justice: comparative analysis, international human rights and research evidence." Youth Justice 6(2): 91-106.

Gooder, C. (2010). A history of sex education in New Zealand, 1939-1985. History. Auckland, Auckland University. PhD.

Grant, I. (1999). Fathers who dare win : strategies for effective fatherhood. Auckland, Pa's Publishing.

Grant, I. and J. Cowan (1999). The White Water Rafting Years : a common-sense guide to parenting teenagers. Auckland, Pa's Publishing.

Grant, J. (2010). "Foucault and the logic of dialectics." Contemporary Political Theory 9(2): 220-238.

Gray, P. (2005). "The politics of risk and young offenders' experiences of social exclusion and restorative justice." British Journal of Criminology 45(6): 938-957.

Gray, P. (2009). "The political economy of risk and the new governance of youth crime." Punishment \& Society 11(4): 443-458.

Green, J. (2011). A discursive analysis of Māori in sexual and reproductive health policy, University of Waikato. Masters.

Grewal, B. (2008). Neoliberalism and discourse: case studies of knowledge policies in the Asia-Pacific. School of Languages and Social Sciences, Auckland University of Technology.

Guy, L. (2009). "“'Moral Panic" or Pejorative Labelling? Rethinking the Mazengarb Inquiry into Underage Sex in the Hutt Valley in 1954." Journal of Religious History 33(4): 435-451.

Hackell, M. (2013). "Taxpayer citizenship and neoliberal hegemony in New Zealand." 
Journal of Political Ideologies 18(2): 129-149.

Hames, M. (2002). The Crisis in New Zealand Schools. E. Forum. Palmerston North, Dunmore Press.

Hames, M. (2002). The crisis in New Zealand schools. Palmerston North, Dunmore Press.

Hamilton, M. and K. Pitt (2011). "Changing policy discourses: Constructing literacy inequalities." International Journal of Educational Development 31(6): 596-605.

Hardie-Boys, M. (1997). Concerning values and virtues: a pamphlet exhibiting a Governor-General's appeal. Christchurch, H Evans.

Harrison, M. (2004). Education Matters. Wellington, Education Forum.

Harvey, D. (2005). A brief history of neoliberalism. Oxford, Oxford University Press.

Harvey, J. (2000). "Hip Hop and Identity." Deep South 6(1).

Harvey, L. and R. Gill (2011a). "The Sex Inspectors." The Handbook of Gender, Sex, and Media: $487-501$.

Harvey, L. and R. Gill (2011b). Spicing it up: sexual entrepreneurs and the Sex Inspector. New Femininities: Postfeminism, neoliberalism and Subjectivity. C. Scharff and R. Gill. London, Palgrave.

Haste, P. (2013). "Sex education and masculinity: the 'problem'of boys." Gender and Education(ahead-of-print): 1-13.

Hay, J., M Maclagan, et al. (2008). New Zealand English. Edinburgh, Edinburgh University Press.

Hayward, G. and R. Williams (2011). "Joining the big society: am I bothered?" London Review of Education 9(2): 175-189.

Hazleden, R. (2009). "Promises of Peace and Passion: Enthusing the Readers of SelfHelp." M/C Journal 12(2).

Herbert, A. (2011). "Māori perspectives on parenting in Aotearoa/New Zealand." Māori and Social Issues: 67487.

Herbert, A. (2001). Whanau Whakapakari: a Māori-centred approach to child rearing and Parent-training programmes, PhD, The University of Waikato.

Heywood, C. (2001). A history of childhood: children and childhood in the West from 
medieval to modern times. Cambridge, Polity Press in association with Blackwell Publishers.

Hier, S. (2003). "Risk and panic in late modernity: Implications of the converging sites of social anxiety." The British journal of sociology 54(1): 3-20.

Hier, S. (2008). "Thinking beyond moral panic Risk, responsibility, and the politics of moralization." Theoretical Criminology 12(2): 173-190.

Hier, S., D. Lett, et al. (2011). "Beyond folk devil resistance: Linking moral panic and moral regulation." Criminology and Criminal Justice: 1748895811401977.

Higgins, J. (1997). "No longer a burning social issue? Employment assistance policy and the closure of the unemployment debate in New Zealand." Journal of Sociology 33(2): 137-152.

Higgins, J. (2002). "Young people and transitions policies in New Zealand." Social Policy Journal of New Zealand: 44-61.

Hine, J. and J. Welford (2011). Girls' Violence: Criminality or Resilience? The Social Ecology of Resilience. M. Ungar. New York, Springer: 157-169.

Hokowhitu, B. (2004). "Tackling Māori masculinity: A colonial genealogy of savagery and sport." The Contemporary Pacific 16(2): 259-284.

Holford, N. (2012). Making Classed Sexualities: Investigating Gender, Power and Violence in Middle-class Teenagers' Relationship Cultures, Cardiff University.

Horvath MAH, L Alys ,et al. (2013) Basically...porn is everywhere. London: The Office of the Children's Commissioner, 2013.

Howden-Chapman, P., S. Hales, et al. (2005). The impact of economic recession on youth suicide: a comparison of New Zealand and Finland, Ministry of Health, New Zealand.

Hughes, D. and H. Lauder (1991). "Human Capital Theory and the Wastage of Talent in New Zealand." New Zealand Journal of Educational Studies 26(1): 5-20.

Humpage, Louise (2002) "Closing the Gaps?" The Politics of Māori Affairs Policy. Ph.D. Albany, NZ: Massey University

Humpage, L. (2006). "An 'inclusive'society: a 'leap forward'for Māori in New Zealand?" Critical Social Policy 26(1): 220-242.

Hunter, P. A. (2013). Problematised History Pedagogy as Narrative Research: SelfFashioning, Dismantled Voices and Reimaginings in History Education, University of 
Waikato.

Hutchings, J. and C. Aspin (2007). Sexuality and the stories of indigenous people. Wellington, Huia Publishers.

Inter-Departmental Committee on Adolescent Offenders (1959). Gang misbehaviour in Wellington. Wellington.

Irving, T. (1991). Youth policy as politics: The Dewar Committee and juvenile delinquency in Queensland in the 1950s in Journal of Australian Studies 15(31):41-50

Irving, T. M Maunders. and G Sherington. (1996). Youth in Australia. Melbourne, MacMillan

Irwin, M. (1998). The Education Debate in the 1990s Intellectual Adventure or Unexamined Orthodoxies. NZBR. Wellington.

Isaksen, J. (2011). Word Up: Hip Hopper' Smart Pose Outwits Masculine Scripts. Mediated Boyhoods: Boys, Teens and Young Men in Popular Media and Culture. A. Wannamaker. New York, Peter Lang Publishing.

Jackson, C. (2006). Lads and ladettes in school. Buckingham, Open University Press. Jackson, S. and A. Weatherall (2010). "Dilemmas of delivery: Gender, health and formal sexuality education in New Zealand/Aotearoa classrooms." Women's Studies Journal 24(1): 47-59.

Jackson, S. and A. Weatherall (2010). "The (im) possibilities of feminist school based sexuality education." Feminism \& Psychology 20(2): 166-185.

Jefferies, M. (2010). Thug Life: Race, Gender and the Meaning of Hip Hop. Chicago, University of Chicago Press.

Jeffs, N. (2005). Counting the beatz: hip hop culture, commercialisation and the state in Aotearoa New Zealand. Communication Studies, Auckland University of Technology. MA: 312.

Jenkins, K. and A. Jones (2000). Māori Education Policy. Politics, Policy, Pedagogy: Education in Aotearoa/New Zealand. J. Marshall. Palmerston North, Dunmore Press.

Jessop, B. (2007). "From micro-powers to governmentality: Foucault's work on statehood, state formation, statecraft and state power." Political Geography 26(1): 3440.

Jessop, B. (2010). Constituting another Foucault effect: Foucault on states and statecraft. Governmentality: Current Issues and Future Challenges. U. Bröckling, S. 
Krasmann and T. Lemke. New York, Routledge: 56-73.

Jessop, B. (2013). "Putting neoliberalism in its time and place: a response to the debate." Social Anthropology 21(1): 65-74.

Jones, A. (2000). Gender Matters in Schooling in Aotearoa/New Zealand. Politics, Policy, Pedagogy: Education in Aotearoa/New Zealand. J MARSHALL, E COXON, K. JENKINS and A. JONES: 71-105.

Jones, G. (2009). Youth, Polity.

Jordan, S. and R. Strathdee (2001). "The training gospel and the commodification of skill: some critical reflections on the politics of skills training in Aotearoa/New Zealand." Journal of Vocational Education and Training 53(3): 391-406.

Kalil, A. (2003). Family Resilience and Good Child Outcomes, Wellington: Centre for Social Research and Evaluation, Ministry of Social Development. Mackay.

Kehily, M. J. (2012). "Contextualising the sexualisation of girls debate: innocence, experience and young female sexuality." Gender and education 24(3): 255-268.

Keightley, K. (2001). Reconsidering rock. The Cambridge companion to pop and rock. S Frith, W Straw and J. Street. Cambridge, Cambridge University Press: 109.

Kelly, M. (2010). The political philosophy of Michel Foucault. New York, Routledge.

Kelly, P. (2006). "The entrepreneurial self and 'youth at-risk': Exploring the horizons of identity in the twenty-first century." Journal of youth studies 9(1): 17-32.

Kendall, G. and G. Wickham (2006). Using Foucault's methods, Sage.

Kendall, G. and G. Wickham (2006). "Problems with the critical posture? Foucault and critical discourse analysis." Paper presented to the Social Change in the $21^{\text {st }}$ Century Conference

Kenway, J. (1996). Reasserting masculinity in Australian schools. Women's Studies International Forum, Elsevier.

Kenway, J., A. Kraack, et al. (2006). Masculinity Beyond the Metropolis. London, Palgrave MacMillan.

Kerner, I. (2012). "Questions of intersectionality: Reflections on the current debate in German gender studies." European Journal of Women's Studies 19(2): 203-218.

Kerr, R. (1998). Restoring Sanity to Education. Turning Pain into Gain. NZBR. Wellington, NZBR: 207-217. 
Kidman, J. (2009). "Shifting Margins, Shifting Centres: Development Paradigms in Māori Education." International Journal of Development Education and Global Learning 2(1): 5-18.

Kidman, J. (2011). Māori Education and Neoliberal Citizenship. Kia Tangi Te Titi: Permission to Speak. P. Whitinui. Wellington, NZCER.

Kimmel, M. (2002). Foreword. Masculinity Studies and Feminist Theory: New Directions. J. Gardiner. New York, Columbia University Press.

King, M. (2004). Penguine History of New Zealand. Auckland, Penguin.

Kirkman, A. and P. Moloney (2005). Sexuality down under: Social and historical perspectives. Dunedin, University of Otago Press.

Labrum, B. (2002). "'Bringing Families up to Scratch'-The Distinctive Workings of Māori State Welfare, 1944-1979." New Zealand Journal of History 36(2): 161-184.

Labrum, B. (2004). "Developing "The Essentials of Good Citizenship and Responsibilities" in Māori Women: Family Life, Social Change, and the State in New Zealand, 1944-70." Journal of Family History 29(4): 446-465.

Labrum, B. (2013). "Not on our street: New urban spaces of interracial intimacy in 1950s and 1960s New Zealand." Journal of New Zealand Studies(14): 67.

Lambeir, B. and S. Ramaekers (2007). "The terror of explicitness: Philosophical remarks on the idea of a parenting contract." Ethics and education 2(2): 95-107.

Lankshear, C. (2011 [1990]). "Illiteracy, Improper Literacy and the Development of an Underclass." Towards Successful Schooling (Rle Edu L Sociology of Education) 185: 175.

Larner, W. (2000). "Post-welfare state governance: Towards a code of social and family responsibility." Social Politics: International Studies in Gender, State \& Society 7(2): 244-265.

Lashlie, C. (2004). It's about Boys: the Good Man Project. Nelson, Nelson College?

Lashlie, C. (2005). He'll be OK : growing gorgeous boys into good men. Auckland, HarperCollins.

Lee, G. and H. Lee (2008). "Comprehensive post-primary schooling in New Zealand: 1935-1975." History of Education Review 37(1): 56-76.

Lemke, T. (2010). "Foucault's hypothesis: from the critique of the juridico-discursive 
concept of power to an analytics of government." Parrhesia (9): 31-43.

Levi-Faur, D. (2014). "The Welfare State: A Regulatory Perspective." Public Administration. 92(3):599-614

Limbrick, L. and M. Aikman. (2008). Literacy and English: a discussion document. Ministry of Education.

Locke, C. (2012). Workers in the Margins: Union Radicals in Post-war New Zealand, Bridget Williams Books.

Lockwood-Smith, A. (1991). Education Policy: Investing in People Our Greatest Asset. NZ Government. Wellington.

Lumby, Catharine \& Albury, Kath (2010), 'Too much? Too young? The sexualization children debate in Australia', Media International Australia, 135: 141-52

Lunt, N. (2006). "Employability and New Zealand welfare restructuring." Policy \& Politics 34(3): 473-494.

Lunt, N. (2008). "From welfare state to social development: winning the war of words in New Zealand." Social policy and society 7(04): 405-418.

Lynch, N. (2012). "Playing catch-up? Recent reform of New Zealand's youth justice system." Criminology and Criminal Justice: 1748895811432013.

Lynch, N. (2013). "“'Contrasts in Tolerance"'in a Single Jurisdiction: The Case of New Zealand." International Criminal Justice Review: 1057567713498094.

Mac an Ghaill, M. and C. Haywood (2011). "Schooling, masculinity and class analysis: Towards an aesthetic of subjectivities." British Journal of Sociology of Education 32(5): 729-744.

MacDonald, K., I Lambie, et al. (1999). Raising Teenagers: A Practical Guide for Parents. Auckland, Oxford University Press.

MacDonald, R., P. Mason, et al. (2001). "Snakes \& ladders: in defence of studies of youth transition." Sociological Research Online, 5(4)

Maclagan, D. (1998). "/h/-dropping in early New Zealand English." New Zealand English Journal: 34-41.

Maharey, S. (2002). Time to pick up the pace: the transition from school to work building partnerships and pathways, NZ Government

Maharey, S. (2003a). The Third Way and how I got on to it, NZ Government. 
Maharey, S. (2003b). The Beeby Vision Today, NZ Government.

Maharey, S. (2003c). Preparing for our future through investment in our people, Minister of Social Development and Employment.

Mallard, T. (2003). Education Priorities for New Zealand: A Summary. Ministry of

Education. Wellington.

Manning, A. (1958). The Bodgie. Wellington, Reed.

Marie, D. (2010). "Māori and Criminal Offending: A Critical Appraisal." Australian \& New Zealand Journal of Criminology 43(2): 282-300.

Marie, D., D. Fergusson, et al. (2008). "Educational achievement in Māori: The roles of cultural identity and social disadvantage." Australian Journal of Education 52(2): 183196.

Marris, M. (1996). Teenagers: A parent's guide for the 90. Auckland, Tandem.

Marshall, J., E. Coxon, et al. (2000). Politics, policy, pedagogy: Education in Aotearoa/New Zealand. Palmerston North, Dunmore Press.

Marshall, J. D. and D. Marshall (1997). Discipline and punishment in New Zealand education, Dunmore Press.

Martin, C. R. (1995). "The naturalized gender order of rock and roll." Journal of Communication Inquiry 19(1): 53-74.

Masters, N., E. Casey, et al. (2013). "Sexual scripts among young heterosexually active men and women: Continuity and change." Journal of Sex Research 50(5): 409-420.

Matheson, D. (2007). "The Interpretative Resources of Aotearoa New Zealand Journalists Reporting on Māori." New Zealand Journal of Media Studies 10(2).

May, H. (1992). Minding Children, Managing Men: Conflict and Compromise in the Lives of Postwar Pākehā Women. Wellington, Bridget Williams.

McCann, R. (1999). Fatherless sons: The experiences of New Zealand men. Auckland, HarperCollins.

McCarry, M. J. (2009). "Justifications and Contradictions: Understanding Young People's Views of Domestic Abuse." Men and Masculinities 11(3): 325-345.

McDonald, G. (1992). Are girls smarter than boys? Women and education in Aotearoa II. S. Middleton and A. Jones. Wellington, Bridget Williams. 
McDowell, L. (2003). Redundant masculinities: employment change and white working class youth. Oxford, Blackwell Publishing.

McDowell, L. (2012). "Post-crisis, post-Ford and post-gender? Youth identities in an era of austerity." Journal of Youth Studies 15(5): 573-590.

McGee, M. (2005). Self-help, Inc.: Makeover culture in American life. New York, Oxford University Press.

McGeorge, C. (1987). "How Katy did at school." New Zealand Journal of Educational Studies 22(1): 101-110.

McLaren, K. (2000). Tough is not Enough: Getting Smart about Youth Crime Wellington, Ministry of Youth Affairs.

McLaren, K. (2002). Youth Development Literature Review, Ministry of Youth Affairs.

McLaren, K. (2003). Reconnecting young people: a review of the risks, remedies and consequences of youth inactivity. Ministry of Social Development

McMASTER, C. (2013). "Working the'Shady Spaces': resisting neoliberal hegemony in New Zealand education." Policy Futures in Education 11(5): 523-531.

McNay, L. (2009). "Self as enterprise dilemmas of control and resistance in Foucault's The Birth of Biopolitics." Theory, Culture \& Society 26(6): 55-77.

McRobbie, A. (2002). From Holloway to Hollywood: Happiness at Work in the New Cultural Economy? Cultural Economy: Cultural Analysis and Commercial Life. P du Gay and M Pryke. London, Sage.

Meikle, P. (1961 [1960]). School and Nation: Post-primary Education since the War. Wellington, NZCER.

Messerschmidt, J. (2000). "Becoming "Real Men": Adolescent Masculinity Challenges and Sexual Violence." Men and Masculinities 2(3): 286-307.

Metge, J. (1963). "THE MĀORI PEOPLE TO-DAY." Geography 48(2): 196-199.

Metge, J. (1995). New growth from old: The whanau in the modern world. Wellington, Victoria University Press.

Metge, J. (2001). Family and whanau in a changing world. Proceedings of social policy forum.

Mills, M. and A. Keddie (2010). "Cultural reductionism and the media: polarising 
discourses around schools, violence and masculinity in an age of terror." Oxford Review of Education 36(4): 427-444.

Ministry of Education (1993). The New Zealand Curriculum Framework. Wellington.

Ministry of Education (1994). Education for the 21st Century. Wellington.

Ministry of Education (1999). Sexuality Education: Revised Guide for Principals, Boards of Trustees and Teachers. Wellington, Learning Media.

Ministry of Education (2002). Building Futures. The Final Report on the Review of Training Opportunities and Youth Training. Wellington.

Ministry of Education (2002). Tertiary Education Strategy 2002/7. Wellington.

Ministry of Education (2003). Education Priorities for New Zealand. Wellington.

Ministry of Education (2004). Educate: Ministry of Education Statement of Intent 20042009. Wellington.

Ministry of Education (2004). Making a Bigger Difference for all Students: A Schooling Strategy Discussion Document. Wellington.

Ministry of Justice \& Ministry of Social Development (2002). Youth Offending Strategy, Wellington.

Ministry of Social Development (2003a). Young People Not in Education, Employment or Training. Wellington.

Ministry of Social Development (2003b). Youth Transition Report 2003. Wellington.

Mitchell, G. A. (2013). "From "Rock" to "Beat": Towards a Reappraisal of British Popular Music, 1958-1962." Popular Music and Society 36(2): 194-215.

Mitchell, G. A. (2013). "Reassessing 'the Generation Gap': Bill Haley's 1957 Tour of Britain, Inter-Generational Relations and Attitudes to Rock 'n'Roll in the Late 1950s." Twentieth Century British History: hwt013.

Mitchell, T. (2001). Kia kaha! (Be strong!): Māori and Pacific Islander hip-hop in Aotearoa-New Zealand. Global Noise: Rap and Hip Hop Outside the USA. T. Mitchell. Middletown CT, Wesleyan University Press.

Mizen, P. (2002). "Putting the politics back into youth studies: Keynesianism, monetarism and the changing state of youth." Journal of Youth Studies 5(1): 5-20.

Moffitt, T., A. Caspi, et al., Eds. (2001). Sex differences in antisocial behaviour: Conduct 
disorder, delinquency, and violence in the Dunedin Longitudinal Study. Cambridge, Cambridge University Press.

Moffitt, T. E. (1993). "The neuropsychology of conduct disorder." Development and psychopathology 5(1-2): 135-151.

Moore, S. (2012). "Controlling passion? A review of recent developments in British sex education." Health, Risk \& Society 14(1): 25-40.

Morgan, E. M. (2011). "Associations between Young Adults' Use of Sexually Explicit Materials and Their Sexual Preferences, Behaviors, and Satisfaction." Journal of Sex Research 48(6): 520-530.

Morgan, P. (2004). Family Matters. Wellington, NZBR.

Morris, A. (2004). "Youth Justice in New Zealand." Crime and Justice: 243-292.

Mulligan, D. G. (1957). Māori Adolescence in Rakau. Rakau Māori Studies. Wellington, Victoria University.

Muncie, J. (2005). "The globalization of crime control-the case of youth and juvenile justice Neo-liberalism, policy convergence and international conventions." Theoretical Criminology 9(1): 35-64.

Muncie, J. (2008). "The Punitive Turn in Juvenile Justice: Cultures of Control and Rights Compliance in Western Europe and the USA." Youth Justice 8(2): 107-121.

Myers, E. (2008). "Resisting Foucauldian ethics: associative politics and the limits of the care of the self." Contemporary Political Theory 7(2): 125-146.

Nairn, K. and J. Higgins (2007). "New Zealand's neoliberal generation: tracing discourses of economic (ir)rationality." International Journal of Qualitative Studies in Education 20(3): 261-281.

Nairn, R., A. Barnes, et al. (2012). "Māori News Is Bad News': That's Certainly So on Television." MAI Journal 1(1).

Nairn, R., J. Higgins, et al. (2012). The Children of Rogernomics: New Zealand's Neoliberal Generation Leaves School. Dunedin, University of Otago Press.

Nairn, R., A. Moewaka-Barnes, et al. (2012). "Māori news is bad news: That's certainly so on television." MAl journal 1(1): 38-49.

Nash, R. (1993). Succeeding generations: Family resources and access to education in New Zealand. Auckland, OUP. 
Nash, R. (2001). "Models of Māori educational attainment: Beyond the 'class' and'ethnicity' debate" Waikato Journal of Education 7: 23-36.

National Council of Churches (1953). Men and Women. Christchurch, Presbyterian Bookroom.

Nealon, J. T. (2008). Foucault beyond Foucault: Power and its intensifications since 1984. Standford CA, Stanford University Press.

Nolan, M. (2000). Breadwinning: New Zealand women and the state, Canterbury University Press Christchurch.

Nolan, M. (2001). "Putting the state in its place: the domestic education debate in New Zealand1." History of education 30(1): 13-33.

Nolan, M. (2002). "A subversive state? Domesticity in dispute in 1950s New Zealand." Journal of Family History 27(1): 60-81.

Nolan, M. (2003). "The high tide of a labour market system: The Australasian male breadwinner model." Labour \& Industry: a journal of the social and economic relations of work 13(3): 73-92.

Nolan, M. (2007). "'The Reality and Myth of New Zealand Egalitarianism: Explaining the Pattern of a Labour Historiography at the Edge Of Empires'." Labour history review 72(2): 113-134.

Nolan, M. (2009). Constantly on the move but going nowhere? Work, community and social mobility. The New Oxford History of New Zealand. G. Byrnes. Melbourne, Oxford University Press: 357-387.

NZBR (1999). Turning Gain into Pain. Wellington, NZBR.

NZBR/Education Forum (1994). Curriculum, Assessment and Qualifications: An Evaluation of Current Reforms. Wellington.

NZBR/Stead, K. (1994). Submission on the English Curriculum. NZBR. Wellington.

O'Hara, S. (2012). "Monsters, playboys, virgins and whores: Rape myths in the news media's coverage of sexual violence." Language and Literature 21(3): 247-259.

O'Neill, J. (2004). "Change and constancy: half a century of secondary schooling in New Zealand." History of Education Review 33(1): 43-59.

Olsen, T., G. Maxwell, et al. (1995). "Māori and youth justice in New Zealand." Popular justice and community regeneration: Pathways of Indigenous reform 45: 55-60. 
Olssen, M., Ed. (1988). Mental testing in New Zealand: Critical and oppositional perspectives. Dunedin, University of Otago Press.

Olssen, M. (1999). Michel Foucault: materialism and education. Westport CT, Greenwood Publishing Group.

Olssen, M. and M. Peters (2005). "Neoliberalism, higher education and the knowledge economy: from the free market to knowledge capitalism." Journal of Education Policy 20(3): 313-345.

O'Mahony, P. (2009). "The risk factors prevention paradigm and the causes of youth crime: A deceptively useful analysis?" Youth justice 9(2): 99-114.

O'Neill, J. (2004). "Change and Constancy: Half a Century of Secondary Schooling in New Zealand." History of Education Review 33(1): 44-59.

Openshaw, R. (1995). Unresolved struggle: Consensus and conflict in state postprimary education. Palmerston North, Dunmore Press.

Openshaw, R. (2010). "'Disadvantaged by a Pākehā Based Education System" The Impact of Biculturalism on Radical Educational Reform in New Zealand." Pacific-Asian education 22(2): 5-20.

Openshaw, R. (2012). "... Nothing Objectionable or Controversial." Struggles over Difference: Curriculum, Texts, and Pedagogy in the Asia-Pacific: 25.

Openshaw, R., G. D. Lee, et al. (1993). Challenging the myths: Rethinking New Zealand's educational history. Palmerston North, Dunmore Press.

Openshaw, R. and M. Walshaw (2010). "What Can We Learn From History? The Early Post-World War Two Debate Over Literacy And Numeracy Standards, 1945-1962 in Perspective." New Zealand Journal of Teachers' Work 7(2): 125-142.

Openshaw, R. and M. Walshaw (2013). "Towards an August Assembly of Suave Venusians? The Early Post-World War Two Debate over New Zealand Literacy and Numeracy Standards in Transnational Context." History of Education Review 42(2): 3-3.

Owen, V. (2001). "Whanake Rangatahi - Rethinking Crime and Punishment." Social Policy Journal of New Zealand 16: 175-190.

Paap, K. (2006). Working construction: why white working-class men put themselves-and the labor movement--in harm's way, Cornell University Press.

Paras, E. (2006). Foucault 2.0: Beyond power and knowledge. New York, Other Press.

Parenting with Confidence (2004). Sex with Attitude. Wellington. 
Payne, G. (2000). "The Politics of Curriculum Change in New Zealand." Auckland College of Education Papers(7).

Peachey, A. (2005). What's up with our schools? Auckland, Random House.

Pearson, B. (1952). "Fretful Sleepers: A Sketch of New Zealand Behaviour and Its Implications for the Artist." Landfall 6(23): 201-230.

Penetito, W. (2010). What's Māori about Māori education? Wellington, Victoria University Press.

Peters, M. (2000). "Education policy, welfare and the language of the market." The Australian Educational Researcher 27(2): 63-85.

Peters, M. (2009). "Education, enterprise culture and the entrepreneurial self: A Foucauldian perspective." The Journal of Educational Enquiry 2(2).

Peters, M. and J. Marshall (1996). Individualism and community: Education and social policy in the postmodern condition. London, Falmer.

Peters, M. and T. Besley (2006). Building knowledge cultures: Education and development in the age of knowledge capitalism, Rowman \& Littlefield.

Peters, M. and T. Besley (2007). Why Foucault?: new directions in educational research, Peter Lang.

Philip, B. (2009). "Analysing the politics of self-help books on depression." Journal of Sociology 45(2): 151-168.

Phillips, J. (1996). A man's country?: the image of the Pākehā male: a history. Auckland, Penguin.

Phipps, A. (2009). "Rape and Respectability: Ideas about Sexual Violence and Social Class." Sociology 43(4): 667-683.

Pihema, L. (2009). Overview of Māori Teen Pregnancy. Wellington, Families Commission.

Pilcher, J. (1994). "Mannheim's sociology of generations: an undervalued legacy." British Journal of Sociology: 481-495.

Poata-Smith, E. S. (1996). "Te ao marama? Cultural solutions to Māori educational inequality: a critique." 
Pool, I., A. Dharmalingam, et al. (2007). The New Zealand family from 1840: A demographic history. Auckland, Auckland University Press.

Povinelli, E. and K. DiFruscia (2012). "A Conversation with Elizabeth Povinelli." (2): 76 90.

Povinelli, E. A. (2002). The cunning of recognition: Indigenous alterities and the making of Australian multiculturalism. Durham, NC, Duke University Press.

Pringle, R. (2008). "'No rugby—no fear': collective stories, masculinities and transformative possibilities in schools." Sport, Education and Society 13(2): 215-237.

Pryor, J. and L. Woodward (1996). Families and parenting. From Child to Adult: The Dunedin Study. P. Silva and W. Stanton. Auckland, OUP.

Pudney, W. and J. Cottrell (1998). Beginning fatherhood: A guide for New Zealand men. Sydney, Tandem.

Quince, K. (2007). "Māori and the criminal justice system in New Zealand." The criminal justice system in New Zealand: 333-359.

Ramazanoglu, C. and J. Holland (2002). Feminist methodology: Challenges and choices. London, Sage.

Rasmussen, M. L. (2010). "Secularism, religion and 'progressive' sex education." Sexualities 13(6): 699-712.

Rasmussen, M. L. (2012). "Pleasure/desire, sexularism and sexuality education." Sex Education 12(4): 469-481.

Rata, E. (2000). A political economy of neotribal capitalism, Lexington Books.

Rata, E. (2011). "Discursive strategies of the Māori tribal elite." Critique of Anthropology 31(4): 359-380.

Rata, E. (2012). The politics of knowledge in education. London, Routledge.

Read, J. (2009). "A genealogy of homo-economicus: Neoliberalism and the production of subjectivity." Foucault studies: 25-36.

Reay, D. (2001). "Finding or losing yourself?: working-class relationships to education." Journal of Education Policy 16(4): 333-346.

Reay, D. (2006). "The zombie stalking English schools: Social class and educational inequality." British journal of educational studies 54(3): 288-307. 
Renold, E., M. Kehily, et al. (2012). "Special issue: Making sense of the sexualisation debates: Schools and beyond." Gender and Education 24(3): 249-254.

Richards, K. (2011). "Restorative Justice and "Empowerment": Producing and Governing Active Subjects through "Empowering" Practices." Critical Criminology 19(2): 91-105.

Richards, T. (1999). Dancing on Our Bones: New Zealand, South Africa, Rugby and Racism. Wellington, Bridget Williams.

Riggs, D. (2008). "All the boys are straight: Heteronormativity in contemporary books on fathering and raising boys." Thymos: Journal of Boyhood Studies 2(2): 186-202.

Rimke, H. (2000). "Governing citizens through self-help literature." Cultural studies 14(1): 61-78.

Roberts, K. (2003). "Problems and priorities for the sociology of youth." Bennet, A. Chieslik, M., Miles, S.(eds.) Researching Youth, Basingstoke: Palgrave, Macmillan: 1326.

Roberts, K. (2007). "Youth transitions and generations: a response to Wyn and Woodman." Journal of youth studies 10(2): 263-269.

Roberts, P. (1998). "The politics of curriculum reform in New Zealand." Curriculum Studies 6(1): 29-46.

Roberts, P. (2003). "Contemporary curriculum research in New Zealand." International handbook of curriculum research: 495-516.

Roberts, S. (2012). "One step forward, one step Beck: a contribution to the ongoing conceptual debate in youth studies." Journal of youth studies 15(3): 389-401.

Rohloff, A. and S. Wright (2010). "Moral Panic and Social Theory Beyond the Heuristic." Current Sociology 58(3): 403-419.

Roper, B. (2005). Prosperity for all?: economic, social and political change in New Zealand since 1935, Social Science Press.

Rose, N. (1993). "Government, authority and expertise in advanced liberalism." Economy and society 22(3): 283-299.

Rose, N. (1996). Governing" advanced" liberal democracies. Foucault and Political Reason: Liberalism, Neo-Liberalism, and Rationalities of Government. T. O. A. Barry, and N. Rose. Chicago, University of Chicago Press: 37.

Rose, N. (1998). Inventing our selves: Psychology, power, and personhood. Cambridge, 
Cambridge University Press.

Rose, N. (1999). Powers of freedom: Reframing political thought. Cambridge, Cambridge university press.

Saltmarsh, S. (2007). "Cultural complicities: Elitism, heteronormativity and violence in the education marketplace." International journal of qualitative studies in education 20(3): 335-354.

Savage, J. (2008). Teenage: The Prehistory of Youth Culture: 1875-1945. New York, Penguin.

Savage, M. (2000). Class analysis and social transformation, Open University Press Buckingham.

Scott, M. (2013). Making New Zealand's Pop Renaissance: State, Markets, Musicians. Burham, UK, Ashgate.

Scott, W. J. (1958). The Meaning of Conformity. Conformity \& Individuality: the 1958 Lectures, Wellington, Association for the Study of Childhood.

Sheehan, M. (2011). "A question of bias? Politics, assessment and the New Zealand history curriculum." History of Education Review 40(2): 176-188.

Shuker, R. (1987). The one best system? A revisionist history of state schooling in New Zealand. Palmerston North, Dunmore Press.

Shuker, R. (2008). Understanding Popular Music Culture. London, Routledge.

Shuker, R., R. Openshaw, et al. (1990). Youth, media and moral panic in New Zealand: from hooligans to video nasties. Palmerston North, Department of Education, Massey University.

Shulruf, B. (2005). Parent support and education programmes : a systematic review. Auckland, Auckland University.

Shute, G. (2004). Hip Hop Music in Aotearoa. Auckland, Reed Publishing.

Sigler, T. and M. Balaji (2013). "Regional place representation in hip-hop music." Communication, Culture and Critique 6(2): 336-352.

Silva, P. A. and W. R. Stanton, Eds. (1996). From child to adult: The Dunedin multidisciplinary health and development study, Oxford University Press.

Skeggs, B. (2004). Class, Self, Culture. London, Routledge. 
Skeggs, B. (2005). "The Making of Class and Gender through Visualizing Moral Subject Formation." Sociology 39(5): 965-982.

Smith, E. (2010). "Underachievement, failing youth and moral panics." Evaluation \& Research in Education 23(1): 37-49.

Smith, G., T. Hoskins, et al. (2012). "Interview: Kaupapa Māori: The dangers of domestication." New Zealand Journal of Educational Studies 47(2): 10.

Smith, G. H. (1991). Reform and Māori educational crisis: a grand illusion, Research Unit for Māori Education, University of Auckland Auckland.

Smith, G. H. (2003). Indigenous struggle for the transformation of education and schooling. Alaskan Federation of Natives Convention. United States.

Smith, G. H. and L. T. Smith (1996). "New mythologies in Māori education." Nga Patai: Racism and Ethnic Relations in AotearoaiNew Zealand: 217-234.

Smith, P. (2012). A Concise History of New Zealand. Cambridge, Cambridge University Press.

Snook, I. and J. O'Neill (2010). "Social class and educational achievement: Beyond ideology." New Zealand Journal of Educational Studies 45(2): 3.

Soler, J. M. (1988). Drifting Towards Moral Chaos: The 1954 Mazengarb Report: a Moral Panic Over Juvenile Immorality. Education. Palmerston North, Massey University. M.Phil.

Spence, L. (2011). Stare in the Darkness: the Limits of Hip Hop and Black Politics. Minneapolis, Minnesota University Press.

Spencer, G., C. Maxwell, et al. (2008). "What does 'empowerment' mean in school-based sex and relationships education?" Sex Education 8(3): 345-356.

Spencer, M. (2008). Orphans of the Imagination: Exploring boundaries of culture/class in New Zealand education. Education. Auckland, Auckland University.

Spoonley, P. and C. Davidson (2004). The changing world of work. Work and working in twenty-first century New Zealand. P. Spoonley, A. Dupuis and A. d. Bruin. Palmerston North, Dunmore Press: 17-40.

Stenning, P. (2005). Māori, crime and criminal justice: over-representation or underrepresentation. FHSS Seminar.

Stephenson, I. J. (2003). Techno-futurism and the knowledge economy in New Zealand. Communication Studies, Auckland University of Technology. MA. 
Strangleman, T. (2008). "Sociology, social class and new working class studies." Antipode 40(1): 15-19.

Strathdee, R. (2013). "Neo-tribal capitalism, socio-economic disadvantage and educational policy in New Zealand." Journal of Education Policy 28(4): 501-516.

Strathdee, R. and R. Engler (2012). "Who is missing from higher education in New Zealand?" British Educational Research Journal 38(3): 497-514.

Sturm, S. and S. Turner (2011). "Knowledge waves: New Zealand as educational enterprise." Australian Journal of Communication 38(3): 153.

Sukarieh, M. and S. Tannock (2011). "The positivity imperative: a critical look at the "new'youth development movement." Journal of youth studies 14(6): 675-691.

Sutch, W. B. (1957). The effect of post primary schooling for all: address to Wellington Branch of Institute of Public Administration, Alexander Turnbull Library.

Sutch, W. B. (1961). Education for New Zealand's Future. Wellington, Department of Industries and Commerce.

Szreter, S. and K. Fisher (2010). Sex before the sexual revolution: Intimate life in England 1918-1963, Cambridge University Press.

Tamati, S. (2004). Window to our World. The Next: An Impression of Hip-Hop Expression. Y Saw, S Tamati and D Waiti. NZ, Global Education Centre.

Tasker, G. and L. Aldridge (2000). Social \& Ethical Issues in Sexuality Education: A Resource for Health Education Teachers of Year 12 and 13 Students, Christchurch College of Education.

Tauri, J. M. (2013). "Indigenous critique of authoritarian criminology." Crime, justice and social democracy: International perspectives: 217-233.

Te Puni Kokiri (2000). Whanake Rangatahi: Programmes and services to address Māori youth offending. Wellington.

Thompson, E. P. (1978). Poverty of theory and other essays. London, Merlin.

Thompson, E. P. (1994). Making history: Writings on history and culture. New York, New Press.

Thomson, R., S. Henderson, et al. (2003). "Making the most of what you've got? Resources, values and inequalities in young women's transitions to adulthood." Educational Review 55(1): 33-46. 
Threadgold, S. (2011). "Should I pitch my tent in the middle ground? On 'middling tendency', Beck and inequality in youth sociology." Journal of youth studies 14(4): 381393.

Thrupp, M. (2007). "Education's inconvenient truth': persistent middle class advantage." Waikato Journal of Education 13.

Thrupp, M. (2008). "Education's 'inconvenient truth': Part two-The middle classes have too many friends in education." New Zealand Journal of Teachers' Work, 5(1), 54-62

Tinsley, B., S. Wilson, et al. (2012). Hip Hop Culture, Youth Creativity, and the Generational Crossroads from a Human Development Perspective. Art and Human Development. C Milbrath and C. Lightfoot, Psychology Press: 83-97.

Tolman, D. (2012). "Female Adolescents, Sexual Empowerment and Desire: A Missing Discourse of Gender Inequity." Sex roles 66(11-12): 746-757.

Tosh, J. (2007). A man's place: Masculinity and the middle-class home in Victorian England. New Haven, CT, Yale University Press.

Tremewan, C. (2005). "Ideological conformity: A fundamental challenge to the social sciences in New Zealand." Sites: a journal of social anthropology and cultural studies 2(1): 1-44.

Turnbull, G. and J. Spence (2011). "What's at risk? The proliferation of risk across child and youth policy in England." Journal of youth studies 14(8): 939-959.

Tyyskä, V. (2014). Youth and society: The long and winding road, Canadian Scholars' Press.

Ungar, S. (2001). "Moral panic versus the risk society: The implications of the changing sites of social anxiety." The British journal of sociology 52(2): 271-291.

Vansieleghem, N. (2010). "The residual parent to come: on the need for parental expertise and advice." Educational theory 60(3): 341-355.

Veit-Wilson, J. (2000). "States of welfare: a conceptual challenge." Social Policy \& Administration 34(1): 1-25.

Wald, E. (2009). How the Beatles destroyed rock'n'roll: An alternative history of American popular music. New York, Oxford University Press.

Walker, R. (2002). "Māori news is bad news." What's news: 215-231.

Walkerdine, V., H. Lucey, et al. (2001). Growing up girl: psycho-social explorations of 
gender and class, Palgrave.

Wall, M. (1997). "Stereotypical Constructions of the Māori 'Race' in the Media." New Zealand Geographer 53(2): 40-45.

Weaver-Hightower, M. (2009). "Issues of boys' education in the United States." The problem with boys' education: Beyond the backlash: 1-27.

Weeks, J. (2005). "Remembering Foucault." Journal of the History of Sexuality 14(1): 186-201.

Weitzer, R. and C. E. Kubrin (2009). "Misogyny in Rap Music: A Content Analysis of Prevalence and Meanings." Men and Masculinities 12(1): 3-29.

Whitcher, G. F. (2011). 'More Than America': Some New Zealand Responses to American Culture in the Mid-twentieth Century. History. Christchurch, University of Canterbury. PhD.

Wilcox, L. (1996). "Saatchi rap: The 'worlding of America'and racist ideology in New Zealand." Continuum 10(1): 121-135.

Willis, P. E. (1977). Learning to labor: How working class kids get working class jobs, Columbia University Press.

Wilson, D. S. (2006). "A New Look at the Affluent Worker: The Good Working Mother in Post-War Britain." Twentieth Century British History 17(2): 206-229.

Wincott, D. (2013). "The (golden) age of the welfare state: interrogating a conventional wisdom." Public Administration 91(4): 806-822.

Wodak, R. and M. Meyer, Eds. (2009). Methods for critical discourse analysis. London, Sage.

Wood, B. and M. Sheehan (2012). "Dislodging knowledge? The New Zealand curriculum in the 21st Century." Pacific-Asian Education 24(1): 17-30.

Woodman, D. (2009). "The mysterious case of the pervasive choice biography: Ulrich Beck, structure/agency, and the middling state of theory in the sociology of youth." Journal of youth studies 12(3): 243-256.

Woodman, D. and J. Wyn (2013). "Youth policy and generations: Why youth policy needs to 'rethink youth'." Social policy and Society 12(02): 265-275.

Worth, H. (2003). "Decoding Responsibility: Welfare recipients and the enforcement of parental obligations." Journal of poverty 7(3): 13-33. 
Worth, H., A. Paris, et al., Eds. (2002). The life of Brian: Masculinities, sexualities and health in New Zealand. Dunedin, University of Otago Press.

Wright, B., A. Caspi, et al. (1999). "Reconsidering the relationship between SES and delinquency: causation but not correlation*." Criminology 37(1): 175-194.

Wright, E. O., Ed. (2005). Approaches to class analysis. Cambridge, Cambridge University Press.

Wright, S. (2010). Angel Faces, Killer Kids, and Appetites for Excess: Reapproaching Moral Panic. Criminology. Wellington, Victoria. PhD.

Wylie, C. (2013). Schools and Inequality. Inequality: A New Zealand Crisis. M. Rashbrook. Wellington, Bridget Williams.

Wylie, C. and R. Hipkins (2006). Growing independence: Competent learners@ 14, New Zealand Council for Educational Research.

Wylie, C., J. Thompson, et al. (2004). Competent children at 12, New Zealand Council for Educational Research.

Wyn, J, and A Harris. "Youth research in Australia and New Zealand." Young 12.3 (2004): 271-289.

Wyn, J. and D. Woodman (2006). "Generation, youth and social change in Australia." Journal of youth studies 9(5): 495-514.

Young, J. (2007). The Vertigo of Late Modernity. London, Sage.

Yska, R. (1993). All shook up: The flash bodgie and the rise of the New Zealand teenager in the fifties. Auckland, Penguin Books.

Zemke-White, K. (2004). Keeping it Real (Indigenous): Hip Hop in Aotearoa as Community, Culture and Consciousness. Cultural Studies in Aotearoa New Zealand: Identity, Space and Place. C. Bell and S. Matthewman. Melbourne: Oxford University Press.

Zemke-White, K. (2005). "How many dudes you know roll like this?" Image \& Narrative 1(10): 1-16.

Zemke-White, K. (2008). Good Girls Gone Bad: Rock-a-Billy Femininity featuring Elvis and the Gender F@\%\#s. Music on the Edge: Selected papers from the 2007 IASPM Australia/New Zealand Conference. Dunedin, Otago University Press: 194-201. 
Selected Newspaper, Magazines and Professional Journals:

Auckland Star

New Zealand Herald

Sunday Star Times

Christchurch Star

Christchurch Star-Sun

The Press

Dominion

Evening Post

Dominion Post

Education: Department of Education Bulletin

National Education

North and South

New Zealand Listener

New Zealand Parent and Child

NZ Woman's Weekly

New Zealand Post Primary Teachers Association (NZPPTA) Bulletin

Official record and publications

Written Submissions to the Mazengarb Committee Report (ATL ref)

Hearings of the Mazengarb Committee Inquiry (ANZ ref)

NZPD New Zealand Parliamentary Debate/Hansard and Appendix to the Journals of the House of Representatives

New Zealand Official Year Books 